\title{
Nanoestructuras funcionales fabricadas mediante un haz de electrones o iones focalizado
}

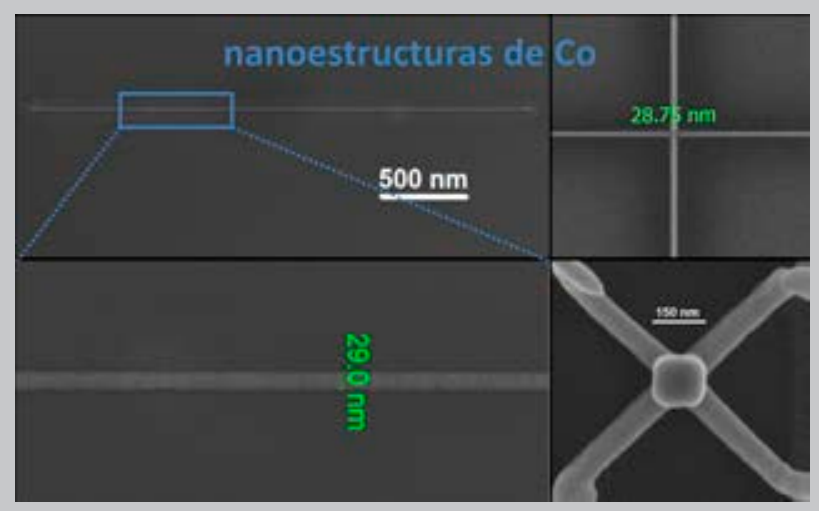

Rosa Córdoba Castillo 

Nanoestructuras funcionales fabricadas mediante un haz de electrones o iones focalizado 


\section{Colección de Estudios de Física}

Vol. 102

Esta colección recoge las tesis presentadas en el Departamento de Física de la Materia Condensada de la Universidad de Zaragoza desde su constitución en 1987. 
Colección de Estudios de Física

Vol. 102

Nanoestructuras funcionales fabricadas mediante un haz de electrones o iones focalizado

Rosa Córdoba Castillo

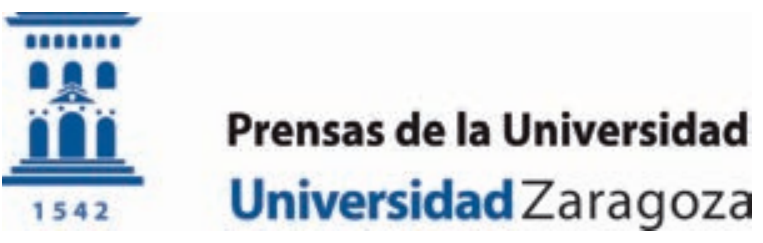


CÓRDOBA CASTILLO, Rosa

Nanoestructuras funcionales fabricadas mediante un haz de electrones o iones focalizado / Rosa Córdoba Castillo. — Zaragoza : Prensas de la Universidad de Zaragoza, 2012

273 p. : il. ; $25 \mathrm{~cm}$. - (Colección de estudios de física ; 102)

Bibliografía: p. 247-268. — ISBN 978-84-15770-08-4

1. Nanoestructuras-Tesis doctorales

$539.24(043.2)$

Cualquier forma de reproducción, distribución, comunicación pública o transformación de esta obra solo puede ser realizada con la autorización de sus titulares, salvo excepción prevista por la ley. Diríjase a CEDRO (Centro Español de Derechos Reprográficos, www.cedro.org) si necesita fotocopiar o escanear algún fragmento de esta obra.

(C) Rosa Córdoba Castillo

(C) De la presente edición, Prensas de la Universidad de Zaragoza $1 .^{a}$ edición, 2012

Prensas de la Universidad de Zaragoza. Edificio de Ciencias Geológicas, c/ Pedro Cerbuna, 12, 50009 Zaragoza, España. Tel.: 976761 330. Fax: 976761063

puz@unizar.es http://puz.unizar.es

Impreso en España

Imprime: Servicio de Publicaciones. Universidad de Zaragoza

D.L.: Z-2373-2012 


\section{Índice}

1 Introducción................................................................................................ 11

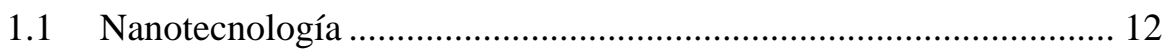

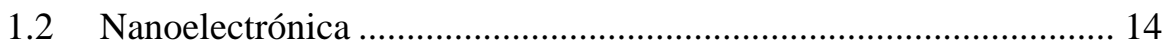

1.3 Nanofabricación mediante "Dual Beam”......................................... 15

1.3.1 Descripción general de un "Dual Beam” ................................ 15

1.3.1.1 Haz de electrones focalizado ........................................ 17

1.3.1.2 Haz de iones focalizado................................................ 18

1.3.2 Grabado inducido mediante un haz de iones focalizado ........ 20

1.3.3 Ataque inducido mediante un haz de electrones o iones ............

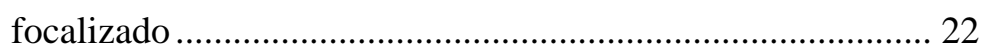

1.3.4 Crecimiento inducido mediante un haz de electrones focalizado

1.3.5 Crecimiento inducido mediante un haz de iones focalizado .. 28

1.3.6 Comparación entre las técnicas FEBID y FIBID .................... 32

1.3.7 Comparación entre FEBID/FIBID con EBL ……………….... 33

$1.4 \quad$ Nanoestructuras estudiadas en esta tesis ............................................ 35

1.5 Nanoestructuras magnéticas.............................................................. 36

1.5.1 Introducción a la Espintrónica ……………………................ 36

1.5.2 Propiedades de nanoestructuras magnéticas ............................ 36

1.5.2.1 Conducción eléctrica ...................................................... 36

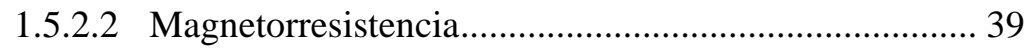

1.5.2.2.1 Magnetorresistencia anisótropa ................................ 40 
1.5.2.2.2 Magnetorresistencia túnel en materiales

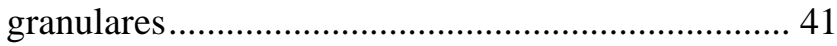

1.5.2.3 Efecto Hall................................................................... 42

1.5.2.3.1 Efecto Hall anómalo ................................................... 43

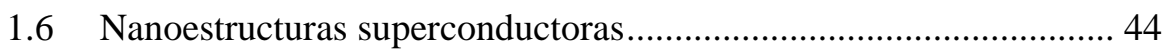

1.6.1 Introducción a la superconductividad .................................... 44

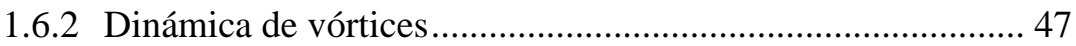

1.6.2.1 Resistencia "flux flow" ................................................. 48

1.6.2.2 Resistencia “phase slip” ................................................ 50

1.6.3 Dinámica de vórtices no local ................................................ 51

1.7 Objetivos y estructura de la tesis.......................................................... 53

2 Técnicas experimentales .......................................................................... 55

2.1 Nanolitografía mediante un "Dual Beam" ...................................... 56

2.1.1 Descripción de un "Dual Beam” "............................................ 56

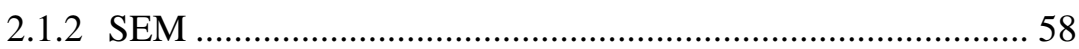

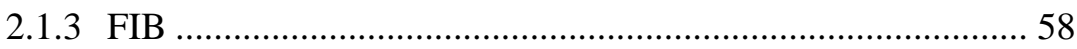

2.1.4 Sistema de inyección de gases y materiales precursores........ 59

2.1.4.1 Sistema de inyección de gases...................................... 59

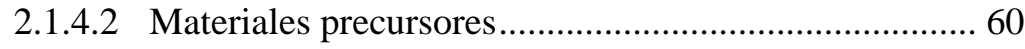

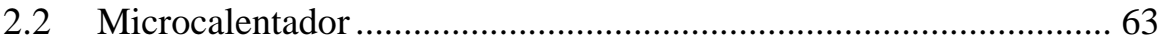

2.3 Espectroscopía de dispersión de energía de rayos-X ......................... 66

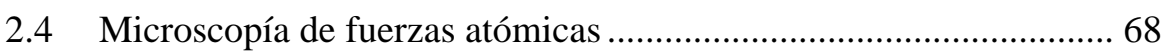

2.5 Caracterización estructural y composicional a escala nanométrica . 70

2.5.1 Preparación de muestras para TEM mediante "Dual Beam” 70

2.5.2 Microscopía electrónica de transmisión ................................. 75

2.5.3 Microscopía electrónica de transmisión de alta resolución.... 75

2.5.4 Microscopía electrónica de transmisión de barrido.................. 77

2.5.5 Espectroscopía de pérdida de energía de los electrones......... 77

2.6 Caracterización del transporte eléctrico .............................................. 80

2.6.1 Medidas de transporte eléctrico in situ.................................. 80 
2.6.2 Medidas de magnetotransporte eléctrico "ex-situ” 81

2.7 Otras técnicas experimentales ........................................................... 83

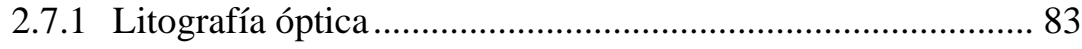

2.7.2 Equipo de microsoldadura....................................................... 84

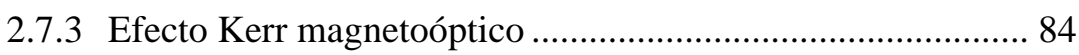

3 Nanodepósitos ferromagnéticos de Co crecidos mediante un haz

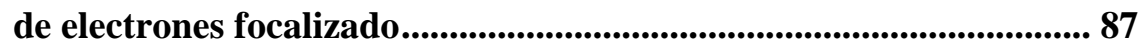

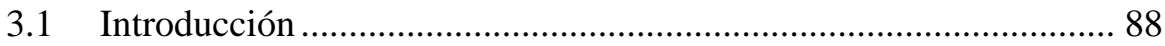

3.2 Crecimiento de nanoestructuras de Co mediante FEBID ................. 90

3.3 Microestructura y composición de los nanodepósitos de Co en la

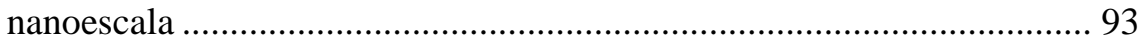

3.4 Influencia de la temperatura del sustrato en la composición de las nanoestructuras: pilares de Co crecidos a baja corriente .................. 103

3.5 Crecimiento de Co mediante el efecto catalítico............................. 110

3.6 Nanoestructuras ultraestrechas de Co y aplicaciones...................... 115

3.6.1 Influencia del flujo de gas precursor ..................................... 115

3.6.2 Nanoestructuras ultraestrechas de Co .................................. 117

3.6.3 Sensores nano-Hall de Co .................................................... 119

3.7 Conclusiones ................................................................................ 124

\section{Depósitos ferromagnéticos de Fe crecidos mediante un haz} de electrones focalizado ......................................................................... 125

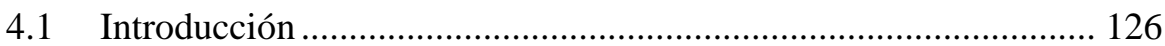

4.2 Crecimiento de microestructuras de Fe mediante FEBID.............. 127

4.3 Microestructura de los depósitos de Fe en la nanoescala................ 131

4.4 Mecanismo de transporte eléctrico …………................................. 134

4.5 Propiedades magnéticas ................................................................... 138

4.5.1 MOKE y MR longitudinal ................................................. 138

4.5.2 Dependencia de la MR perpendicular con la temperatura ... 142

4.5.3 Estudio del efecto Hall gigante .......................................... 148 
5 Depósitos superconductores de W crecidos mediante un haz

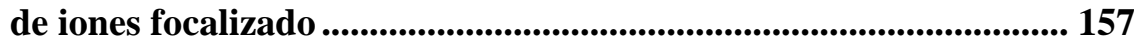

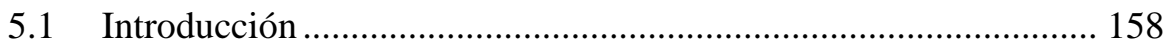

5.1.1 Crecimiento de depósitos de W mediante FIBID.................. 158

5.1.2 Superconductividad en depósitos de W crecidos mediante FIBID. 160

5.1.3 Estudio de películas delgadas superconductoras basadas

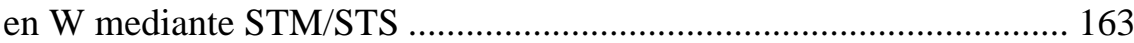

5.2 Crecimiento de nanoestructuras de W mediante FIBID ................. 166

5.3 Microestructura de los nanodepósitos de W en la nanoescala ........ 171

5.4 Influencia del ángulo de incidencia del FIB ................................. 173

5.5 Transporte eléctrico en modo local en depósitos

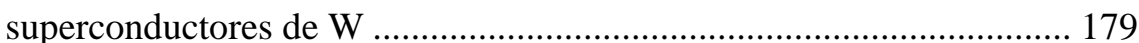

5.5.1 Microhilos superconductores de W.................................... 179

5.5.2 Nanohilos superconductores de W .................................... 182

5.5.2.1 Configuración de medida ......................................... 182

5.5.2.2 Dependencia de la resistencia con la temperatura...... 183

5.5.2.3 Dependencia de la resistencia con la corriente............ 184

5.5.2.4 Dependencia de la resistencia en función del

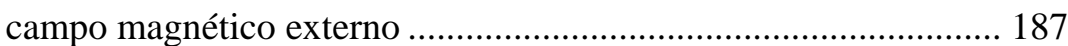

5.5.3 Nanohilos superconductores de W ultraestrechos................. 189

5.5.4 Resumen y conclusiones ........................................................ 197

5.6 Transporte eléctrico en modo no local en nanohilos

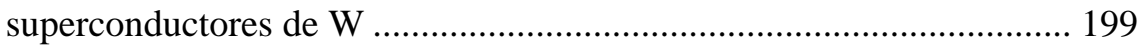

5.6.1 Configuración de medida .................................................... 201

5.6.2 Dependencia del voltaje no local con la corriente bajo campo magnético externo

5.6.3 Dependencia de la resistencia no local en función del campo magnético externo. 
6 Resumen y Conclusiones generales.

A Nanodepósitos de W crecidos mediante un haz de electrones focalizado

A.1 Crecimiento y caracterización de nanoestructuras de W mediante FEBID

A.2 Medidas de transporte eléctrico in situ 218

A.3 Medidas de transporte eléctrico "ex-situ"

B Nanodepósitos de Pt crecidos mediante un haz de electrones o iones focalizado

B.1 Crecimiento de nanoestructuras de Pt mediante FEBID y FIBID

B.2 Análisis de la composición y microestructura de los depósitos de Pt

C Nanodepósitos de C crecidos mediante un haz de iones

focalizado 236

Acrónimos 243

Bibliografía ... 247

Listado de publicaciones. 269 



\section{Capítulo 1}

\section{Introducción}

En este capítulo comenzaremos describiendo los conceptos de Nanotecnología y Nanoelectrónica, a continuación nos detendremos en los fundamentos generales de la fabricación de nanoestructuras con interés en Espintrónica y Superconductividad mediante las técnicas FEBID y FIBID. Éste es el marco general en el que se encuadra esta tesis, dedicada en gran medida al crecimiento y caracterización de nanoestructuras que exhiben propiedades ferromagnéticas o superconductoras.

Por ello, abordaremos los principios de las técnicas de nanofabricación de las que nos hemos servido, FEBID y FIBID. Además, introduciremos los fenómenos físicos asociados a nanoestructuras ferromagnéticas que vamos a tratar, como por ejemplo la magnetorresistencia y el efecto Hall anómalo; para continuar con los fenómenos asociados a nanoestructuras superconductoras, como por ejemplo, la dinámica de vórtices local y no local, entre otros. 


\subsection{Nanotecnología}

La Nanotecnología aborda el estudio y control de la materia a pequeña escala, entre 1 y 100 nm, siendo el nanómetro la millonésima parte de un milímetro, es decir, $1 \times 10^{-9} \mathrm{~m}$, equivalente a unos 5 átomos puestos en fila (véase la Figura 1.1).

Resulta increíblemente fascinante disponer de las herramientas adecuadas para manipular los átomos que constituyen la materia y, así mismo, comprender sus fenómenos asociados con las bases teóricas de la física de la materia condensada ya establecidas. En 1959 Richard Feynman, premio Nobel en Física, predijo que de acuerdo a las leyes de la física conocidas en aquella época, los átomos serían estudiados y manipulados de forma individual ${ }^{1}$. Parece que una vez más, el sueño de un hombre motivó y alentó a la comunidad científica en el desarrollo de las herramientas necesarias para que aquella predicción se hiciera realidad; y de lo que no hay duda es de que la Nanotecnología ha revolucionado nuestras industrias y nuestras vidas desde finales del siglo XX.

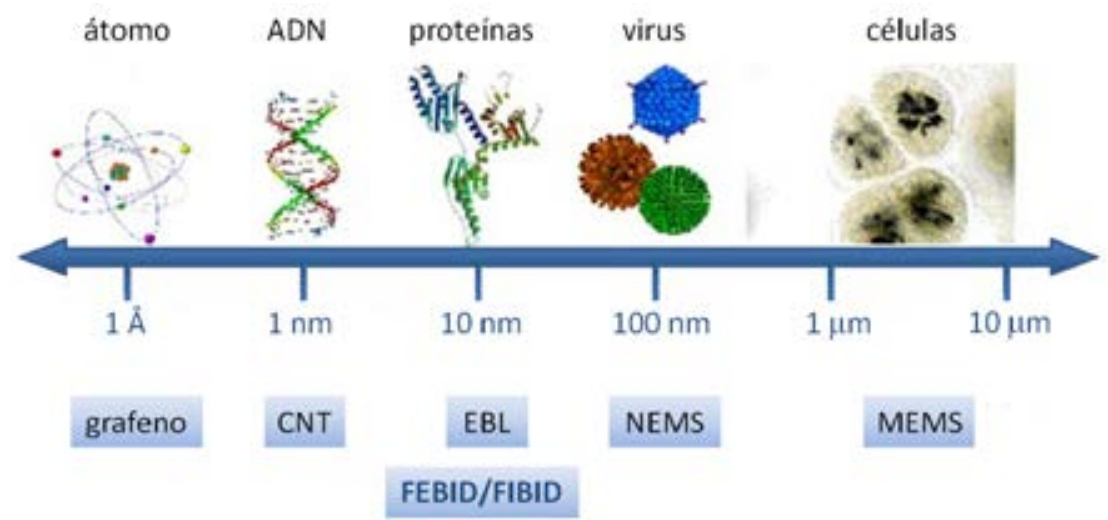

Figura 1.1: Diagrama que ilustra la escala métrica en la cual se aplica la Nanociencia y Nanotecnología. Desde el tamaño de los MEMS (sistemas micro-electro-mecánicos), NEMS (sistemas nano-electro-mecánicos), la resolución en EBL (litografía electrónica), FEBID (crecimiento inducido por un haz de electrones focalizado), FIBID (crecimiento inducido por una haz de iones focalizado), el tamaño de los CNTs (nanotubos de carbono) hasta llegar al grafeno, una monocapa de átomos de carbono. 
La Nanociencia y la Nanotecnología son campos multidisciplinares de la ciencia, que agrupan disciplinas tales como la Física, Química, Ingeniería, Biología y Medicina. Por tanto, el impacto y la repercusión de los hallazgos que se generan alrededor de la Nanotecnología pueden tener dimensiones incalculables, tanto a nivel económico como social. Destacamos los avances y aplicaciones en Medicina a través del diagnóstico, tratamiento y prevención; en energía mediante nanopartículas; en electrónica con memorias magnéticas para ordenadores, dispositivos electrónicos, películas delgadas; en textiles con la fabricación de nanocomposites para calzado y textil; en construcción con nuevos materiales, recubrimientos, CNTs; en Ingeniería, Química y Biotecnología a través de microreactores, biosensores, catalizadores nanoestructurados (véase la Figura 1.2).

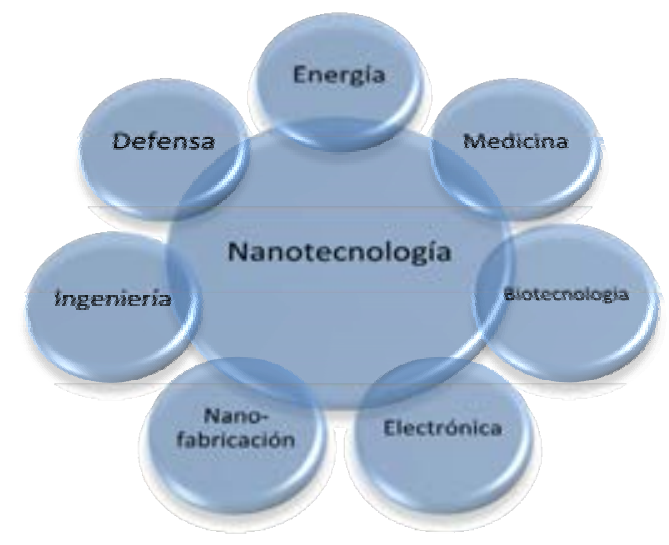

Figura 1.2: Diagrama en el cual se indican algunos de los más importantes campos de aplicación de la Nanociencia y la Nanotecnología.

Los materiales a escala nanométrica pueden mostrar diferentes propiedades comparadas con las que exhiben en la macroescala. Esto hecho nos permite estudiar fenómenos físicos fundamentales, como los efectos de tamaño cuántico que permiten aplicaciones únicas en nanoelectrónica. 


\subsection{Nanoelectrónica}

La industria del almacenamiento de datos genera billones de dólares al año en Estados Unidos, mediante cientos de millones de dispositivos electrónicos. El almacenamiento de datos magnéticos es ampliamente usado en aplicaciones tan comunes hoy día, como los discos duros de los ordenadores, las memorias no volátiles, las tarjetas de crédito y otros dispositivos electrónicos, etc ${ }^{2}$.

Un disco duro se compone de tres partes: "storage medium” es el disco dónde los datos se guardan en forma de pequeñas áreas imanadas. La cabeza de escritura consiste en una bobina con núcleo de material magnético, que genera un campo magnético cuando se le aplica una corriente. El campo magnético escribe los datos imanando los pequeños bits de datos en la "storage medium”. Por último, la cabeza lectora detecta las áreas imanadas grabadas, mediante la inversión de la inducción electromagnética usada en el proceso de escritura o bien a través de la magnetorresistencia, que es el cambio de la resistencia de un material al someterlo a un campo magnético.

El estudio de materiales magnéticos y sus propiedades nos permitirán mejorar en el almacenamiento de la información, la fabricación de sensores, y otros dispositivos. Tal y como ha tenido lugar en las últimas décadas con el descubrimiento de la magnetorresistencia anisótropa (AMR), la magnetorresistencia gigante (GMR) y la magnetorresistencia túnel (TMR). Nuevos conceptos basados en el magnetismo de materiales, como la nucleación y/o la propagación de las paredes de dominio serán útiles en lógica magnética, procesando la información a través de circuitos magnéticos que forman parte de estos nuevos transistores ${ }^{3}$.

La aparición de nuevos materiales con excelentes propiedades eléctricas como el grafeno; cuyo descubrimiento en $2004^{4,5}$ llevó a la concesión del Premio Nobel de Física para A. Geim y K. S. Novoselov en $2010^{6}$ constituye hoy día una nueva revolución en micro y nanoelectrónica ${ }^{7}$. 


\subsection{Nanofabricación mediante "Dual Beam"}

\subsubsection{Descripción general de un "Dual Beam”}

Un equipo compuesto por un haz de electrones focalizado, en inglés "Focused Electron Beam” (FEB) o también denominado microscopio electrónico de barrido, en inglés "Scanning Electron Microscope" (SEM) y un haz de iones focalizado, en inglés "Focused Ion Beam" (FIB) es comúnmente conocido por la comunidad científica con el nombre de Doble Haz, en inglés “Dual Beam”; gracias al gran acierto que tuvo la empresa FEI Company al seleccionar este término, como nombre comercial de su producto. Otras empresas que comercializan este tipo de microscopios lo llaman “Cross Beam” o simplemente, FIB-SEM.

Obviamente, las partes principales del "Dual Beam", son su columna de electrones y su columna de iones. La columna de electrones está situada en la vertical de la cámara de vacío, y la columna de iones a $52^{\circ}$ respecto a la columna de electrones. El sistema de vacío utilizado en la columna de electrones se compone de dos bombas iónicas, una para la fuente de electrones que se sitúa en la parte superior de la columna, con una presión de $\sim 2.5 \times 10^{-10}$ mbar y otra para el resto de la columna, con una presión de $\sim 2 \times 10^{-7}$ mbar. En la columna de iones tenemos una bomba de vacío iónica, con una presión de $\sim 2 \times 10^{-7}$ mbar. Además, el sistema de vacío en la cámara de proceso está compuesto por una bomba rotatoria y una turbomolecular operando en alto vacío, siendo la presión base de la cámara del orden de $\sim 1 \times 10^{-6}$ mbar. La posición y movimiento del portamuestras en los ejes $\mathrm{x}, \mathrm{y}, \mathrm{z}$, rotación e inclinación dentro de la cámara de proceso está controlado por una plataforma motorizada, posicionando la muestra bajo el haz de electrones y alineando el haz de iones, es posible tomar simultáneamente imágenes del mismo objeto con ambos haces. Diferentes tipos de detectores son utilizados para atraer electrones secundarios (SEs), electrones retrodispersados (BSEs) e iones secundarios (SIs) 
emitidos por la muestra para la formación de una imagen. En la Figura 1.3 podemos ver un esquema de las partes más importantes de un "Dual Beam”.

La micro- y nanofabricación mediante un "Dual Beam” tiene varias ventajas sobre otras técnicas de microfabricación, como la fotolitografía. La fabricación directa de motivos de tamaño nanométrico es posible sin la necesidad de utilizar máscaras, ni resinas. Además, es posible alcanzar una resolución de $3 \mathrm{~nm}{ }^{8}$ y es una técnica muy versátil para una gran variedad de materiales y geometrías. Algunas de las aplicaciones de este sistema ya están desarrolladas e integradas en la industria de semiconductores, como en la fabricación de circuitos integrados, para la reparación de máscaras utilizadas en procesos de fotolitografía ${ }^{9}$, diagnóstico de errores en los procesos, edición y reestructuración de circuitos, la preparación de muestras para microscopía electrónica de transmisión, etc. ${ }^{10,11}$.

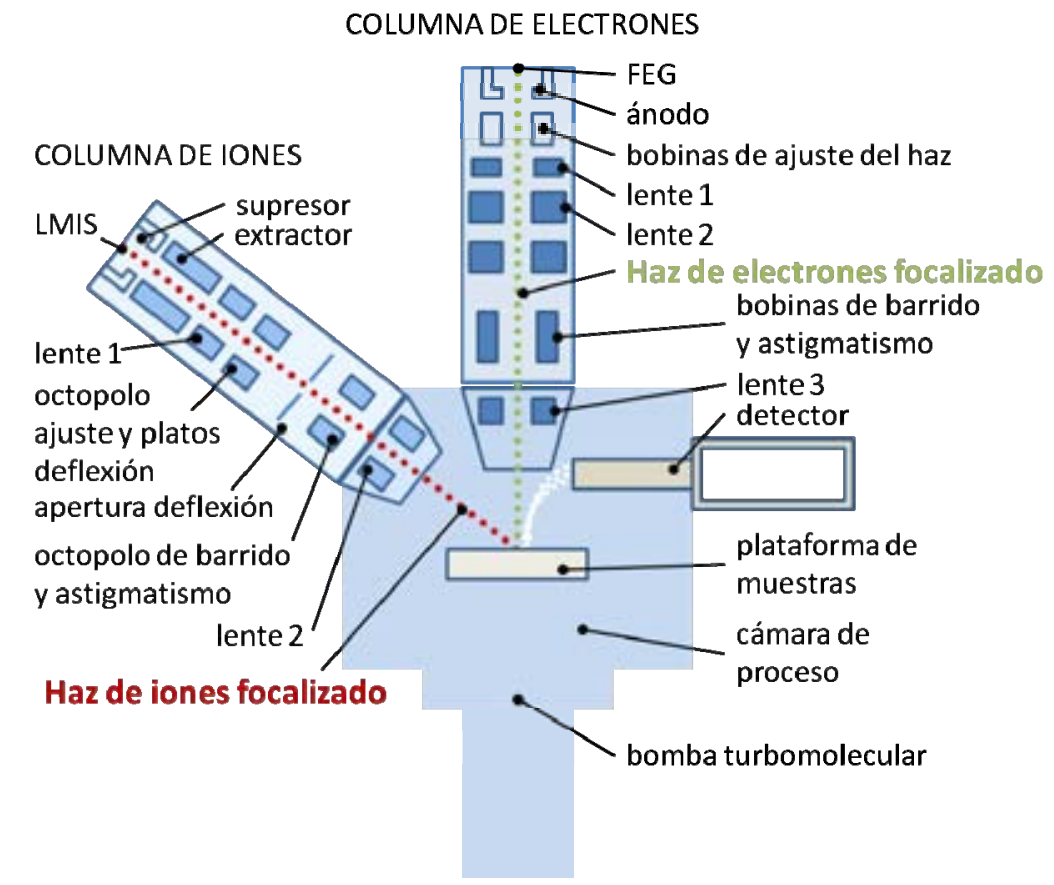

Figura 1.3: Diagrama de un sistema "Dual Beam". 


\subsubsection{Haz de electrones focalizado}

La columna de electrones está basada en una fuente de electrones de emisión de campo, en inglés “Field Emission Gun” (FEG). Los electrones se extraen a partir de un filamento de wolframio al aplicar una diferencia de potencial de $200 \mathrm{~V}$ a $30 \mathrm{kV}$. El haz de electrones acelerado sale de la fuente y es focalizado por las lentes condensadora y objetivo. De esta forma, se consigue obtener una resolución en imagen de $\sim 0.9 \mathrm{~nm}$. Las bobinas de barrido controlan el camino que siguen los electrones a través de la columna para guiar al haz punto a punto sobre la superficie de la muestra, desde dónde se emiten las señales que recopilan los detectores, como el ETD (“Everhart-Thornley Detector”).

En la irradiación de electrones, los electrones energéticos interaccionan con los átomos del sustrato. En la Figura 1.4(a) se indican los procesos físicos más relevantes a los que dan lugar, como los SEs, los BSEs y las señales de rayos-X y en la (c) mostramos una simulación realizada con el programa CASINO ("monte CArlo SImulation of electroN trajectory in sOlids”) ${ }^{12,13}$, en la que se indica que el valor del volumen de interacción del FEB, acelerado a $30 \mathrm{kV}$ y con un ángulo de incidencia perpendicular al sustrato de silicio oxidado térmicamente (250 $\mathrm{nm}$ de $\mathrm{SiO}_{2}$ ) es de $\sim 6$ $\mu \mathrm{m}$. Sólo una pequeña fracción de la energía del FEB incidente puede ser transferida al núcleo de los átomos, debido a la conservación del momento. Por tanto, una elevada energía del FEB (energía umbral) sería necesaria para desplazar un átomo. Por ejemplo, una energía del FEB de $100 \mathrm{keV}$ sería necesaria para transferir aproximadamente $20 \mathrm{eV}$ a un átomo de carbono. Habitualmente, este tipo de transferencia de energía no nos lleva a desplazamientos de los átomos, pero puede dañar el sustrato debido a las reacciones químicas locales estimuladas por el haz ${ }^{14}$. 

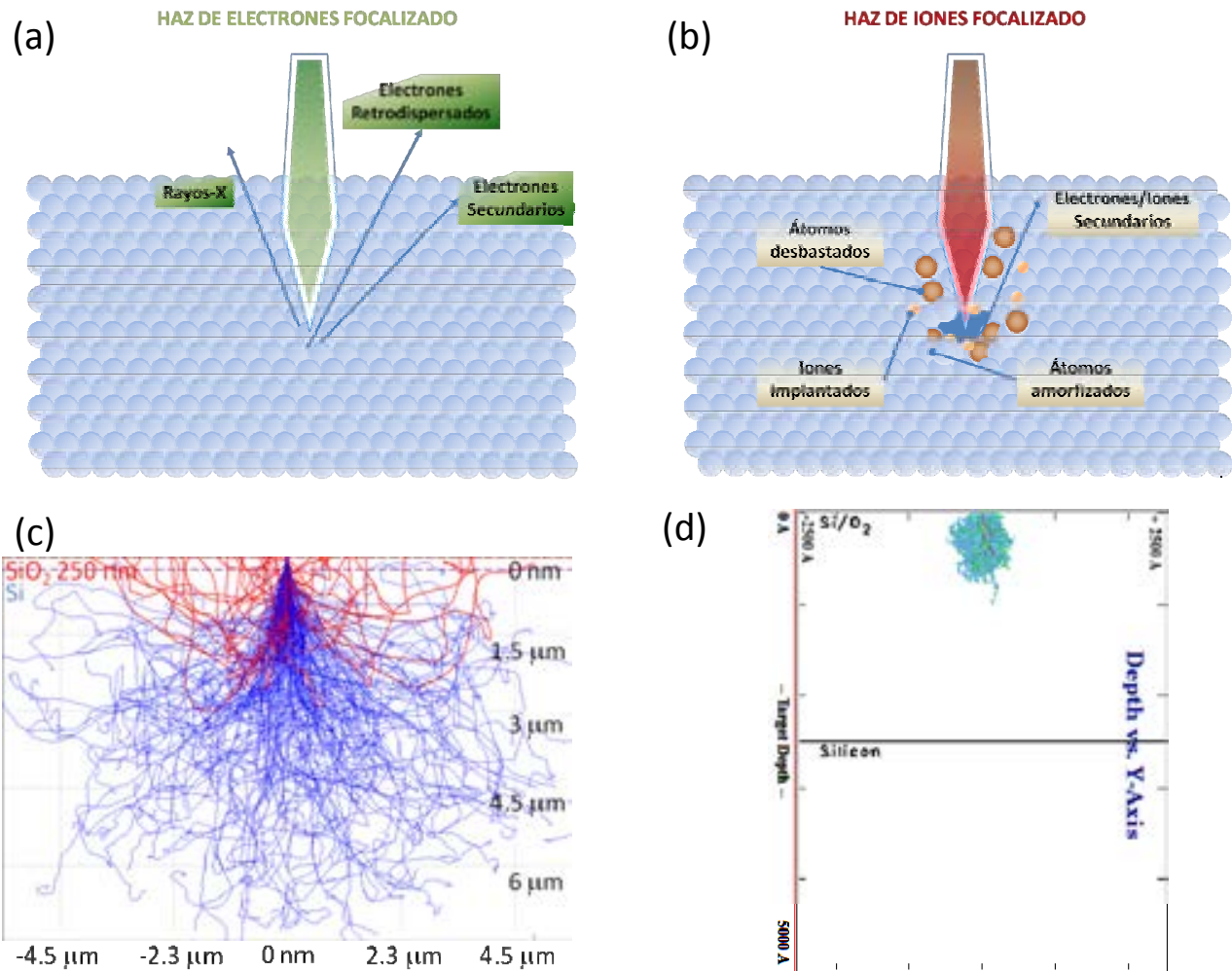

(d)

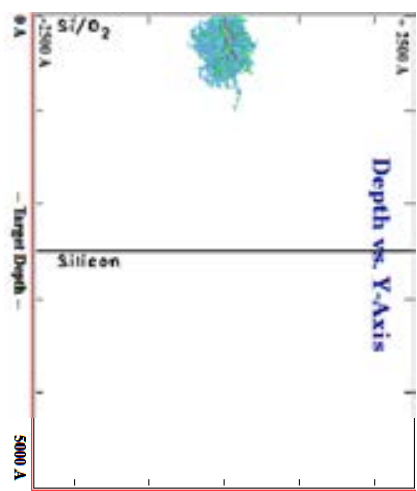

Figura 1.4: (a) Esquema de las interacciones más relevantes que se producen entre el FEB y (b) el FIB y un sólido. (c) Simulación de las interacciones del FEB a 30 kV con un ángulo de incidencia perpendicular a la superficie del sustrato de Si oxidado térmicamente realizada mediante el programa CASINO y (d) igual que la simulación de (c) pero con el FIB de $\mathrm{Ga}^{+}$y realizada mediante el programa SRIM.

\subsubsection{Haz de iones focalizado}

La columna de iones está basada en una fuente de iones metálicos en fase líquida, en inglés, "Liquid Metal Ion Source” (LMIS) ${ }^{15}$. Los iones se extraen mediante un campo eléctrico desde la capa de metal líquido, en este caso $\mathrm{Ga}^{+}$, que cubre un electrodo de punta afilada de wolframio. Mediante un sistema óptico adecuado, el haz se focaliza hasta obtener $\sim 5 \mathrm{~nm}$ de diámetro y puede operar con un voltaje de aceleración entre 0.5-30 kV. El FIB opera de forma similar al SEM, pero usando un 
haz de iones en vez de un haz de electrones (véase la Figura 1.5) que nos permitirá tomar imágenes, grabar motivos y crecer material.

En la Figura 1.4(b) se representan las interacciones más importantes entre el FIB y un sólido. Asimismo, en (d) mostramos una gráfica a partir de una simulación realizada con el programa TRIM, que indica que el valor del volumen de interacción del FIB de $\mathrm{Ga}^{+}$, acelerado a $30 \mathrm{kV}$ y con un ángulo de incidencia perpendicular al sustrato de silicio oxidado térmicamente $\left(250 \mathrm{~nm}\right.$ de $\mathrm{SiO}_{2}$ ) es de $100 \mathrm{~nm}$. TRIM/SRIM ("Transport of Ions in Matter/Stopping and Range of Ions in Matter”) ${ }^{16}$ es el programa estándar para evaluar las interacciones entre iones acelerados y un sólido. Usa algoritmos estadísticos para calcular como los iones pierden su energía en el sólido y se obtienen distribuciones espaciales en tres dimensiones de los iones en materiales simples o más complejos. Como no es posible distinguir cuando una cascada pasa de cascada lineal a régimen de punta caliente, se asume el tratamiento de las colisiones como colisiones binarias independientes. Sin embargo, TRIM rara vez puede ser usado para estimaciones cuantitativas de la interacción y distribución de defectos en nanosistemas fuertemente anisotrópicos, porque el programa asume que la muestra irradiada es una estructura amorfa con una densidad de masa homogénea.

El grabado en el material tiene lugar como resultado de la pulverización física de un sustrato y se produce por una serie de colisiones elásticas donde el momento de los iones incidentes se transfiere a los átomos del sustrato dentro de una cascada de colisiones. Un átomo de la superficie puede ser expulsado como una partícula pulverizada si recibe una componente de energía cinética lo suficientemente superior a la energía de enlace superficial del sustrato. Detalladamente, cuando una partícula energética, como es el caso de los iones de $\mathrm{Ga}^{+}$penetra en un sólido, ésta colisiona con el núcleo y los electrones del sustrato, así la energía de los iones se transfiere a los átomos del sustrato. Si los átomos que reciben la colisión adquieren la suficiente energía cinética para abandonar su posición en la red atómica, pueden aparecer varios defectos a escala atómica sobre el sustrato. La pérdida de energía de los iones en un sustrato sólido puede ser dividido en dos mecanismos diferentes: la pérdida de energía nuclear y la pérdida de energía electrónica. La pérdida de energía nuclear se origina de 
las colisiones elásticas entre los iones y los núcleos de los átomos en el sólido, así la energía cinética de los iones es parcialmente transmitida a los átomos del sólido como un todo, resultando en su movimiento de traslación. Las colisiones entre los núcleos a elevadas energías suelen ocurrir como consecuencia de colisiones binarias independientes de los átomos, entre los cuales el ión se mueve casi con una trayectoria recta. La cascada de colisiones llega a ser un fenómeno muy complejo que lleva a la desintegración completa de la red. Mientras que la pérdida de energía electrónica es gobernada por colisiones inelásticas entre los iones en movimiento y los electrones del sólido, los cuales pueden estar enlazados o libres. Muchos procesos físicos diferentes contribuyen a la pérdida de energía electrónica: ionización de los átomos del sólido, excitación de los electrones en la banda de conducción, plasmones, etc. ${ }^{10,14}$.
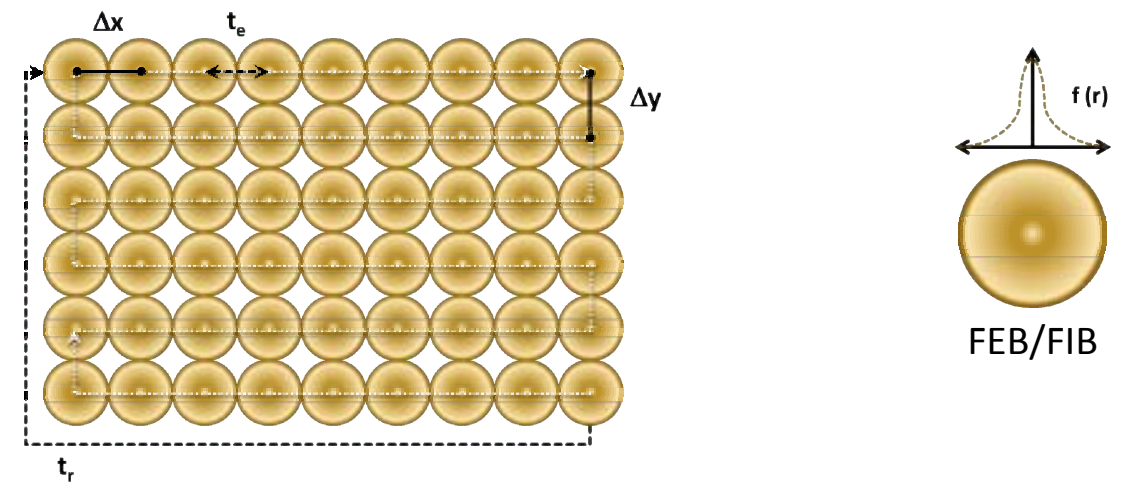

FEB/FIB

Figura 1.5: Esquema del barrido en forma de serpentín (de abajo a arriba) que puede realizar tanto el FEB como el FIB. El haz tiene un perfil Gaussiano, el tiempo que el haz permanece en cada punto es $t_{\mathrm{e}}$, el movimiento del haz de un punto a otro en el eje $\mathrm{x}$ es $\Delta \mathrm{x}$ y en el eje $\mathrm{y}, \Delta \mathrm{y}$. El barrido del diseño se repite después del tiempo de refresco, $\mathrm{t}_{\mathrm{r}}$. un número determinado de veces, en función del espesor de la nanoestructura.

\subsubsection{Grabado inducido mediante un haz de iones focalizado}

Metafóricamente podríamos hablar del FIB como de una caja repleta de pinceles de distintos grosores a disposición del talento del artista. Así, como si de un lienzo se tratara plasmamos con sutileza y precisión nanométrica trazos más o menos gruesos, 
en función de su diámetro, definiendo líneas, áreas y motivos, que finalmente forman un diseño. De tal manera, que si dejáramos a un lado la funcionalidad de estos, el grabado o tallado de estructuras mediante FIB, no sería más que arte a escala nanométrica. Las interacciones del FIB y el sólido suceden a partir de la pérdida de energía cinética inicial de los iones. Por tanto, si el ión no se puede dispersar fuera de la superficie del sustrato, se implantará a cierta profundidad de la superficie del sustrato. Algunos ejemplos de estas "piezas de arte” se exponen en la Figura 1.6 en la cual encontramos imágenes tomadas de los logos que se han grabado como muestra de agradecimiento a las instituciones que me han permitido el uso de las infraestructuras y equipamiento fundamentales para el desarrollo del trabajo experimental realizado en esta tesis. (a) Imagen SEM del logo de la Universidad de Zaragoza sobre un sustrato de Si, (b) imagen FIB del logotipo del Laboratorio de Microscopías Avanzadas sobre un sustrato de $\mathrm{Cu}$ y (c) imagen FIB del logo del Instituto de Nanociencia de Aragón sobre un sustrato de $\mathrm{Cu}$.

Desde el punto de vista funcional, el grabado mediante FIB permite un nuevo enfoque en sistemas de micro y nanoelectrónica, como por ejemplo el diseño o modificación de dispositivos nanomecánicos que forman parte de transistores ${ }^{17}{ }^{18}$, el tallado de nanoestructuras ${ }^{19-21}$, nanofabricación en tres dimensiones ${ }^{11}$, nanofabricación de puntas atómicas ${ }^{22,23}$, etc.
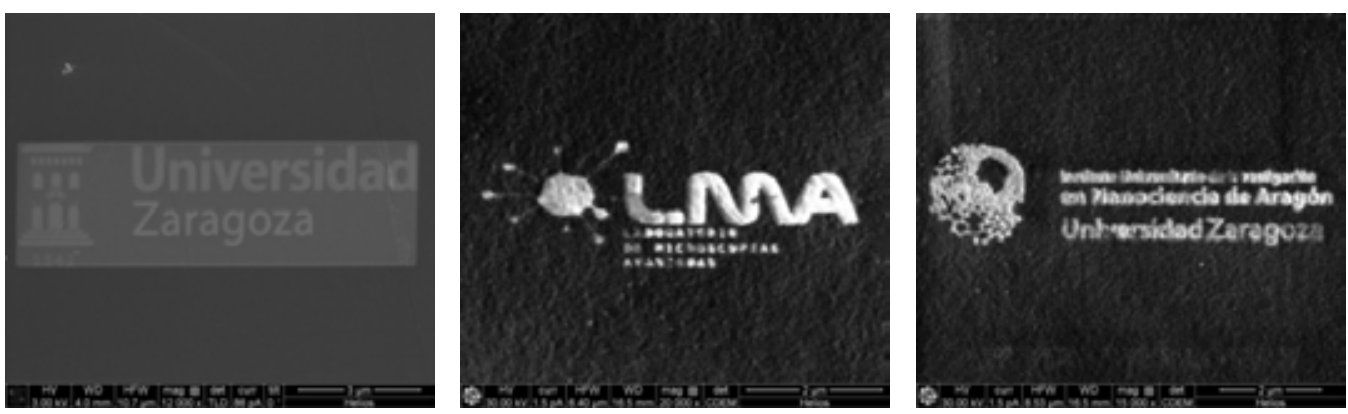

Figura 1.6: Grabado mediante FIB de los logotipos (de izquierda a derecha) de la Universidad de Zaragoza, el Laboratorio de Microscopías Avanzadas y el Instituto de Nanociencia de Aragón. 


\subsubsection{Ataque inducido mediante un haz de electrones $o$ iones focalizado}

El ataque inducido por un haz de electrones o iones focalizado, FEBIE o FIBIE, respectivamente son técnicas comparables con la conocida "reactive ion etching" (RIE), con la diferencia que en los casos que presentamos el grabado es local y no global. Las diferencias entre el FEB y el FIB obviamente tienen una gran influencia en el resultado de los grabados cuando usamos gases de ataque. El mecanismo por el cual los gases de ataque consiguen el resultado final puede ser debido a uno o a varios efectos. Los gases pueden adsorberse en la superficie de la muestra y directamente reaccionar con esta, sin que sea necesario el haz para activar la reacción. O bien, pueden ser activados por los electrones secundarios generados y que alcanzan la superficie de la muestra. Las moléculas de gas adsorbidas pueden reaccionar con la superficie del material y atacarlo fácilmente. También pueden reaccionar con el material pulverizado cerca de la superficie para evitar su redepósito ${ }^{24}$.

Cualquier proceso en el que se usen gases de ataque tiene un mayor grado de difusión lateral. El proceso de pulverización física del FIB tendrá una mayor eficiencia al añadir este tipo de gases comparado con el proceso de ataque químico con el FEB, debido a que éste último por sí mismo no es capaz de grabar estructuras en un material. Sin embargo, como ya hemos comentado previamente, el FIB puede grabar cualquier material sin la necesidad de un gas adicional. Así, los procesos realizados mediante FIB en los cuales se usa un gas de ataque siempre serán más rápidos, en condiciones estándares, que los realizados mediante FEB.

El uso de gases de ataque junto con el FIB es muy útil a bajas corrientes para aumentar la velocidad de grabado en el material y para hacer que el material pulverizado reaccione formando un compuesto volátil y así evitar que se redeposite. Por ejemplo, el $\mathrm{I}_{2}$ reacciona con el $\mathrm{Al}$, y con el $\mathrm{W}$ crecido mediante FIBID más rápido que con el $\mathrm{SiO}_{2}$ y así permite cortar un contacto minimizando el grabado en el material aislante ${ }^{25}$. 
Como ya hemos comentado, el FEB no tiene un efecto de pulverizado físico a los voltajes de aceleración con los que se trabaja en un SEM convencional y los procesos de ataque se basan en la reactividad del gas adsorbido y en la volatilidad de los productos de la reacción. El proceso ha sido demostrado en materiales como por ejemplo, $\mathrm{SiO}_{2}$, $\mathrm{SiN}, \mathrm{Al}, \mathrm{Cr}, \mathrm{CrO}_{\mathrm{x}}, \mathrm{TaN}, \mathrm{GaAs}$ y Ge $\mathrm{G}^{26-33}$ usando como gases de ataque $\mathrm{XeF}_{2}, \mathrm{NOCl}, \mathrm{o}_{2}$. Además, el Ti es susceptible de ser atacado tanto por FEBIE ${ }^{34}$, véase la Figura 1.7, como por FIBIE ${ }^{35}$ utilizando el $\mathrm{XeF}_{2}$ como gas de ataque.

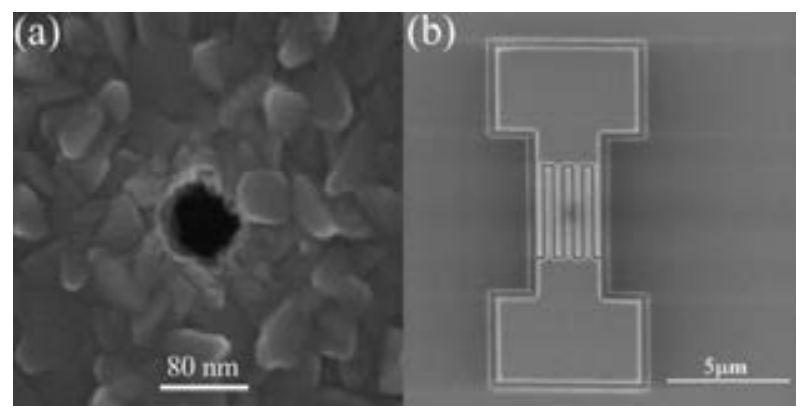

Figura 1.7: Ataque sobre una película delgada de Ti de $200 \mathrm{~nm}$ de espesor mediante FEBIE con $\mathrm{XeF}_{2}$ : (a) Imagen SEM de un ataque con forma de agujero de $80 \mathrm{~nm}$ de diámetro. (b) Nanoelectrodos interdigitados con una resolución de $\sim 200 \mathrm{~nm}$. Figura extraída de la referencia ${ }^{34}$.

\subsubsection{Crecimiento inducido mediante un haz de electrones focalizado}

El crecimiento inducido por un haz de electrones focalizado (FEBID) es una técnica que comenzó a desarrollarse en los años 1980s ${ }^{36-38}$, la cual utiliza un haz de electrones, normalmente de un SEM/FEB, para disociar un material precursor, creando un depósito de forma selectiva. Las principales ventajas de esta técnica respecto a las tradicionales son: (1) el crecimiento sobre cualquier tipo de sustrato y en cualquier posición a la que alcance la imagen mediante el FEB, (2) es un proceso en un solo paso, (3) el crecimiento de estructuras en tres dimensiones, y (4) el control de su tamaño lateral y espesor a escala nanométrica. El mecanismo de crecimiento se puede considerar como el bien conocido, crecimiento químico en fase vapor 
(“Chemical Vapour Deposition”, CVD) asistido por un haz de electrones focalizado, utilizando generalmente compuestos organometálicos como materiales precursores, véase la Figura 1.8(a). La mejor resolución alcanzada mediante esta técnica fue conseguida por Van Kouwen ${ }^{8}$, dónde se crecieron puntos de Pt de 3 nm. Estas técnicas desarrolladas en los últimos 30 años, ofrecen unas apasionantes perspectivas de futuro en un amplio rango de aplicaciones dentro del ámbito de los sistemas micro y nanoelectrónicos. Información más detallada acerca del proceso FEBID se puede encontrar en los siguientes resúmenes publicados por diferentes autores ${ }^{24,39-41}$.

Al profundizar en el proceso FEBID, primero debemos tener en cuenta las interacciones que se producen, como la que tiene lugar entre las moléculas de precursor y el sustrato, la interacción entre el FEB y el sustrato, y la que ocurre entre los electrones generados en el sustrato y las moléculas de precursor. La adsorción de las moléculas de precursor en la superficie del sustrato se puede llevar a cabo mediante quimiadsorción o fisiadsorción, cuyo tiempo de residencia es un parámetro importante a tener en cuenta. Cuanto mayor es el tiempo de residencia, mayor es la probabilidad de que el FEB disocie las moléculas. Sin embargo, en cuanto el proceso de crecimiento comienza, la interfase se modifica, pasa de ser la superficie del sustrato a la superficie del depósito. Recientemente se ha publicado un estudio en el cual aportan datos acerca de las reacciones que transcurren en la superficie del sustrato al irradiar con el FEB las moléculas adsorbidas a bajas temperaturas $(<100 \mathrm{~K})$ y en sistemas de ultra alto vacío $\left(\sim 10^{-8} \mathrm{mbar}\right)^{42}$.
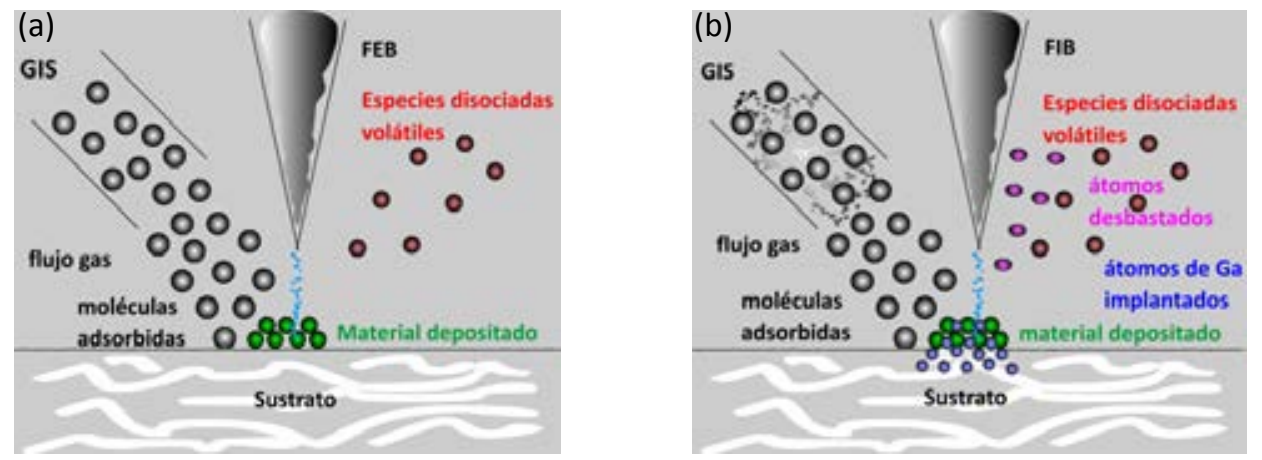

Figura 1.8: Diagramas básicos del (a) crecimiento inducido mediante un haz de electrones focalizado y del (b) crecimiento inducido mediante un haz de iones focalizado. 
Como pudimos ver en la Figura 1.4(a), entre el FEB y el sustrato tienen lugar varias interacciones. En primer lugar, el haz primario colisiona con el sólido y se desvía de su trayectoria inicial. Si la colisión es inelástica, parte de la energía inicial puede ser transferida del haz primario a otros electrones en el sólido. Esos electrones interaccionarán con el sólido y se dispersarán. Los electrones generados de baja energía, menor de 50 eV se llaman SEs, los de alta energía se llaman electrones BSEs. La forma y el tamaño del "cono" de interacciones generadas bajo el FEB dependen de su voltaje de aceleración, del ángulo de incidencia y de la naturaleza del sustrato. Como hemos comentado previamente, el proceso es algo más complejo porque los SEs y los BSEs se generan sobre un sustrato que se modifica durante el propio proceso. El ejemplo más evidente es cuando crecemos pilares, debido a que los electrones que contribuyen al crecimiento cada vez están más confinados en éste, y también porque se puede generar un calentamiento inducido por el FEB al tener menos posibilidad de que se disipe por el sustrato ${ }^{43}$. La medida directa de la temperatura local producida por los electrones es imposible de realizar porque no hay un dispositivo que permita la suficiente resolución espacial, temporal y térmica. Sin embargo, muchos autores han realizado cálculos analíticos y simulaciones que indican que el aumento de temperatura es insignificante en un sustrato masivo. La velocidad de crecimiento aumenta cuando desciende la temperatura del sustrato, por tanto, el proceso depende de las moléculas adsorbidas en la superficie y la velocidad depende del tiempo de residencia de las éstas ${ }^{44}$.

La interacción más importante entre el FEB y las moléculas de precursor es la descomposición de éstas, aunque no debemos olvidar que el FEB también puede estimular la desorción de las moléculas de precursor. La probabilidad de que un electrón induzca la escisión de un enlace de la molécula del precursor depende de su energía y se expresa como la eficiencia, “cross section" $\sigma_{(\mathrm{E})}\left(\mathrm{cm}^{2}\right)$. Cuanto mayor sea $\sigma_{(\mathrm{E})}$, mayor será la probabilidad de que los enlaces de las molécula se disocien. Sin embargo, es una probabilidad que depende de muchos parámetros, como por ejemplo las energías de enlace de la molécula o de la geometría específica de adsorción de la molécula. Los electrones de baja energía del orden de decenas de eV pueden inducir la 
disociación de los enlaces de las moléculas de precursor, de la misma forma que permiten la disociación de especies contaminantes, como hidrocarburos que se encuentran dentro de la cámara de proceso durante el barrido del FEB al tomar imágenes. Así, los electrones de baja energía, como los SEs, juegan un papel principal en el proceso de disociación de las moléculas de precursor y por tanto del crecimiento del depósito. Sin embargo, no podemos excluir de este proceso las contribuciones debidas a los electrones de elevada energía, como el haz primario o los BSEs, porque el número absoluto de electrones generados bajo el haz puede ser lo suficientemente elevado como para que su contribución al crecimiento del depósito sea significativa (véase la Figura 1.9).

Teniendo en cuenta los tres tipos de interacciones, se han observado dos regímenes de crecimiento. En el primero, el régimen limitado por los electrones, el crecimiento está limitado por la densidad de corriente del FEB y es independiente del flujo de gas precursor. En el segundo régimen, llamado limitado por el precursor, el crecimiento está limitado por el número de moléculas que alcanzan la superficie del área irradiada; de tal manera que se descomponen las moléculas adsorbidas en la superficie irradiada y las que se difunden hacia el área irradiada.

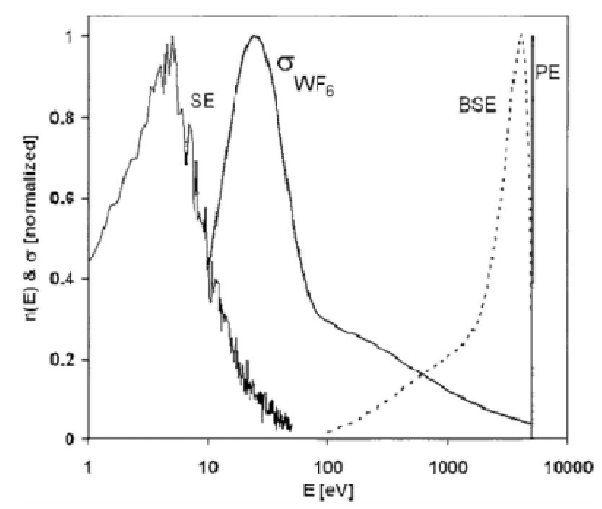

Figura 1.9: Simulación de la distribución de energía de SEs y BSEs emitidos desde un sustrato de Ge y la eficiencia estimada de la disociación de la molécula de $\mathrm{WF}_{6}$ en función de la energía del FEB. Figura extraída de la referencia ${ }^{45}$. 
El proceso de crecimiento mediante FEBID se produce por una serie de complejos fenómenos físicos, y los modelos que intentan simular los resultados experimentales deben tener en cuenta un número elevado de factores o parámetros; como por ejemplo, la densidad de electrones y distribución espacial y de energía, la probabilidad de que la molécula de precursor se disocie en función de la energía del FEB, el tiempo de residencia del precursor, el calentamiento inducido por el haz de electrones, etc. Las simulaciones basadas en el modelo de Monte-Carlo permiten estudiar la distribución espacial y el espectro de energía de los electrones generados en un sólido, por lo que en este sentido se convierten en una herramienta muy útil ${ }^{43}$.

La velocidad de crecimiento viene expresada por la siguiente ecuación:

$$
R=\int_{0}^{E_{0}} f(E) \sigma_{\text {diss }}(E) N d E
$$

dónde $E_{0}$ es la energía del haz primario, $f(E)$ es el flujo de electrones y $\sigma_{\text {diss }}(E)$ es la probabilidad de que se disocien los enlaces de las moléculas de precursor a una energía dada y $\mathrm{N}$ es la densidad molecular en la superficie del sustrato. Algunos autores encontraron experimentalmente un máximo en la $\sigma_{\text {diss }}(E)$ para un valor de energía de unas decenas de $\mathrm{eV}^{46}$. Estos valores están muy próximos a la posición del máximo de la distribución de SEs generados por el FEB, y así a la mayor disociación de moléculas de precursor.

Sin embargo, la descomposición del material precursor no es completa debido a su naturaleza, sus energías de enlace y su disposición a disociarse bajo las condiciones de trabajo convencionales de un microscopio electrónico. Estas condiciones de trabajo son las siguientes: la temperatura ambiente en la cámara de proceso, la atmósfera de alto vacío (en el rango de $10^{-6} \mathrm{mbar}$ ), en ausencia de gases reactivos y por otra parte, la baja generación de electrones secundarios producidos a los voltajes típicos de trabajo (entre 1-30 kV). Estos últimos son los principales responsables del proceso de descomposición del material precursor y como consecuencia del crecimiento de materiales. De esta forma, el material crecido está compuesto por el elemento 
deseable, cuya naturaleza normalmente es metálica, más carbono y oxígeno que provienen del material precursor y de especies contaminantes (hidrocarburos, oxígeno y vapor de agua) presentes en la cámara de vacío, en general empeorando la funcionalidad de las nanoestructuras. En la literatura encontramos el crecimiento de nanoestructuras de distintos tipos de materiales, como Pt, Pd, Cr, W, Co, Fe, etc, con un contenido metálico $<50 \%{ }^{24,40,41,47}$. En la Figura 1.10 mostramos una imagen SEM de unos motivos navideños de Pt crecidos mediante FEBID. Diferentes estrategias centradas en la purificación de estos depósitos para mejorar el contenido metálico y así la propiedades físicas de estos han sido estudiadas en los últimos años $47-50$.

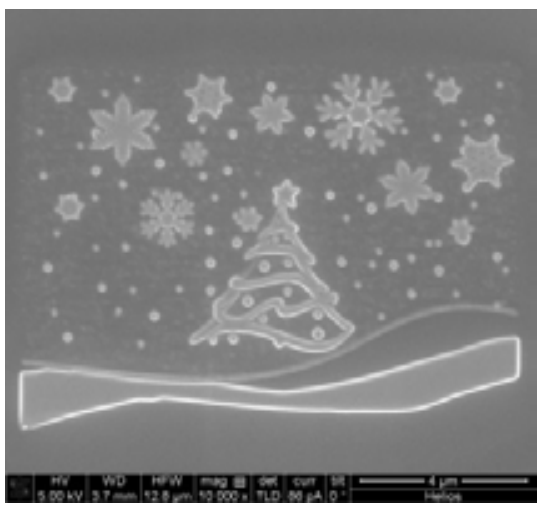

Figura 1.10: Imagen SEM de motivos navideños de Pt crecidos mediante un haz de electrones focalizado sobre un sustrato de Si.

\subsubsection{Crecimiento inducido mediante un haz de iones focalizado}

El crecimiento inducido por un haz de iones focalizado (FIBID) es una técnica análoga al crecimiento mediante FEBID, salvo que se utiliza un haz de iones focalizado en vez de un FEB, véase la Figura 1.8(b). Por tanto, se aplica lo comentado en el apartado 1.3.4 del presente Capítulo ${ }^{10,41}$. Sin embargo, no debemos olvidar que la acción del impacto y pulverización del FIB no ha desaparecido. En el balance de los procesos, esta contribución debe ser superada por la velocidad de crecimiento. Para conseguir un crecimiento adecuado debemos seleccionar la corriente del FIB acorde 
con el volumen de material a crecer, porque si la densidad de corriente del FIB es demasiado alta desbastaremos la superficie del sustrato en vez de crecer un depósito. Mientras que, si la densidad de la corriente del FIB es demasiado baja, la velocidad de crecimiento será baja y el material crecido contendrá una elevada concentración de material sin reaccionar.

Existen varios efectos secundarios que influyen en el proceso de fabricación mediante FIBID como por ejemplo, la implantación de iones, generación local de calor, redepósito de material, efectos de los SEs y el crecimiento debido a los iones dispersados. En los procesos de fabricación se suelen utilizar un FIB de iones pesados como el $\mathrm{Ga}^{+}$, en los cuales los iones dispersados pueden tener una influencia significativa en el crecimiento de nanoestructuras al compararlos con los efectos producidos por los electrones secundarios. Durante el proceso FIBID, los iones dispersados golpean la superficie del sustrato cerca de la base de la nanoestructura que está creciendo mediante el FIB y descompone las moléculas de precursor adsorbidas sobre éste, ensanchando su base. Ese depósito se genera hasta distancias de algunas micras desde la base de las nanoestructuras, y depende de la energía y el flujo de iones primarios utilizado en el proceso de crecimiento. Por tanto, el halo generado en los depósitos crecidos mediante FIBID es debido en gran medida a la escisión de las moléculas de precursor producida por los iones de $\mathrm{Ga}^{+}$dispersados que escapan del borde de la estructura que se está creciendo. El perfil y el espesor del halo son directamente proporcionales al flujo de iones de $\mathrm{Ga}^{+}$dispersados y la intensidad de iones dispersados cerca de la base de la estructura será muy elevada debido al pequeño ángulo de dispersión. El proceso está esquemáticamente ilustrado en la Figura 1.11, dónde se indican el FIB, el flujo de iones dispersados, la estructura de Pt crecida y el perfil del halo generado.

Además, podrían existir otros fenómenos como el pulverizado y la ruptura inducida mediante los SEs de los enlaces de las moléculas, etc. Así, en regiones muy próximas a la estructura, el perfil de crecimiento cerca de la base se atisba bastante complejo. Sin embargo, la influencia de esos fenómenos puede ser insignificante para 
relativamente largas distancias, por encima de $200 \mathrm{~nm}$ de distancia de la base de la estructura crecida ${ }^{51}$.

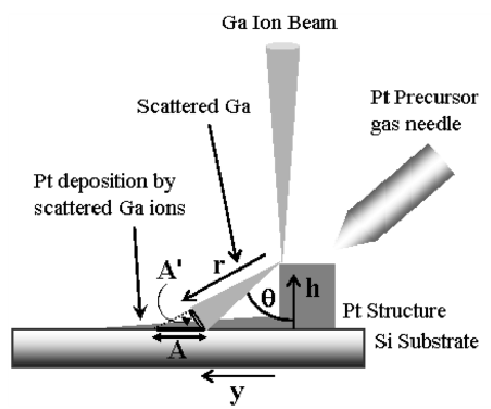

Figura 1.11: Representación esquemática de halo generado por los iones de $\mathrm{Ga}^{+}$ dispersados. Imagen extraída de la referencia ${ }^{51}$.

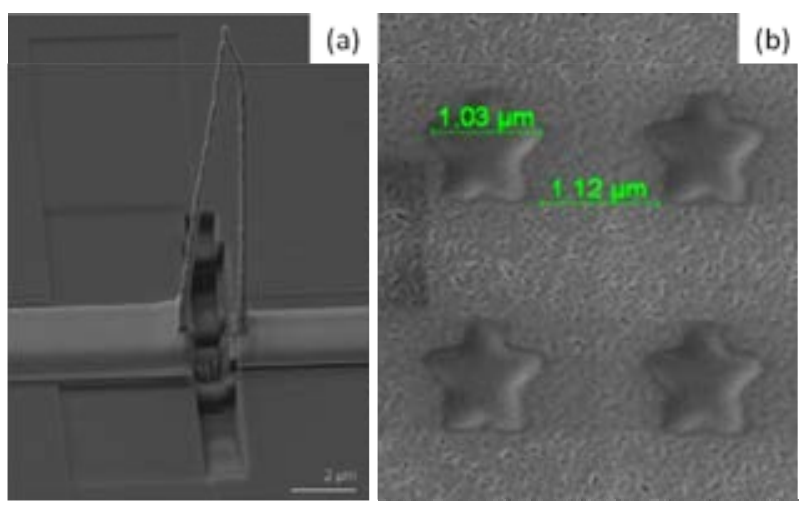

Figura 1.12: Imágenes SEM de estructuras de W crecidas mediante FIBID (a) Puente suspendido (imagen con un ángulo de inclinación de $54^{\circ}$ ) extraída de la referencia ${ }^{53}$; (b) Estrellas de cinco puntas.

En la literatura podemos encontrar numerosos estudios en los que el crecimiento de nanoestructuras mediante FIBID podría tener un papel crucial en innumerables aplicaciones en el campo de la Nanotecnología. Como ejemplos, podemos enumerar el crecimiento de estructuras en tres dimensiones de $\mathrm{W}$ como se puede observar en la Figura 1.12(a) y de Pt en la Figura 1.13, las cuales se podrían utilizar para contactar nanopartículas, nanohilos, etc. ${ }^{52-57}$; el crecimiento de estructuras con formas muy 
diversas, como podemos ver en la Figura 1.12(b); el uso de los depósitos de $\mathrm{SiO}_{2}$ en el sellado hermético de dispositivos (bajo condiciones de vacío) MEMS ${ }^{58}$; depósitos de Pt crecidos mediante FIBID como películas protectoras en la fabricación de muestras para TEM mediante FIB; la reparación de circuitos integrados mediante W crecido por FIBID ${ }^{25,59}$, entre otros muchos.

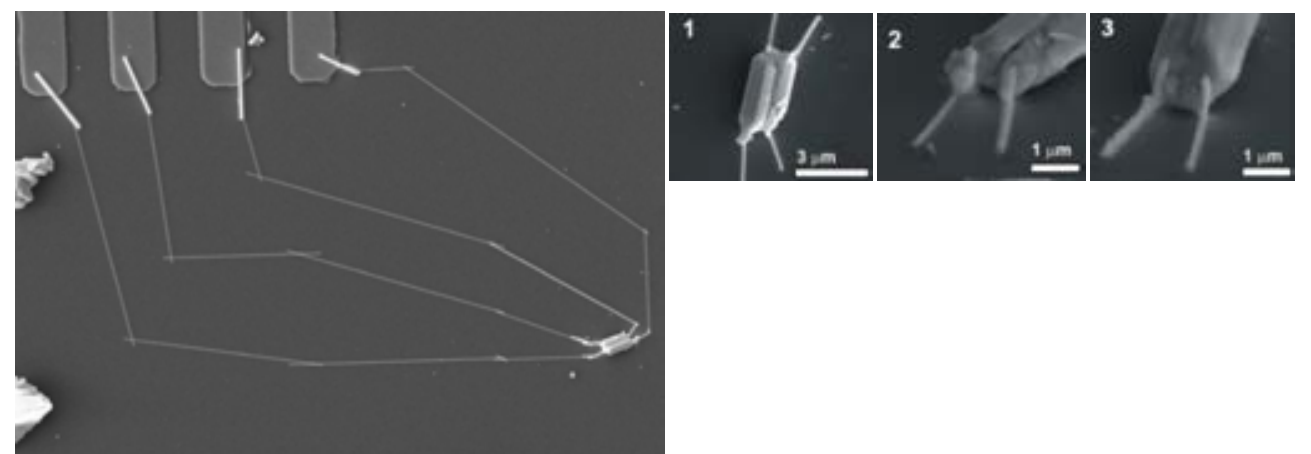

Figura 1.13: Imágenes SEM de depósitos de Pt crecidos mediante FIBID que contactan una partícula permitiendo el estudio de sus propiedades eléctricas. Figura extraída de la referencia ${ }^{57}$.

También nos gustaría mencionar el crecimiento inducido por los iones de $\mathrm{Ga}^{+}$ dispersados en las diferentes caras de estructuras fabricadas previamente. Este fenómeno sucede al irradiar con el FIB en las cercanías de esas estructuras (incluso a varias micras de distancia) con la presencia de un gas precursor como podemos ver en la Figura $1.14^{60}$. Primero se fabrica un pilar de carbono mediante FIBID, a continuación crecen al lado un hilo de Pt y el pilar de carbono se cubre de Pt. Sin embargo, si en primer lugar se fabrica un pilar de Pt mediante FIBID y después crecen al lado un hilo de carbono, el pilar de Pt no se cubre de carbono. En el primer caso, se crea el depósito de Pt sobre el pilar de carbono, debido a la disociación de las moléculas de gas precursor que están adsorbidas sobre el mismo, producida por los iones de $\mathrm{Ga}^{+}$dispersados. Estos se generan al impactar con los núcleos de los átomos de Pt a medida que va creciendo el depósito. En el caso del carbono, al ser un elemento más ligero que el $\mathrm{Ga}^{+}$, el impacto de los iones nunca puede producir una 
dispersión de estos con un ángulo ( $\theta$ ) superior a $90^{\circ}$. Por tanto, el crecimiento debido a los iones de $\mathrm{Ga}^{+}$dispersados sólo es posible para aquellos elementos que son más pesados que el $\mathrm{Ga}^{+} 61$.

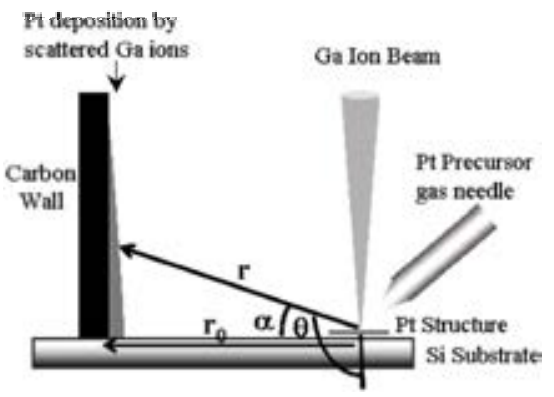

Figura 1.14: Representación esquemática del crecimiento de un depósito sobre una estructura ya crecida mediante los iones de $\mathrm{Ga}^{+}$dispersados. Figura extraída de la referencia ${ }^{61}$.

\subsubsection{Comparación entre las técnicas FEBID y FIBID}

\begin{tabular}{l|l}
\hline \multicolumn{1}{c|}{ FEBID } & \multicolumn{1}{c}{ FIBID } \\
\hline Baja velocidad de crecimiento & Alta velocidad de crecimiento \\
Generación de halo & Generación de halo \\
- & Pulverización del sustrato \\
- & Implantación de iones de $\mathrm{Ga}^{+}$ \\
- & Amorfización del sustrato \\
Bajo contenido de metal, salvo excepciones & Alto contenido de metal \\
- & Iones pueden afectar las propiedades \\
Depósitos de tamaño lateral $<3 \mathrm{~nm}$ & Depósitos de tamaño lateral $<10 \mathrm{~nm}$ \\
\hline
\end{tabular}

Tabla 1.1: Diferencias principales entre FEBID y FIBID. 
Las nanoestructuras estudiadas en esta tesis fueron fabricadas mediante estas dos técnicas. De ahí, la relevancia que se les está otorgando en este Capítulo. En la Tabla 1.1 resumiremos las principales diferencias entre ellas.

\subsubsection{Comparación entre FEBID/FIBID con EBL}

En la Figura 1.15 resumimos las ventajas más significativas de las técnicas de nanofabricación FEBID y FIBID frente a las de técnicas más convencionales y bien instauradas en distintos campos de la Nanotecnología, como es la litografía electrónica.

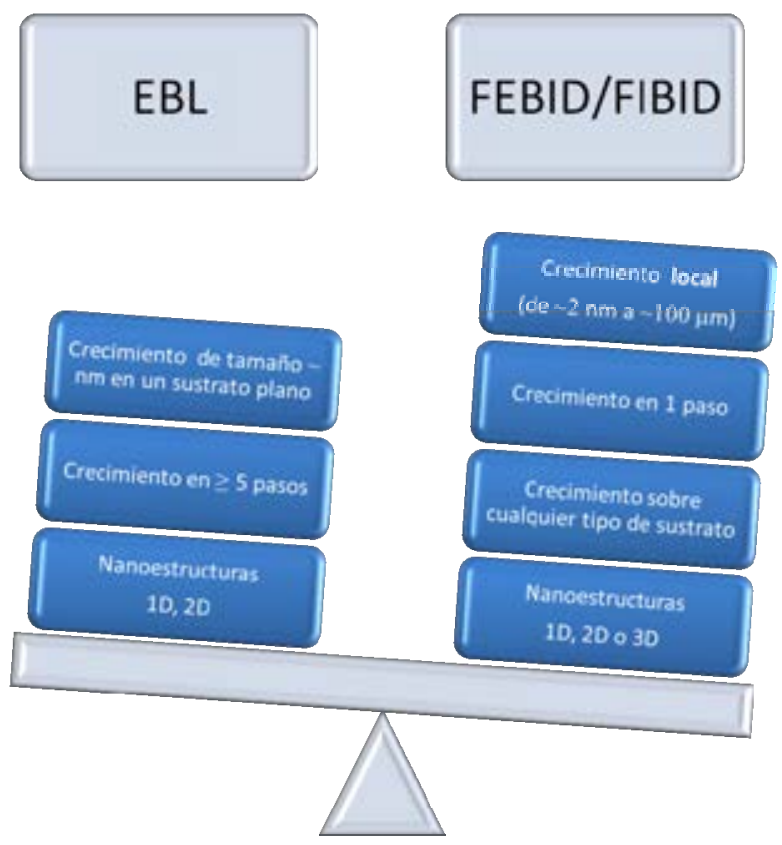

Figura 1.15: Diagrama comparativo a modo de balanza de las virtudes de las técnicas FEBID/FIBID frente a las de la litografía electrónica.

Tras comentar la versatilidad y las numerosas ventajas que exhiben estas novedosas técnicas debemos ser conscientes del elevado número de parámetros que se 
deben estudiar y optimizar para obtener los mejores resultados: dimensiones del depósito en el plano, espesor del depósito, voltaje de aceleración del haz, corriente del haz, tiempo de permanencia del haz en cada punto, la distancia entre cada punto, tiempo de refresco, flujo de gas precursor, presión base de la cámara, naturaleza y limpieza del sustrato, temperatura del sustrato, posición de la aguja del gas precursor respecto de la zona de interés de la muestra, número de barridos, estrategia de barrido. No debemos olvidar los inconvenientes o deficiencias que pueden presentar. En el caso del FEBID: aparición del halo, bajo contenido metálico 30\% atómico, salvo en el contenido de $\mathrm{Fe}>80 \%$ y, Co $>90 \%$, elevada resistividad, varios órdenes de magnitud respecto al metal puro salvo en el Co y el Fe, como mostraremos en los Capítulos 3 y 4 de esta tesis, bajo volumen por dosis $\left(0.01-0.0005 \mu \mathrm{m}^{3} / \mathrm{nC}\right)$. En el caso del FIBID: aparición del halo, implantación de $\mathrm{Ga}^{+}$, induce amorfización, desorden (en el caso de los depósitos de $\mathrm{W}$ es una ventaja como veremos en el Capítulo 5) y pulverización de los primeros nanómetros del sustrato. 


\subsection{Nanoestructuras estudiadas en esta tesis}

Hoy en día pueden fabricarse nanoestructuras mediante técnicas más convencionales y bien instauradas en nanotecnología como el MBE ("molecular beam epitaxialy”), PLD (“pulsed laser deposition”), “sputtering”, CVD, combinadas con EBL, etc. Sin embargo, las ventajas esgrimidas en anteriores apartados nos llevaron al estudio y desarrollo de nanoestructuras funcionales mediante otras técnicas más recientes y menos explotadas. Las nanoestructuras fabricadas en esta tesis fueron crecidas mediante las técnicas FEBID y FIBID ampliamente documentadas en los anteriores apartados. 


\subsection{Nanoestructuras magnéticas}

\subsubsection{Introducción a la Espintrónica}

Espintrónica o Magnetoelectrónica es una tecnología emergente que utiliza el fenómeno de transporte que depende del espín en dispositivos de almacenamiento magnético de datos, lógica magnética, sensores magnéticos, etc. De esta manera, en los últimos años se ha desarrollado una nueva generación de dispositivos espintrónicos basados en nuevos materiales a escala nanométrica.

\subsubsection{Propiedades de nanoestructuras magnéticas}

\subsubsection{Conducción eléctrica}

La carga eléctrica en el interior de un material en presencia de un campo eléctrico aplicado se desplaza por medio de colisiones con el entorno en una dirección paralela a la corriente eléctrica aplicada. Estas colisiones pueden ser debidas, por ejemplo a la red de núcleos atómicos y sus vibraciones (relacionadas con la temperatura) y a las imperfecciones de la red como defectos puntuales (impurezas, vacantes), defectos lineales (dislocaciones) y defectos superficiales (maclas, fronteras de granos). Por lo tanto, el número de colisiones depende de la estructura cristalina del material y de su temperatura. Esas imperfecciones de la red cristalina dispersan las ondas electrónicas disminuyendo su movilidad y por tanto la conductividad eléctrica. La temperatura hace que aumente la energía de vibración de los átomos de la red, por lo que dispersan más las ondas electrónicas disminuyendo la movilidad de los electrones y por tanto la conductividad eléctrica.

En los siguientes apartados centraremos la introducción de las propiedades de las nanoestructuras magnéticas, en los fenómenos de transporte eléctrico asociados a metales granulares, siendo este tipo de sistema de naturaleza similar a las estructuras magnéticas (Co y Fe) crecidas mediante FEBID. Los metales granulares consisten en una mezcla de compuestos metálicos y no metálicos; cuándo la composición de este 
sistema desordenado cambia, sus propiedades eléctricas también lo hacen. Distinguimos tres regímenes de conducción eléctrica: metálico, transición de metal a aislante y aislante o semi-aislante.

Régimen metálico: en el régimen metálico, la resistividad eléctrica viene influenciada por las interacciones electrón-fonón de la estructura metálica. Para elevadas temperaturas, esas interacciones son las responsables del aumento de la resistividad. Además, los metales tienen un ratio de la resistividad residual ("Residual Resistivity Ratio”, RRR) positivo, que se define como $\mathrm{RRR}=\mathrm{R}(\mathrm{T}) / \mathrm{R}(0 \mathrm{~K})$

\section{Régimen de transición de metal a aislante ("Metal-Insulator Transition",} MIT): el cambio de régimen de conducción de metal a aislante en materiales granulares indica que la conductividad pasa de metálica a aislante al descender el contenido metálico, pero en ningún caso se observa un comportamiento metálico o aislante puro. La conducción metálica se produce en materiales con elevada concentración de metal, que percolan conectando los caminos de conducción. Al descender el contenido metálico, los caminos de percolación disminuyen y la activación de los electrones entre islas metálicas comienza a ser significativa en el mecanismo de conducción.

Régimen aislante o semi-aislante: la conductividad se encuentra en el régimen aislante o semi-aislante en sistemas granulares cuando las islas metálicas están completamente rodeadas por una matriz aislante. Así, la conducción es principalmente basada en el túnel o "hopping” de los electrones de isla a isla.

La conductividad en este régimen puede explicarse con un modelo estándar ${ }^{62}$ basado en dos hipótesis: la primera, el transporte de electrones es debido al efecto túnel entre vecinos cercanos y además es térmicamente activado; la segunda, el electrón necesita una suma de energía para saltar hacia la isla cargada para superar la energía electrostática adicional. Para sistemas granulares desordenados, se encontró que la conductividad $\sigma$ debería comportarse como:

$$
\sigma \propto \exp \left(-\left(T_{0} / T\right)^{x}\right)
$$


$\mathrm{T}_{0} \mathrm{y} \mathrm{x} \sim 0.5$ son constantes ${ }^{63}$. Ello indica que los caminos de conducción varían en función de la temperatura, y además se produce un cambio en el balance entre la distancia de "hopping” y la energía de activación. Este mecanismo se conoce como "variable range hopping", VRH.

La teoría de VRH describe el comportamiento de la resistividad a baja temperatura en sistemas altamente desordenados, en los cuales los estados están localizados. Considerando dos estados localizados a una distancia R, el estado de la izquierda está a una energía $E_{1}$ y el estado de la derecha a una energía $E_{2}$. Suponiendo que $\mathrm{W}=\mathrm{E}_{2}-\mathrm{E}_{1}>0$, un electrón puede saltar de la izquierda a la derecha mediante la absorción de un fonón con una energía $\omega$, tal que $\hbar \omega \geq \mathrm{W}$.

(a)

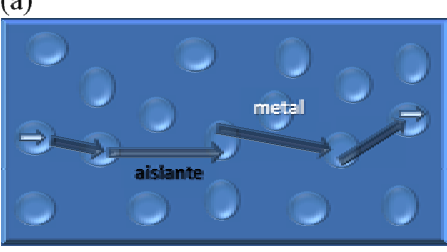

(b)

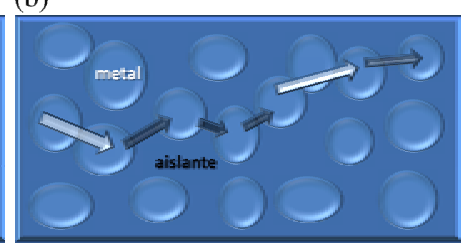

(c)

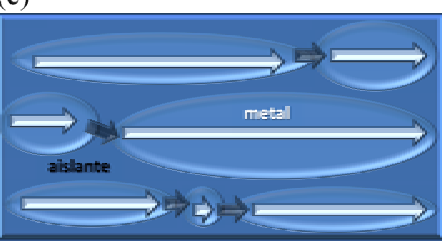

Figura 1.16: Ilustraciones que indican varios tipos de conducción en sistemas granulares en función del contenido de metal y su microestructura. (a) conducción de tipo túnel, comportamiento semi-aislante o aislante, muy bajo contenido metálico; (b) conducción de tipo túnel o “hopping” con algunos caminos metálicos, MIT; (c) conducción metálica.

En la Figura 1.16 representamos unas ilustraciones en las que se diferencian varios tipos de conducción eléctrica en función de la composición y microestructura de un sistema dado. En (a), la concentración de metal es baja, las partes metálicas están formando pequeñas islas aisladas embebidas en una matriz aislante. La conductividad eléctrica es relativamente pequeña y necesita una activación térmica. Se le puede atribuir un mecanismo de conducción túnel o “hopping” entre las partículas metálicas. En (b), aumenta la concentración de metal dentro de la matriz aislante, aunque seguimos teniendo una estructura semi-aislante cerca de la transición metalaislante. En (c), la concentración de metal es elevada y la microestructura consiste en 
una matriz metálica con pequeñas inclusiones o islas aislantes. Por tanto, en este sistema la conducción es puramente metálica.

\subsubsection{Magnetorresistencia}

La magnetorresistencia (MR) es la propiedad que posee un material para cambiar su resistencia eléctrica al aplicarle un campo magnético externo y se define como el cociente entre el cambio de resistencia al aplicar campo y la resistencia a campo cero.

$$
M R(\%)=100 \frac{\rho(H)-\rho(H=0)}{\rho(H=0)}
$$

Un material que tiene un valor de resistencia superior en presencia de campo que en ausencia de éste tendrá una magnetorresistencia positiva. Mientras que si con campo se reduce la resistencia, la magnetorresistencia será negativa. Este fenómeno ha sido ampliamente estudiado en un elevado número de investigaciones de gran interés, con la consecuencia de que hoy día numerosos materiales magnetorresistivos están disponibles en la tecnología de uso comercial, como sensores magnéticos, cabezas de grabación magnética, y dispositivos de almacenamiento masivo, los cuales se basan en fenómenos como la magnetorresistencia gigante, GMR (“Giant magnetoresistance”), la MR anisótropa (AMR) o la MR túnel (TMR), véase la Tabla 1.2.

La GMR fue descubierta en 1988 por Albert Fert ${ }^{64}$, fascinante hallazgo por el cual le concedieron el premio Nobel de Física en 2007 junto con Peter Grünberg. Su origen es debido al tipo de dispersión que experimenta el electrón en razón de su dirección de espín y que tiene lugar en materiales magnéticos. De este modo, se observa la existencia de dos estados, uno de baja y otro de alta resistencia en multicapas de materiales magnéticos separadas por una capa de material no magnético. Las capas magnéticas se acoplan de forma paralela o antiparalela en función del espesor de la capa no magnética a campo magnético nulo. Si a campo cero el estado magnético es antiparalelo, al aplicar un campo magnético se producirá un 
alineamiento paralelo, y por tanto un cambio de resistencia. Este tipo dispositivos pueden operar en cabezas lectoras de los discos duros de los ordenadores.

\begin{tabular}{l|ll}
\hline \multicolumn{1}{c|}{ Tipo } & \multicolumn{1}{|c}{ Materiales } & \multicolumn{1}{c}{ MR (\%) } \\
\hline AMR & Ferromagnéticos & $\sim 5 \%$ \\
GMR & $\begin{array}{l}\text { Multicapas o granulares } \\
\text { (ferromagnético/metal/ferromagnético) }\end{array}$ & $\sim 20 \%$ \\
TMR & $\begin{array}{l}\text { Heteroestructuras o granulares } \\
\text { (ferromagnéticos/aislante/ferromagnético) }\end{array}$ \\
\hline
\end{tabular}

Tabla 1.2: Comparación de los valores de los distintos tipos de MR a temperatura ambiente.

\subsection{Magnetorresistencia anisótropa}

El origen físico de la AMR viene dado por la interacción o acoplamiento espínórbita y fue explicado por primera vez en 1962 por Kondo ${ }^{65}$. Los electrones que ayudan a la conducción en un metal, como el Fe, Co, Ni, son los electrones de los estados $4 \mathrm{~s}$ y $3 \mathrm{~d}$. Los electrones del estado $4 \mathrm{~s}$ se consideran electrones libres y contribuyen mayoritariamente a la conducción, mientras que los electrones 3d contribuyen a la conducción sólo en cierta medida debido a que están más localizados. Los estados 3d vacíos o incompletos pueden estar ocupados temporalmente por electrones de conducción 4s. La propiedad característica de los metales de transición es que las densidades del espín-arriba y del espín-abajo en los estados 3d son distintas. Los electrones $4 \mathrm{~s}$ se dispersan en función de la orientación del momento angular orbital de los electrones 3d. Por lo tanto, la resistencia en ambos canales es distinta. Al aplicar un campo magnético externo, los espines se orientan, los orbitales se reorientan, modificando la dispersión de los electrones y como resultado se observan cambios en la resistencia. En el caso del cobalto o del hierro policristalinos, una 
corriente aplicada paralela a la dirección del campo externo, implica una resistencia mayor, debido a que la probabilidad de colisión de los electrones es mayor. Una corriente aplicada perpendicular a la dirección del campo externo, implica una resistencia menor, debido a que la probabilidad de colisión de los electrones es menor (véase la Figura 1.17).
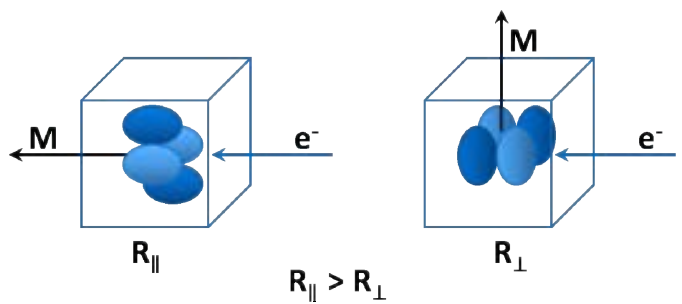

Figura 1.17: Dibujo explicativo sobre el origen de la AMR.

\subsection{Magnetorresistencia túnel en materiales granulares}

El origen físico de la TMR viene dado por la diferente probabilidad de la intensidad del efecto túnel de los electrones desde un material ferromagnético a otro a través de una barrera aislante en función de la orientación de su espín ${ }^{66}$.

Los sistemas granulares son materiales compuestos desordenados formados por nanopartículas magnéticas embebidas en una matriz aislante. De tal manera, que el mecanismo de conducción eléctrico puede darse por el efecto túnel entre las nanopartículas si el contenido metálico es inferior al umbral de percolación (entre 20$60 \%$ atómico). Si las nanopartículas son ferromagnéticas, los vectores de imanación estarán desalineados en ausencia de campo magnético externo, por tanto en un estado de elevada resistencia. A medida que aumentamos el campo magnético, los vectores de imanación se alinean aumentando la probabilidad de efecto túnel de los electrones entre nanopartículas contiguas, pasando a un estado de baja resistencia (Figura 1.18). Se han observado ejemplos de este fenómeno en películas granulares de Co-Al-O, de $\mathrm{FeSiO}_{2}{ }^{67-69}$ y Fe-MgO ${ }^{70}$. 

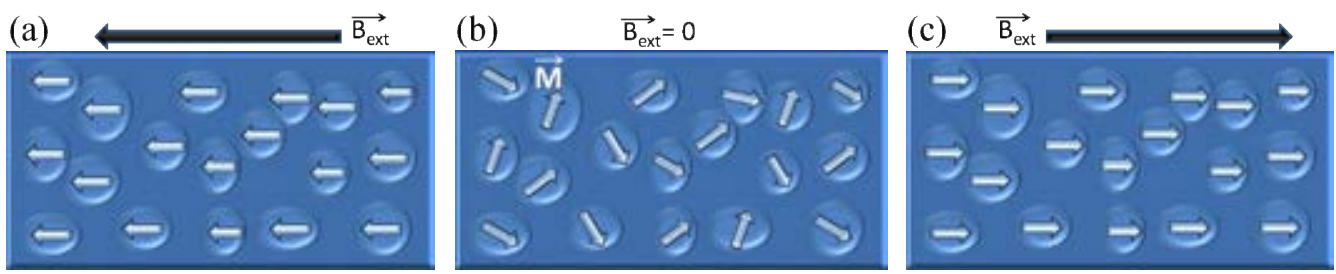

Figura 1.18: Ilustración de la configuración magnética de las nanopartículas magnéticas embebidas en una matriz aislante. (a) Los vectores de imanación están alineados al aumentar el campo magnético aplicado, aumentando la probabilidad de que la conducción se lleva a cabo mediante el efecto túnel de los electrones de las nanopartículas, llevándonos a un estado de baja resistividad. (b) Los vectores de imanación están desalineados en ausencia de campo magnético, estado de elevada resistividad. (c) igual que en (a), pero al aumentar el campo magnético aplicado en el sentido contrario.

\subsubsection{Efecto Hall}

El efecto Hall consiste en la aparición de un voltaje perpendicular a la corriente cuando se aplica un campo magnético perpendicular a ésta. En el caso más sencillo de un solo tipo de portadores (electrones o huecos), el efecto Hall en materiales no magnéticos es una función lineal del campo magnético aplicado y su intensidad está relacionada con la densidad de portadores de carga. La imanación en materiales ferromagnéticos produce fuertes desviaciones de la linealidad, de tal manera que la resistividad Hall $\left(\rho_{\mathrm{H}}\right)$ viene definida por la siguiente expresión (1.4) ${ }^{65}$.

$$
\rho_{H}=\frac{V_{H} e}{I}=\rho_{O H E}+\rho_{A H E}=\mu_{0}\left(R_{0} H+R_{S} M\right)
$$

Donde $\mathrm{V}_{\mathrm{H}}$ es el voltaje Hall medido, transversal a la dirección de la corriente (I) y $e$ es el espesor de la película. Como hemos comentado, en materiales magnéticos, $\rho_{\mathrm{H}}$ viene dada por la contribución ordinaria ( $\left.\rho_{\mathrm{OHE}}\right)$ relacionada con el campo magnético externo aplicado y la contribución anómala $\left(\rho_{\mathrm{AHE}}\right)$ relacionada con la imanación, dónde $\mathrm{R}_{0} \mathrm{y} \mathrm{R}_{\mathrm{S}}$ son los coeficientes Hall ordinario y anómalo, respectivamente. 


\subsection{Efecto Hall anómalo}

La resistividad Hall anómala depende en gran medida de la resistividad de la película tal como se indica en la ecuación $(1.5)^{71}$ :

$$
\rho_{A H E}=a \rho+b \rho^{2}
$$

donde $a$ y $b$ son dos constantes. El término lineal viene dado por el mecanismo extrínseco de dispersión "skew scattering” de los electrones en impurezas y defectos. El término cuadrático está gobernado por la contribución intrínseca inducida sólo por la estructura de bandas y que es independiente de la dispersión de los electrones o bien por el mecanismo extrínseco de dispersión “side jump” de los electrones ${ }^{72-74}$. El "skew scattering” describe el ángulo de deflexión de la trayectoria de los portadores de carga en la dispersión. En el "side jump” se desplaza completamente la trayectoria del electrón de su camino original (Figura 1.19).

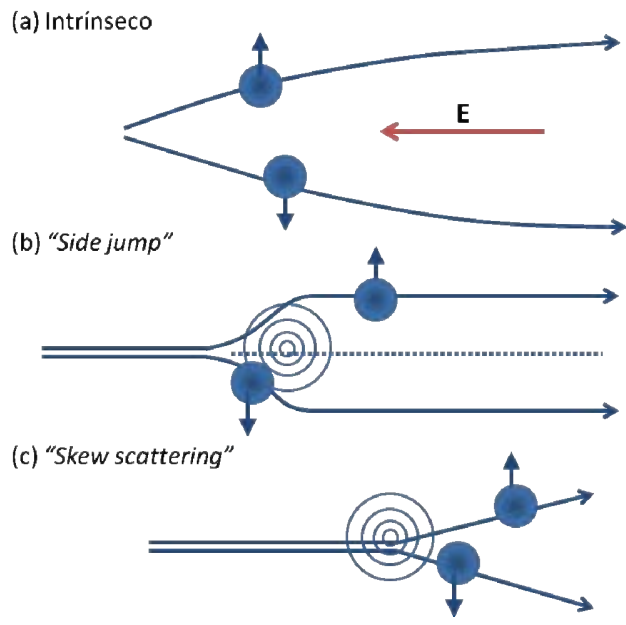

Figura 1.19: Ilustración de los tres mecanismos que pueden gobernar el AHE. (a) Contribución intrínseca (b) Contribución tipo “side jump”. (b) Contribución tipo “skew scattering”. Figura inspirada de la referencia ${ }^{71}$. 


\subsection{Nanoestructuras superconductoras}

\subsubsection{Introducción a la superconductividad}

Desde que en 1911 Kamerling Onnes descubriera la conductividad perfecta (no hay resistencia al paso de corriente eléctrica), a la cual denominó superconductividad ${ }^{75}$, numerosos hallazgos le han sucedido convirtiéndola en una de las principales áreas de investigación en física de la materia condensada ${ }^{76}$. Estudios básicos recientes de gran interés están relacionados con la superconductividad en una dimensión ${ }^{77}$, el confinamiento de vórtices ${ }^{78}$, el anclaje de vórtices ${ }^{79}$, etc. Además, no podemos obviar las recientes aplicaciones en la fabricación de nanoSQUIDS ${ }^{80-82}$, bits superconductores cuánticos (SQB) ${ }^{83,84}$, etc.

En 1986, Bednorz y Müller descubrieron una nueva clase de superconductores de alta-temperatura. Así, el compuesto $\mathrm{LaBaCuO}_{4}$ transitaba al estado superconductor por debajo de $30 \mathrm{~K}^{85}$, rápidamente la $\mathrm{T}_{\mathrm{c}}$ de esta familia de superconductores alcanzó los 130 K. Más recientemente, en 2008 se descubrieron los superconductores basados en Fe, con $\mathrm{T}_{\mathrm{c}} \sim 50 \mathrm{~K}^{86}$. Estos nuevos descubrimientos nos guían hacia nuevas rutas en la preparación y caracterización de materiales superconductores con el objetivo de implantarlos en el área de la Nanotecnología asociada a la física de la materia condensada.

Retomando los inicios de este nuevo estado, además de la ausencia de resistencia por debajo de una temperatura crítica $\mathrm{T}_{\mathrm{c}}$, característica de cada material, en 1933 Meissner y Ochsenfeld descubrieron el diamagnetismo perfecto ${ }^{87}$. Un material superconductor bajo campo magnético expulsa el campo al ser enfriado por debajo de su $\mathrm{T}_{\mathrm{c}}$. Este hecho no podría explicarse con el fenómeno de la conductividad perfecta, el cual tendería a atrapar dentro del mismo el flujo magnético. De hecho, en cada material el estado superconductor viene delimitado por unos valores críticos de temperatura, campo magnético y densidad de corriente (véase la Figura 1.20). 


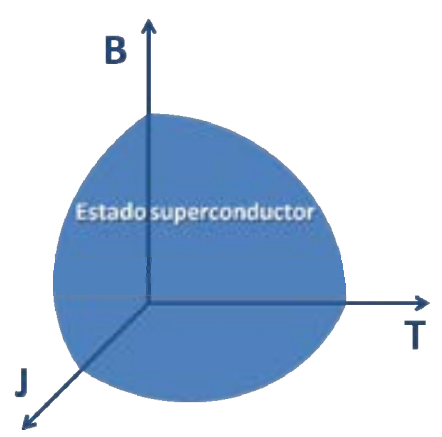

Figura 1.20: Diagrama esquemático del estado superconductor acotado por los valores de temperatura, campo magnético externo y densidad de corriente aplicada; los cuales son característicos de cada material.

En un material superconductor el campo es expulsado por unas supercorrientes superficiales que apantallan el campo magnético externo. Sin embargo, el campo no es completamente expulsado en la superficie dónde se generan las supercorrientes, descendiendo su valor de forma exponencial desde la superficie hasta una longitud característica, llamada longitud de penetración de London, $\lambda_{\mathrm{L}}$.

La teoría macroscópica de Ginzburg-Landau (GL) $)^{88}$ permite describir inhomogeneidades o variaciones espaciales de la densidad de los electrones superconductores, $\mathrm{n}_{\mathrm{s}}$ mediante la introducción de un parámetro de orden $\Psi=|\Psi| e^{i \varphi}$, cuyo módulo al cuadrado $|\Psi|^{2}$ representa $\mathrm{n}_{\mathrm{s}}$. De esta manera, la teoría de GL permite explicar otro comportamiento del material superconductor respecto al campo magnético externo diferente al efecto Meissner. Cuando el campo magnético penetra en un superconductor se generan zonas normales que coexisten con las zonas superconductoras en las cuales el campo es expulsado. En esas regiones normales el parámetro de orden se anula, mientras que recupera su posición de equilibrio en las regiones superconductoras. En la Figura 1.21(a) podemos observar como el módulo del parámetro de orden se anula completamente en la región normal recuperando su valor inicial a una longitud característica, llamada longitud de coherencia, $\xi$. Como hemos comentado, el campo magnético no es completamente expulsado del material 
superconductor por las supercorrientes generadas, sino que penetra desde la superficie hacia el núcleo normal de forma exponencial una longitud característica, llamada longitud de penetración, $\lambda$. El cociente entre estos dos parámetros, $\lambda / \xi$ es conocido como el parámetro adimensional de Ginzburg-Landau, $\kappa$. Si $\kappa>1$, las líneas de campo penetrarán en el material superconductor, distinguiéndolo de los sistemas que describen el efecto Meissner. Por ello se estableció un criterio para clasificar a los materiales superconductores en función de su comportamiento bajo campo magnético. Los superconductores que presentan el efecto Meissner puro son los llamados de tipo I. Sin embargo, la mayoría de superconductores se comportan de forma distinta, los conocidos como superconductores de tipo II, en los cuales como hemos comentado el campo magnético no es expulsado completamente en todas las regiones del material, y se distinguen zonas que presentan un comportamiento normal y zonas superconductoras, el estado mixto.

La forma en la cual el campo magnético penetra en un superconductor de tipo II fue explicada en 1957 por A. A. Abrikosov ${ }^{89}$. El campo penetra en el superconductor formando líneas de flujo magnético, llamadas vórtices. Cada vórtice tiene asociado un cuanto de flujo, $\phi_{0}=\mathrm{h} / 2 \mathrm{e}=2.07 \times 10^{-15} \mathrm{~Wb}$. En el centro tenemos el núcleo normal y alrededor de éste supercorrientes circulares, dónde el campo no es expulsado completamente. La configuración energética más favorable para el ordenamiento de los vórtices debido a sus interacciones es una red regular con simetría hexagonal o cuadrada como se indica en la Figura 1.21(b) ${ }^{90}$.
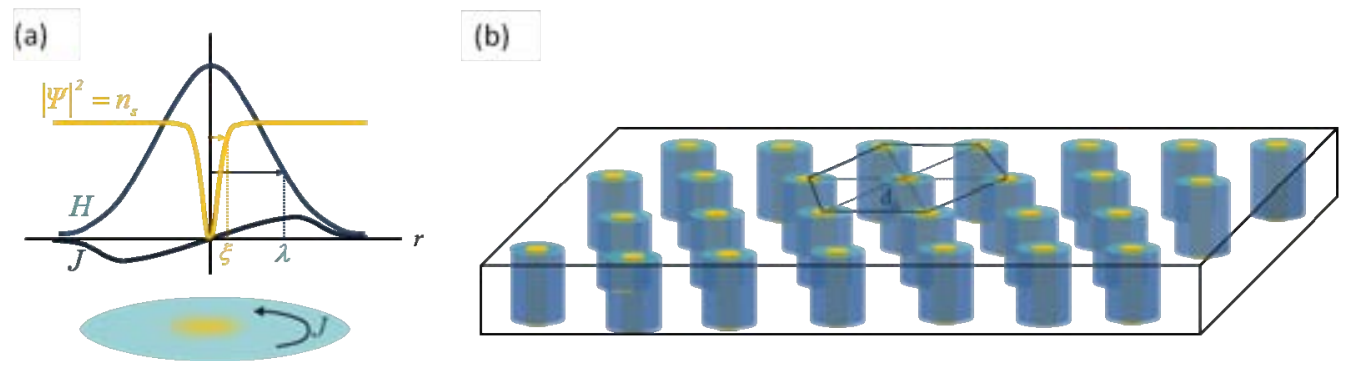

Figura 1.21: (a) Variación radial del módulo del parámetro de orden (naranja), el campo magnético (azul) y la densidad de corriente en un vórtice (azul oscuro). (b) Representación esquemática de la red de vórtices de Abrikosov con simetría hexagonal. Figura extraída de ${ }^{90}$. 
La teoría microscópica de Bardeen-Cooper-Schrieffer (BCS) explicó el origen de la ausencia de resistencia en el estado superconductor ${ }^{91}$. La idea se basa en la atracción débil de dos electrones cercanos al nivel de Fermi que se enlazan para formar lo que conocemos como par de Cooper con una energía inferior a la $E_{F}{ }^{92}$. Dicha interacción atractiva está generada por la interacción electrón-fonón-electrón predicha en la referencia ${ }^{93}$.

\subsubsection{Dinámica de vórtices}

Los vórtices se comportan como objetos que pueden moverse debido a la presencia de una corriente. El movimiento de los vórtices viene gobernado por la ecuación $(1.6)^{76}$,

$$
\vec{f}_{L}-\eta \vec{v}_{\phi}-\vec{f}_{p}=0
$$

dónde la fuerza de Lorentz por unidad de longitud de vórtice viene definida por $\vec{f}_{L}=\vec{\jmath}_{x} \times \vec{\Phi}_{0}, \eta$ es la viscosidad del movimiento del vórtice, $\vec{v}_{\phi}$ es la velocidad del vórtice y $\vec{f}_{p}$ es la fuerza de anclaje.

En presencia de una corriente aplicada, las líneas de flujo experimentan una fuerza de Lorentz por unidad de longitud que tiende a mover los vórtices de forma transversal respecto a la corriente aplicada, ese movimiento produce una disipación de energía que genera un campo eléctrico y por ende induce un voltaje longitudinal o resistencia finita.

Siguiendo la ley de Faraday,

$$
\vec{E}=-\vec{\nabla} U=\vec{B} \times \vec{v}_{\phi}
$$


El voltaje inducido en el movimiento de vórtices es $\mathrm{U}_{\mathrm{x}}=\Phi_{0} v_{\Phi, \mathrm{y}} / \mathrm{L}$ a una densidad de vórtices dada $\mathrm{n}_{\phi}=\mathrm{B} / \Phi_{0}$, así el número de vórtices en un nanohilo de longitud, $\mathrm{L}$ y ancho, a es $\mathrm{N}=\mathrm{n}_{\phi} \mathrm{La}$. El campo eléctrico viene dado por la ecuación (1.8).

$$
E_{\chi}=N \frac{U_{x}}{a}=\frac{N \Phi_{0} v_{\Phi, y}}{L a}=B v_{\Phi, y}
$$

Junto con la ecuación (1.6), el campo eléctrico generado por el movimiento de los vórtices viene dado por la ecuación (1.9).

$$
E_{x}=\frac{B}{\eta}\left(f_{L}-f_{p}\right)
$$

En la mayoría de superconductores de tipo II, el movimiento de vórtices encuentra una oposición debida a pequeñas inhomogeneidades que pueden anclar los vórtices, por lo que no se observaría una resistencia finita hasta que la fuerza de Lorentz superara la fuerza de anclaje de los vórtices. Cuando la fuerza de Lorentz supera la fuerza de anclaje de los vórtices, los vórtices se mueven a una velocidad que depende de la viscosidad del material y por tanto, $E_{x}>0$. Cuando la fuerza de anclaje es superior a la fuerza de Lorentz, los vórtices están anclados y $E_{x}=0$.

En hilos superconductores, el anclaje es muy fuerte por lo que la densidad de corriente que se puede aplicar sin disipación es muy elevada. Este hecho se pondrá de manifiesto en el Capítulo 5 de esta tesis, dónde se presentan las medidas de transporte eléctrico en nanohilos superconductores de wolframio. El estudio del anclaje de vórtices ya sea por un desorden estructural o bien inducido artificialmente por diseños de ingeniería ha sido una de las mayores líneas de investigación en superconductividad durante las últimas décadas ${ }^{94}$.

\subsubsection{Resistencia "flux flow"}

En el caso ideal donde no existe el anclaje de los vórtices, su movimiento generado por la fuerza de Lorentz sólo es impedido por la fuerza generada por la 
viscosidad del material, es el régimen de "flux flow" puro. Simplicando la expresión (1.6), alcanzamos la (1.10).

$$
\begin{aligned}
& J \Phi_{0}=\eta v_{\phi} \\
& \rho_{f}=\frac{\mathrm{E}}{J}=B \frac{\Phi_{0}}{\eta c^{2}} \\
& \eta=\frac{\Phi_{0}^{2}}{2 \pi a^{2} c^{2} \rho_{n}} \approx \frac{\Phi_{0} H_{c 2}}{\rho_{n} c^{2}}
\end{aligned}
$$

Sustituyendo la ecuación (1.12) en (1.11), obtenemos una expresión más reducida de la resistividad “flux flow” en la expresión (1.13).

$$
\rho_{f}=\rho_{n} \frac{2 \pi a^{2} B}{\Phi_{0}} \approx \rho_{n} \frac{B}{B_{c 2}}
$$

Todos los materiales reales tienen defectos, ya sea por la presencia de impurezas, inhomogeneidades, corrugación de la superficie, etc., que pueden generar centros de anclaje, ya que los vórtices tienden a ocupar las posiciones energéticamente más estables. En investigación básica del "flux flow” puro, el anclaje de los vórtices es un efecto indeseable que complica su estudio; mientras que en aplicaciones, este efecto puede convertirse en una ventaja debido a que es una forma de reducir la disipación de energía al inmovilizar las líneas de flujo, útil en solenoides de altos campos magnéticos.

En el fenómeno de "flux creep" la energía térmica puede permitir que las líneas de flujo salten de un punto de anclaje a otro como una unidad o paquete, en respuesta a la fuerza de movimiento generada por la densidad de corriente. Sin aplicar una corriente como se representa en la Figura 1.22(a), la probabilidad de pasar de un mínimo de energía a izquierda o derecha es la misma. Mientras que en la Figura 1.22(b), el vórtice o paquete de vórtices pasará en la dirección en la que desciende la densidad de corriente con mayor probabilidad. Presumiblemente, la velocidad de salto 
de las líneas de flujo tendría una dependencia de tipo exponencial, como la expresada en la ecuación (1.14).

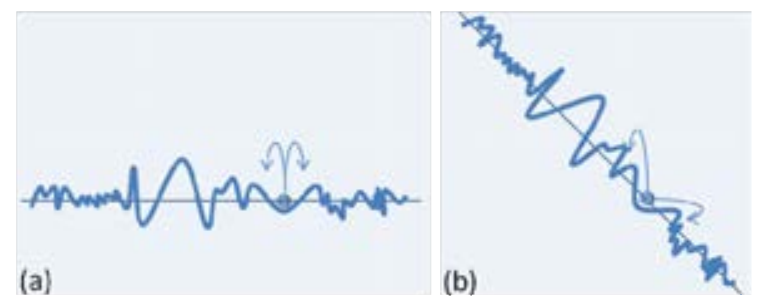

Figura 1.24: Representación esquemática de los vórtices saltando barreras de energía al centro de anclaje adyacente. (a) Fuerza de movimiento es cero. (b) Fuerza de movimiento debido a la corriente favorece los saltos en la dirección de bajada.

$$
R \sim a e^{-\Delta F / k T}
$$

La disipación de energía debida al movimiento de los vórtices depende de la distribución de los electrones normales en el núcleo, los cuales pueden producir V(I) no lineales con densidades de corriente muy elevadas. Se diferencian dos casos de efectos no lineales: la teoría de Larkin y Ovchinnkov que predice inestabilidades en el "flux flow" a temperaturas cercanas a la $\mathrm{T}_{\mathrm{c}}$ atribuidas al encogimiento del núcleo del vórtice y a temperaturas muy por debajo de $\mathrm{T}_{c}$, donde el efecto es debido al calentamiento de los electrones ${ }^{95}$.

\subsubsection{Resistencia "phase slip"}

En este apartado comentamos brevemente el mecanismo de disipación de energía mediante "phase slips" que se puede observar en superconductores de 1D, por ejemplo en nanohilos con un espesor o ancho del línea del orden de su $\xi^{76,77,96-98}$ o bien en estructuras con constricciones cuya dimensión de ésta sea comparable a la $\xi$. La resistencia de nanohilos de estas dimensiones es distinta de cero por debajo de la $T_{c}$ debido a fluctuaciones del parámetro de orden del superconductor, cuando el 
mecanismo de disipación está gobernado por el "phase slips". Las fluctuaciones térmicas son significativas a temperaturas próximas a la $T_{c}$. La fase relativa del parámetro de orden del superconductor cambia respecto de un punto del nanohilo a otro $2 \pi$ produciendo un voltaje o resistencia finita.

La teoría de los "phase slips” activados térmicamente (TAPS) fue desarrollada por Langer y Ambegaokar en $1967{ }^{99}$ y completada por McCumber y Halperin en $1970{ }^{100}$. La teoría LAMH explica la disipación de energía y resistencia finita en nanohilos de $1 \mathrm{D}$ por debajo de la $\mathrm{T}_{\mathrm{c}}$. Las activaciones térmicas del sistema TAPS suceden a una velocidad gobernada por una dependencia de tipo exponencial como en la expresión (1.15) cuando se sobrepasa una barrera de potencial, $\Delta \mathrm{F}$.

$$
R \sim a e^{-\Delta F / k T}
$$

Tal y como hemos relatado existen diferentes regímenes para el movimiento de los vórtices en materiales superconductores. En el Capítulo 5 abordaremos el estudio de la dinámica de vórtices en microhilos, nanohilos, y nanohilos ultraestrechos de wolframio crecidos mediante FIBID, un material superconductor de tipo II en el límite sucio, con anclaje débil que lo hace ideal para este tipo de estudios ${ }^{101,102}$.

\subsubsection{Dinámica de vórtices no local}

En 1965, Giaever demostró experimentalmente el movimiento de líneas de flujo mediante medidas eléctricas y el movimiento no local de vórtices en las zonas dónde la corriente no circula ${ }^{103}$.

El paso de una corriente en una estructura superconductora de tipo II y de anclaje débil como la mostrada en la Figura 1.23 puede originar un voltaje no local en una zona alejada que está conectada por una canal por donde los vórtices se mueven. 
El voltaje no local perpendicular a la dirección de movimiento de los vórtices fue predicho teóricamente por Wortis y Huse ${ }^{104}$ y comprobado experimentalmente en superconductores de alta temperatura, que presentan elevada viscosidad y cerca de la transición al fundido ${ }^{105}$. En principio este efecto desaparecería a distancias mayores que unos pocos parámetros de red en ausencia de una corriente de circulación ${ }^{78}$.

Sin embargo, Grigorieva et al. encontró un efecto no local diferente, en el cual el movimiento de los vórtices en un nanohilo superconductor de tipo II se disipaba en un voltaje medido en unos conectores transversales al nanohilo superconductor, por donde no circulaba la corriente. En este caso el movimiento de los vórtices no local permanece a lo largo de varios cientos de distancias entre vórtices, en contraste con el efecto dinámico inducido por la viscosidad ${ }^{78,106-109}$.

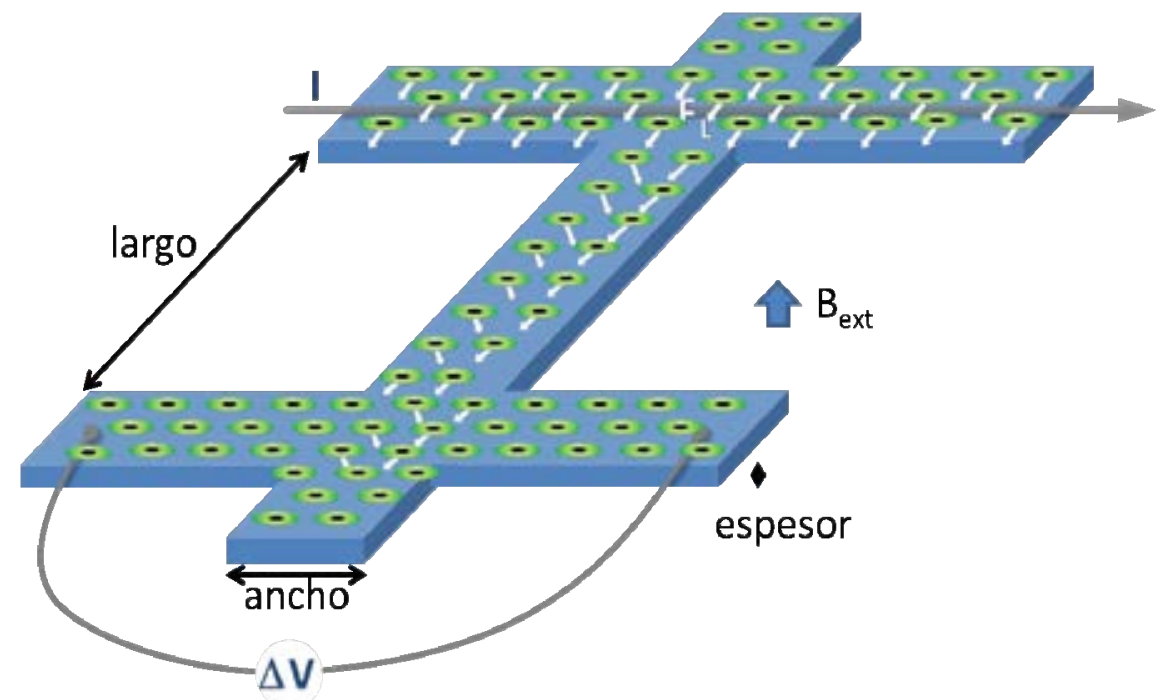

Figura 1.23: Representación esquemática de la geometría de la muestra utilizada para medir el voltaje no local en nuestras muestras al pasar corriente por el nanohilo horizontal superior y medir la caída de voltaje que se genera por el movimiento de los vórtices en el hilo horizontal inferior.

En el marco del estudio de la dinámica de vórtices no local se fabricaron y caracterizaron nanohilos de wolframio mediante FIBID con la configuración propuesta por Grigorieva, cuyos resultados mostraremos en el Capítulo 5. 


\subsection{Objetivos y estructura de la tesis}

La motivación de esta tesis ha sido la fabricación de materiales a escala nanométrica utilizando unas técnicas novedosas como son las técnicas de crecimiento mediante FEBID/FIBID. El objetivo que conlleva la fabricación de estas nanoestructuras es que sean funcionales en el ámbito de la Nanotecnología. En primer lugar, abordaremos el estudio de las nanoestructuras que presentan un comportamiento ferromagnético, como el Co FEBID en el Capítulo 3, y el Fe FEBID en el Capítulo 4, cuyas aplicaciones más relevantes son el diseño de dispositivos magnéticos para la industria de la micro/nanoelectrónica como memorias, sensores magnéticos, etc. En segundo lugar, nos centraremos en el estudio de nanoestructuras superconductoras de W crecidas mediante FIBID, cuyas aplicaciones más reseñables son el diseño de dispositivos superconductores para la industria de la micro/nanoelectrónica como fabricación de SQUIDs, nanocontactos sin resistencia finita, sensores de partículas o fotones, etc.

Esta tesis está agrupada en seis Capítulos y tres Apéndices:

En el Capítulo 2 se resumen las principales técnicas experimentales utilizadas a lo largo de la tesis, tanto para el crecimiento de nanoestructuras (SEM/FIB) como para su caracterización mediante técnicas de microscopía (SEM; AFM, microscopía de fuerzas atómicas; STEM, microscopia electrónica de transmisión de barrido; HRTEM, microscopia electrónica de transmisión de alta resolución), de espectroscopía (EDS, espectroscopía de dispersión de energía de rayos-X; EELS, espectroscopía de pérdida de energía de los electrones), y medidas de magnetotransporte por cuatro puntas (PPMS, sistema de medida de propiedades físicas).

El crecimiento y caracterización de nanodepósitos ferromagnéticos de Co mediante FEBID se investigó en el Capítulo 3, variando parámetros con gran incidencia en sus posteriores propiedades magnéticas. El análisis composicional de los nanodepósitos fabricados se llevó a cabo in situ. El estudio de su microestructura y composición en la nanoescala se ha realizado mediante técnicas de microscopía 
electrónica de transmisión. Mientras que, las propiedades magnéticas de nanoestructuras ultraestrechas, de hasta $30 \mathrm{~nm}$ de tamaño lateral, se han estudiado mediante medidas de magnetotransporte.

Los depósitos ferromagnéticos de Fe fabricados mediante FEBID se estudiaron en el Capítulo 4. El control del contenido de Fe y la microestructura ha permitido explorar la transición de metal a aislante, la evolución de la magnetorresistencia, y el efecto Hall.

En el Capítulo 5 presentamos el crecimiento y caracterización de nanodepósitos superconductores de W mediante FIBID. En primer lugar, estudiamos la influencia que tienen algunos parámetros de crecimiento, como el voltaje de aceleración del haz, y su ángulo de incidencia en la composición de los nanodepósitos. En segundo lugar, presentamos las propiedades superconductoras de estructuras de $\mathrm{W}$ de distinto tamaño lateral (desde microhilos hasta nanohilos ultraestrechos) obtenidas mediante las medidas de transporte eléctrico local. Por último, estudiamos la generación de una señal no local debida al movimiento de los vórtices mediante las medidas de transporte eléctrico no local.

Las principales conclusiones y perspectivas de esta tesis se encuentran resumidas en el Capítulo 6.

En los Apéndices se describen brevemente las características principales de los nanohilos de $\mathrm{W}$ crecidos mediante FEBID, de los depósitos de Pt crecidos mediante FIBID y FEBID y de los nanohilos de C crecidos mediante FIBID.

Por último, podemos consultar la bibliografía en la que nos hemos documentado para la consecución de esta tesis en las últimas páginas, junto con una lista de acrónimos y un listado de los artículos publicados como resultado de este trabajo. 


\section{Capítulo 2}

\section{Técnicas experimentales}

En este capítulo presentamos las técnicas experimentales utilizadas en el desarrollo de esta tesis, tanto para la preparación de las muestras como para su posterior caracterización. La preparación de muestras a estudio se llevó a cabo en tres equipos "Dual Beam" (SEM/FIB) de características similares, Nova Nanolab 200, Helios Nanolab 600 emplazados en el Laboratorio de Microscopías Avanzadas-Instituto de Nanociencia de Aragón (LMA-INA) de la Universidad de Zaragoza y el Nova Nanolab 600 instalado en la Eindhoven University of Technology (TU/e). La caracterización de las muestras se realizó tanto in situ (SEM, EDS, medidas de transporte eléctrico), como "ex-situ" (AFM, PPMS, HRTEM, STEM/EELS,...). El diseño de las pistas metálicas sobre los sustratos que dan soporte a la nanolitografía, se llevó a cabo mediante técnicas de litografía óptica en la Sala Blanca del LMA-INA. 


\subsection{Nanolitografía mediante un "Dual Beam”}

\subsubsection{Descripción de un “Dual Beam”}

En el Capítulo 1 realizamos una descripción general de un equipo "Dual Beam”, detallando las partes fundamentales que lo componen y su amplio rango de aplicaciones. Debido a la relevancia que ha tenido esta herramienta en el desarrollo de nuestras líneas de investigación, con la elaboración de las muestras que posteriormente caracterizamos, sin duda lo consideramos “el corazón” de esta tesis. En la Figura 2.1 podemos ver una fotografía exterior del equipo Helios Nanolab 600, uno de los "Dual Beam” utilizado para la fabricación de nanoestructuras.

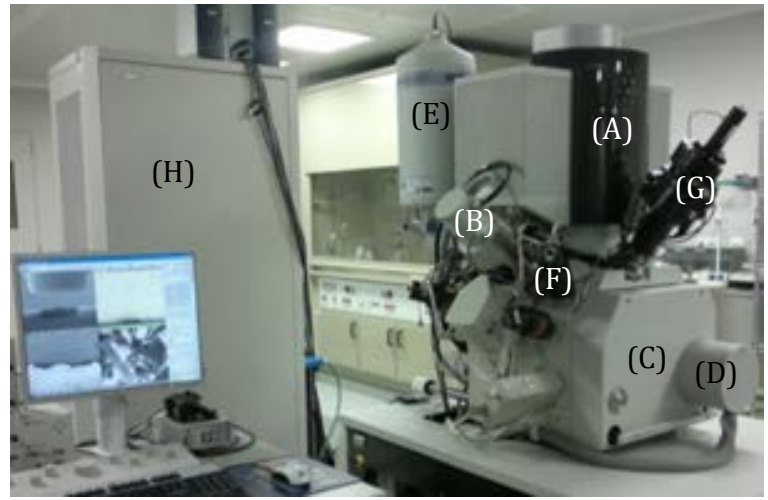
(A) SEM
(B) FIB
(C) Cámara de proceso
(D) Motor de la plataforma
(E) Detector EDS
(F) Sistema de inyección de gases
(G) Nanomanipulador
(H) Electrónica
(I) Detector ETD
(J) Detector TLD
(K) Detector CDEM
(L) Detector STEM
(M) Cámara CCD

Figura 2.1: Fotografía del equipo “Dual Beam”, Helios Nanolab 600 instalado en la sala blanca del LMA-INA.

La parte interior de las cámaras de proceso del Nova Nanolab 200 (otro de los "Dual Beam" utilizado ampliamente para el crecimiento de nanoestructuras en el desarrollo de esta tesis) y del Helios Nanolab 600 las podemos apreciar en la Figura 2.2, parte izquierda y derecha, respectivamente. Dada la relevancia de estos sistemas en el desarrollo de esta tesis doctoral, a continuación indicaremos qué aspectos o herramientas del equipo se han utilizado concretamente:

1. Adquisición de imágenes de alta resolución mediante detectores SEM, STEM y FIB. 
2. Grabado mediante FIB: cortes transversales, etc...

3. Nanofabricación mediante SEM: crecimiento de nanodepósitos de Co, Fe, W y Pt.

4. Nanofabricación mediante FIB: crecimiento de nanodepósitos de W, Pt y C.

5. Análisis composicional de los nanodepósitos fabricados mediante la técnica EDS.

6. Caracterización eléctrica in situ de los nanodepósitos fabricados, mediante medidas eléctricas por cuatro puntas.

7. Manipulación de micro y nanoestructuras mediante un nanomanipulador.

8. Preparación de muestras para TEM.
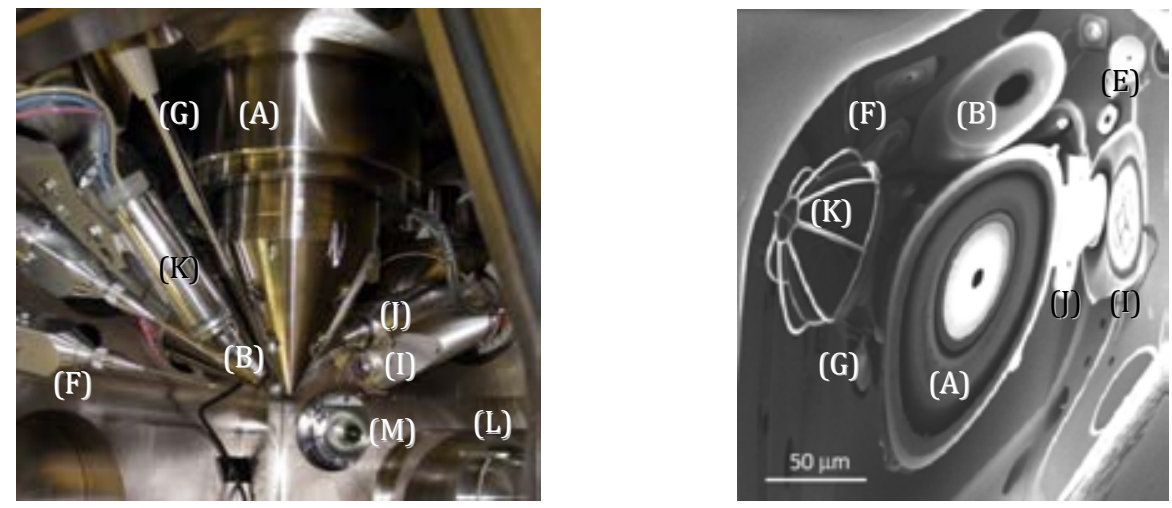

Figura 2.2: Interior de la cámara de proceso de un Dual Beam. A la izquierda, fotografía del Nova Nanolab 200 instalado en el LMA-INA; a la derecha, imagen SEM de un material aislante que al cargarse por la irradiación del FEB actúa de “espejo electrónico” y nos permite obtener una fascinante imagen de algunas piezas del Helios Nanolab 600 desde la perspectiva de la muestra. 


\subsubsection{SEM}

La columna de electrones está basada en una fuente de electrones de emisión de campo, con un filamento de W (véase la Figura 2.3). La óptica de la columna consigue focalizar el haz de electrones para obtener la mejor resolución posible, $0.9 \mathrm{~nm}$ operando a $15 \mathrm{kV}, 11 \mathrm{pA}$.

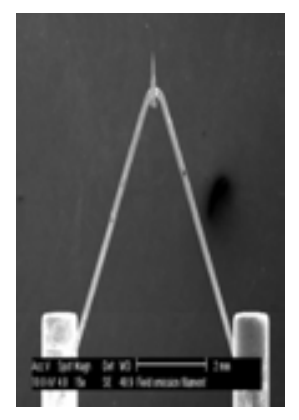

Figura 2.3: Imagen SEM de una fuente de electrones de emisión de campo (FEG), por cortesía de FEI.

\subsubsection{FIB}

La columna de iones permite focalizar el haz de iones hasta $5 \mathrm{~nm}$ de diámetro usando la apertura más pequeña del sistema ( 1 pA), lo cual nos otorga la posibilidad de tallar o crecer estructuras ultraestrechas del orden de unos pocos nanómetros.
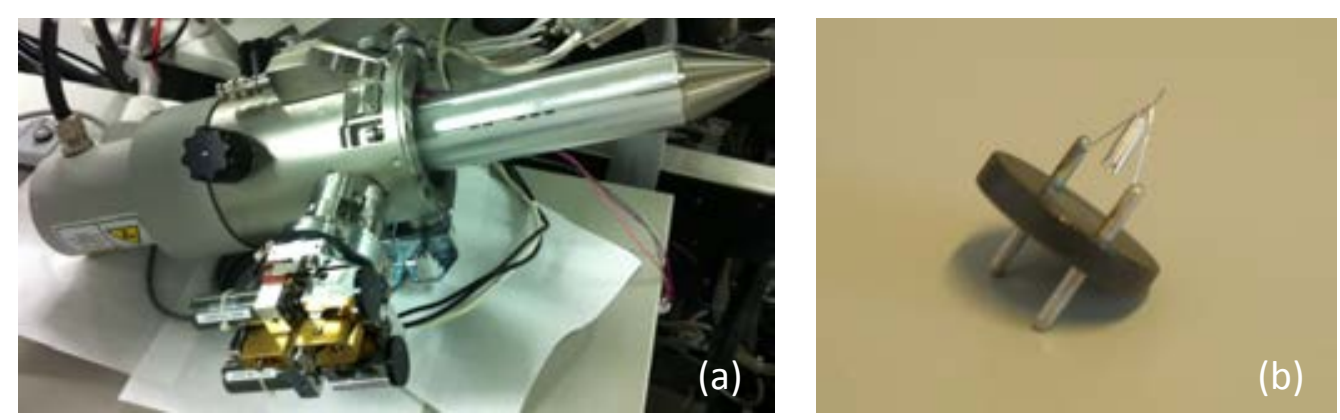

Figura 2.4: (a) Fotografía de la columna de iones Magnum instalada en el Nova Nanolab 200 y el Helios Nanolab 600; (b) Fotografía de una fuente de iones de $\mathrm{Ga}^{+}$. 
La máxima apertura de la columna Magnum instalada en el Nova Nanolab 200 y el Helios Nanolab 600 nos permite operar con una corriente de 21 nA (diámetro del haz 411 nm), muy útil para el grabado de grandes áreas o zanjas, como ocurre en la preparación de muestras para TEM.

\subsubsection{Sistema de inyección de gases y materiales precursores}

\subsubsection{Sistema de inyección de gases}

El sistema de inyección de gases (GIS) es muy compacto e individual para cada material precursor, como podemos ver en la Figura 2.5. Tanto la inserción como retracción del GIS y la apertura de la válvula que permite la entrada del gas precursor en la cámara de proceso son muy rápidas, funcionan abriendo y cerrando su respectiva válvula neumática integrada.

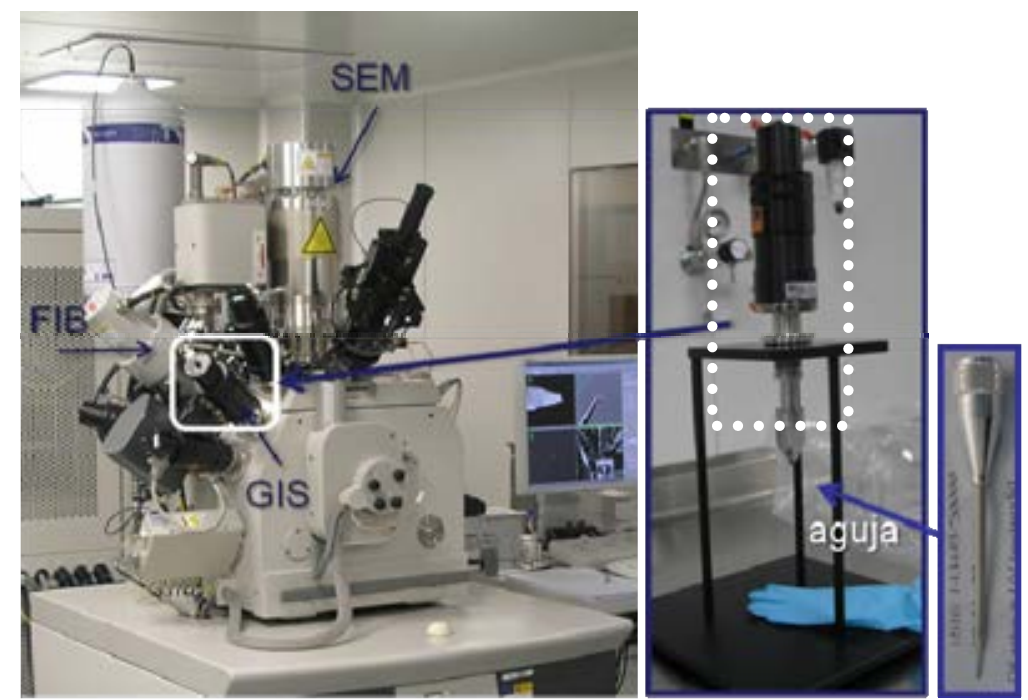

Figura 2.5: Fotografía del “Dual Beam”, en el cual se indica uno de los puertos dónde se instala el GIS. En los recuadros azules claro vemos la aguja por donde sale el gas precursor y el GIS sobre una plataforma. Señalamos la carcasa negra exterior y la parte de acero inoxidable que se introduce en la cámara con el recipiente que se rellena de material precursor. 
La temperatura del recipiente, en el que se aloja el material precursor y la aguja que está enroscada a éste, es homogénea y está controlada. Por tanto, la presión en el recipiente es constante y como consecuencia de ello, el flujo de moléculas que se liberan a través de la aguja sólo está relacionado con la presión de vapor de saturación y la impedancia de la aguja al paso de gas. La presión de vapor de un material precursor viene dada por la ecuación de Clausius-Clapeyron, donde $\log (\mathrm{P}) \propto 1 / \mathrm{T}$. Teniendo en cuenta esta ecuación, un cambio de $\pm 0.1{ }^{\circ} \mathrm{C}$ en la temperatura del recipiente produciría una variación en la presión de alrededor del 1\%. El sistema de control del GIS permite la estabilización de la temperatura en ese rango de valores, por lo que el flujo que sale por la aguja puede tener una variación de $\pm 1 \%$. La válvula se abre automáticamente en los GIS, salvo en el caso de los precursores de Co y Fe, que se abren manualmente para evitar una abrupta subida de la presión en la cámara de proceso. Para el resto, el flujo está fijado en un nivel en el cual el sistema de alto vacío trabaja en un rango válido ( $\mathrm{P}_{\text {proceso }} \sim 1 \times 10^{-5} \mathrm{mbar}$ ). Por otra parte, la temperatura del precursor no debe ser demasiado elevada para evitar que la composición química del precursor se modifique por la natural descomposición térmica ${ }^{110}$. Los materiales precursores que se utilizaron en el desarrollo de esta tesis operan entre 22 y $55^{\circ} \mathrm{C}$.

Además del flujo de gas que sale por la aguja del GIS, es importante conocer el área de la muestra que queda cubierta por las moléculas de gas precursor. Este área depende de varios factores, como por ejemplo el ángulo de incidencia de la aguja, la altura de la aguja respecto de la superficie, la distancia del borde de la aguja con la zona de interés de la muestra, efecto de sombra, etc. ${ }^{111}$.

\subsubsection{Materiales precursores}

La mayoría de los materiales precursores utilizados en las técnicas de crecimiento FEBID o FIBID son de origen organometálico, ampliamente conocidos e implantados en otras técnicas de crecimiento como por ejemplo, el CVD. Para una sencilla implantación e instalación en los puertos del "Dual Beam" es preferible que a temperatura ambiente sean sólidos o líquidos (salvo excepciones como el difloruro de 
xenón, $\mathrm{XeF}_{2}$ ) y que su temperatura de sublimación sea próxima a la temperatura ambiente. Otras consideraciones a tener en cuenta en la selección de materiales precursores adaptables al "Dual Beam" se basan en su toxicidad y riesgos para la salud.
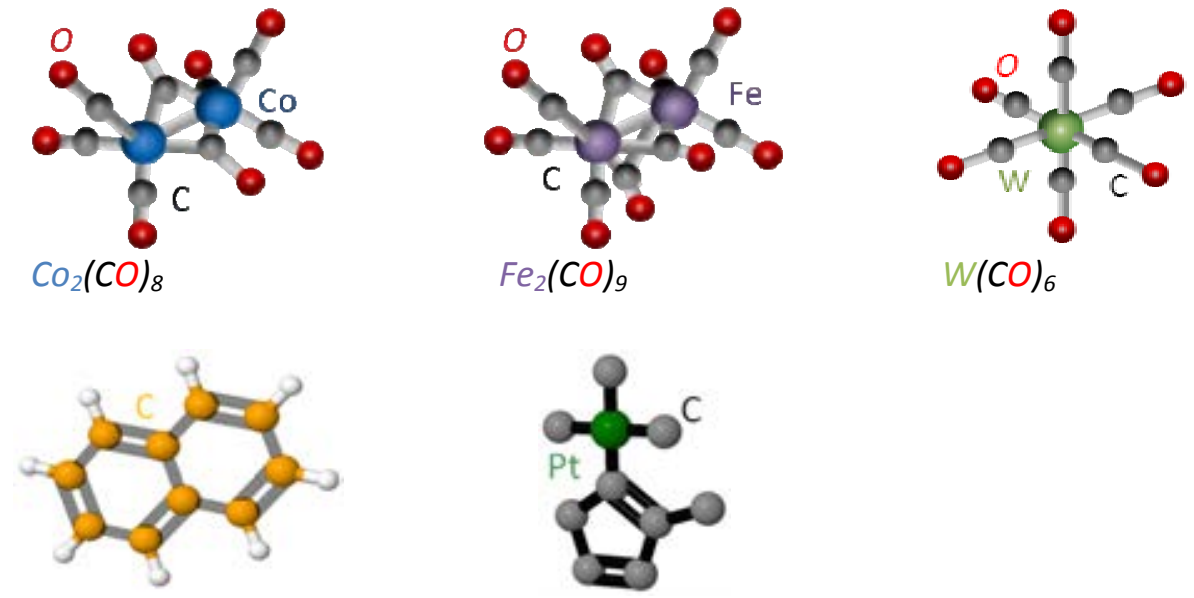

$\mathrm{C}_{10} \mathrm{H}_{12}$

$$
\mathrm{CH}_{3} \mathrm{PtC}_{\mathrm{p}}\left(\mathrm{CH}_{3}\right)_{3}
$$

Figura 2.6: Materiales precursores utilizados en esta tesis para el crecimiento de nanoestructuras.

Los materiales precursores utilizados para crecer los nanodepósitos caracterizados en esta tesis son los siguientes (véase la Figura 2.6):

1. Octacarbonilo de dicobalto, $\mathrm{Co}_{2}(\mathrm{CO})_{8}$, temperatura del GIS $=27^{\circ} \mathrm{C}$

2. Nonacarbonilo de dihierro, $\mathrm{Fe}_{2}(\mathrm{CO})_{9}$, temperatura del GIS $=28^{\circ} \mathrm{C}$

3. Hexacarbonilo de wolframio, $\mathrm{W}(\mathrm{CO})_{6}$, temperatura del GIS $=55^{\circ} \mathrm{C}$

4. Naftaleno, $\mathrm{C}_{10} \mathrm{H}_{12}$, temperatura del GIS $=35^{\circ} \mathrm{C}$

5. Metilciclopentadienil trimetil platino, $\left(\mathrm{CH}_{3}\right)_{3}\left(\mathrm{CH}_{3} \mathrm{C}_{\mathrm{p}} \mathrm{Pt}\right)$, temperatura del $\mathrm{GIS}=45{ }^{\circ} \mathrm{C}$ 
La diferente naturaleza de cada material precursor influye en la descomposición de éste bajo la influencia del FEB o el FIB. Por tanto, las nanoestructuras crecidas con cada precursor presentan diferente composición, microestructura y propiedades físicas como desarrollaremos en los sucesivos capítulos. 


\subsection{Microcalentador}

En este apartado comentaremos brevemente el montaje que utilizamos para estudiar la influencia que tiene la temperatura del sustrato en la descomposición del material precursor, $\mathrm{Co}_{2}(\mathrm{CO})_{8}$ durante el crecimiento de nanoestructuras, cuyos resultados se mostrarán en el apartado 3.4 del Capítulo 3.

El elemento principal del montaje experimental es un micro-calentador basado en una lámina de Pt, que utiliza el efecto Joule para convertir la potencia eléctrica en potencia calorífica al introducirle una corriente directa mediante una fuente DC de voltaje o de corriente. Así, produce su aumento de temperatura alcanzando incluso $\sim 650{ }^{\circ} \mathrm{C}$ (véase la Figura 2.7).
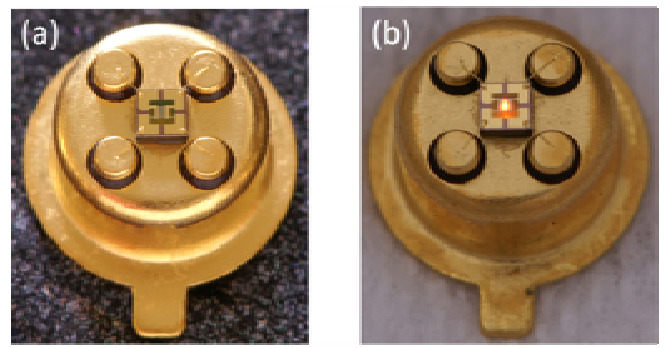

Figura 2.7: Fotografías del micro-calentador KMHP-100 de Kebaili Corporation. (a) a temperatura ambiente; (b) a elevada temperatura observándose la iluminación del microcalentador al calentarse.

Para tener acceso eléctrico desde el exterior del microscopio al micro-calentador se diseñaron y fabricaron una serie de piezas de conexión que forman parte del montaje que a continuación resumimos en un listado de los elementos más importantes:

1. Micro-calentador comercial KMHP-100 de Kebaili Corporation basado en una película de Pt de $\sim 400 \mathrm{~nm}$ de espesor embebido en una membrana suspendida tipo sandwich de $\mathrm{SiO}_{2}\left(\sim 500 \mathrm{~nm}\right.$ de espesor) $/ \mathrm{Si}_{3} \mathrm{~N}_{4}(\sim 1.5 \mu \mathrm{m}$ 
de espesor) $/ \mathrm{SiO}_{2}$ ( $\sim 400 \mathrm{~nm}$ de espesor), con un área de trabajo de alrededor de $250 \times 150 \mu \mathrm{m}^{2}$ (véase la Figura 2.8(d)).
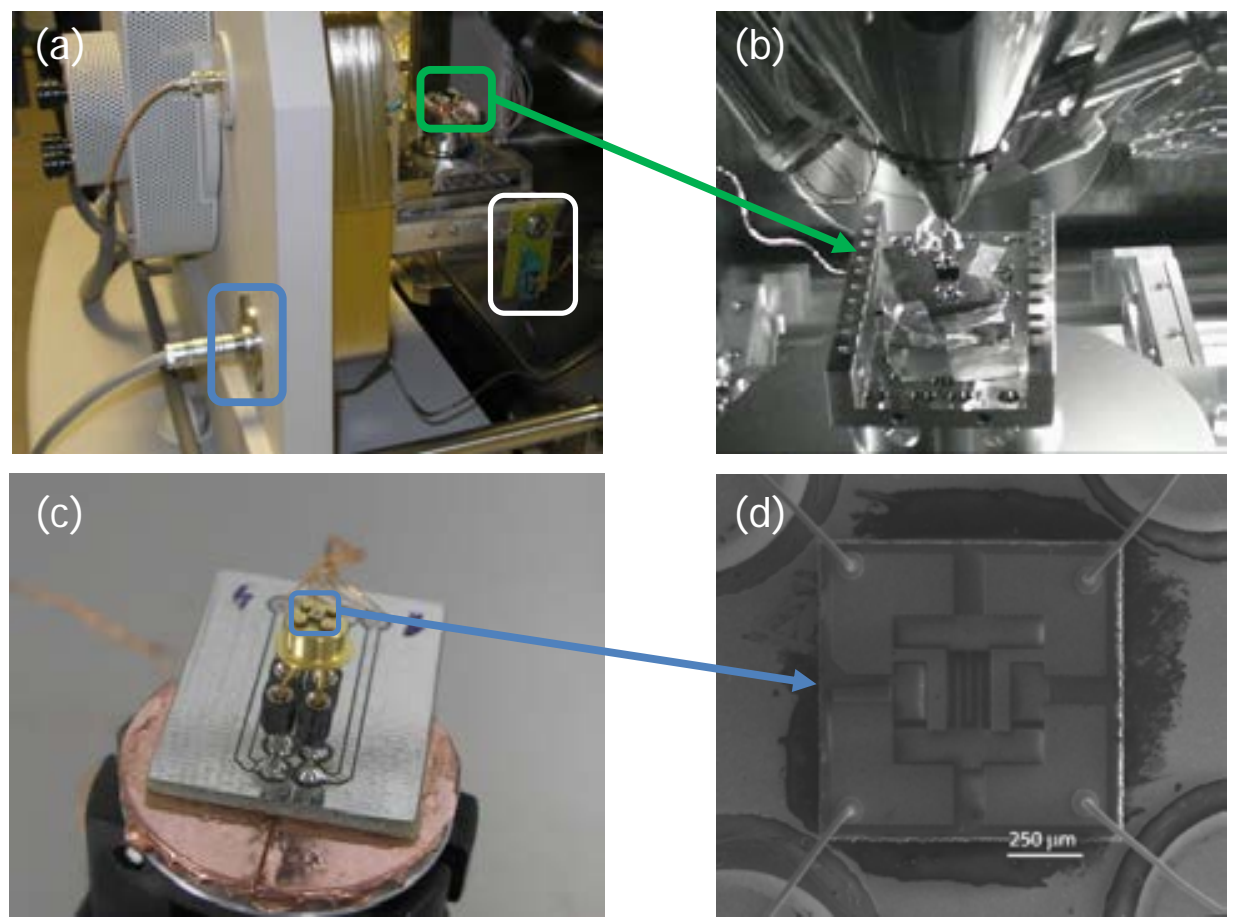

Figura 2.8: (a) Fotografía del "Dual Beam" con la cámara de proceso abierta, a la izquierda con un recuadro azul se indica el conector que sale del equipo, en la parte derecha podemos ver la plataforma donde está instalado el micro-calentador indicado por un recuadro verde y en la que se conecta con un recuadro de color blanco; (b) Fotografía del interior de la cámara de proceso del "Dual Beam", donde podemos observar el micro-calentador; (c) Fotografía del micro-calentador acoplado al portamuestras que se instala en la cámara de proceso; (d) Imagen de SEM del micro-calentador conectado a cuatro bornes.

2. Placa de soporte con cuatro bornes para encajar el micro-calentador y cuatro contactos metálicos a los que van soldados los cuatro cables (véase la Figura 2.8(c)). 
3. Portamuestras en el que se instala la placa del punto 2, indicado por un cuadrado verde en la Figura 2.8(a) que queda perfectamente acoplado en la cámara de proceso (véase la Figura 2.8(b)).

4. Conector al puerto de la puerta de la cámara de proceso, indicado por un rectángulo blanco en la Figura 2.8(a).

5. Conector desde la puerta de la cámara de proceso a una caja de conexiones está señalado por un cuadrado azul en la Figura 2.8(a)).

6. Fuente de voltaje DC.

7. Caja de conexiones. 


\subsection{Espectroscopía de dispersión de energía de rayos-X}

El análisis composicional de las nanoestructuras crecidas mediante FEBID y FIBID en el "Dual Beam” se llevó a cabo in situ gracias al detector de espectroscopía de dispersión de energía de rayos-X de Oxford Instruments (véase la Figura 2.1 y 2.2), el cual recoge la señal de rayos-X generada en la muestra cuándo el FEB incide sobre ella.

Los electrones incidentes producen estados atómicos excitados y la energía de los fotones de rayos-X emitidos en la desexcitación es específica de cada elemento, la cual permite una determinación semicuantitativa de la composición de la muestra utilizando el método de $\mathrm{ZAF}^{112}$ (véase la Figura 2.9). Es una técnica sencilla de usar y particularmente sensible a los elementos más pesados.

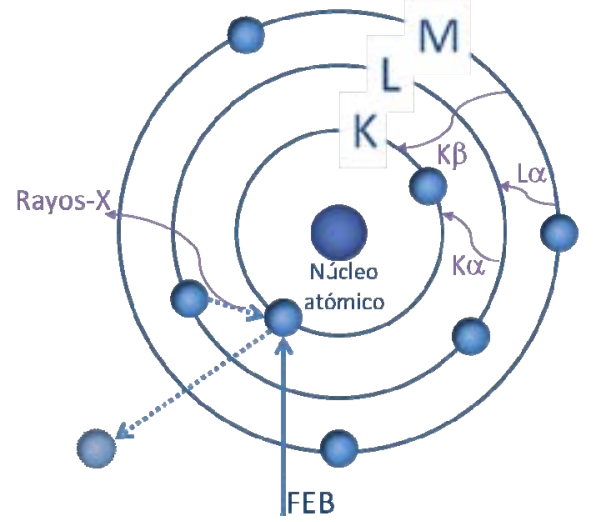

Figura 2.9: Representación esquemática del fundamento físico de la técnica de EDS.

El volumen de interacción del FEB depende principalmente del voltaje de aceleración del FEB, del ángulo de incidencia del FEB con el sustrato y de la naturaleza del sustrato. La resolución en energía es del orden de $\sim 125$ eV y la resolución espacial dependerá del volumen de interacción y de la sonda del FEB que utilicemos (véase la Figura 2.10). Así, en el análisis de nanoestructuras como es nuestro caso debemos tener especial precaución en los parámetros seleccionados para 
obtener un espectro lo más representativo de la nanoestructura fabricada. Como los nanodepósitos crecidos a partir de diferentes precursores tienen una composición completamente distinta, debemos seleccionar las mejores condiciones de la toma de espectros de forma individual. Simplemente para encontrar un punto de partida para todos ellos, si analizamos nanohilos de ancho lateral y espesor inferiores a $100 \mathrm{~nm}$, deberíamos usar un voltaje de aceleración del FEB bajo para disminuir el volumen de interacción y una sonda o diámetro del FEB $<100$ nm, siempre que los elementos que queremos analizar tengan transiciones atómicas por debajo del voltaje escogido. De esta manera, evitaremos introducir en el espectro analizado las transiciones atómicas propias del sustrato que más tarde deberíamos eliminar en el tratamiento de los datos.

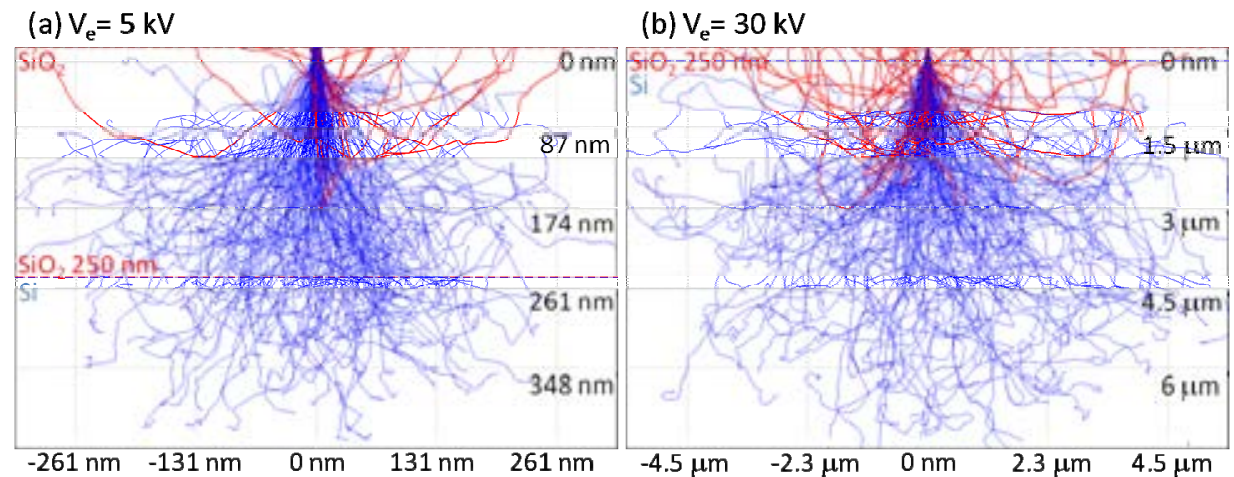

Figura 2.10: Simulación del volumen de interacción de un FEB sobre un sustrato de silicio oxidado térmicamente mediante el programa CASINO ("monte CArlo SImulation of electroN trajectory in sOlids") ${ }^{13}$ (a) a $5 \mathrm{kV}$ y (b) a $30 \mathrm{kV}$. 


\subsection{Microscopía de fuerzas atómicas}

La caracterización morfológica a nivel nanométrico del espesor, rugosidad y uniformidad de las estructuras fabricadas con el "Dual Beam" se llevó a cabo mediante microscopía de fuerzas atómicas. El AFM es un microscopio de sonda de barrido basado en la interacción de una punta afilada con la superficie de la muestra. La fuerzas que se generan entre la punta del cantiléver y la muestra producen la deflexión del cantiléver que se puede modelizar por la ley de Hooke. Las fuerzas que producen la deflexión del cantiléver pueden ser fuerzas de contacto, fuerzas de Van der Waals, fuerzas de capilaridad, fuerzas electrostáticas, fuerzas magnéticas, etc. Normalmente la deflexión se mide con un laser reflejado desde la punta del cantiléver a una matriz de fotodiodos. La punta afilada con un radio de curvatura de unos pocos nanómetros (en nuestro caso de 7-10 nm) es la parte final de un cantiléver de silicio o de nitruro de silicio de dimensiones micrométricas, que barre la superficie de la muestra. El AFM también es utilizado como herramienta en el diseño de nanoestructuras, nanolitografía “dip-pen”, oxidación local, etc.

Las imágenes de AFM se tomaron en el Instituto de Carboquímica, por Eva Terrado, con un AFM Veeco TMC Nanoscope V, modo “tapping” y en el LMA-INA por José Luis Diez, con el mismo modelo de equipo (véase la Figura 2.11).

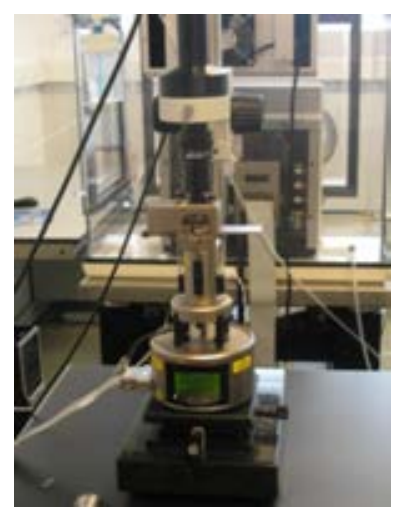

Figura 2.11: Fotografía del AFM, Veeco TMC Nanoscope V instalado en el LMA-INA. 
En el modo “tapping” o modo de contacto dinámico utilizado en nuestras medidas, el cantiléver es excitado externamente cerca de su frecuencia de resonancia. La amplitud de la oscilación, fase y frecuencia de resonancia se modifican por las fuerzas de interacción entre punta y muestra (fuerzas de Van der Waals). Estos cambios en la oscilación externa de referencia producidos por estas fuerzas proporcionan la información sobre la superficie de la muestra formando una imagen de las nanoestructuras. La imagen AFM ofrece un perfil de superficie en tres dimensiones que nos permite extraer información del espesor de las nanoestructuras, su rugosidad y su uniformidad a lo largo de su longitud. Una de las ventajas del modo “tapping” respecto al modo de contacto es que reducimos el daño ocasionado por la punta sobre la superficie de la muestra. 


\subsection{Caracterización estructural y composicional a escala nanométrica}

\subsubsection{Preparación de muestras para TEM mediante "Dual Beam"}

Con los recientes avances tecnológicos en microscopía electrónica de transmisión, los cuales nos permiten estudiar átomos de forma individual, la preparación de muestras adecuadas para estos estudios se ha convertido en la pieza angular de un posterior exitoso análisis. El espesor de estas muestras debe ser inferior a $100 \mathrm{~nm}$ para que el FEB atraviese la muestra y se puedan recoger los electrones transmitidos, incluso para la adquisición de imágenes de alta resolución las muestras deben ser aún más delgadas, $\sim 50 \mathrm{~nm}$ de espesor.

El continuo desarrollo de las técnicas basadas en el uso de un "Dual Beam” ha restado tiempo y complejidad al proceso de preparación de muestras para TEM. Como ejemplo de ello es el uso de un portamuestras específico para el proceso completo de preparación de lamelas de vista transversal sin tener que romper el vacío de la cámara. En la Figura 2.12 mostramos una fotografía de este portamuestras montado sobre la plataforma del microscopio, indicando la muestra sobre la que tomaremos una porción y la rejilla de $\mathrm{Cu}$ estándar utilizada como soporte, dónde quedará la lamela para su posterior manipulación y estudio mediante TEM.

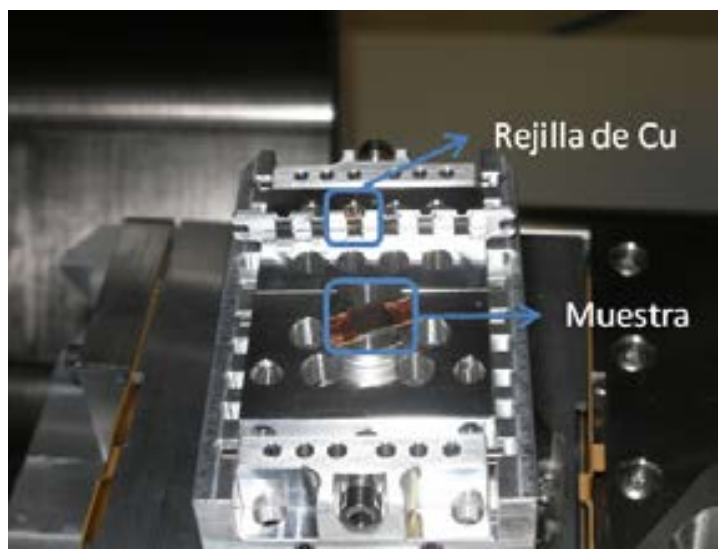

Figura 2.12: Fotografía del portamuestras específico para la preparación de muestras para TEM. 
En el proceso de preparación se combinan varias de las técnicas disponibles en el equipo “Dual Beam”, como por ejemplo el crecimiento de materiales, el uso del FIB para hacer zanjas, y el control del nanomanipulador. Además, como únicamente se trabaja sobre un área de unos $50 \mu \mathrm{m}^{2}$, el resto de la muestra queda preservada para otro tipo de estudios.

A continuación detallaremos los pasos a seguir para la preparación de lamelas ${ }^{10}$ 113-115:

1. Crecimiento de Pt mediante un haz de electrones focalizado. Esta película de Pt sirve para proteger el área de interés del desbastado mediante FIB (véase Figura 2.13(a)). Este crecimiento por electrones evita el daño o amorfización que ocasionaría en los primeros nanómetros de la superficie una capa de Pt crecida mediante FIBID. Dimensiones del depósito: $15 \times 2$ $\times 0.1 \mu \mathrm{m}^{3}$ (largo $\times$ ancho $\times$ espesor) .

2. Crecimiento de Pt mediante un haz de iones focalizado. Película depositada sobre la crecida previamente mediante FEBID para proteger el área de interés de las siguientes etapas de desbastado (véase Figura 2.13(b)). Dimensiones del depósito: $15 \times 2 \times 1 \mu \mathrm{m}^{3}$ (largo $\times$ ancho $\times$ espesor).

3. Desbastado grueso mediante FIB. Se elimina el material a ambos lados de la zona característica cubierta con Pt (véase Figura 2.13(c), (d) y (e)). Dimensiones de las zanjas: $18 \times 9 \times 4 \mu^{3}$ (largo $\times$ ancho $\times$ profundidad). El espesor de la lamela después de esta etapa es de $\sim 1 \mu \mathrm{m}$.

4. Desbastado fino mediante FIB. Se elimina el material a ambos lados de la zona característica cubierta con Pt. Dimensiones de las zanjas: $18 \times 1 \times 4$ $\mu \mathrm{m}^{3}$ (largo $\times$ ancho $\times$ profundidad). El espesor de la lamela después de esta etapa es de $\sim 0.5 \mu \mathrm{m}$. 
5. Corte mediante FIB en forma de U invertida, pero sin liberar completamente la lamela del sustrato (véase Figura 2.13(f)).
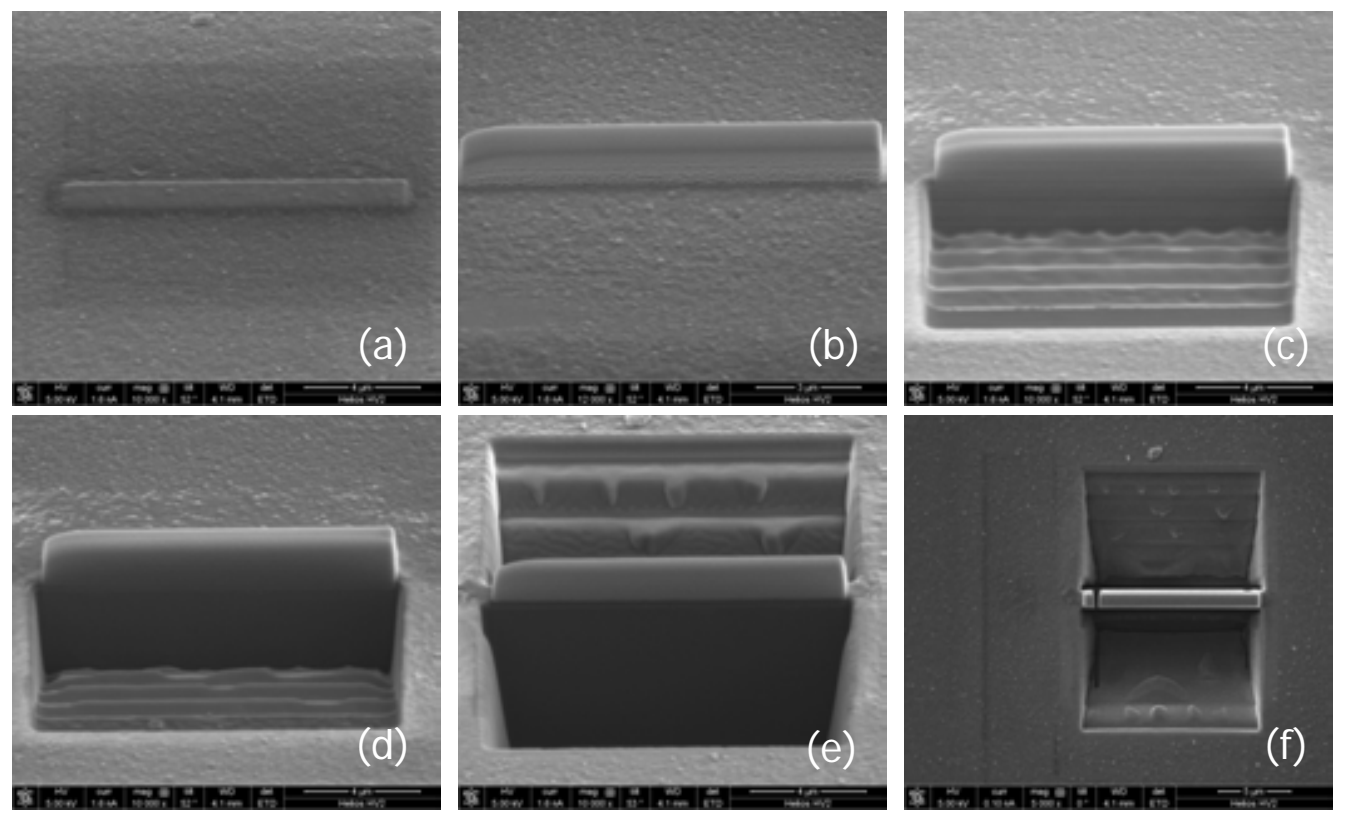

Figura 2.13: Imágenes de SEM que ilustran las etapas del proceso de preparación de muestras para TEM, excluyendo el "lift-out” y el adelgazamiento y pulido final.

6. "Lift-out" mediante un nanomanipulador de Omniprobe, modelo 200 (véase la Figura 2.14(a) y (b)). El nanomanipulador es una punta de wolframio afilada a un micrómetro de diámetro, se inserta dentro de la cámara de proceso y sus movimientos se motorizan en el plano y en el eje z con una precisión nanométrica (máxima resolución de 10 nm). Así, el nanomanipulador se aproxima a la zona de interés hasta prácticamente tocar la lamela (véase Figura 2.15(a)). A continuación, "soldamos" el nanomanipulador a la lamela mediante un depósito de Pt FIBID y liberamos la lamela del sustrato mediante tres cortes con el FIB, en forma de U invertida (véase Figura 2.15(b)). Una vez que tenemos liberada la lamela del sustrato y unida al nanomanipulador (véase Figura 2.15(c)), nos aproximamos a la rejilla de TEM (véase Figura 2.14(c) y 2.15(d)) y 
volvemos a utilizar el Pt FIBID para soldar el otro extremo de la lamela a la rejilla (véase Figura 2.15(e)). Por último, liberamos el nanomanipulador de la rejilla mediante un corte con el FIB (véase Figura 2.15(f)). Después del "lift-out", el nanomanipulador se afila para el próximo uso y se retrae a su posición inicial.

(a)

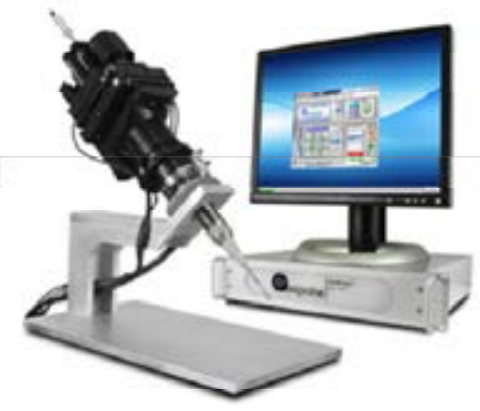

(b)

(c)

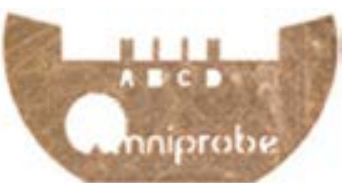

Figura 2.14: (a) Fotografía del nanomanipulador Omniprobe modelo 200, junto con la electrónica y software de control. (b) Fotografía de la punta de wolframio. (c) Fotografía de una rejilla de Cu estándar de espesor de entre 25-30 $\mu \mathrm{m}$ y 3 mm de diámetro utilizadas como soporte de las muestras de TEM.

7. Adelgazamiento. Desbastado fino mediante FIB. Se elimina el material a ambos lados de la zona característica cubierta con Pt. Dimensiones de los cortes: $10 \times 0.1 \times 2 \mu \mathrm{m}^{3}$ (largo $\times$ ancho $\times$ profundidad) (véase Figura 2.15(g)). Repetir el proceso pero reduciendo el largo del diseño a $\sim 4 \mu \mathrm{m}$ hasta que el espesor de la lamela sea de $50 \mathrm{~nm}$ (véase Figura 2.15(h)).

8. Pulido mediante FIB a bajo voltaje $(<5 \mathrm{kV})$. Dimensiones de los cortes: 4 $\times 0.01 \times 1 \mu \mathrm{m}^{3}$ (largo $\times$ ancho $\times$ profundidad). Repetir el proceso hasta que el espesor de la lamela sea de $\sim 30 \mathrm{~nm}$ (véase Figura 2.15(i)).

9. Transferencia de la rejilla de $\mathrm{Cu}$ con la lamela soldada a un microscopio TEM/STEM para su estudio en imagen y análisis. 
El pulido se realiza a bajo voltaje del FIB porque el espesor de la capa de amorfización que se genera en la lamela depende de este voltaje. Puede alcanzar alrededor de $20 \mathrm{~nm}$ por debajo de su superficie cuando el FIB opera a $30 \mathrm{kV}$. Sin embargo, si reducimos el voltaje a $2 \mathrm{kV}$, el espesor de la capa dañada se reduce a 2 nm.
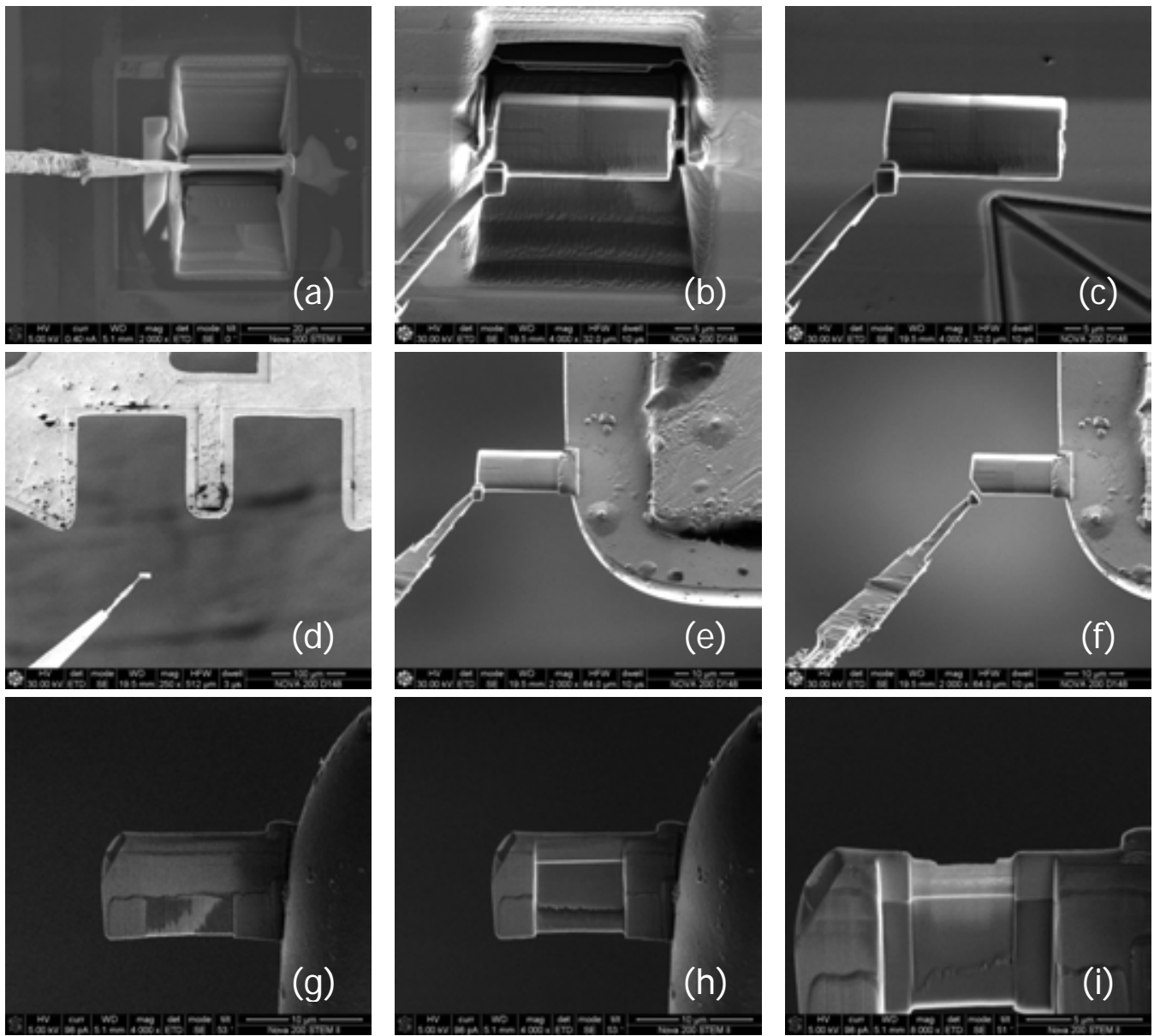

Figura 2.15: Imágenes de SEM y FIB que ilustran las etapas más delicadas del proceso de preparación de muestras para TEM: el "lift-out” y el adelgazamiento y pulido final.

El proceso completo de preparación de muestras de corte transversal para TEM puede llevar varias horas, pero aún así es mucho más rápido y menos destructivo que la preparación manual de muestras, cuyo método requiere un elevado número de 
procesos, como por ejemplo, sucesivos cortes de la muestra mediante una sierra de diamante, pegado de la muestra en forma de sandwich, curado del pegado en un horno, el pulido mecánico, pulido iónico,... que nos puede llevar desde varias horas a varios días de trabajo en función del tipo de material con el que trabajemos.

Algunos ejemplos de los resultados obtenidos gracias a la buena preparación de lamelas mediante FIB en el LMA-INA quedan reflejados en las siguientes referencias $^{116-122}$.

\subsubsection{Microscopía electrónica de transmisión}

La microscopía electrónica de transmisión, en inglés “Transmission Electron Microscopy" (TEM), es una técnica que permite obtener información estructural de una muestra muy delgada (espesor $<100 \mathrm{~nm}$ ). El haz de electrones es relativamente ancho e ilumina simultáneamente toda la región de trabajo atravesando todo el espesor de la muestra, su interacción se refleja en los electrones transmitidos a partir de los cuales se genera la imagen proyectada en el espacio real y su correspondiente diagrama de difracción en el espacio recíproco. Normalmente, el voltaje de aceleración del haz se encuentra entre 100 kV y 300 kV. La imagen TEM puede formarse a partir de los electrones difractados o dispersados al usar una variedad de mecanismos de contraste que proporcionan información acerca de la morfología de la muestra, la cristalografía y composición, con una resolución espacial en la escala atómica de $0.1 \mathrm{~nm}$. No debemos olvidar que ofrece una proyección en dos dimensiones de objetos tridimensionales.

\subsubsection{Microscopía electrónica de transmisión de alta resolución}

La microscopía electrónica de transmisión de alta resolución (HRTEM) es un modo de imagen de TEM, que permite la proyección de la imagen de la estructura 
cristalográfica de una muestra a escala atómica. Es importante tener en cuenta que la imagen recogida no es una representación directa de la estructura cristalográfica de la muestra. La relación entre la onda de la imagen y la fase de salida no es lineal y depende de las aberraciones del microscopio. La resolución en imagen se determina por las imperfecciones o aberraciones de la lente objetivo. Dos tipos de aberraciones comunes son las aberraciones esféricas, en las cuales los electrones que vienen de un punto del objeto, viajan a través de las lentes a distintas distancias del eje óptico, por lo que el FEB se focaliza en diferentes puntos en la imagen; y las aberraciones cromáticas, en las cuales los electrones que vienen de un punto del objeto tienen diferentes energías, por lo que el FEB es focalizado en diferentes puntos en la imagen.

Las imágenes de HRTEM de los Capítulos 3 y 4 fueron tomadas en el Laboratorio de Microscopías Avanzadas, Instituto de Nanociencia de Aragón, Universidad de Zaragoza, por el Dr. César Magén con un equipo Titan $^{3}$ High-base (véase la Figura 2.16) acelerado a $300 \mathrm{kV}$ con un corrector de aberración esférica, $\mathrm{C}_{\mathrm{s}}$ (coeficiente de aberración esférica). La corrección de la aberración esférica de la lente objetivo permite alcanzar una resolución espacial de al menos $0.1 \mathrm{~nm}$.

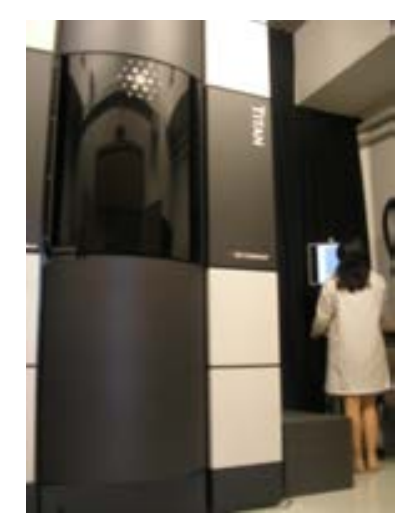

Figura 2.16: Fotografía del Titan $^{3}$ High-base a $300 \mathrm{kV}$ de FEI con un corrector de aberración esférica $\mathrm{C}_{\mathrm{s}}$.

Las imágenes de HRTEM de los depósitos de Pt crecidos mediante FEBID y FIBID resumidas en el Apéndice B y de los depósitos de W crecidos mediante FIBID 
y FEBID resumidas en el Capítulo 5 y el Apéndice A fueron tomadas en los Servicios Científico-Técnicos de la Universidad de Barcelona, por el Dr. Jordi Arbiol con un microscopio Jeol 2010F acelerado a $200 \mathrm{kV}$, de 0.19 nm en resolución espacial.

\subsubsection{Microscopía electrónica de transmisión de barrido}

Un TEM puede ser modificado o convertido en un STEM al añadirle un sistema de barrido del haz a lo largo de la muestra que forma una imagen, al ser combinado con los detectores apropiados. La deflexión del haz se realiza mediante bobinas de barrido, así como un movimiento electrostático. Realmente, se puede hacer STEM usando una columna de SEM a relativamente bajas energías $(30 \mathrm{kV})$ o como hemos comentado antes, a partir de una columna TEM a alto voltaje (100-300 kV). Voltajes elevados proporcionan una mejor resolución y la habilidad de atravesar muestras más gruesas. Los STEM de alta energía consiguen resoluciones próximas a las de un TEM.

La intensidad del haz transmitida en cada punto se mide y se graba digitalmente, generando una imagen en serie de la muestra que se está barriendo con el haz. La resolución se determina por el tamaño de la sonda que llega a la muestra. El detector de campo claro recoge los electrones que tienen pequeños ángulos de dispersión, principalmente de los electrones dispersados inelásticamente o no difractados. El detector de campo oscuro recoge los electrones dispersados de alto ángulo.

\subsubsection{Espectroscopía de pérdida de energía de los electrones}

En la espectroscopía de pérdida de energía de los electrones, en inglés “Electron energy loss spectroscopy” (EELS), el material a analizar está expuesto a un haz de electrones con un rango pequeño de distribución de energías cinéticas conocidas. Algunos de los electrones primarios sufren una dispersión inelástica, pierden energía que se transfiere a los electrones o átomos de la muestra y se desvían de su trayectoria al azar. La cantidad de energía perdida por el electrón se puede medir mediante un 
espectrómetro de electrones e interpretada en términos del origen de esa pérdida de energía. Los principales tipos de mecanismos de interacciones inelásticas pueden ser debidos a la excitación de fonones, la excitación de plasmones, la excitación de electrones, y la pérdida de radiación incidente.

Esta técnica es capaz de medir la composición, el enlace químico, y la valencia a escala nanométrica. Suele funcionar mejor para elementos ligeros, de bajo número atómico y su resolución en energía puede ser del orden de $\sim 1 \mathrm{eV}$. Los umbrales de ionización de EELS se clasifican usando la notación estándar en espectroscopia, por ejemplo K es la excitación para la ionización de los electrones $1 \mathrm{~s}, \mathrm{~L}_{1}$ para los $2 \mathrm{~s}, \mathrm{~L}_{2}$ para los $2 \mathrm{p}_{1 / 2}, \mathrm{~L}_{3}$ para los $2 \mathrm{p}_{3 / 2}, \mathrm{M}_{1}$ para los $3 \mathrm{~s}$, etc. El subíndice indica el número cuántico del momento angular total del electrón, j, que es el mismo que el momento angular del orbital, l, más el número cuántico del espín, s. Para un electrón 2p, l= 1 y éste se puede acoplar al espín del electrón de dos formas, $\mathrm{j}=\mathrm{l}+\mathrm{s}=1+1 / 2=3 / 2\left(\mathrm{~L}_{3}\right)$ o j=1$1 / 2=1 / 2\left(\mathrm{~L}_{2}\right)$.

El análisis de la estructura fina se realiza mediante el método de determinación ELNES, el cual da información detallada de la estructura de ionización y por tanto del enlace asociado a cada especie atómica. Las “White lines” son espectros muy definidos, con características muy abruptas debidas a transiciones estrechas de las bandas d o f.

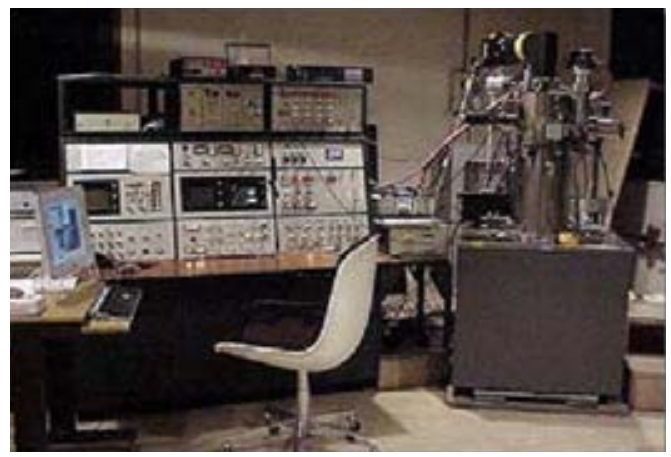

Figura 2.17: Fotografía del STEM VG HB 501 con cañón de emisión de campo frío (“cold-FEG”) operado a $100 \mathrm{kV}$, espectrómetro Gatan 666, ópticamente acoplado a una cámara CCD. 
Las imágenes de STEM y los espectros EELS que se pueden encontrar en el Capítulo 3 de esta tesis fueron tomados y analizados por el Dr. Rodrigo FernándezPacheco en el STEM Group- Laboratoire de Physique des Solides (CNRS-UMR 8502), Université Paris-Sud, con un equipo STEM VG HB 501 con un haz de electrones de emisión de campo acelerado a $100 \mathrm{kV}$ y ajustado con un espectrómetro Gatan 666, ópticamente acoplado a una cámara CCD (véase la Figura 2.17). 


\subsection{Caracterización del transporte eléctrico}

\subsubsection{Medidas de transporte eléctrico in situ}

En este apartado describiremos el sistema de medidas de transporte eléctrico in situ adaptado al equipo "Dual Beam”.

La estación de micropuntas se puede utilizar para investigar la resistencia de estructuras fabricadas o bien medir las estructuras durante su fabricación o modificación. En el LMA-INA contamos con una unidad de cuatro micropuntas motorizadas de Kleindiek. Cada punta tiene tres motores que permiten su movimiento en los ejes $\mathrm{x}, \mathrm{y}$, z, cubriendo un área de $20 \mathrm{~mm}^{2}$ en el plano y $5 \mathrm{~mm}$ verticalmente. La velocidad de movimiento puede ser controlada de un modo preciso con varios niveles de velocidad. La resolución del movimiento cuando se opera en modo fino controlado por piezos es de 4 nm (véase la Figura 2.18).

La estación de micropuntas está conectada en el interior de la cámara de proceso del "Dual Beam" a un puerto que da salida al exterior del equipo. De ahí se conecta a una fuente de corriente Keithley 6221 DC \& AC y a un nanovoltímetro Keithley 2182A. Se inyecta corriente por dos puntas y se mide la caída de voltaje por las otras dos puntas, de esta forma garantizamos la no contribución de resistencias de contacto en la resistencia de medida.
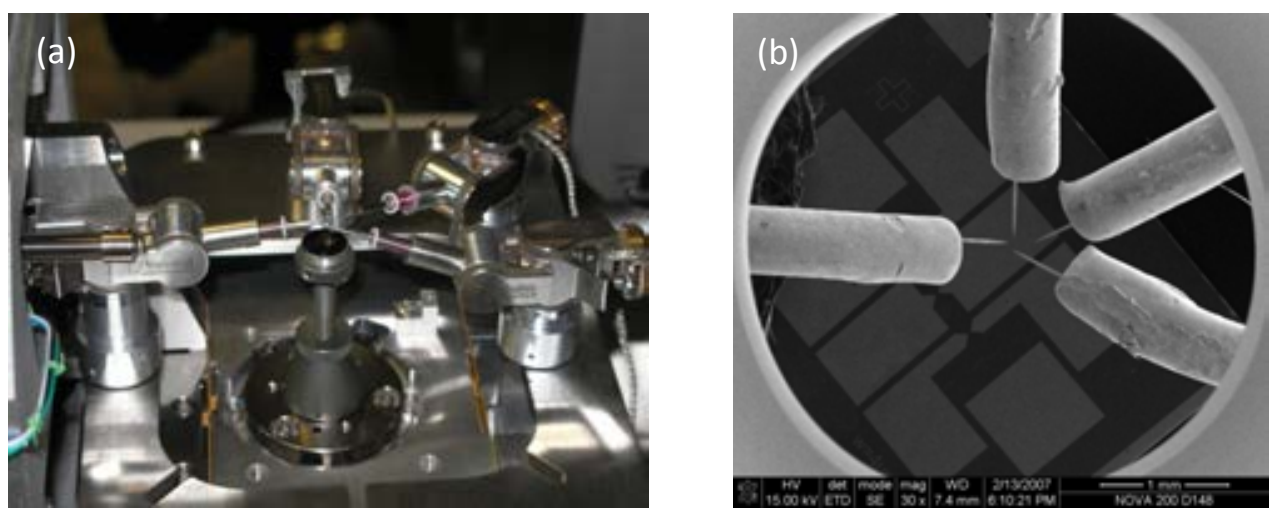

Figura 2.18: Micropuntas Kleindiek. (a) Fotografía de las cuatro micropuntas sobre la plataforma del “Dual Beam”, (b) Imagen SEM de las cuatro micropuntas. 


\subsubsection{Medidas de magnetotransporte eléctrico "ex-situ”}

La caracterización eléctrica de nuestras muestras en un amplio rango de temperaturas de 0.3 a $300 \mathrm{~K}$ y campo magnético aplicado perpendicular al sustrato de +9 a -9 T se realizó en el Servicio de Instrumentación Científica, Área de Medidas Físicas, Universidad de Zaragoza, con un equipo comercial "Physical Properties Measurements System”, PPMS de Quantum Design (véase la Figura 2.19). La opción utilizada para la caracterización de nuestros depósitos crecidos mediante FEBID y FIBID mediante cuatro contactos en la mayoría de los casos fue la de resistividad en modo AC. En casos específicos que desarrollaremos en el Capítulo 5, se utilizó el modo de medida DC y el modo AC con el sistema de refrigeración de ${ }^{3} \mathrm{He}$. Para realizar medidas por debajo de $2 \mathrm{~K}$, el sistema PPMS tiene la opción de trabajar con un sistema de refrigeración de ${ }^{3} \mathrm{He}$ que permite enfriar hasta $300 \mathrm{mK}$ (véase la Figura 2.19).

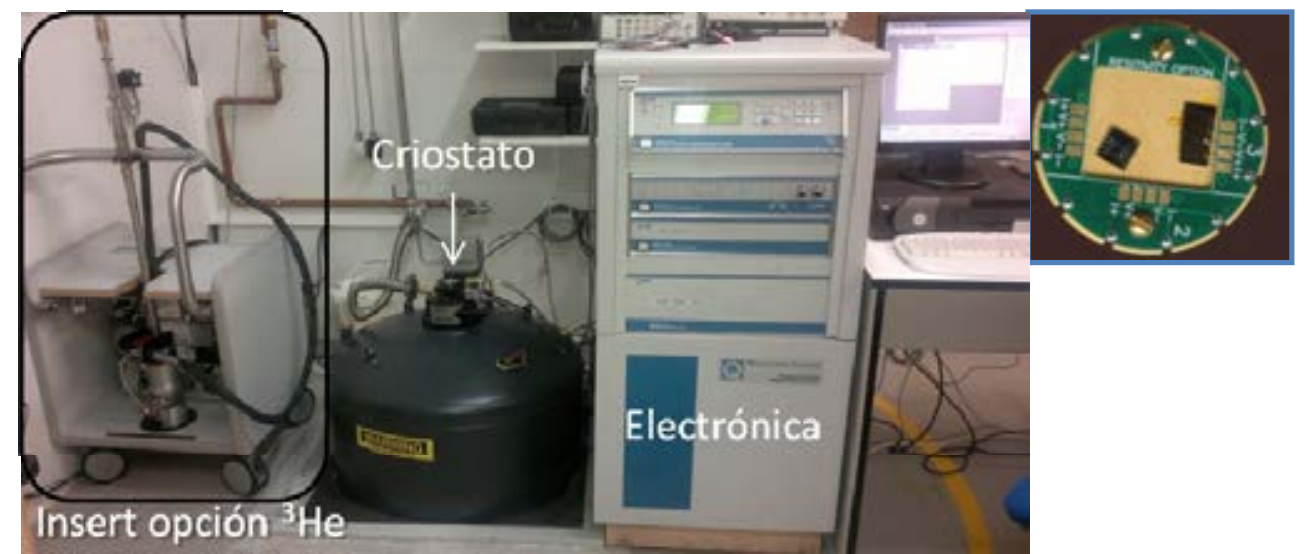

Figura 2.19: Fotografía del equipo PPMS de Quantum Design instalado en el Servicio de Medidas Físicas de la Universidad de Zaragoza. En el recuadro mostramos una fotografía del portamuestras del PPMS de Quantum Design provisto de tres canales de medida distintos para medidas por cuatro puntas y utilizado en la opción de resistividad.

Como hemos comentado anteriormente, el PPMS permite operar con dos modos distintos de medida AC y DC. En el modo AC, se toma una lectura de la caída de 
voltaje al aplicar una excitación a la muestra, después se invierte la corriente y se vuelve a tomar una lectura de la caída de voltaje. La medida obtenida es la media del valor absoluto de las lecturas de voltaje positivo y negativo. La excitación AC se realiza mediante una onda cuadrada sincronizada a la frecuencia de la línea AC de 50 $\mathrm{Hz}$ para eliminar el ruido de la línea. Con este modo eliminamos los errores de los voltajes offset de DC y se obtienen lecturas más exactas. Mientras que en el modo DC, se realizan dos lecturas de voltaje consecutivas con la misma polaridad obteniéndose un voltaje de lectura menos exacto que en el modo AC. Sin embargo, es un modo de medida muy útil para muestras a las que les afecta significativamente la inversión de la polaridad. 


\subsection{Otras técnicas experimentales}

\subsubsection{Litografía óptica}

Los sustratos litografiados, base fundamental para las medidas de magnetotransporte de las nanoestructuras estudiadas en esta tesis, se fabricaron en la sala blanca del LMA-INA por parte de Isabel Rivas y Rubén Valero. En la Figura 2.21 mostramos parte del equipamiento utilizado en este proceso.
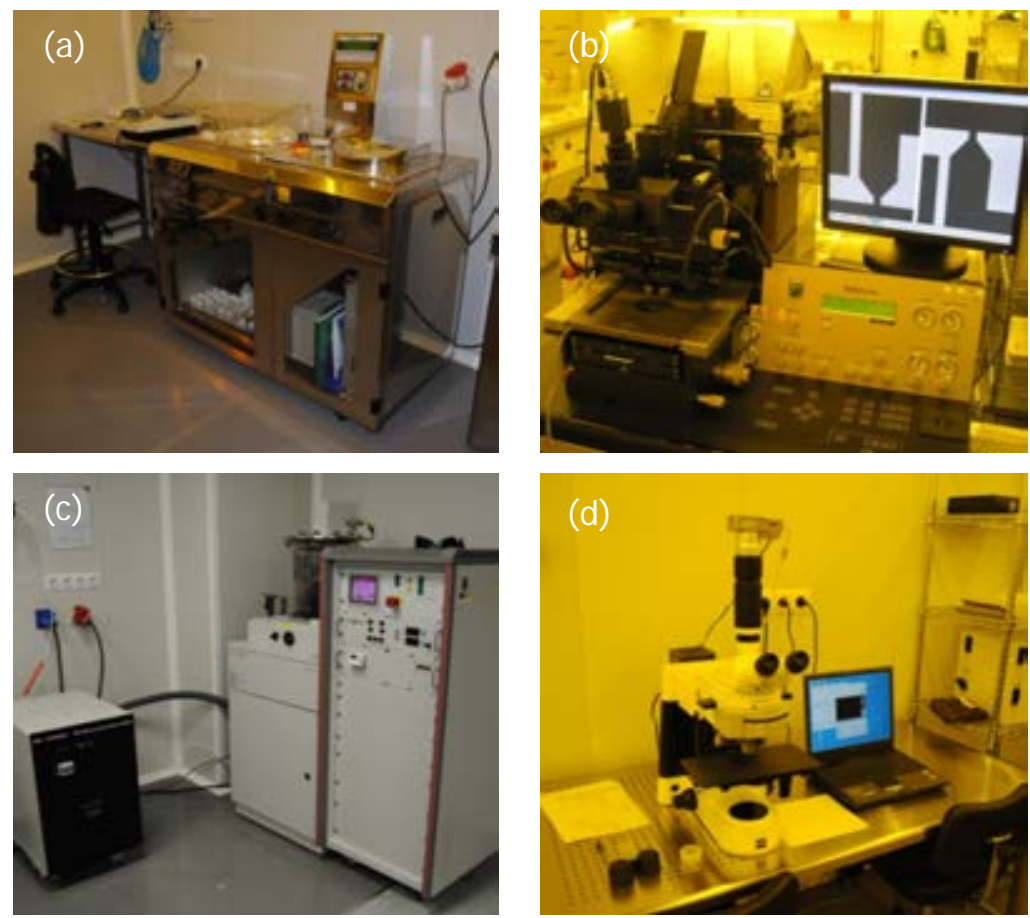

Figura 2.21: Fotografías de equipos utilizados en la litografía óptica. (a) Estación de depósito de resinas, (b) alineador de máscaras; (c) evaporador por un haz de electrones; (d) microscopio óptico.

Los electrodos de Ti se fabricaron sobre un sustrato de Si oxidado térmicamente (250 nm de $\mathrm{SiO}_{2}$ ) asegurando así el aislamiento eléctrico con el silicio. El proceso “lift-off” de litografía óptica se realizó mediante la exposición de luz ultravioleta de una máscara inversa sobre la fotorresina. El crecimiento de metal se llevó a cabo con 
un evaporador por haz de electrones, de Edwards Company. Por último, los sustratos se sumergen en acetona para disolver la resina y que sólo permanezcan sobre el sustrato los electrodos metálicos diseñados. El diseño de la máscara se preparó para tener al menos cuatro contactos metálicos para las medidas de magnetotransporte por cuatro puntas, la distancia entre cada electrodo es de $\sim 4 \mu \mathrm{m}$.

\subsubsection{Equipo de microsoldadura}

El equipo de microsoldadura modelo Kulicke \& Suffa 4526 ubicado en la sala blanca del LMA-INA, se utilizó para contactar nuestros nanodepósitos por cuatro puntas, foco del estudio de magnetotransporte eléctrico "ex-situ”, al portamuestras del PPMS. El hilo utilizado para este propósito es de Al, cuyo diámetro es $25 \mu \mathrm{m}$ (véase la Figura 2.22).

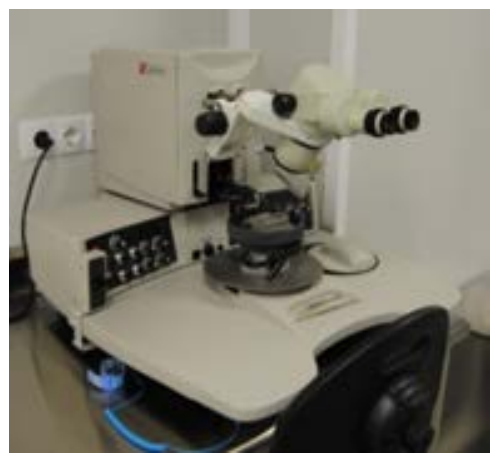

Figura 2.22: Fotografía del equipo de microsoldadura modelo K\&S 4526.

\subsubsection{Efecto Kerr magnetoóptico}

Las propiedades magnéticas a temperatura ambiente se determinaron utilizando la técnica del Efecto Kerr magnetoóptico longitudinal, en inglés “Magneto-optical Kerr effect" (MOKE). Se utilizaron tanto un microscopio Kerr de campo ancho de Evico Magnetics (véase la Figura 2.23), como un sistema con láser focalizado de diámetro 
por debajo de $\sim 2 \mu \mathrm{m}$, permitiendo la detección del efecto Kerr en nanoestructuras. Las medidas MOKE del Capítulo 4 se realizaron en la Eindhoven University of Technology (TU/e).

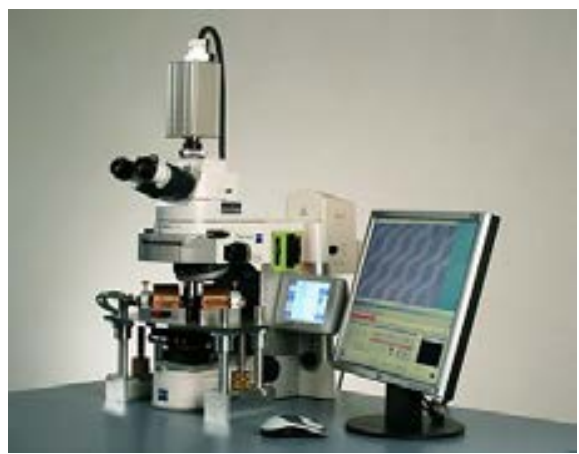

Figura 2.23: Fotografía del equipo microscopio Kerr de campo ancho de Evico Magnetics. 



\section{Capítulo 3}

\section{Nanodepósitos ferromagnéticos de Co crecidos mediante un haz de electrones focalizado}

En este capítulo presentamos la fabricación y caracterización de nanodepósitos de Co variando parámetros de crecimiento con gran incidencia en sus posteriores propiedades magnéticas, como la corriente de electrones, el voltaje de aceleración del haz, el flujo de precursor, y la temperatura del sustrato, entre otros. El análisis composicional de los nanodepósitos fabricados se lleva a cabo in situ.

El estudio de su microestructura y composición en la nanoescala se ha realizado mediante técnicas de microscopía electrónica de transmisión, mientras que las propiedades magnéticas de nanoestructuras ultraestrechas se han estudiado mediante medidas de magnetotransporte. Los resultados obtenidos nos permiten vincular este tipo de nanoestructuras con potenciales aplicaciones en el campo de la Nanotecnología. 


\subsection{Introducción}

El interés suscitado en las nanoestructuras ferromagnéticas viene dado por sus prometedoras aplicaciones debido al carácter magnético que presentan. Este tipo de propiedades intrínsecas de los depósitos permite su utilización en una gran variedad de aplicaciones en nanotecnología: en la fabricación de sensores ${ }^{123}$, almacenamiento de información magnética ${ }^{124}$, lógica magnética ${ }^{3}$ y biosensores ${ }^{125}$.

En el crecimiento de nanoestructuras magnéticas mediante FEBID, la concentración del elemento magnético en el depósito es crucial debido a la rápida degradación de las propiedades magnéticas con la presencia de residuos propios del material precursor, como por ejemplo C y O, entre otros. Uno de los depósitos que con más éxito se ha fabricado y caracterizado mediante FEBID es el que está basado en cobalto; siendo el octacarbonilo de dicobalto, $\mathrm{Co}_{2}(\mathrm{CO})_{8}$ el precursor utilizado por excelencia para este fin ${ }^{126-130}$. Por lo general, los depósitos de Co crecidos a partir del $\mathrm{Co}_{2}(\mathrm{CO})_{8}$ consisten en nanocristales de cobalto cuyo tamaño oscila entre 3-5 nm embebidos en una matriz de carbono amorfa.

En la literatura existen trabajos previos en los cuales se muestran diferentes estrategias para mejorar el contenido metálico de los depósitos de Co crecidos mediante FEBID al modificar los distintos parámetros de crecimiento, como por ejemplo la corriente de electrones ${ }^{127}$; o someterlos a tratamientos térmicos in situ o "ex-situ” 47.

Recientemente, algunos autores han comenzado a utilizar el nitrosil tricarbonilo de cobalto $\mathrm{Co}(\mathrm{CO})_{3}(\mathrm{NO}){ }^{131}$, 132, como material precursor en el crecimiento de estructuras basadas en Co. Sin embargo, en ningún caso los resultados y propiedades magnéticas exhibidas mejoran los conseguidos utilizando el $\mathrm{Co}_{2}(\mathrm{CO})_{8}$ como material de partida.

En este capítulo, hemos investigado minuciosamente los depósitos de Co crecidos mediante FEBID, utilizando como material precursor el $\mathrm{Co}_{2}(\mathrm{CO})_{8}$. Asimismo, debemos dar especial relevancia a la selección de los parámetros de crecimiento, 
crucial en la obtención de nanoestructuras ferromagnéticas de 30-100 nm de ancho lateral. El control de los distintos parámetros de crecimiento es primordial en la obtención de nanoestructuras con elevado contenido de Co. Hemos llevado a cabo un estudio de fabricación de nanoestructuras de Co modificando algunos de los parámetros, como por ejemplo, el voltaje de aceleración del FEB $\left(\mathrm{V}_{\mathrm{e}}\right)$, la corriente de electrones $\left(I_{e}\right)$, la temperatura del sustrato, la naturaleza del sustrato, y el flujo de precursor. Estas nanoestructuras han sido caracterizadas in situ o bien "ex-situ" mediante técnicas avanzadas de microscopía y espectroscopía tales como EDS, STEM, HRTEM, EELS, holografía electrónica, y medidas de magnetotransporte por cuatro puntas. 


\subsection{Crecimiento de nanoestructuras de Co mediante FEBID}

La fabricación de nanoestructuras de Co se llevó a cabo asistido por un haz de electrones focalizado, junto con un sistema de inyección de gases (GIS) en el sistema Nova Nanolab 200. Este proceso de crecimiento, conocido como FEBID, se explicó en detalle en el apartado 1.3.4 del Capítulo 1. Los parámetros de crecimiento de los nanodepósitos de Co son los siguientes: material precursor= octacarbonilo de dicobalto, $\mathrm{Co}_{2}(\mathrm{CO})_{8}$; temperatura de material precursor $=27{ }^{\circ} \mathrm{C} \pm 1{ }^{\circ} \mathrm{C}$; volumen por dosis (VD) $5 \times 10^{-4} \mu \mathrm{m}^{3} / \mathrm{nC}$; $\mathrm{T}_{\text {sustrato }}=$ temperatura ambiente; tiempo de permanencia del haz en cada punto $\left(t_{p}\right)=1 \mu \mathrm{s}$; solapamiento del haz $(s)=50 \%$; tiempo de refresco $\left(\mathrm{t}_{\mathrm{r}}\right)=0 \mathrm{~s}$; presión base de la cámara de proceso $\left(\mathrm{P}_{\text {base }}\right)=1 \times 10^{-6}$ mbar; presión de la cámara de proceso durante el crecimiento $\left(\mathrm{P}_{\text {proceso }}\right)=6 \times 10^{-6} \mathrm{mbar}$; estrategia de barrido= modo serpentín, de abajo a arriba; rango de voltaje de aceleración del haz de electrones utilizado $\left(\mathrm{V}_{\mathrm{e}}\right)=5 \mathrm{kV}-30 \mathrm{kV}$; rango de corriente de electrones estudiado $\left(\mathrm{I}_{\mathrm{e}}\right)=21 \mathrm{pA}-9.5 \mathrm{nA}$. En los casos particulares que variemos alguno de estos parámetros se comentará en el texto. Los sustratos más utilizados en los experimentos fueron: Si dopado con boro (dopaje tipo p), Si (dopaje tipo p) oxidado térmicamente (con este método obtenemos una capa de $250 \mathrm{~nm}$ de material aislante $\left.\left(\mathrm{SiO}_{2}\right)\right)$, y membranas de $\mathrm{Si}_{3} \mathrm{~N}_{4}$ de $50 \mathrm{~nm}$ de espesor. Los contactos de Ti se fabricaron sólo sobre el sustrato de Si oxidado mediante técnicas de litografía óptica.

Los primeros nanodepósitos de Co estudiados en este apartado de dimensiones, $0.5 \times 1 \times 0.2 \mu \mathrm{m}^{3}$ fueron crecidos sobre Si oxidado térmicamente, variando $\mathrm{I}_{\mathrm{e}} \mathrm{y} \mathrm{V}_{\mathrm{e}}$ para estudiar la dependencia de estos dos parámetros en la composición de los nanodepósitos.

El análisis composicional de los nanodepósitos de Co se realizó in situ mediante EDS tras el proceso de crecimiento, así los depósitos no estuvieron expuestos a las condiciones ambientales, evitando la posibilidad de que su composición se hubiera modificado por agentes externos. Los espectros son recogidos utilizando un voltaje de aceleración del haz de electrones de $5 \mathrm{kV}$. En la Tabla 3.1, mostramos los resultados obtenidos en diferentes nanoestructuras de Co crecidas variando $\mathrm{I}_{\mathrm{e}} \mathrm{y} \mathrm{V}_{\mathrm{e}}$. 


\begin{tabular}{|c|c|c|c|c|c|}
\hline Muestra & $\begin{array}{c}V_{e} \\
(k V)\end{array}$ & $\begin{array}{c}I_{e} \\
(n A)\end{array}$ & $\begin{array}{c}\text { Co } \\
\text { (\%at. } \pm 2 \%)\end{array}$ & $\begin{array}{c}C \\
\text { (\%at. } \pm 2 \%)\end{array}$ & $\begin{array}{c}O \\
(\% a t . \pm 2 \%)\end{array}$ \\
\hline 1 & 5 & 0.40 & 83 & 15 & 2 \\
\hline 2 & 5 & 1.60 & 83 & 13 & 4 \\
\hline 3 & 5 & 6.30 & 91 & 7 & 1 \\
\hline 4 & 10 & 0.13 & 81 & 9 & 10 \\
\hline 5 & 10 & 0.54 & 92 & 5 & 3 \\
\hline 6 & 10 & 2.10 & 95 & 4 & 1 \\
\hline 7 & 10 & 8.40 & 94 & 5 & 1 \\
\hline 8 & 18 & 9.20 & 88 & 9 & 2 \\
\hline 9 & 30 & 0.15 & 62 & 19 & 19 \\
\hline 10 & 30 & 9.50 & 97 & 3 & - \\
\hline
\end{tabular}

Tabla 3.1: Composición de los nanodepósitos de Co crecidos sobre Si oxidado térmicamente para estudiar la dependencia del contenido de Co con $\mathrm{I}_{\mathrm{e}} \mathrm{y} \mathrm{V}_{\mathrm{e}}$.

Los resultados presentados en la Tabla 3.1 ponen de manifiesto una dependencia del contenido de Co en los depósitos en función de la corriente de electrones utilizada en el crecimiento, de tal manera que se consiguen concentraciones por encima del 90\% cuándo $\mathrm{I}_{\mathrm{e}}$ está en el rango de $\sim \mathrm{nA}$.

En la Figura 3.1 mostramos como ejemplo, la dependencia de la composición de nanodepósitos crecidos a $10 \mathrm{kV}$ en función de $\mathrm{I}_{\mathrm{e}}$, dónde podemos observar claramente como el contenido de Co aumenta desde un $80 \%$ usando una $\mathrm{I}_{\mathrm{e}}$ de $0.13 \mathrm{nA}$ hasta alcanzar un 95\% por encima de $1 \mathrm{nA}$.

Utke y colaboradores encontraron esta dependencia previamente ${ }^{127}$. Sin embargo, el máximo contenido de Co obtenido no superaba el $\sim 80 \%$, probablemente debido a que su equipo consta de un filamento de wolframio termoiónico y por tanto la densidad de corriente de electrones generada es sensiblemente menor que la que se alcanza con una fuente de emisión de campo como la que tiene nuestro equipo. Otra razón a esgrimir sería que la presión base que alcanza nuestro sistema es un orden de magnitud mejor que la de su microscopio, por tanto, la contaminación de la cámara 
contribuye sensiblemente a la menor concentración de Co obtenida. La explicación por la cual la mayor parte de autores nos hemos decantado para explicar este fenómeno es que el calor generado de forma local, por el haz de electrones al usar corrientes en el rango de nA con una fuente de emisión de campo, facilita la descomposición de este material precursor, cuya temperatura de descomposición es relativamente baja si la comparamos con otros precursores de similar naturaleza ${ }^{47,133}$.

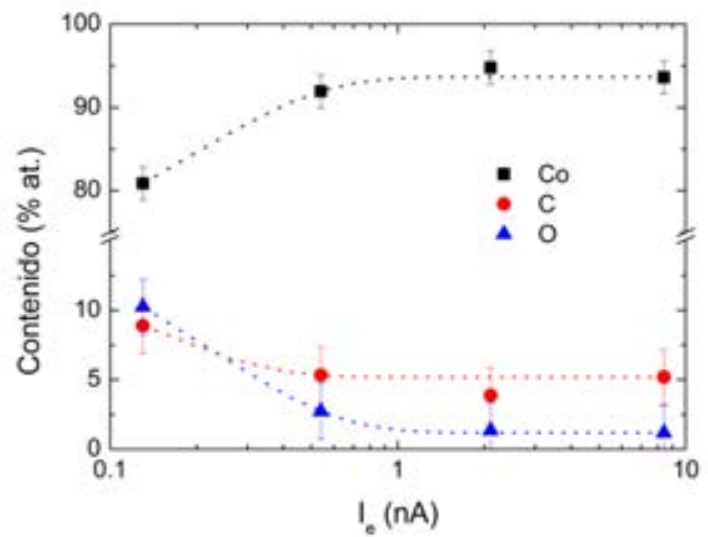

Figura 3.1: Composición de los nanodepósitos de Co crecidos a 10 kV en función de $\mathrm{I}_{\mathrm{e}}$. 


\subsection{Microestructura y composición de nanodepósitos de Co en la nanoescala}

Una vez observadas las diferencias en el contenido de Co entre depósitos crecidos mediante FEBID a baja y alta corriente de electrones, profundizamos en el estudio de su microestructura y composición en la nanoescala. El objetivo de este estudio es analizar el estado de valencia y la estructura cristalina de los depósitos de Co. Asimismo, pretendemos explicar desde el punto de vista químico y estructural en la micro- y nanoescala, las propiedades químicas, estructurales y magnéticas estudiadas en este tipo de nanodepósitos por nuestro grupo ${ }^{133}$.

Para realizar este tipo de observación local, la técnica más apropiada es el (S)TEM. Concretamente, EELS es la técnica ideal para analizar el estado de oxidación y el entorno químico en la escala local de los tres elementos presentes en el depósito: carbono, oxígeno y cobalto. En un STEM, los espectros EELS pueden ser resueltos y relacionados con su posición en la muestra mediante la adquisición simultánea de imágenes de campo oscuro anular de alto ángulo (HAADF). Por otra parte, la adquisición y el análisis de imágenes HRTEM permite extraer información acerca de la estructura cristalina a escala atómica.

Ambas técnicas confirmaron el alto contenido metálico en las nanoestructuras crecidas usando corrientes de electrones en el rango de nA estudiado. Para estudiar la influencia de la corriente del haz de electrones, $\mathrm{I}_{\mathrm{e}}$, en la microestructura y composición de los nanodepósitos basados en Co en la escala nanométrica, se fabricaron nanodepósitos de Co a $30 \mathrm{kV}$ sobre una oblea de Si oxidada térmicamente (250 nm $\mathrm{SiO}_{2}$ ) variando $\mathrm{I}_{\mathrm{e}}$. El resto de parámetros son los mismos que los utilizados en el apartado 3.2 de este capítulo.

El depósito 1 se creció a baja $\mathrm{I}_{\mathrm{e}}(44 \mathrm{pA})$ y el depósito 2 a alta corriente $\mathrm{I}_{\mathrm{e}}(2.4 \mathrm{nA})$ de dimensiones $=0.5 \times 1.0 \times 0.2 \mu \mathrm{m}^{3}$ (ancho $\times$ largo $\times$ espesor); la distancia entre puntos es de $\left(\mathrm{d}_{\mathrm{FEB}}\right) \sim 2.21 \mathrm{~nm}$ (44 pA), y de $13.16 \mathrm{~nm}(2.4 \mathrm{nA})$.

Una vez finalizado el crecimiento de los nanodepósitos, se realizaron análisis EDS in situ. Los resultados en \% atómico para el depósito 1 son 64:17:19 (Co:C:O) y 
93:5:2 (Co:C:O) para el depósito 2. Antes de la preparación de las muestras para TEM o lamelas de vista transversal, los depósitos de Co se cubrieron con 2 capas protectoras, primero una capa de Pt crecido mediante FEBID y a continuación una segunda capa de Pt crecido mediante FIBID. Este procedimiento estándar comentado en detalle en el Capítulo 2 se realiza para proteger los depósitos de Co del daño (amorfización) que puede ocasionar el FIB durante la preparación de las lamelas. El proceso de preparación y extracción de las lamelas de los depósitos de Co se realiza in situ en el mismo equipo, sin romper el vacío de la cámara de proceso. El adelgazamiento y pulido final de las lamelas se realiza usando un $\mathrm{V}_{\mathrm{i}}$ (voltaje de aceleración del haz de iones) de $5 \mathrm{kV}$, para disminuir el espesor de la capa de amorfización que produce el FIB. Al finalizar el protocolo de preparación, conseguimos lamelas de alta calidad con un espesor de $\sim 30 \mathrm{~nm}$ para los estudios posteriores en los cuales pretendemos alcanzar resoluciones atómicas.

Como hemos comentado previamente, la microestructura de los nanodepósitos fue investigada mediante HRTEM, cuyas medidas fueron realizadas en un equipo Titan $^{3}$ High-base a $300 \mathrm{kV}$ de FEI con un corrector de aberración esférica $\mathrm{C}_{\mathrm{s}}$. La corrección de la aberración esférica de la lente objetivo nos permite obtener una resolución espacial inferior a $0.1 \mathrm{~nm}$. La composición de los nanodepósitos en la escala nanométrica fue investigada mediante el análisis químico realizado en un STEM VG HB 501 con cañón de emisión de campo frío (cold-FEG) operado a 100 kV, espectrómetro Gatan 666, ópticamente acoplado a una cámara CCD.

Para cada muestra, se llevó a cabo un análisis químico y estructural en la nanoescala mediante EELS y HRTEM. Junto con el análisis químico en la parte interior de cada depósito, se han realizado análisis de las interfases Pt-Co y $\mathrm{SiO}_{2}$-Co para entender las diferencias en la composición química entre el centro y la superficie del depósito. Los espectros EELS permiten determinar en cada muestra el contenido de cobalto metálico y su estado de oxidación. La forma de proceder es la siguiente: en la configuración STEM se genera una sonda muy fina, inferior a $1 \mathrm{~nm}$ de diámetro, al converger el haz de electrones. Esta sonda barre la muestra y simultáneamente se recoge una serie de espectros punto a punto. Los espectros obtenidos pueden ser 
correlacionados con el punto de la muestra dónde se han recogido; esta técnica es conocida como espectro-línea, en inglés “spectrum-line” o "linescan" ${ }^{134}$. Para cada “spectrum-line", los espectros se adquirieron con pasos de $1 \mathrm{~nm}$. El estado químico del Co fue analizado mediante el cociente de intensidades de los picos $\mathrm{L}_{2}$ y $\mathrm{L}_{3}$ del umbral $\mathrm{L}_{2,3}$ del Co ( $\mathrm{IL}_{2}, \mathrm{IL}_{3}$, respectivamente), y luego comparado con los valores de referencia de $\mathrm{I}\left(\mathrm{L}_{2}\right) / \mathrm{I}\left(\mathrm{L}_{3}\right)=0.31$ para el Co metálico y 0.27 para el óxido de Co $(\mathrm{CoO})$ 135 calculados mediante la misma técnica. $\mathrm{IL}_{2}$ y $\mathrm{IL}_{3}$ se calcularon como el máximo de intensidad para cada pico.

Para el análisis de la composición química en función de la dirección de crecimiento, se adquirieron 200 espectros para cada punto, posteriormente realineados y sumados. Para disminuir el ruido experimental y así obtener un mejor cociente entre señal y ruido, se aplicó el método de Análisis de Componentes Principales, en inglés “Principal Components Analysis” (PCA) para cada serie de espectros ${ }^{136}$. Después de aplicar el PCA a cada espectro para cada punto, 5 espectros consecutivos de un "spectrum-line" se sumaron y las intensidades de las líneas blancas fueron calculadas después de restar el fondo y realizar un ajuste lineal de los picos.

Por otra parte, las concentraciones relativas de O/Co se calcularon integrando sus respectivas intensidades de señal para series de 200 espectros EELS sumados en cada punto dentro del depósito y divididos por sus respectivas secciones eficaces. Para el análisis de la estructura fina de cada elemento se utilizó una dispersión en energía de $0.2 \mathrm{eV} /$ canal. Para la cuantificación de la concentración relativa de cada elemento se utilizó una dispersión en energía de 0.5 eV/canal, con un ángulo de colección de 24 mrad y un ángulo de convergencia de 7.5 mrad. Para ambos experimentos el tiempo de adquisición fue de 0.8 s/espectro.

La observación directa de las imágenes HRTEM del depósito 1 crecido a 30 kV y 44 pA muestran que la parte interior del depósito está constituida por nanopartículas de Co policristalinas de $\sim 2-3 \mathrm{~nm}$, embebidas en una matriz de carbono amorfa (véase Figura 3.2 como ejemplo). La presencia de este tipo de nanocristales de Co confirma los resultados de otros autores ${ }^{128}$. La imagen de HRTEM está dominada por el 
contraste de la matriz amorfa, dando lugar a una FFT borrosa debido a la dispersión electrónica sin periodicidad cristalina. Así, sólo pueden ser identificadas unas débiles reflexiones asociadas con el Co metálico de estructura cristalina hcp. Aunque un preciso análisis cuantitativo de este tipo de muestras granulares no es sencillo, la presencia de cobalto metálico y especies de óxido de cobalto es muy probable, sobre todo tomando en consideración el análisis composicional in situ realizado mediante EDS, en el cual se detecta un 19\% (atómico) de oxígeno.

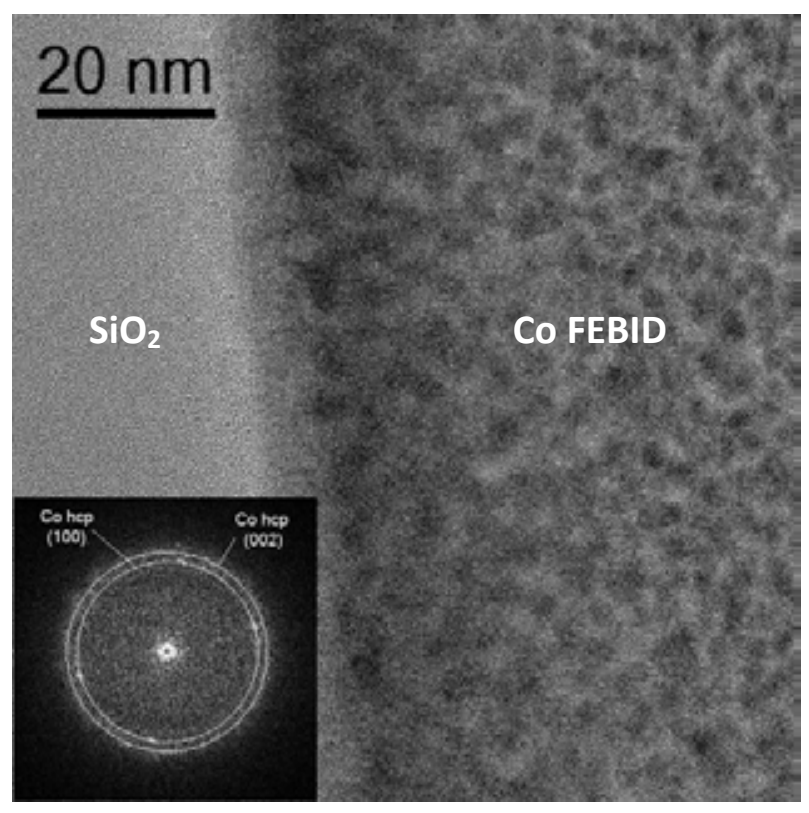

Figura 3.2: Imagen de HRTEM de la muestra 1, en el recuadro vemos la FFT de la misma.

Adicionalmente, para identificar el estado de oxidación del Co se estudió mediante EELS el umbral $\mathrm{L}_{2,3}$ del $\mathrm{Co}$ y el umbral $\mathrm{K}$ del oxígeno mediante espectroscopía EELS. Los espectros obtenidos pueden ser comparados con los datos EELS de la bibliografía para comprobar si existe un cambio en la posición de energía o alguna variación del umbral en la estructura fina. 

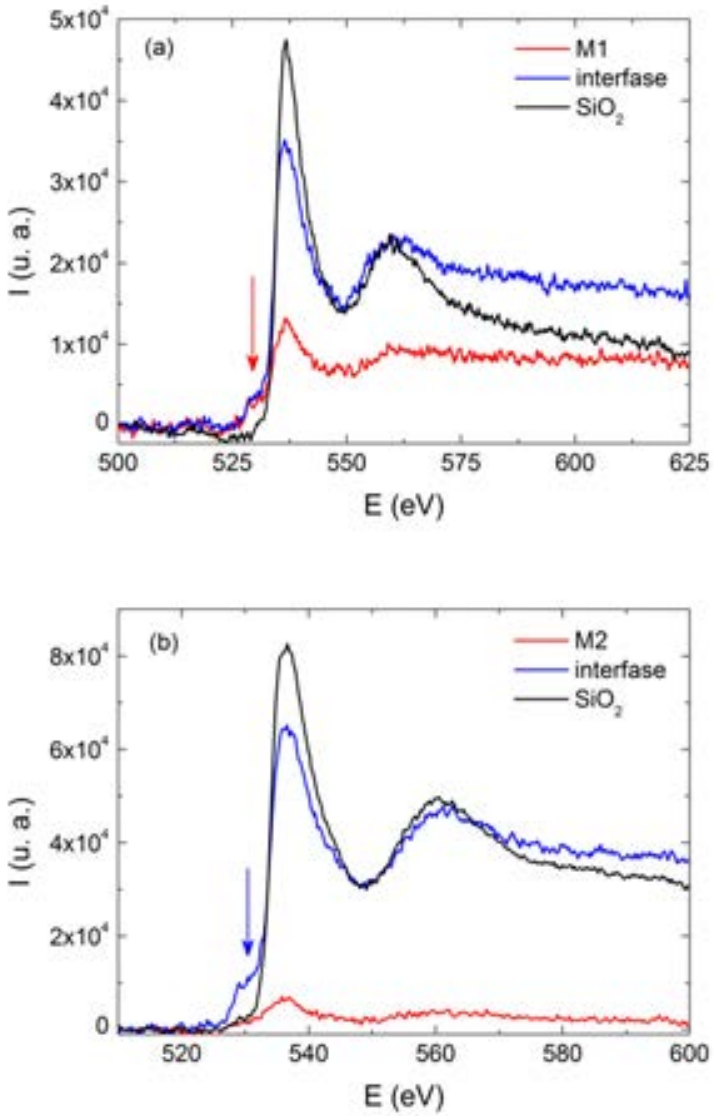

Figura 3.3: Espectro del umbral $\mathrm{K}$ del $\mathrm{O}$ recogido en la interfase $\mathrm{SiO}_{2} / \mathrm{Co}$ (a) de la muestra 1 y (b) de la muestra 2. La sonda barre desde el sustrato de $\mathrm{SiO}_{2}$, la interfase entre ambos materiales y finalmente la parte interior de la muestra. La estructura del umbral $\mathrm{K}$ del $\mathrm{O}$ se modifica (aparición de un pequeño pre-pico señalado con una flecha), prácticamente desapareciendo dentro de la microestructura de la muestra 2.

En la Figura 3.3(a) se muestra el umbral $\mathrm{K}$ del $\mathrm{O}$ de la muestra 1 recogida en diferentes puntos de la muestra. Así, confirmamos la existencia de $\mathrm{O}$ en el espectro capturado en el núcleo del depósito, como se observó mediante EDS. Además, la presencia de un pequeño pre-pico a $531 \mathrm{eV}$ en la estructura fina del umbral $\mathrm{K}$ del $\mathrm{O}$ obtenido en el depósito y la interfase (no observado en el espectro tomado del $\mathrm{SiO}_{2}$ ) es un signo inconfundible de la presencia de $\mathrm{CoO}^{137}$. También, el análisis ELNES del 
umbral $\mathrm{L}_{2,3}$ del Co puede darnos mucha información. Así, el cociente de intensidades $\mathrm{L}_{2} / \mathrm{L}_{3}$ entre los picos de las líneas blancas del espectro del Co nos indican el estado de oxidación del Co: cuando el cociente $\mathrm{L}_{2} / \mathrm{L}_{3}$ desciende, el estado de oxidación aumenta 138

En la Figura 3.4 se muestra una comparativa de las líneas blancas del umbral $\mathrm{L}_{2,3}$ del Co para las muestras 1 y 2 y las referencias del Co metálico y del óxido de cobalto (CoO). Los análisis EELS para la muestra 1 muestran la presencia de cobalto oxidado, como se puede deducir por la forma del umbral $\mathrm{L}_{2,3}$ del espectro del cobalto, y el bajo cociente $\mathrm{L}_{2} / \mathrm{L}_{3}$ obtenido de $\sim 0.27$.

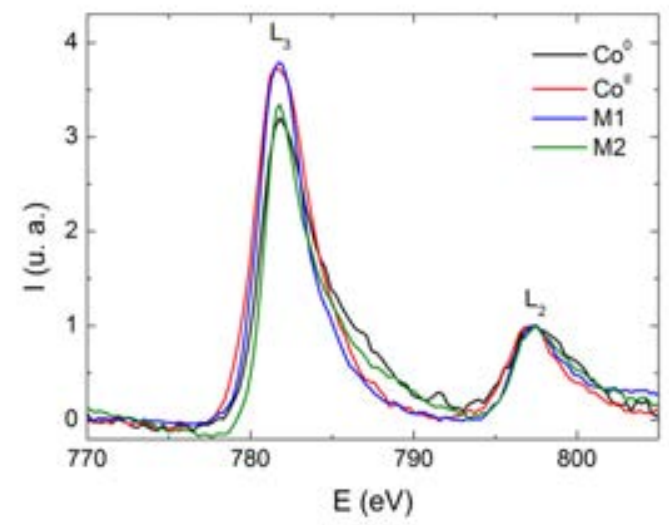

Figura 3.4: Comparación de los espectros EELS del umbral $\mathrm{L}_{2,3}$ del Co (a una energía de $779 \mathrm{eV}$ ) de las muestras 1, 2 y las referencias para el Co metálico y el Cobalto (II).

La muestra 2 presenta una microestructura y composición diferente a la obtenida en la muestra 1. En la imagen de HRTEM mostrada en la Figura 3.5 se observan nanocristales de Co de 7-10 nm. Los granos de Co están más regularmente distribuidos y compactos dentro del depósito. La estructura cristalina obtenida por la indexación del difractograma digital es compatible con la mezcla de Co hcp y fcc (ver la FFT en el recuadro de la Figura 3.5). 
Respecto a los espectros EELS, el estudio ELNES del umbral $\mathrm{L}_{2,3}$ del Co revela espectros más homogéneos y regulares con las características líneas blancas del Co metálico, como veíamos en la Figura 3.4. De hecho, para el Co metálico, la línea $\mathrm{L}_{3}$ muestra una forma asimétrica ancha comparada con la estrecha línea $\mathrm{L}_{3}$ del óxido de cobalto. Además, el carácter metálico de los nanocristales se confirma por el cociente $\mathrm{L}_{2} / \mathrm{L}_{3}$ de 0.30 y el insignificante contenido de oxígeno (cociente atómico O/Co de $0.04)$.

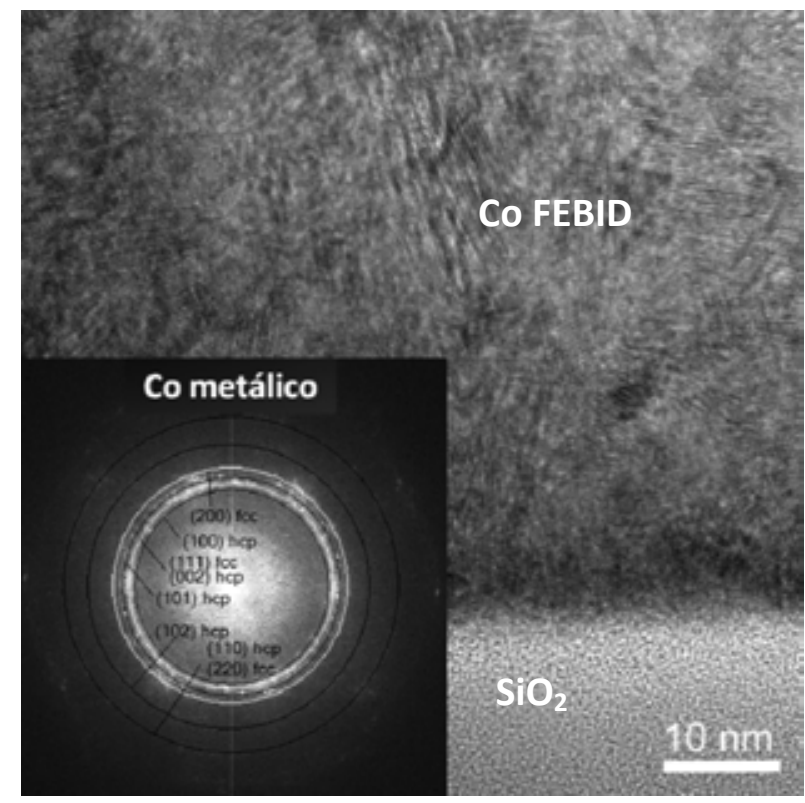

Figura 3.5: Imagen de HRTEM de la muestra 2, en el recuadro vemos la FFT de la misma.

En la Figura 3.3(b) se muestran los espectros EELS de la región del umbral K del $\mathrm{O}$ en la interfase $\mathrm{SiO}_{2} / \mathrm{Co}$. Centrándonos en la estructura fina de la interfase entre el sustrato $\mathrm{SiO}_{2}$ y el depósito de Co, en los primeros nanómetros del crecimiento de la estructura, se puede observar la presencia del pre-pico a $531 \mathrm{eV}$, el cual es característico de la presencia de Co oxidado $(\mathrm{CoO})$. A medida que la sonda barre la parte interior del depósito, la señal del oxígeno prácticamente desaparece. La presencia de $\mathrm{CoO}$ detectada podría ser debida a la típica presencia de especies 
contaminantes en sistemas de alto vacío, como moléculas de vapor de agua adsorbidas en el sustrato, antes de comenzar el proceso de crecimiento FEBID.

En la Tabla 3.2 se resumen las condiciones de crecimiento para las muestras 1 y 2 y el análisis ELNES, que nos proporcionó información acerca de la forma y la intensidad de los detalles más importantes para ambos umbrales $\mathrm{K}$ del O y $\mathrm{L}_{2,3}$ del Co. Para estimar el estado de oxidación del cobalto se analizó el cociente de intensidades entre los picos $L_{2} / L_{3}$ del umbral $L_{2,3}$ del Co. Como se espera de los análisis EDS previos, el depósito crecido a elevada $\mathrm{I}_{\mathrm{e}}$ (rango de $\mathrm{nA}$ ) presenta un menor cociente O/Co y un mayor cociente de intensidades $L_{2} / L_{3}$ (cerca del cobalto metálico) que el crecido a baja $\mathrm{I}_{\mathrm{e}}$ (rango de pA). Además, los análisis EELS muestran que el depósito 2 presenta rasgos característicos de cobalto metálico, un hecho confirmado por la ausencia del umbral K del O para este depósito. Por otra parte, el cobalto está oxidado en la muestra 1, como se puede deducir de la forma del espectro del umbral $\mathrm{L}_{2,3}$ del Co y el elevado cociente $\mathrm{L}_{2} / \mathrm{L}_{3}$, así como de la presencia del característico pre-pico a 531 eV del umbral K del O.

\begin{tabular}{c|cccc}
\hline Muestra & $\boldsymbol{V}_{\boldsymbol{e}}(\mathbf{k V})$ & $\boldsymbol{I}_{\boldsymbol{e}}(\mathbf{n A})$ & $\boldsymbol{O} / \mathbf{C o}$ & $\mathbf{I}\left(\mathbf{L}_{2}\right) / \mathbf{I}\left(\mathbf{L}_{3}\right)$ \\
\hline 1 & 30 & 0.044 & 0.85 & 0.27 \\
$\mathbf{2}$ & 30 & 2.400 & 0.04 & 0.30 \\
\hline
\end{tabular}

Tabla 3.2: Resumen de los parámetros de crecimiento de las muestras, voltaje de aceleración $\left(\mathrm{V}_{\mathrm{e}}\right)$ y corriente del haz de electrones $\left(\mathrm{I}_{\mathrm{e}}\right)$, cociente de cuantificación EELS entre el oxígeno y el cobalto y la media entre los cocientes de intensidad $\mathrm{L}_{2} / \mathrm{L}_{3}$ en el umbral $\mathrm{L}_{2,3}$ del Co.

Sin embargo, las imágenes HRTEM del depósito 1 revelan la presencia de Co hcp, un hecho confirmado mediante los análisis EELS, los cuales mostraron pequeños rasgos de cobalto metálico. Para conjugar la presencia de $\mathrm{CoO}$ con Co metálico en muestras crecidas a baja corriente, podemos asumir que las partículas que crecen en el depósito son tan pequeñas que la mayoría de los átomos están presentes en la superficie, oxidándose muy fácilmente y en una gran proporción. 
En la Figura 3.6, se ilustra el estudio de la homogeneidad en composición y carácter metálico a lo largo de la dirección de crecimiento en la muestra 2. La cuantificación relativa de los elementos presentes en el depósito confirmó el estado metálico del Co. El cociente O/Co es muy bajo, menor que 0.1 en todo el espesor del depósito analizado. Sólo los primeros nanómetros del depósito parecen estar parcialmente oxidados. Esto está de acuerdo con el cociente de intensidades $\mathrm{IL}_{2} / \mathrm{IL}_{3}$ a lo largo del depósito, el cual muestra cocientes que corresponden a un carácter metálico a lo largo de todo el depósito, excepto en las primeras etapas del crecimiento en las que el cociente de intensidades desciende hasta 0.27 (véase la Figura 3.6(b)).
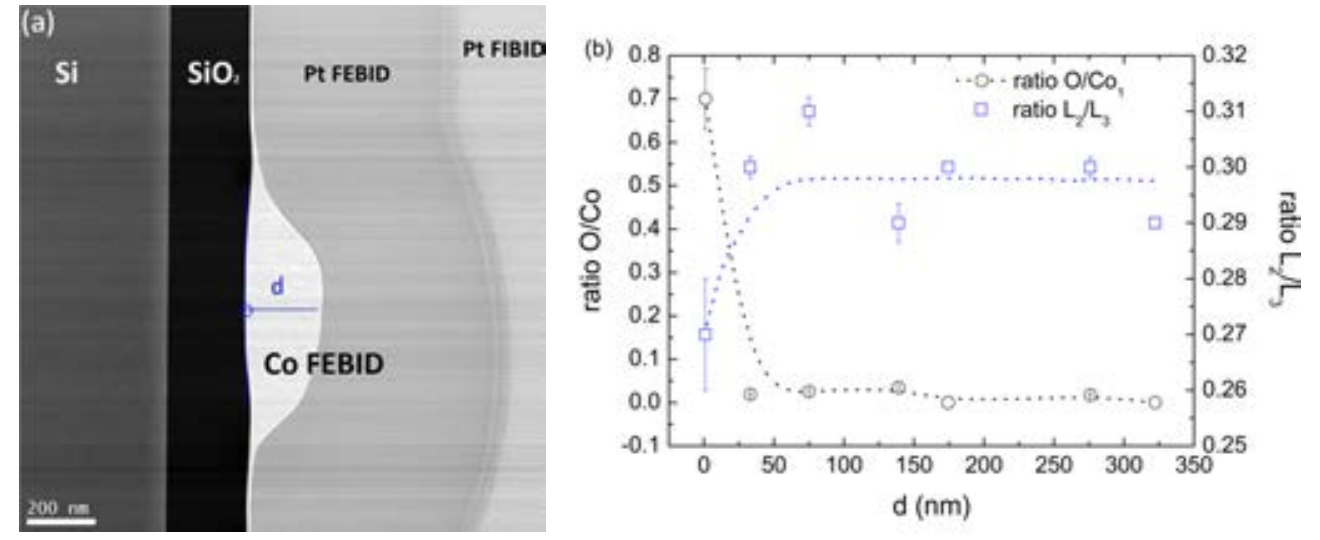

Figura 3.6: (a) Imagen STEM-HAADF de la muestra 2; (b) Perfiles de la concentración relativa $\mathrm{O} / \mathrm{Co}$ y el cociente de intensidades $\mathrm{L}_{2} / \mathrm{L}_{3}$ a lo largo de la dirección de crecimiento (línea azul señalada en (a)).

Resumiendo, en las condiciones de crecimiento escogidas, las cuales entran dentro del estudio realizado en el apartado 3.2 de este Capítulo y cuyos trabajos ya han sido publicados ${ }^{130,133,139}$; la $\mathrm{I}_{\mathrm{e}}$ juega un papel clave en el contenido metálico de los depósitos, siendo uno de los parámetros decisivos que conducen a la fabricación de nanoestructuras puras de Co metálico. Los depósitos crecidos a altas $\mathrm{I}_{\mathrm{e}}$ (rango de nA) tienen un alto contenido de Co, mientras que se ha detectado una significativa suma de cobalto oxidado junto con Co metálico en los depósitos crecidos a baja $\mathrm{I}_{\mathrm{e}}$ (rango de $\mathrm{pA})$. 
No obstante, el proceso FEBID envuelve complejos fenómenos y otros mecanismos relevantes han sido señalados en la literatura usando diferentes parámetros de crecimiento. Por ejemplo, la influencia del efecto de autocatálisis ${ }^{140} \mathrm{y}$ la influencia del $t_{p}$ en la composición inicial ${ }^{141}$. Así, en una estructura de Co con una geometría definida, el contenido de Co estará determinado por un conjunto de parámetros de crecimiento ( $\mathrm{T}_{\text {sustrato }}$, flujo de precursor, $\mathrm{t}_{\mathrm{p}}, \mathrm{t}_{\mathrm{r}}, \mathrm{I}_{\mathrm{e}}, \ldots$ ) y no sólo por la $\mathrm{I}_{\mathrm{e}}$. Algunos de estos parámetros de proceso relevantes en el contenido final de los depósitos serán estudiados en los sucesivos apartados con resultados significativos.

Las fuertes diferencias en la microestructura y la naturaleza química de los depósitos encontrados en este estudio sistemático pueden explicar los diferentes mecanismos de transporte y propiedades magnéticas exhibidas en la literatura para este tipo de nanoestructuras basadas en Co crecidas mediante FEBID. Así, en las mismas condiciones de crecimiento que las escogidas en nuestros trabajos previos ${ }^{130}$, 133, 139, las muestras crecidas a elevada $I_{e}$ muestran un transporte eléctrico metálico y un carácter ferromagnético ${ }^{130,133}$ mientras que los depósitos crecidos a baja $\mathrm{I}_{\mathrm{e}}$ revelan un carácter semiconductor ${ }^{133}$.

Debemos destacar que nuestro trabajo ha sido el primer estudio en el cual se aclara la naturaleza y el estado electrónico del cobalto dentro de los depósitos crecidos mediante FEBID a escala nanométrica y que ha podido abordarse gracias al uso de las técnicas apropiadas: STEM, EELS y HRTEM. 


\subsection{Influencia de la temperatura del sustrato en la composición de las nanoestructuras: pilares de Co crecidos a baja corriente}

Como comentamos en sucesivas ocasiones en el apartado 1.3.4 del Capítulo 1 de esta tesis, la principal desventaja de la técnica FEBID es que el depósito final no contiene el $100 \%$ del elemento deseado, debido principalmente a la descomposición parcial del material precursor. Los elementos que normalmente lo suelen acompañar son carbono y oxígeno, los cuales suelen empeorar las propiedades físicas del material crecido comparándolas con las del elemento puro ${ }^{116}$. Con el objetivo de mejorar el contenido metálico de los depósitos y por ende sus propiedades y futuras aplicaciones, se han llevado a cabo diferentes estrategias como por ejemplo tratamientos térmicos in situ y tratamientos térmicos “ex-situ” ${ }^{47}$. Sin embargo, una excepción a esta problemática generalizada la encontramos al utilizar como material precursor $\mathrm{Co}_{2}(\mathrm{CO})_{8}$. Varios autores, entre ellos nuestro grupo, han dedicado sus esfuerzos al estudio de depósitos crecidos utilizando este material de partida, intentado explicar su mecanismo de crecimiento, mejorar su contenido metálico y encontrar aplicaciones en el campo de la Nanotecnología; como por ejemplo la fabricación de sensores magnéticos, creación y propagación de información a través de paredes de dominio, etc 49 , 50, 126-130, 133, 139, 141-143. En los últimos años, los distintos autores coincidíamos en la necesidad de generar calor en la zona de crecimiento para aumentar el contenido metálico de los depósitos y así obtener depósitos de alta pureza (>90\% Co); esto último lo consiguió nuestro grupo usando elevadas $\mathrm{I}_{\mathrm{e}}$ como comentamos en el apartado 3.2 de este capítulo. Sin embargo, con el uso de altas $I_{e}$ se limita la resolución lateral de los depósitos, debido a que el diámetro del haz escala con la raíz cuadrada de la corriente del haz ${ }^{144}$. De forma que, para obtener depósitos con alta resolución lateral debemos trabajar a bajas $\mathrm{I}_{\mathrm{e}}(\sim \mathrm{pA})$.

En este estudio, presentamos la fabricación de nanoestructuras de Co usando bajas $\mathrm{I}_{\mathrm{e}}(\sim \mathrm{pA})$, aumentando de forma independiente la temperatura del sustrato y su posterior análisis composicional in situ ${ }^{48}$. El objetivo es fabricar nanoestructuras de Co puras usando corrientes de electrones en el rango de pA, y aclarar la influencia que tiene el calentamiento local del sustrato en el contenido de Co de los depósitos. En 
nuestro caso particular, estos experimentos son factibles debido a la relativamente baja temperatura a la que el material precursor, $\mathrm{Co}_{2}(\mathrm{CO})_{8}$ se descompone ${ }^{145,146}$. Ye et al. obtuvieron las máximas velocidades de crecimiento mediante CVD entre 140 y $200{ }^{\circ} \mathrm{C}$ a $1.3 \times 10^{-5}$ mbar, temperatura fácilmente alcanzable usando un micro-calentador.

Los nanopilares de Co se crecieron directamente sobre la capa de $\mathrm{SiO}_{2}$ del microcalentador utilizando el modo "spot", $\mathrm{V}_{\mathrm{e}}=5,30 \mathrm{kV}, \mathrm{I}_{\mathrm{e}}=25,44 \mathrm{pA}, \mathrm{P}_{\text {proceso }}=4 \times 10^{-6}$ mbar, $\mathrm{t}_{\text {proceso }}=5 \mathrm{~min}, \mathrm{~T}_{\text {sustrato }}=$ variable. $L \mathrm{~T}_{\text {sustrato }}$ durante el crecimiento la variamos para cada nanopilar utilizando un micro-calentador comercial (KMHP-100 de Kebaili Corporation) basado en una resistencia calefactora de Pt embebida en una membrana suspendida tipo sandwich de $\mathrm{SiO}_{2} / \mathrm{Si}_{3} \mathrm{~N}_{4} / \mathrm{SiO}_{2}$, con un área de trabajo de alrededor de $250 \times 150 \mu \mathrm{m}^{2}$ (véase la Figura 3.7) del que hablamos extensamente en el apartado 2.2 del Capítulo 2.
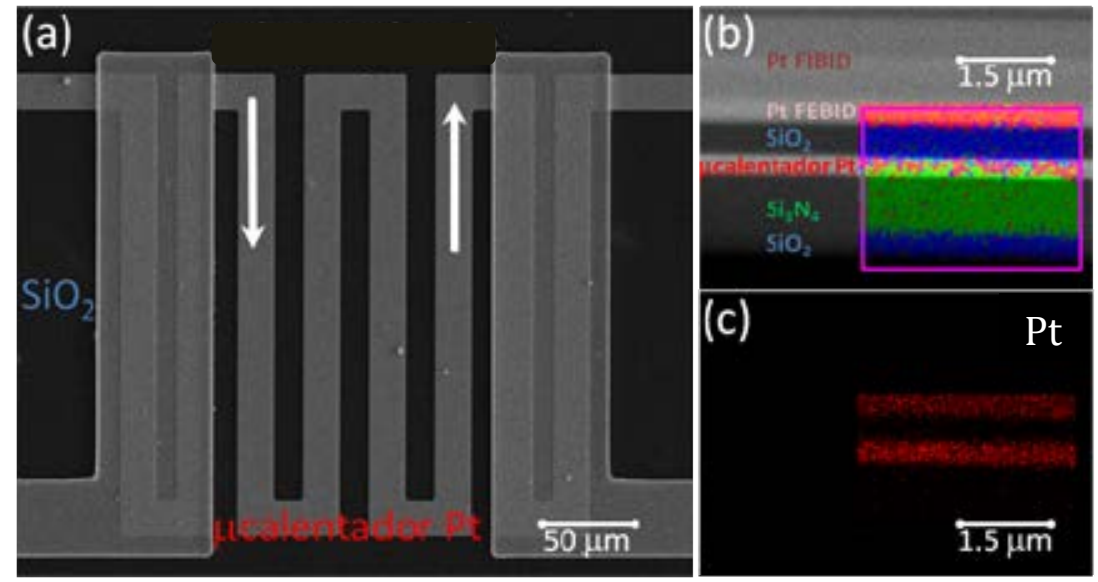

Figura 3.7: (a) Imagen SEM del micro-calentador (Kebaili) a bajos aumentos con el portamuestras a $0^{\circ}$ de inclinación. Vemos indicado por las flechas el serpentín de Pt, por el que circula la corriente para calentar la membrana suspendida tipo sándwich. (b) Imagen SEM a altos aumentos de un corte transversal del micro-calentador con el portamuestras a $52^{\circ}$ de inclinación. Encima de éste se han crecido dos capas de Pt, una por FEBID y otra por FIBID para proteger la zona y dar contraste. En el área recuadrada se indican mediante colores los espectros de EDS recogidos de esa zona, distinguiendo claramente las capas que forman el microcalentador. (c) Mapeo del espectro EDS del Pt, en el cual se distingue la capa de Pt del micro-calentador y la capa de Pt FEBID que hemos crecido para proteger y dar contraste. 
Nosotros diseñamos un portamuestras con conexiones eléctricas al microcalentador que son extraídas de la cámara de proceso a través de un puerto y conectadas a una fuente de voltaje DC, como comentamos en el apartado 2.2 del Capítulo 2. El micro-calentador fue calibrado bajo nuestras condiciones de vacío usando los valores de resistencia de la calibración realizada a presión atmosférica por el fabricante. Como era de esperar, es necesario aplicar una potencia menor al microcalentador para alcanzar la temperatura deseada.

En la Figura 3.8 podemos ver imágenes SEM de los nanopilares crecidos a $30 \mathrm{kV}$, $44 \mathrm{pA}$ en (a) y a $5 \mathrm{kV}, 25 \mathrm{pA}$ en (b) con la $\mathrm{T}_{\text {sustrato }}$ correspondiente indicada. Observando las imágenes podemos ver que el volumen y el diámetro de la base de los nanopilares crecen al aumentar la $\mathrm{T}_{\text {sustrato, }}$, hasta que alcanzamos $100{ }^{\circ} \mathrm{C}$. Por encima de esta temperatura, observamos un efecto no deseado, el crecimiento de un gran y anómalo halo alrededor del nanopilar. El halo es una consecuencia de la técnica FEBID debido a los SEs producidos por los BSEs al interaccionar el FEB con el sustrato, dónde se encuentran adsorbidas las moléculas del gas precursor ${ }^{40}$.
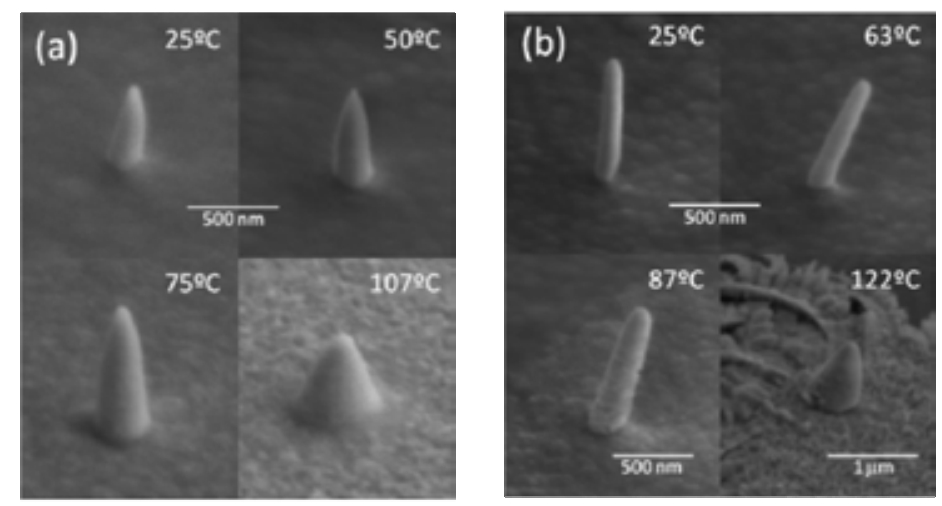

Figura 3.8: Imágenes SEM (vista con una inclinación de 52º ) de los nanopilares de Co (a) crecidos a $30 \mathrm{kV}$ y 44 pA y (b) crecidos a $5 \mathrm{kV}$ y 25 pA con la $\mathrm{T}_{\text {sustrato }}$ indicada.

Sin embargo, en nuestro caso es más grande en volumen de lo habitual, debido a que junto a los SEs de $2^{\circ}$ orden que hemos comentado previamente, contamos con el factor de la elevada $\mathrm{T}_{\text {sustrato }}>100{ }^{\circ} \mathrm{C}$. Así, parece que se produce una disminución de la 
energía de disociación de los enlaces de la molécula cuándo aumentamos la $\mathrm{T}_{\text {sustrato }}$. Como consecuencia de este aumento de la $\mathrm{T}_{\text {sustrato }}$, habría un cambio en la curva de la eficiencia de disociación $\sigma_{(\mathrm{E})}$, cuyo máximo se desplazaría hacia energías más bajas. De esta manera, se espera que los SEs que alcanzan distancias lejanas del centro del pilar, y como consecuencia tiene menor energía, sean capaces de disociar las moléculas de gas a mayor velocidad a medida que aumenta la $\mathrm{T}_{\text {sustrato. }}$

Por otra parte, la altura de los nanopilares aumenta en función de la $\mathrm{T}_{\text {sustrato }}$ hasta llegar a $\sim 100{ }^{\circ} \mathrm{C}$, aunque es bien conocido que el tiempo de residencia de las moléculas adsorbidas en la superficie del sustrato desciende con $\mathrm{T}_{\text {sustrato }} \mathrm{y}$ por tanto el ritmo de crecimiento debería disminuir al aumentar la $\mathrm{T}_{\text {sustrato. }}$ Esto puede ser explicado por el régimen de crecimiento, el cual se espera que esté limitado por el flujo de gas. La altura de los nanopilares podría aumentar al incrementar la $\mathrm{T}_{\text {sustrato, }}$, debido a la modificación de la curva de la eficiencia de la disociación. El volumen total del depósito debería saturar a una temperatura dada cuándo no hay más gas precursor disponible. Simulaciones cuantitativas detalladas serían necesarias para confirmar dicha explicación cualitativa, las cuales van más allá de los objetivos de este estudio.

En la Figura 3.9, representamos el contenido atómico obtenido mediante EDS de varios nanopilares crecidos usando los mismos parámetros de crecimiento $\left(V_{e}, I_{e} y t_{p}\right)$

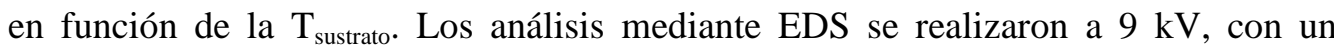
diámetro de haz de $7.5 \mathrm{~nm}$. La interacción de los electrones a $9 \mathrm{kV}$ en los nanopilares de Co fue estimada con el programa CASINO que está basado en las simulaciones del modelo de Monte Carlo ${ }^{13}$. Así, comprobamos que las trayectorias de los electrones acelerados a $9 \mathrm{kV}$ sobre nuestros nanopilares no continúan fuera de ellos, sin necesitar corrección alguna debida a la contribución del sustrato. El contenido de Co aumenta desde el $60 \%$ a $\mathrm{T}_{\text {ambiente }}$ hasta el $93 \%$ a $\mathrm{T}_{\text {sustrato }}=107{ }^{\circ} \mathrm{C}$ en nanopilares crecidos a 30 $\mathrm{kV}, 44 \mathrm{pA}$ y desde el $72 \%$ a $\mathrm{T}_{\text {ambiente }}$ hasta el $85 \%$ a $\mathrm{T}_{\text {sustrato }}=122{ }^{\circ} \mathrm{C}$ en nanopilares crecidos a $5 \mathrm{kV}, 25 \mathrm{pA}$. El contenido de Co obtenido coincide con los resultados obtenidos a $\mathrm{T}_{\text {ambiente }}$ en el apartado 3.2 de este capítulo y publicado en la referencia ${ }^{133}$. 
Estos resultados indican que el contenido de Co aumenta en los nanopilares al incrementar la $\mathrm{T}_{\text {sustrato. }}$ El contenido de oxígeno es en todos los casos inferior al $2 \%$. Las pequeñas diferencias encontradas en el contenido de Co entre nanopilares crecidos a 5 y $30 \mathrm{kV}$ pueden ser debidas al distinto calor generado por el FEB en cada caso. El equilibrio para fabricar nanoestructuras de Co puras sin cambios apreciables en las dimensiones laterales está en torno a una $\mathrm{T}_{\text {sustrato }} \sim 100^{\circ} \mathrm{C}$.

En este caso concreto, en nuestras condiciones de crecimiento y de trabajo comentadas previamente, observamos que la combinación de calor local generado por el FEB y la elevada $\mathrm{T}_{\text {sustrato }}$ son los responsables de la descomposición del gas precursor y por ende de la purificación de los nanodepósitos.

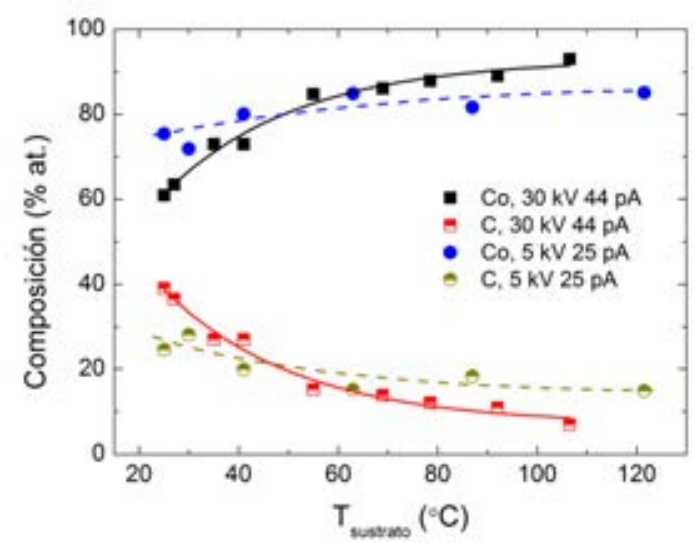

Figura 3.9: Composición de los nanopilares de Co en \% atómico crecidos a 30 kV, 44 pA y a 5 kV, 25 pA en función de la $T_{\text {sustrato. }}$.

En nuestras condiciones de trabajo, la descomposición espontánea del $\mathrm{Co}_{2}(\mathrm{CO})_{8}$ que se pone en contacto con el micro-calentador sin la asistencia del FEB se ha observado a una $\mathrm{T}_{\text {sustrato }} \sim 200{ }^{\circ} \mathrm{C}$. Este valor de temperatura resulta consistente con el máximo valor de la velocidad de crecimiento de Co obtenido mediante CVD entre $140-200{ }^{\circ} \mathrm{C}$ a $1.3 \times 10^{-5}$ mbar utilizando el mismo precursor ${ }^{146}$. En la Figura 3.10(a) vemos los cristales de Co que se forman sobre el micro-calentador a $\sim 197^{\circ} \mathrm{C}$ (zona 
señalada por la elipse blanca), zona en la que el GIS ha liberado el gas precursor. Es posible distinguir diferentes tamaños de los granos de Co, con o sin la capa de Pt debajo, debido a pequeñas diferencias en la temperatura de cada zona (véase Figura 3.10(b)). En las zonas en las que la capa de Pt por la que circula la corriente está debajo, la $\mathrm{T}_{\text {sustrato }}$ será superior y los granos de Co tienen un tamaño de $\sim 800 \mathrm{~nm}$. Mientras que en las zonas donde no está la capa de Pt debajo, el tamaño de los granos es de $\sim 600 \mathrm{~nm}$. En la Figura 3.10(c) y (d) podemos ver granos y nanocristales de Co con un tamaño inferior a $100 \mathrm{~nm}$ crecidos sobre una zona donde se encuentra la capa de Pt debajo. El análisis composicional de estos cristales realizado in situ mediante EDS indica que el contenido de Co es del $99 \%$ (atómico).

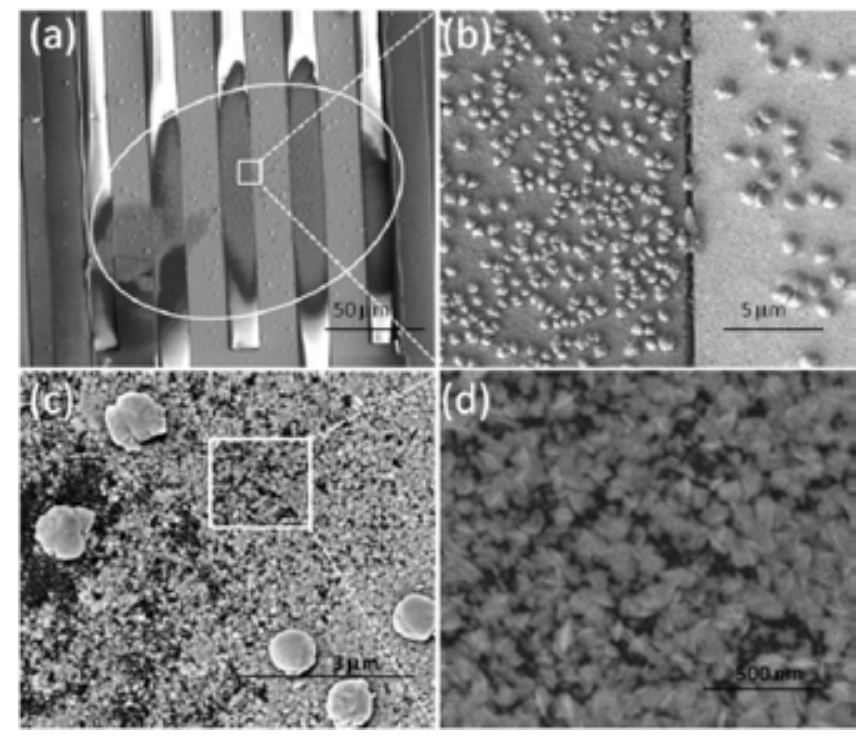

Figura 3.10: Imágenes SEM de partículas de Co puras obtenidas a través de la descomposición térmica del $\mathrm{Co}_{2}(\mathrm{CO})_{8}$, cuando éste entra en contacto con el micro-calentador a $\sim 197^{\circ} \mathrm{C}$. (a) La elipse de color blanco indica el área donde las moléculas de gas que salen del GIS se han adsorbido sobre el micro-calentador e inmediatamente se han disociado sin la incidencia del FEB. (b) El tamaño de partículas depende ligeramente de la localización en el sustrato siendo mayores si la capa de Pt está debajo. 
Con el objetivo de aclarar la importancia de la $\mathrm{T}_{\text {sustrato }}$ durante el crecimiento de los depósitos, se han realizado tratamientos térmicos in situ después del crecimiento, como ya se estudió con éxito en NWs de Pt ${ }^{147}$. Se crecieron NWs de Co a $30 \mathrm{kV}$ y 44 pA a $\mathrm{T}_{\text {ambiente, }}$ cuyas dimensiones son $1.2 \mu \mathrm{m} \times 250 \mathrm{~nm} \times 100 \mathrm{~nm}$ (largo $\times$ ancho $\times$ espesor). El contenido de Co detectado fue del 60\% (atómico), resultado que coincide con los resultados mostrados en la Figura 3.9. Una vez que los NWs están fabricados, aumentamos la temperatura del micro-calentador hasta alcanzar $600{ }^{\circ} \mathrm{C}$, y ahí permaneció constante durante 40 minutos. Tras el tratamiento térmico, volvimos a analizar la composición sin observar cambios en el contenido de los NWs. Este experimento evidencia la relevancia que tiene la combinación simultánea del FEB y la elevada $\mathrm{T}_{\text {sustrato }}$ durante el crecimiento de las nanoestructuras para conseguir nanoestructuras de Co puras. Una vez que el material se deposita sobre el sustrato, la matriz de carbono formada no puede ser descompuesta mediante un tratamiento térmico a $600{ }^{\circ} \mathrm{C}$ bajo nuestras condiciones de vacío. 


\subsection{Crecimiento de Co mediante el efecto catalítico}

En la literatura se pueden encontrar varios trabajos en los cuales se produce un efecto específico llamado autocatálisis, en el cual las moléculas de gas precursor se descomponen, disociándose los enlaces entre el metal y los ligandos de forma autocatalítica y así, permitiendo el crecimiento de metales puros sin la irradiación del FEB. Este efecto se suele producir a temperatura ambiente. Algunos ejemplos se han observado en sistemas de ultra alto vacío, UHV a $\mathrm{P}_{\text {base }} \sim 10^{-10}$ mbar usando como precursor, el $\mathrm{Fe}(\mathrm{CO})_{5}{ }^{148-150}$, el $\mathrm{Si}_{2} \mathrm{H}_{6}$ y el $\mathrm{WF}_{6}{ }^{150-152}$. Algunos autores fueron más allá y hablaron del barrido del FEB como de tinta invisible al exponer o irradiar un diseño sobre $\mathrm{SiO}_{2}$ sin inyectar gas precursor. Al parecer, el FEB sensibiliza la superficie que barre y posteriormente al liberar el gas precursor, éste se descompone autocatalíticamente formando selectivamente estructuras puras de Fe en el lugar por donde ha pasado el FEB. Sin embargo, la causa de la disociación inicial de la molécula que haría de activación para la disociación del resto de ellas no está muy clara. La hipótesis por la que se aboga es que el proceso de activación puede ser una consecuencia de la formación de vacantes de $\mathrm{O}$ generadas por la desorción inducida por el FEB, así el $\mathrm{SiO}_{2}$ se reduce a $\mathrm{SiO}$ y éste podría ser la especie activa que provoca la descomposición inicial del precursor.

Estos resultados en los cuales se consigue el crecimiento selectivo de metales puros a escala nanométrica sirve de inspiración a nuestro estudio utilizando como material precursor el $\mathrm{Co}_{2}(\mathrm{CO})_{8}$. Sin embargo, el primer contratiempo que encontramos es que en nuestro sistema trabajamos en alto vacío, HV, la presión en la cámara de proceso suele estar alrededor de $1 \times 10^{-6} \mathrm{mbar}$. Con lo cual, debemos tener en cuenta que contamos con especies contaminantes dentro de la cámara de proceso como por ejemplo, vapor de agua, moléculas hidrocarbonosas, etc., las cuales se adsorben sobre la superficie del sustrato y se depositan en el mismo al ser irradiadas por el FEB, creándose una especie de barrera protectora. Por lo tanto, en un sistema que opera en $\mathrm{HV}$ es muy difícil que las moléculas de un material precursor, como el $\mathrm{Co}_{2}(\mathrm{CO})_{8}$ se descompongan autocatalíticamente sobre la superficie por donde el haz de electrones haya barrido previamente. 
Con el objetivo de estudiar y analizar un efecto autocatalítico o catalítico del $\mathrm{Co}_{2}(\mathrm{CO})_{8}$ se han realizado una serie de experimentos sobre varios tipos de sustratos. El sustrato A: Si; sustrato B: Si + Co FEBID; sustrato C: Si + una capa de Co (20 nm) + una capa de $\mathrm{Al}$ ( $2 \mathrm{~nm})$, ambas crecidas mediante "sputtering”.

Los experimentos sobre el sustrato A consistieron en: 1) exponer al sustrato de $\mathrm{Si}$ (siempre limpiado previamente con acetona, alcohol y agua en un baño de ultrasonidos, y sin ser sometido al FEB) a una atmósfera del gas precursor $\left(\mathrm{P}_{\text {proceso }}=1\right.$ $\times 10^{-5}$ mbar) durante 50 minutos. 2) Exponer al sustrato de Si al barrido del FEB utilizando $5 \mathrm{kV}$ y 86 pA en forma de líneas de ancho $<100 \mathrm{~nm}$ durante 5 minutos, una dosis total de $258 \mathrm{nC} / \mu^{2}$. Posteriormente, se sometió a una atmósfera de gas precursor $\left(\mathrm{P}_{\text {proceso }}=1 \times 10^{-5} \mathrm{mbar}\right)$ durante 50 minutos. La inspección posterior de la superficie donde debería producirse la reacción autocatalítica del precursor debido a la orientación del GIS, no muestra ningún tipo de crecimiento de Co en ninguno de los casos. Por lo tanto, podemos concluir que no se produce el efecto autocatalítico sobre el sustrato A.

El experimento sobre el sustrato B consistió en crecer pilares de Co mediante FEBID que se utilizarían como siembra o activación para la posterior descomposición autocatalítica del precursor. Los pilares de Co fueron crecidos utilizando tanto corrientes en el rango de pA, como en el rango de nA, para así estudiar si el contenido de Co tiene una incidencia en la descomposición catalítica. El contenido de Co en estos pilares va del $60-90 \%$. Tras el crecimiento de lo que denominamos como siembra, exponemos las nanoestructuras a una atmósfera del gas precursor $\left(\mathrm{P}_{\text {proceso }}=1\right.$ $\times 10^{-5}$ mbar) durante 50 minutos. La inspección de los pilares de Co crecidos mediante FEBID, no muestran ningún tipo de crecimiento de Co posterior al de los mismos. Así, podemos concluir que tampoco se produce el efecto catalítico sobre el sustrato B.

Sobre el sustrato $\mathrm{C}$, realizamos un grabado mediante FIB de 10 cuadrados de dimensiones $1 \mu \mathrm{m} \times 1 \mu \mathrm{m} \times 3-25 \mathrm{~nm}(\mathrm{x} \times \mathrm{y} \times \mathrm{z})$ usando $30 \mathrm{kV}$ y $10 \mathrm{pA}$; con el objetivo de realizar una serie de desbastados, eliminando de forma controlada las capas de Co y Al crecidas por "sputtering”. En primer lugar, desbastamos la capa de 2 
nm de $\mathrm{Al}$ y seguidamente la capa de $20 \mathrm{~nm}$ de Co hasta llegar al sustrato de $\mathrm{Si}$. A continuación, exponemos estas estructuras durante 30 minutos al gas precursor. La presión dentro de la cámara varía de la $\mathrm{P}_{\text {base }}=1 \times 10^{-6}$ mbar hasta la $\mathrm{P}_{\text {proceso }}=1 \times 10^{-5}$ mbar. De esta forma, vemos el momento en el cual comienza a tener lugar el efecto de descomposición catalítico sobre el Co crecido por “sputtering” usado como siembra y cuando el efecto deja de producirse al carecer de la siembra.

En la Figura 3.11, mostramos varias imágenes SEM como ejemplos del estudio realizado sobre el sustrato C. En (a), se muestra una imagen SEM de la superficie tras ser irradiado por el FIB un volumen $1 \times 1 \times 0.003 \mu \mathrm{m}^{3}$ y en (b), se muestra una imagen SEM de la superficie tras ser irradiado por el FIB un volumen $1 \times 1 \times 0.003$ $\mu \mathrm{m}^{3}$ y ser expuesto a 30 minutos del gas precursor. Podemos ver el crecimiento de nanocristales de Co de $\sim 5 \mathrm{~nm}$ que forman aglomerados de cristales de unos $40 \mathrm{~nm}$. El análisis de su composición mediante la técnica EDS confirma que se trata de Co puro. La velocidad de crecimiento estimada de los nanocristales de Co es de $1.33 \mathrm{~nm} / \mathrm{min}$. En (c), se muestra una imagen SEM de la superficie tras ser irradiado por el FIB un volumen $1 \times 1 \times 0.007 \mu \mathrm{m}^{3}$ y en (d), se muestra una imagen SEM de la superficie tras ser irradiado por el FIB un volumen $1 \times 1 \times 0.007 \mu \mathrm{m}^{3}$ y ser expuesto a 30 minutos del gas precursor. En esta imagen se pone de manifiesto la aparición de pequeños nanocristales de Co de $\sim 5 \mathrm{~nm}$ dentro del área irradiada. Sin embargo, observamos que tanto el tamaño como la cantidad de nanocristales es menor que en (b). La velocidad de crecimiento estimada es de $0.17 \mathrm{~nm} / \mathrm{min}$, significativamente inferior que la velocidad de crecimiento en (b). Este efecto puede ser explicado por la mayor dosis de iones de Ga que recibe este sustrato, implantándose en el mismo y modificando la superficie de Co. Así, la superficie contaminada con iones de Ga impediría la eficiente descomposición del gas precursor. En (e), mostramos una imagen SEM de la superficie del sustrato virgen. En (f), se muestra una imagen SEM de la superficie tras ser irradiado por el FIB un volumen $1 \times 1 \times 0.025 \mu^{3}$ de forma que eliminamos completamente la capa de Co y el sustrato expuesto a 30 minutos del gas precursor es el silicio. No se observa la aparición de pequeños nanocristales de Co, de modo que 
tenemos una prueba más de que el efecto catalítico no tiene lugar sino contamos con una siembra o activación externa.

Las conclusiones de este estudio son que en nuestro sistema de alto vacío, con una $\mathrm{P}_{\text {base }} \sim 1 \times 10^{-6}$ mbar y bajo nuestras condiciones de trabajo no se produce el efecto autocatalítico o catalítico sobre los sustratos A (Si), B (Si/Co FEBID) y C (Si/Co/Al) sin eliminar completamente la capa de Al. En A, debido a las especies contaminantes presentes en la cámara de proceso, las cuales se adsorben sobre la superficie del sustrato y se depositan al ser irradiadas con el FEB, creándose una especie de barrera protectora. En B, utilizamos como catalizador de la reacción los nanopilares de Co FEBID, que tienen un alto porcentaje de Co, pero no es Co puro. El hecho de que no se produzca la descomposición indica que es fundamental para que el proceso se lleve a cabo que el catalizador inicial sea Co puro. Ahí es cuando llegamos al sustrato C, cuyos experimentos y resultados se han detallado en la Figura 3.11. En el sustrato C, se observa el efecto catalítico como vemos por la aparición de nanocristales de Co de $5 \mathrm{~nm}$ de tamaño en las Figuras 3.11(b), (c) y (d). La descomposición del precursor sobre el Co crecido por "sputtering" se produce hasta que alcanzamos el sustrato de Si (Figura 3.11(f)), en el cual ya no se observa el efecto catalítico al carecer de catalizador inicial o siembra para el comienzo de la reacción de descomposición del precursor. Estos resultados demuestran que no hay ninguna evidencia que relacione el elevado contenido de Co ( $90 \%)$ en las nanoestructuras fabricadas mediante FEBID presentadas en este capítulo, con la descomposición catalítica del gas precursor $\left(\mathrm{Co}_{2}(\mathrm{CO})_{8}\right)$, 


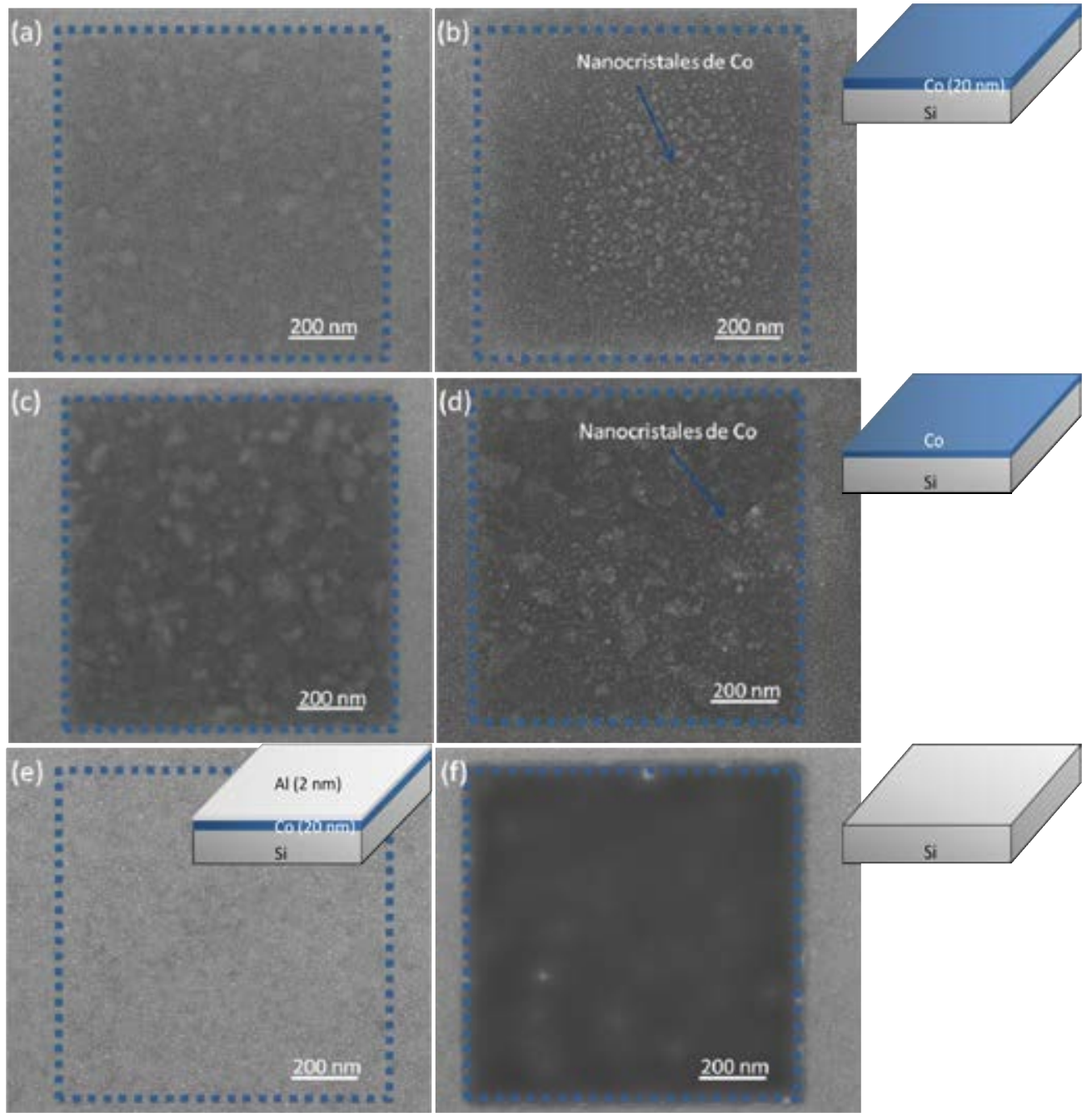

Figura 3.11: Imágenes SEM del estudio de la descomposición catalítica del $\mathrm{Co}_{2}(\mathrm{CO})_{8}$ sobre el sustrato C. (a) Imagen de la superficie del sustrato tras desbastar un volumen de $1 \times 1$ $\times 0.003 \mu \mathrm{m}^{3}$ mediante FIB; (b) Imagen de la superficie del sustrato tras desbastar un volumen de $1 \times 1 \times 0.003 \mu \mathrm{m}^{3}$ mediante FIB y ser expuesto a 30 minutos del gas precursor; (c) Imagen de la superficie del sustrato tras desbastar un volumen de $1 \times 1 \times 0.007 \mu \mathrm{m}^{3}$ mediante FIB; (d) Imagen de la superficie del sustrato tras desbastar un volumen de $1 \times 1 \times 0.007 \mu \mathrm{m}^{3}$ mediante FIB y ser expuesto a 30 minutos del gas precursor; (e) Imagen de la superficie del sustrato virgen; (f) Imagen de la superficie del sustrato tras desbastar un volumen de $1 \times 1 \times 0.025 \mu^{3}$ mediante FIB y ser expuesto a 30 minutos del gas precursor. 


\subsection{Nanoestructuras ultraestrechas de Co y aplicaciones}

En este apartado, describimos los experimentos realizados para conseguir el crecimiento de nanoestructuras de Co puras usando bajas corrientes del haz de electrones a temperatura ambiente. Tal y como describimos en los apartados 3.2, 3.3 y 3.4, y como otros autores también han confirmado ${ }^{141}$, el ajuste de ciertos parámetros de crecimiento nos permite afinar el contenido de Co en los depósitos creados mediante esta técnica. Teniendo esta idea siempre presente, mantenemos constante el valor de la corriente del haz de electrones (en el rango de pA) para obtener nanoestructuras estrechas y estudiamos la influencia del flujo de precursor en el contenido de Co de los depósitos.

\subsubsection{Influencia del flujo de gas precursor}

El estudio de la influencia del flujo de precursor en el contenido de Co de los depósitos se lleva a cabo creciendo cuadrados de Co de $100 \mathrm{~nm}$ de lado y $100 \mathrm{~nm}$ de espesor sobre un sustrato de Si (dopaje p) variando el flujo de gas precursor. El flujo de gas se controla y ajusta abriendo gradualmente la válvula, la evolución del proceso está monitorizada en todo momento a través del cambio de presión en la cámara de proceso. El análisis composicional de las nanoestructuras de Co se realizó mediante EDS a un voltaje de aceleración del FEB de 3 kV.

Los parámetros relevantes en el proceso de FEBID utilizados son los siguientes: $\mathrm{V}_{\mathrm{e}}=3 \mathrm{kV} ; \mathrm{I}_{\mathrm{e}}=21 \mathrm{pA} ; \mathrm{P}_{\text {base }}=1.3 \times 10^{-6}$ mbar; $\mathrm{t}_{\text {proceso }}=103 \mathrm{~s} ; \mathrm{P}_{\text {proceso }}=$ variable. $\mathrm{El}$ contenido de Co presenta una variación en función del flujo de gas precursor como se indica en la Figura 3.12. Al máximo y al mínimo valor de flujo de gas precursor, el contenido de Co es del $\sim 65 \%$. Sin embargo, a valores intermedios de flujo de gas, podemos obtener nano-cuadrados con un contenido de Co superior al $\sim 93 \%$. Estos resultados se pueden entender teniendo en cuenta los diferentes regímenes de crecimiento que pueden tener lugar en el proceso FEBID comentados ampliamente en el apartado 1.3.4 del Capítulo 1 y que, en este caso concreto se presentan en función 
del flujo de gas. En el caso de tener un flujo de precursor bajo, el crecimiento se realiza en el régimen limitado por el precursor, en el cual la disociación de las especies residuales que se encuentran dentro de la cámara de proceso juegan un papel relevante, provocando el co-crecimiento de éstas junto con el depósito como tal y por tanto, la contaminación de la muestra ${ }^{141}$. Cuando el flujo de precursor es elevado, el crecimiento se realiza en el régimen limitado por los electrones, las moléculas se reponen tan rápidamente en la superficie del sustrato que a los electrones operando a baja $\mathrm{I}_{\mathrm{e}}$, les resulta imposible descomponer o disociar todos los enlaces del precursor, de modo que las moléculas parcialmente descompuestas se incorporan al nanodepósito.

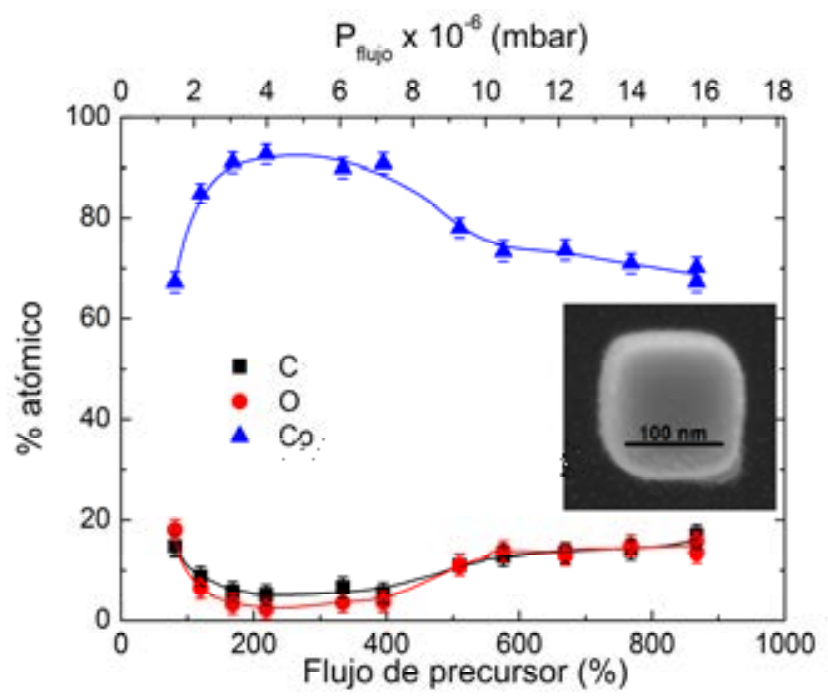

Figura 3.12: Dependencia de la composición de nanodepósitos de Co crecidos a 3 kV, 21 pA en función del flujo de gas precursor. En el recuadro se muestra una imagen SEM del tipo de estructuras de cobalto estudiadas. El cambio relativo de flujo de precursor se define mediante la expresión: flujo de precursor (\%) $=100 \times P_{\text {flujo }} / P_{\text {base }}$; siendo $P_{\text {flujo }}=P_{\text {proceso }}-P_{\text {base }}$

En el caso de liberar un valor de flujo de precursor intermedio, el crecimiento se realiza entre el régimen limitado por el precursor y el régimen limitado por el FEB. Así, es posible conseguir un balance perfecto entre el flujo de precursor y la $\mathrm{I}_{\mathrm{e}}$, para producir la descomposición total de las moléculas de precursor adsorbidas sobre el 
sustrato, mientras se evita la incorporación de especies residuales. El fruto de este estudio es la posibilidad de crecer nanoestructuras de tamaño $<50 \mathrm{~nm}$ y con un contenido de Co> 90\% atómico a temperatura ambiente y previsiblemente sobre distintos tipos de sustrato.

Los valores obtenidos en el estudio del flujo de gas precursor son adecuados para nanoestructuras de Co de dimensiones próximas a $100 \mathrm{~nm}$ y utilizando los mismos parámetros de crecimiento $\left(\mathrm{V}_{\mathrm{e}}=3 \mathrm{kV} ; \mathrm{I}_{\mathrm{e}}=21 \mathrm{pA} ; \mathrm{t}_{\mathrm{p}}=1 \mu \mathrm{s} ; \mathrm{s}=50 \%\right.$; $\mathrm{t}_{\mathrm{r}}=0 \mathrm{~s}$; $\mathrm{t}_{\text {proceso }}=$ $\left.103 \mathrm{~s} ; \mathrm{P}_{\text {base }}=1.82 \times 10^{-6} \mathrm{mbar}\right)$. En otras condiciones, se deberían realizar nuevos experimentos para encontrar el flujo de gas precursor adecuado. No debemos olvidar que otros parámetros relevantes para afinar el contenido de Co en las nanoestructuras son el $t_{p}, t_{r}$ y el tamaño de las estructuras de Co como ya lo observaron otros autores 140, 141, 153, 154 y como se ha estudiado en profundidad en el seno de nuestro grupo de investigación ${ }^{155}$.

\subsubsection{Nanoestructuras ultraestrechas de Co}

Una vez controladas las condiciones de crecimiento para nanodepósitos de Co de tamaño $<50 \mathrm{~nm}$, fabricamos dos tipos de nanoestructuras magnéticas funcionales que se muestran en la Figura 3.13. El tipo 1 (véanse Figuras 3.13(a) y (b)) son NWs ultraestrechos de alta pureza con futuras aplicaciones relacionadas con la Espintrónica ${ }^{142}$ y lógica magnética basada en la manipulación de paredes de dominio ${ }^{139}$. El tipo 2 se trata de sondas nano-Hall para la fabricación de nanosensores ${ }^{142,}{ }^{143}$, como mostramos en las Figuras 3.13(c) y (d).

Las nanoestructuras ultraestrechas de tipo 1 presentadas en este estudio son NWs ultraestrechos crecidos a $3 \mathrm{kV}$ y 21 pA. La composición de los mismos en porcentaje atómico es de 90:8:2 (Co:C:O). La resolución lateral alcanzada es de $30 \mathrm{~nm}$, casi 4 veces mejor que en los estudios previos, en los cuales era necesario utilizar $I_{e}$ del orden de nA, para obtener depósitos de alto contenido de Co (>90\%) ${ }^{133}$. La caracterización magnética de estructuras de tamaño tan pequeño se puede llevar a cabo 
mediante técnicas de TEM, como por ejemplo la holografía electrónica ${ }^{71,156-158}$. Un estudio de holografía electrónica en NWs ultraestrechos se realizó en el microscopio Titan $^{3}$ High-base con corrector de aberración esférica en la lente objetivo. La inducción magnética obtenida, a través de holografía electrónica en NWs de 30 nm de ancho y $9 \mathrm{~nm}$ de espesor es de $1.8 \mathrm{~T}$, valor muy cercano al valor de la imanación de saturación del Co puro. Se han estudiado NWs de varios espesores, en algún caso el valor de la inducción magnética disminuye hasta un 20\%, probablemente debido a pequeños cambios en la composición de los NWs. Así, las medidas magnéticas cuantitativas realizadas mediante holografía electrónica demuestran su magnetismo y su funcionalidad para aplicaciones en Espintrónica ${ }^{155}$.
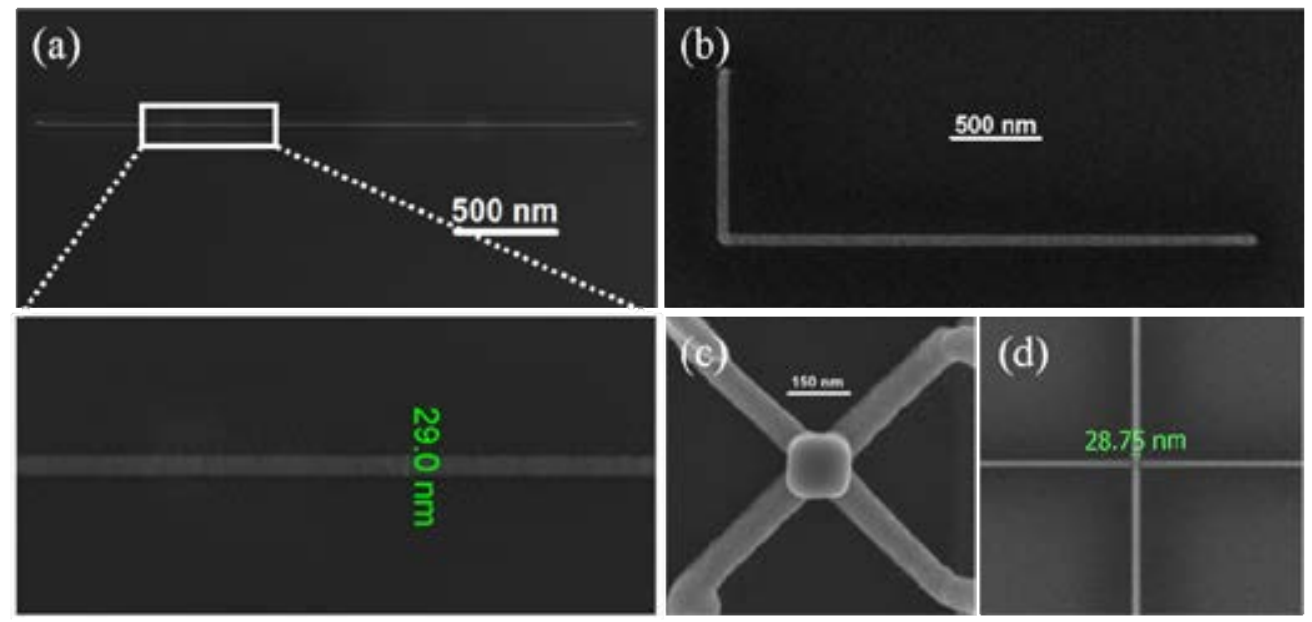

Figura 3.13: Imágenes SEM de nanoestructuras ferromagnéticas ultraestrechas de Co crecidas a $3 \mathrm{kV}, 21 \mathrm{pA}$. (a) NW de $29 \mathrm{~nm}$ de ancho, $3 \mu \mathrm{m}$ de largo y $30 \mathrm{~nm}$ de espesor (imagen tomada con un ángulo de inclinación de la plataforma de $52^{\circ}$ ). En el recuadro vemos una ampliación del NW (imagen tomada con un ángulo de inclinación de $0^{\circ}$ ); (b) Nanoestructura en forma de "L", parte horizontal de $3 \mu \mathrm{m}$ de largo y la parte perpendicular a este de $1 \mu \mathrm{m}$ de largo (imagen tomada con un ángulo de inclinación de $0^{\circ}$ ), $40 \mathrm{~nm}$ de ancho y $30 \mathrm{~nm}$ de espesor; (c) Nanoestructura en forma de sonda nano-Hall basada en 4 contactos independientes de Co de $75 \mathrm{~nm}$ de ancho y un cuadrado central con un área activa de $150 \mathrm{~nm} \times 150 \mathrm{~nm}$ (imagen tomada con un ángulo de inclinación de $0^{\circ}$ ); (d) Nanoestructura en forma de cruz nano-Hall, con un ancho $<30 \mathrm{~nm}$ (imagen tomada con un ángulo de inclinación de $0^{\circ}$ ). 
Respecto al tipo 2 de nanoestructuras ultraestrechas, los sensores Hall de tan pequeño tamaño ofrecen la posibilidad de aumentar la sensibilidad de detección expresada en flujo magnético por debajo de $10^{-6} \phi_{0} / \mathrm{Hz}^{-1 / 2}$ ( $\phi_{0}=\mathrm{h} / 2 \mathrm{e}$, es un cuanto de flujo) ${ }^{143}$. La fabricación de tales dispositivos en la escala nanométrica tiene un destacado interés en el campo de los biosensores para la detección de fracciones biológicas conjugadas a nanopartículas magnéticas y en general para diferentes aplicaciones en nanosensores, como por ejemplo microscopía Hall de barrido, nanomagnetómetro, sensores de corriente, interruptores de proximidad, etc. ${ }^{159,160}$.

\subsubsection{Sensores nano-Hall de Co}

El crecimiento de sensores nano-Hall de Co fue realizado a $3 \mathrm{kV}$ y $21 \mathrm{pA}$ sobre sustratos de Si (dopaje p) térmicamente oxidado. Las obleas oxidadas son sometidas a procesos de litografía óptica para definir pistas metálicas de Ti.

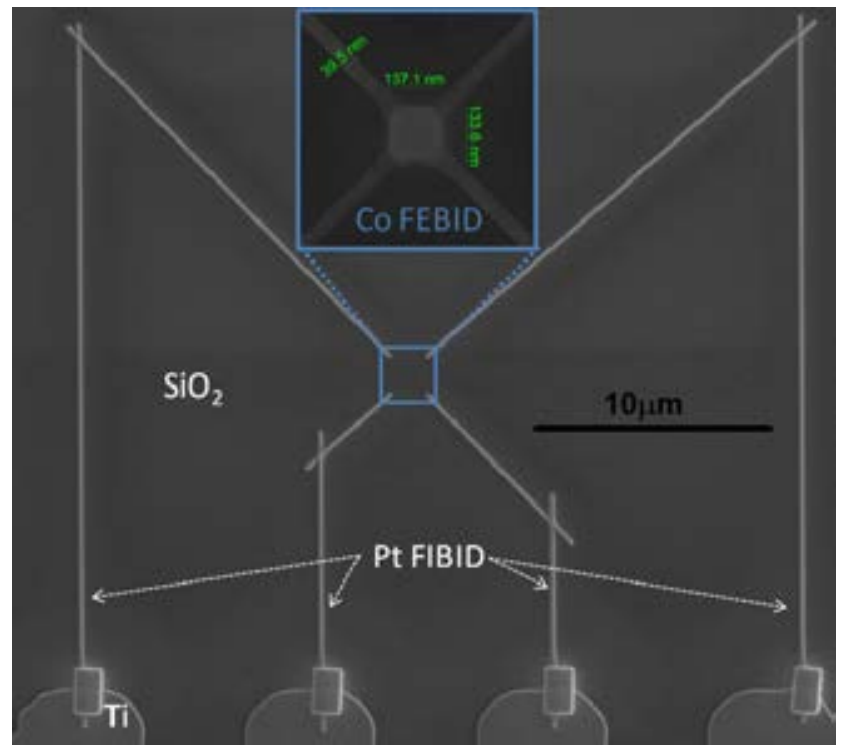

Figura 3.14: Imagen SEM del procedimiento que se lleva a cabo en la fabricación de los nanosensores Hall de Co. En primer lugar, se crecen los 4 NWs de Pt FIBID y en el hueco señalado por el cuadrado, se crecen los 4 NWs de Co FEBID y por último el cuadrado de Co FEBID. 
En primer lugar, se crecieron 4 nanocontactos auxiliares de Pt mediante FIBID, que usaremos para conectar los sensores Hall que fabriquemos a las pistas de Ti y van desde los 4 microcontactos de $\mathrm{Ti}$ al sustrato, como podemos observar en la Figura 3.14. Los contactos se realizan para medir por cuatro puntas. Después de esto, crecemos 4 NWs independientes de Co de 40-75 nm de anchos, que contactan los NWs de Pt crecidos previamente. Finalmente, un cuadrado de Co con un ancho típico de 140-150 nm (el área activa del sensor) se crece en el centro de los 4 NWs independientes de Co, cerrando el circuito eléctrico. Los análisis composicionales realizados mediante EDS del área activa del sensor indican que el contenido de Co es del $\sim 90 \%$.

Las medidas del efecto Hall se realizaron en el PPMS descrito en el apartado 2.6.2 del Capítulo 2 en un rango de temperaturas de 300 a $2 \mathrm{~K}$. El campo magnético aplicado es perpendicular al sustrato y va de +9 a $-9 \mathrm{~T}$. La corriente de medida aplicada sobre los nanosensores va de $10 \mu \mathrm{A}$ hasta $1.2 \mathrm{~mA}$. En la Figura 3.15, representamos la resistividad Hall del sensor indicado en la Figura 3.13(c) en función del campo magnético aplicado a 300 y $10 \mathrm{~K}$. La resistividad Hall viene dada por la ecuación (1.4).

Las líneas en la Figura 3.15 reflejan las contribuciones individuales del OHE y el AHE. El punto de coincidencia entre el comportamiento a bajo campo, positivo en signo y dominado por el AHE y el comportamiento a alto campo, negativo en signo y dominado por el OHE, tiene lugar a $\sim 2 \mathrm{~T}$, como ocurre en el cobalto puro ${ }^{156} \mathrm{y}$ en el Co crecido mediante FEBID a alta corriente de electrones ${ }^{133}$. Debemos mencionar que sensores Hall fabricados mediante FEBID con bajo contenido de Co no presentan este claro corte o punto de coincidencia entre el AHE y el OHE ${ }^{142,143 .}$

La máxima resistividad Hall a temperatura ambiente de los nanosensores investigados en este estudio es de alrededor de $2.7 \mu \Omega \mathrm{cm}$, un orden de magnitud superior a los obtenidos previamente en nanodepósitos de Co crecidos a alta corriente 133. La diferencia puede ser ocasionada por la relativamente alta resistividad longitudinal de estos nanodepósitos (debido al ligeramente menor contenido 
metálico); puesto que hay una directa relación entre la resistividad Hall y la resistividad longitudinal ${ }^{71}$. La sensibilidad de campo $\left(\mathrm{S}_{\mathrm{I}}\right)$ es un parámetro importante para caracterizar los sensores Hall. A partir de la ecuación 3.1, se obtiene y se representa su valor en función del campo magnético en el recuadro de la Figura 3.15.

$$
S_{I}=\frac{\delta V_{H} / \delta B}{I}
$$

La $\mathrm{S}_{\mathrm{I}}$ a bajo campo de los sensores Hall estudiados a $300 \mathrm{~K}$ está entre 0.13 y 0.07 $\Omega / \mathrm{T}$ para nanosensores con una composición en porcentaje atómico de Co:C:O de 88:8:4 y 84:9:7, respectivamente. Los valores de $S_{\text {I }}$ obtenidos son similares a los ya publicados en la referencia ${ }^{142}$ para sensores con más bajo contenido en Co, pero el parámetro más importante para comparar los sensores Hall es el valor mínimo de flujo magnético detectable $\left(\phi_{\min }\right)$. En la referencia ${ }^{143}$, el valor de $\phi_{\min }$ estimado es de alrededor de $4.5 \times 10^{-6} \phi_{0}$, cuyo resultado es mejor que los obtenidos previamente en otras sondas nano-Hall. En el régimen de ruido térmico, $\phi_{\min }$ es proporcional a la raíz cuadrada de la resistencia del sensor longitudinal y al área del sensor. Como tanto la resistencia longitudinal como el área del sensor son significativamente menores en nuestros nanosensores de alto contenido en Co comparados con los de la referencia ${ }^{143}$, esperamos mejorar el valor de $\phi_{\min }$ más de un orden de magnitud. Experimentos dedicados a esclarecer esta cuestión están en proceso, lo cual constituye una atractiva línea de investigación en sensores magnéticos en la nanoescala.

En este apartado se han crecido nanoestructuras de Co sobre tres tipos de sustratos distintos: silicio, óxido de silicio $(\sim 250 \mathrm{~nm})$ sobre silicio y membranas de $50 \mathrm{~nm}$ de espesor de nitruro de silicio. Como mostramos en la Tabla 3.3, la concentración de Co no varía significativamente en nanodepósitos crecidos utilizando los mismos parámetros de crecimiento. 


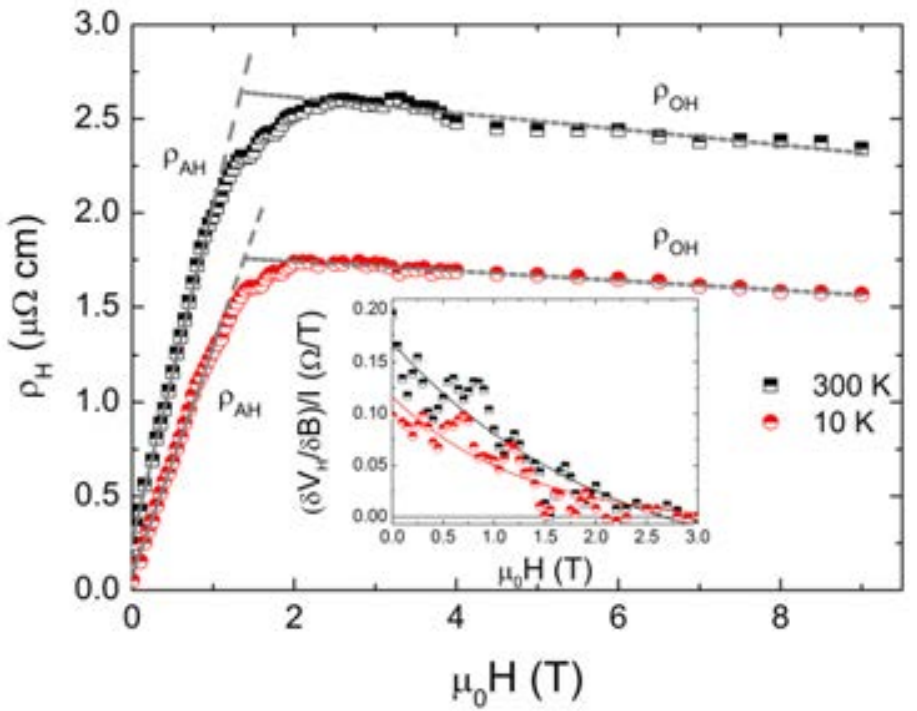

Figura 3.15: Resistividad Hall del sensor Hall mostrado en la Figura 3.13(c) a 300 y $10 \mathrm{~K}$. El recuadro muestra la sensibilidad magnética del sensor en función del campo magnético aplicado a 300 y $10 \mathrm{~K}$.

\begin{tabular}{l|ccc}
\hline Sustrato & C (\% at. \pm 2\%) & O (\% at. $\pm 2 \%)$ & Co (\% at. $\pm 2 \%)$ \\
\hline $\mathrm{Si}$ & 6 & 10 & 85 \\
$\mathrm{Si}_{3} \mathrm{~N}_{4}$ & 7 & 8 & 85 \\
$\mathrm{SiO}_{2}$ & 2 & 7 & 91 \\
\hline
\end{tabular}

Tabla 3.3: Composición de los nanodepósitos de Co crecidos sobre los distintos tipos de sustrato a $3 \mathrm{kV}, 21 \mathrm{pA}$ utilizados en los experimentos realizados en este apartado.

Asimismo, hemos dado un gran paso hacia la comprensión del mecanismo de crecimiento que tiene lugar en el proceso FEBID, y más concretamente el mecanismo que envuelve este particular precursor, el $\mathrm{Co}_{2}(\mathrm{CO})_{8}$. Siempre con el propósito de encontrar los parámetros de crecimiento adecuados para la obtención de 
nanoestructuras ferromagnéticas de Co ultraestrechas (véase Figura 3.16). Este objetivo está cumplido con NWs y sensores nano-Hall con un tamaño de $30 \mathrm{~nm}$.

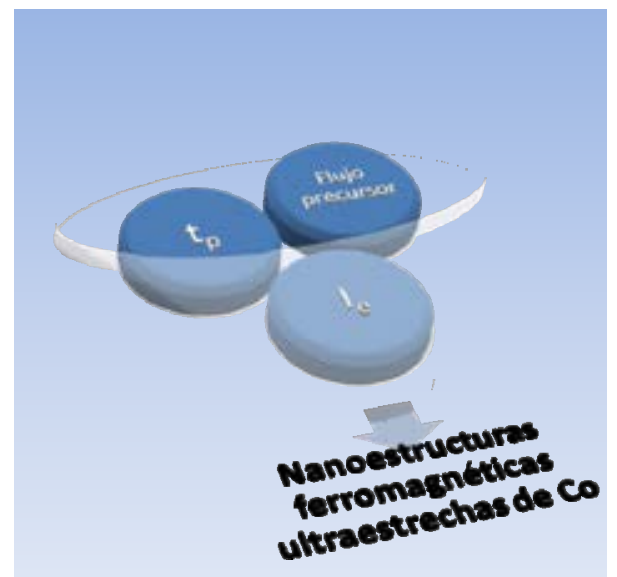

Figura 3.16: Representación esquemática de los principales parámetros de crecimiento para obtener nanoestructuras ferromagnéticas de Co ultraestrechas. 


\subsection{Conclusiones}

A lo largo de este capítulo, hemos estudiado minuciosamente los depósitos de Co crecidos mediante FEBID, utilizando como material precursor el $\mathrm{Co}_{2}(\mathrm{CO})_{8}$ y a través de diversas caracterizaciones, tales como EDS, STEM, HRTEM, EELS, EH, y medidas de magnetotransporte.

Adicionalmente, hemos variado de forma controlada los distintos parámetros de crecimiento que pueden mejorar sensiblemente el contenido de Co, como la $\mathrm{I}_{\mathrm{e}}$, la temperatura del sustrato, la naturaleza del sustrato y el flujo de precursor. El contenido de Co en los depósitos tiene una gran influencia en sus propiedades magnéticas y por ende en sus futuras aplicaciones en el campo de la lógica, sensores y almacenamiento magnético. El crecimiento de nanoestructuras ferromagnéticas de $30 \mathrm{~nm}$ de ancho lateral es un gran avance para la funcionalidad de la técnica FEBID. Sin embargo, sólo nos encontramos en los primeros estadíos de este proyecto en el cual la obtención de estructuras por debajo de $10 \mathrm{~nm}$ es posible ${ }^{8}$, así como la fabricación de estructuras ferromagnéticas en tres dimensiones ${ }^{161}$. 


\section{Capítulo 4}

\section{Depósitos ferromagnéticos de Fe crecidos mediante un haz de electrones focalizado}

Se ha realizado un estudio detallado de las propiedades de magnetotransporte y la microestructura en microhilos de hierro crecidos mediante un haz de electrones focalizado en función del contenido de Fe, que varía desde el $45 \%$ hasta el $70 \%$. Los mecanismos de magnetotransporte han sido investigados en profundidad en un amplio rango de temperaturas y campos magnéticos aplicados. El control del contenido de Fe y la microestructura en los microhilos nos ha permitido explorar la transición de aislante a metal. Asimismo, hemos observado una evolución progresiva de la magnetorresistencia, modificándose desde un comportamiento de magnetorresistencia anisótropa a otro de magnetorresistencia túnel intergranular. Además, las medidas del efecto Hall revelan una contribución del efecto Hall anómalo gigante debido a la fuerte dispersión de los electrones producida por las impurezas magnéticas, las cuales están presentes como hierro y especies de óxidos de hierro embebidas en la matriz de Fe:O:C amorfa. 


\subsection{Introducción}

Como se ha discutido en los capítulos previos, gracias a técnicas de fabricación, tales como FEBID y FIBID ${ }^{40,41}$ es posible el control del crecimiento de materiales en una sola etapa sobre cualquier tipo de sustrato, sea conductor o aislante, incluso el dominio a escala y precisión nanométrica del lugar de crecimiento, el ancho lateral y el espesor.

Como segundo paradigma de la nanofabricación de diseños magnéticos mediante estas técnicas se han publicado trabajos del crecimiento de nanoestructuras magnéticas basadas en Fe mediante FEBID utilizando diferentes materiales precursores, como $\mathrm{Fe}(\mathrm{CO})_{5}, \mathrm{Fe}_{2}(\mathrm{CO})_{9}$ and $\mathrm{Fe}_{2}(\mathrm{CO})_{12}{ }^{145}, 162-168$. Extraordinariamente, ha sido posible crecer NWs de Fe puro utilizando un sistema de UHV ${ }^{148-150,169,}{ }^{170}$. Sin embargo, ninguno de estos trabajos mostró medidas de magnetotransporte, estudios de microestructura y composición en depósitos de Fe crecidos mediante FEBID hasta el sistemático estudio publicado por nuestro grupo en colaboración con la Eindhoven University of Technology (TU/e) ${ }^{121}$. 


\subsection{Crecimiento de microestructuras de Fe mediante FEBID}

El crecimiento de nanoestructuras de Fe se realizó mediante FEBID, en el equipo comercial "Dual Beam" Nova 600i Nanolab en la Eindhoven University of Technology (TU/e). Los parámetros de crecimiento de los nanodepósitos de Fe son los siguientes: material precursor= nonacarbonilo de dihierro, $\mathrm{Fe}_{2}(\mathrm{CO})_{9}$; temperatura de material precursor $=28^{\circ} \mathrm{C} ; \mathrm{T}_{\text {sustrato }}=22^{\circ} \mathrm{C} \pm 1{ }^{\circ} \mathrm{C} ; \mathrm{t}_{\mathrm{p}}=1 \mu \mathrm{s} ; \mathrm{s}=50 \% ; \mathrm{t}_{\mathrm{r}}=0 \mathrm{~s} ; \mathrm{P}_{\text {base }}=2 \times$ $10^{-6} \mathrm{mbar} ; \mathrm{P}_{\text {proceso }}=4 \times 10^{-6} \mathrm{mbar}$ (la válvula del gas precursor se abre completamente durante el proceso de crecimiento); $\mathrm{V}_{\mathrm{e}}=2 \mathrm{kV}-30 \mathrm{kV}$; $\mathrm{I}_{\mathrm{e}}=0.7 \mathrm{nA}-22 \mathrm{nA}$. La aguja del material precursor se ajusta a alrededor de $150 \mu \mathrm{m}$ de la superficie del sustrato (z) y a alrededor de $50 \mu \mathrm{m}$ en la dirección del plano, es decir, en x/y. El sustrato utilizado como soporte para el crecimiento de los microhilos fue Si dopado con boro (dopaje tipo p), sometido a un proceso de oxidación para asegurar el buen aislamiento eléctrico. Con este método obtenemos una capa de $250 \mathrm{~nm}$ de material aislante $\left(\mathrm{SiO}_{2}\right)$. Estos sustratos se sometieron a procesos de litografía óptica para definir cuatro o seis contactos de titanio o aluminio necesarios para las medidas por cuatro puntas, ya sean de resistividad, magnetorresistencia o bien del efecto Hall. Las dimensiones típicas de los microhilos de Fe destinados a las posteriores medidas de transporte "ex-situ" fueron de longitud $(\mathrm{l})=12 \mu \mathrm{m}$, ancho $(\mathrm{a})=500-1000 \mathrm{~nm}$ y espesor $(\mathrm{e})=200 \mathrm{~nm}$.

Los depósitos de Fe estudiados en este apartado fueron crecidos variando $V_{e}$ e $I_{e}$ para estudiar la dependencia de estos dos parámetros con la composición de aquellos. El análisis del contenido de Fe se llevó a cabo in situ mediante la técnica EDS descrita ampliamente en el apartado 2.3 del Capítulo 2. La energía de aceleración del haz de electrones seleccionada en los análisis de depósitos de tamaño $500 \times 500 \times 100 \mathrm{~nm}^{3}(1$ $\times \mathrm{a} \times \mathrm{e}$ ) es de $2 \mathrm{kV}$, para evitar la contribución del sustrato en los espectros analizados. Sólo fueron detectados los elementos Fe:C:O, los cuales corresponden al material precursor de partida y a los posibles contaminantes provenientes de la cámara de proceso. Además, el ajuste se corresponde perfectamente a la línea L del Fe y las líneas $\mathrm{K}$ del $\mathrm{O}$ y del $\mathrm{C}$. En la Tabla 4.1, resumimos los resultados conseguidos en diferentes nano-cuadrados de Fe crecidos variando $V_{e}$ e $I_{e}$. 


\begin{tabular}{|c|c|c|c|c|c|c|}
\hline Muestra & $\begin{array}{c}V_{e} \\
(k V)\end{array}$ & $\begin{array}{c}I_{e} \\
(n A)\end{array}$ & $\begin{array}{c}F e \\
(\% \text { at. } \pm 2 \%)\end{array}$ & $\begin{array}{c}C \\
(\% a t . \pm 2 \%)\end{array}$ & $\begin{array}{c}O \\
(\% \text { at. } \pm 2 \%)\end{array}$ & $\mathrm{Fe} / \mathrm{O}$ \\
\hline 1 & 2 & 1.61 & 52.2 & 23.6 & 24.2 & 2.2 \\
\hline 2 & 2 & 6.70 & 72.1 & 15.8 & 12.1 & 6.0 \\
\hline 3 & 2 & 21.6 & 78.4 & 13.4 & 8.20 & 9.6 \\
\hline 4 & 5 & 0.71 & 60.9 & 15.0 & 24.1 & 2.5 \\
\hline 5 & 5 & 2.00 & 66.8 & 13.5 & 19.7 & 3.4 \\
\hline 6 & 5 & 9.90 & 73.6 & 13.7 & 12.7 & 5.8 \\
\hline 7 & 5 & 15.5 & 75.2 & 16.5 & 8.30 & 9.1 \\
\hline 8 & 5 & 22.1 & 76.3 & 15.9 & 7.80 & 9.8 \\
\hline 9 & 15 & 4.30 & 69.6 & 12.5 & 17.9 & 3.9 \\
\hline 10 & 15 & 17.6 & 74.5 & 13.1 & 12.4 & 6.0 \\
\hline 11 & 15 & 22.3 & 76.2 & 12.3 & 11.5 & 6.6 \\
\hline 12 & 30 & 4.20 & 59.0 & 17.7 & 23.2 & 2.5 \\
\hline 13 & 30 & 17.0 & 70.1 & 16.5 & 13.4 & 5.2 \\
\hline 14 & 30 & 22.0 & 71.5 & 15.7 & 12.8 & 5.6 \\
\hline
\end{tabular}

Tabla 4.1: Análisis composicional obtenido mediante EDS de los nano-cuadrados de Fe crecidos a varios voltajes de aceleración del FEB $\left(\mathrm{V}_{\mathrm{e}}\right)$ y corrientes de electrones $\left(\mathrm{I}_{\mathrm{e}}\right)$.

Como ya observamos en los depósitos de Co del Capítulo 3, la concentración máxima de metal en el proceso FEBID se obtiene a alta $\mathrm{I}_{\mathrm{e}}$ (en el rango de $\mathrm{nA}$ ) y a bajo $\mathrm{V}_{\mathrm{e}}{ }^{127,133}$. Además, podemos observar que el contenido de $\mathrm{C}$ permanece prácticamente constante alrededor del $\sim 16 \pm 3 \%$ atómico, mientras que la proporción Fe/O varía. La concentración máxima de Fe se consigue a la máxima $\mathrm{I}_{\mathrm{e}}$, 22 nA y es del $\sim 76 \%$, junto con el mínimo de O 8\%. En la Figura 4.1(a), mostramos los resultados obtenidos en depósitos crecidos a $5 \mathrm{kV}$. De la misma forma que describimos en el caso de los nanodepósitos de Co en el Capítulo 3, este fenómeno puede estar relacionado con un efecto de calentamiento local producido por el uso de altas $I_{e}{ }^{47,127,133}$. Otro efecto que afectará al contenido de $\mathrm{Fe}$, es la elevada velocidad de crecimiento que se produce a bajo $\mathrm{V}_{\mathrm{e}} \mathrm{y}$ a elevadas $\mathrm{I}_{\mathrm{e}}$ (Figura 4.1(b)). De esta forma, se impediría la incorporación de especies contaminantes presentes en la cámara de proceso en el depósito ${ }^{141,148}$. Con el objetivo de determinar el régimen de crecimiento se ha estudiado la velocidad de crecimiento en función de la $\mathrm{I}_{\mathrm{e}}$ (Figura 4.1(b)). El volumen de los depósitos ha sido estimado mediante AFM. La dependencia lineal de la velocidad de crecimiento 
respecto a la $\mathrm{I}_{\mathrm{e}}$ indica que nos encontramos en el régimen limitado por los electrones y su pendiente es el valor del volumen por dosis, $3.2 \times 10^{-4} \mu \mathrm{m}^{3} / \mathrm{nC}$, a un valor dado de $\mathrm{V}_{\mathrm{e}}$, en este caso $2 \mathrm{kV}$.
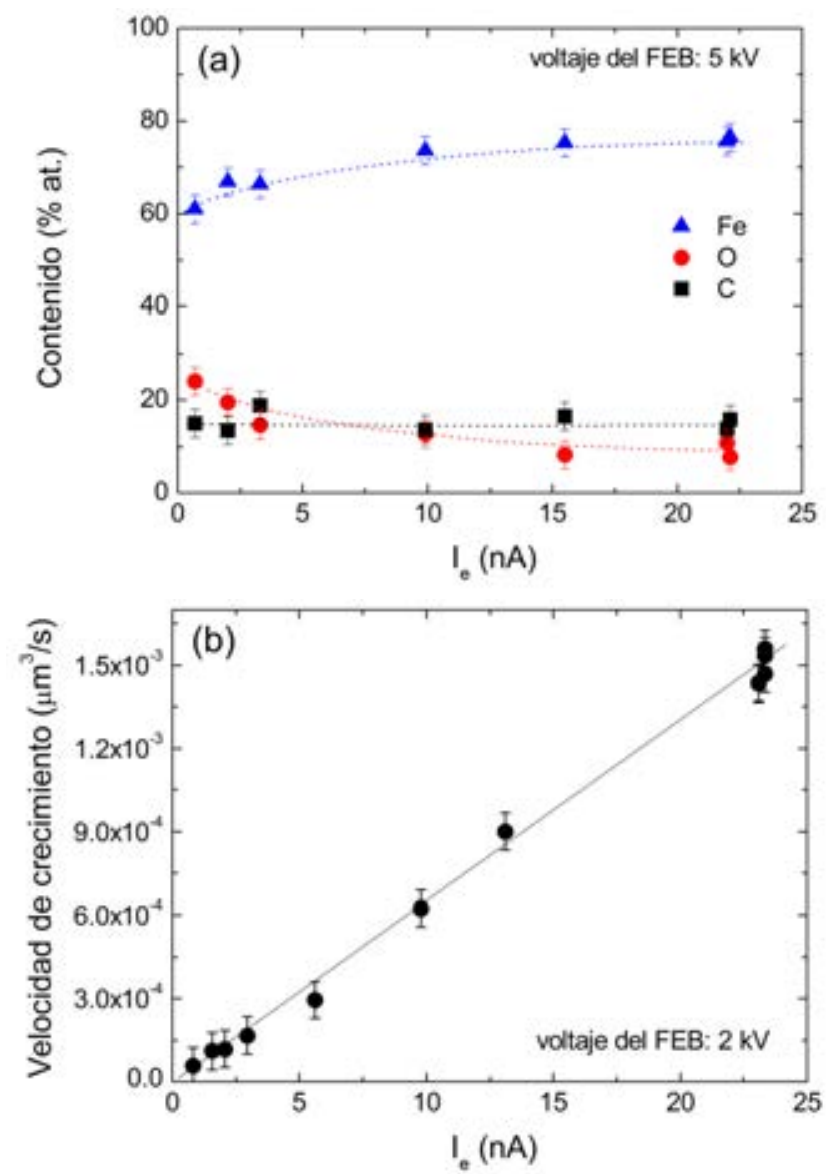

Figura 4.1: (a) Contenido de los depósitos (\% atómico) crecidos a $5 \mathrm{kV}$ en función de la $\mathrm{I}_{\mathrm{e}}$. (b) Velocidad de crecimiento de los depósitos a $2 \mathrm{kV}$ en función de la $\mathrm{I}_{\mathrm{e}}$.

En la Figura 4.2(a) se representa el contenido de Fe en función de la presión base de la cámara de proceso. La presión base de la cámara de proceso varía en función del tiempo de bombeo, por lo que aquí los depósitos se realizaron entre 0.5 y $3 \mathrm{~h}$ de tiempo de bombeo. En el recuadro se muestra la presión parcial de las principales especies contaminantes que se encuentran de la cámara de proceso medidas mediante 
un analizador de gas residual (RGA) de MKS Instruments, modelo Vac-Check $L M 78 R G A$, en función del tiempo de bombeo. La presión parcial de $\mathrm{H}_{2} \mathrm{O}$ y $\mathrm{O}_{2}$ desciende bruscamente en las primeras $7 \mathrm{~h}$ de bombeo. Una débil dependencia en el contenido de Fe se observa en función de la presión base. Sin embargo, el contenido de $\mathrm{O}$ aumenta y el de $\mathrm{C}$ desciende cuando la presión base es elevada. Esto indicaría que elevadas presiones parciales de $\mathrm{H}_{2} \mathrm{O}$ y $\mathrm{O}_{2}$ oxidan al Fe y al C ${ }^{171}$.
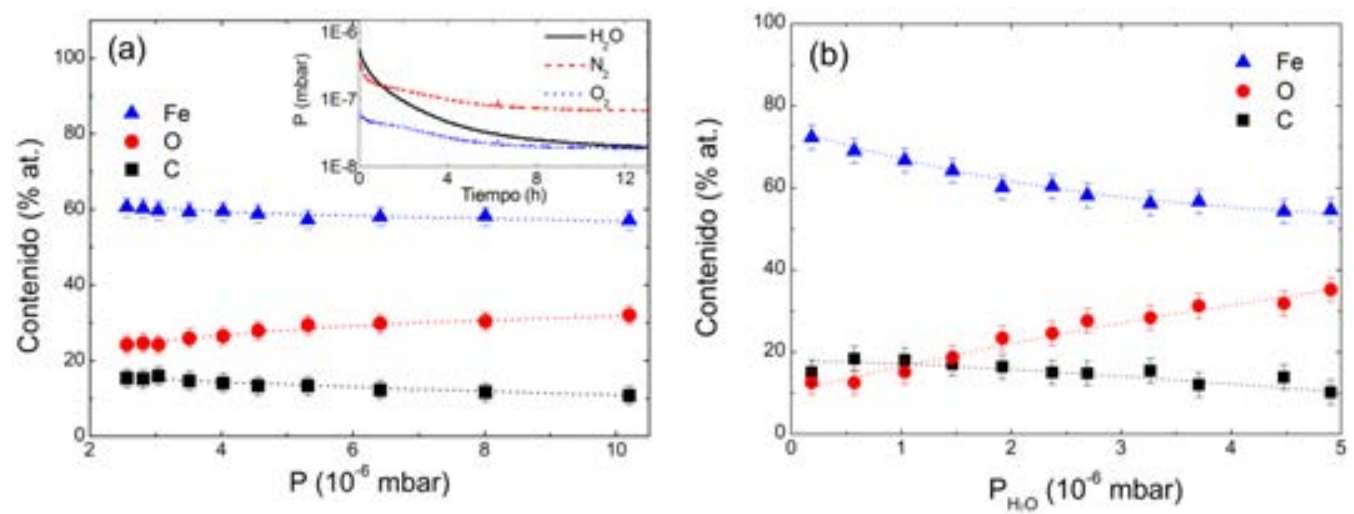

Figura 4.2: (a) Contenido de los depósitos (\% atómico) crecidos a 2 kV y 13 nA en función de la presión de la cámara de proceso justo antes del crecimiento. La presión de la cámara mínima tomada en el experimento es después de 3 h de bombeo. En el recuadro se indica la presión parcial de las principales especies contaminantes en función del tiempo de bombeo después de cerrar la cámara de vacío. (b) Contenido de los depósitos (\% atómico) crecidos a 5 kV y 22 nA en función de la presión parcial de $\mathrm{H}_{2} \mathrm{O}$ introducida.

Con la intención de modificar el contenido de Fe en los depósitos, añadimos vapor de $\mathrm{H}_{2} \mathrm{O}$ a través del material precursor, sulfato de magnesio heptahidratado $\mathrm{MgSO}_{4}\left(\mathrm{H}_{2} \mathrm{O}\right)_{7}$. El vapor de $\mathrm{H}_{2} \mathrm{O}$ se libera dentro de la cámara de proceso a través de una aguja del mismo tipo que la que utilizamos para el resto de materiales precursores y se monitoriza su presión parcial base de $\mathrm{H}_{2} \mathrm{O}$ mediante el RGA. Los resultados obtenidos se muestran en la Figura 4.2(b), en la cual se observa un claro descenso del contenido de $\mathrm{Fe}$ al incrementar la presión parcial de vapor $\mathrm{H}_{2} \mathrm{O}$. Obviamente, se detecta un aumento en el contenido de $\mathrm{O}$ y un pequeño descenso en el contenido de $\mathrm{C}$. 
Ello indica que el vapor de $\mathrm{H}_{2} \mathrm{O}$ tiene un efecto directo en la oxidación del Fe y un efecto menor en la oxidación del $\mathrm{C}$, el cual forma especies volátiles que son fácilmente bombeadas fuera de la cámara de proceso ${ }^{171}$. La descomposición parcial del material precursor comparada con la inclusión y la reacción de los gases residuales en la cámara determina la composición final de los depósitos.

\subsection{Microestructura de los depósitos de Fe en la nanoescala}

El estudio de la microestructura de los depósitos de Fe tiene como objetivo, explicar las propiedades estructurales y magnéticas que desarrollaremos en los próximos apartados.

Los microhilos de Fe se crecieron a $5 \mathrm{kV}$ y 22 nA sobre Si oxidado térmicamente (250 nm de $\mathrm{SiO}_{2}$ ), cuyas dimensiones fueron $12 \mu \mathrm{m} \times 1 \mu \mathrm{m} \times 200 \mathrm{~nm}(\mathrm{l} \times \mathrm{a} \times \mathrm{e})$. El análisis composicional (en \% atómico) de los tres microhilos en los que centramos el estudio es el siguiente: (A) Fe:40 O:59 C:1, (B) Fe:64 O:28 C:8 y (C) Fe:76 O:12 $\mathrm{C}: 12$. Al microhilo (A) de menor contenido de Fe se le añadió vapor de $\mathrm{H}_{2} \mathrm{O}$ durante el proceso de crecimiento con una presión parcial de $\mathrm{H}_{2} \mathrm{O}$ de $1.52 \times 10^{-6}$ mbar; mientras que a los microhilos (B) y (C) no se les añadió vapor de $\mathrm{H}_{2} \mathrm{O}$.

Las muestras para TEM de vista transversal se prepararon con el método convencional descrito en el apartado 2.5.1 del Capítulo 2 usando un microscopio "Dual Beam", modelo Helios 600 Nanolab de FEI. El estudio de la microestructura de las lamelas de los microhilos de Fe se realizó mediante un microscopio Titan $^{3}$ High-base a 300 kV de FEI con un corrector de aberración esférica $\mathrm{C}_{\mathrm{s}}$.

En la Figura 4.3 se visualizan las imágenes de los experimentos HRTEM realizados en los tres microhilos (A), (B) y (C). La muestra (A) es un buen ejemplo para estudiar la microestructura de muestras a las que se les añadió vapor de $\mathrm{H}_{2} \mathrm{O}$ y de esta forma poder compararla con las muestras a las que no se les añadió. En la muestra (A) se ha observado la formación de cristales tipo espinela, cuyas dimensiones son de 
200 nm de longitud coincidiendo con el espesor del depósito y 20 nm de ancho. El análisis de las imágenes mediante la FFT indica que la mayoría de las franjas de la red cristalina se corresponden a óxidos de hierro con alto contenido en oxígeno, como el $\mathrm{Fe}_{2} \mathrm{O}_{3}$ o el $\mathrm{Fe}_{3} \mathrm{O}_{4}$. Un ejemplo de esto está ilustrado en el recuadro de la Figura 4.3(b), dónde la FFT de un grano muestra puntos correspondientes a la estructura de espinela de óxidos de hierro. Aunque un análisis cuantitativo en este tipo de muestras no es factible, es evidente que la presencia de óxidos de hierro tipo espinela es predominante en la muestra (A). Esto está de acuerdo con el análisis composicional que se llevó a cabo sobre el microhilo, en el cual se detectó un elevado contenido de oxígeno, probablemente formando un compuesto con el hierro. La presencia de Fe metálico no puede ser excluida en el depósito ya que muchas de sus periodicidades son cercanas a las de otros óxidos de hierro y es muy difícil distinguirlas, aunque su aportación en el depósito sería siempre de forma residual.

Sin embargo, la muestra (B) presenta una microestructura totalmente distinta, formada principalmente por una matriz amorfa, como se dedujo a partir de la ausencia de reflexiones en la mayor parte de la Figura 4.3(d) y de una predominante dispersión difusa en la FFT. Esta matriz amorfa contiene pequeñas partículas cristalinas de 1-2 nm de tamaño, las cuales pueden ser fácilmente indexadas como Fe- $\alpha$. Finalmente, la muestra (C) exhibe una microestructura similar a la de la muestra (B) como podemos ver en las Figuras 4.3(e) y (f). De nuevo, se observa una matriz amorfa aunque comparada con la muestra (B), con una menor cantidad de nanocristales.

Estos resultados nos permiten concluir que en presencia de una alta presión parcial de $\mathrm{H}_{2} \mathrm{O}$, el mecanismo de crecimiento es diferente formando cristales de $\mathrm{FeO}_{\mathrm{x}}$, tipo espinela. Como comentamos en el apartado anterior de este capítulo, el agua añadida puede actuar como catalizador oxidando directamente el $\mathrm{Fe}$, formando los cristales de $\mathrm{FeO}_{\mathrm{x}}$ que hemos detectado en la muestra (A). A bajas presiones parciales de vapor de agua, el mecanismo de crecimiento tiende a formar una película amorfa de $\mathrm{Fe}$, C y O, en la cual aparecen unos pocos granos cristalinos de Fe- $\alpha$. 

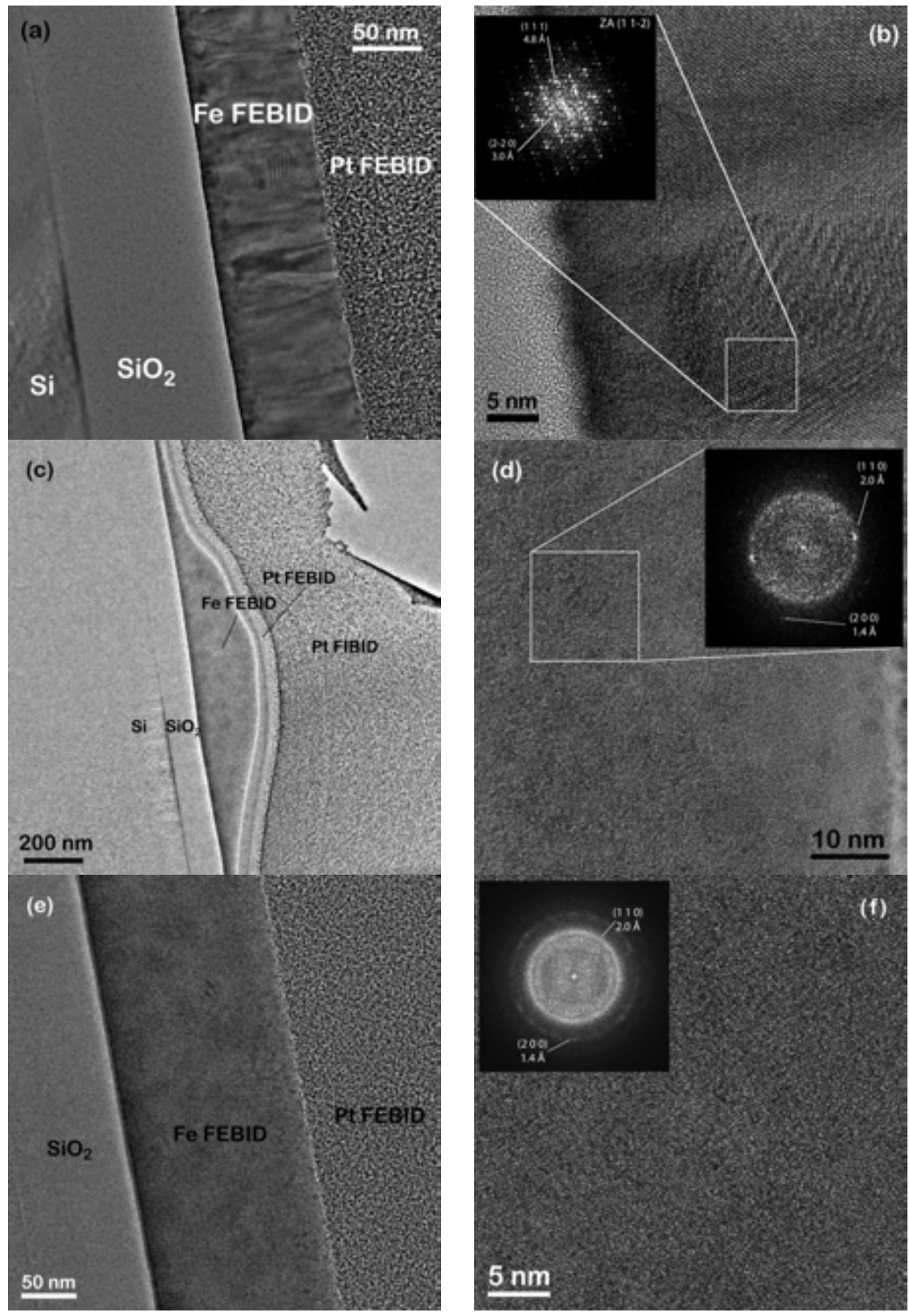

Figura 4.3: Imágenes HRTEM a bajos y altos aumentos de los microhilos (A), (B) y (C) con diferente composición de Fe: (a) y (b) microhilo (A), Fe:40 O:59 C:1; (c) y (d) microhilo (B), Fe:64 O:28 C:8; y (e) y (f) microhilo (C), Fe:76 O:12 C:12. Los recuadros en (b) y (d) indican la FFT de las áreas marcadas con cuadrados blancos y el recuadro en (f) indica la FFT de toda la imagen. 


\subsection{Mecanismo de transporte eléctrico}

El mecanismo de transporte eléctrico en nuestros depósitos y en relación con su microestructura está lejos de ser trivial. Los microhilos de Fe sometidos a este estudio se crecieron a $5 \mathrm{kV}$ y $22 \mathrm{nA}$ sobre $\mathrm{Si}$ oxidado térmicamente (250 nm de $\mathrm{SiO}_{2}$ ), de dimensiones $12 \mu \mathrm{m} \times 1 \mu \mathrm{m} \times 200 \mathrm{~nm}(\mathrm{l} \times \mathrm{a} \times \mathrm{e})$. Las medidas se realizaron en el sistema PPMS que describimos en el apartado 2.6.2 del Capítulo 2 por el método de cuatro puntas (véase Figura 4.4), operando en un rango de temperaturas de 300 a 2 K.

(a)

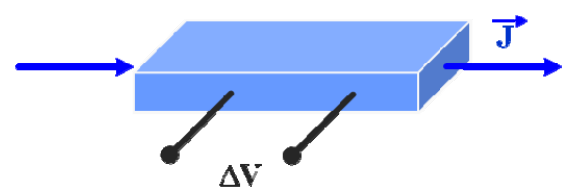

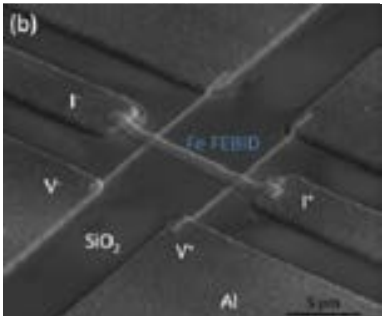

Figura 4.4: (a) Diagrama explicativo de la geometría utilizada para las medidas de resistividad por el método de cuatro puntas. (b) Imagen SEM de la configuración de medida.

En la Figura 4.5(a) se representa la resistividad $(\rho)$ en función de la temperatura de quince microhilos con distinta composición (de S1 a S15), cuyos valores de $\rho$ a temperatura ambiente varían desde $186 \mu \Omega \mathrm{cm}$ (S1) hasta $3.84 \times 10^{5} \mu \Omega \mathrm{cm}$ (S15), en función del contenido de Fe. Como se espera de una matriz de Fe:O:C, la $\rho$ depende fuertemente del contenido de $\mathrm{Fe}$ en los microhilos. Así, microhilos con un bajo contenido de Fe presentan un comportamiento típico de un material semiconductor; mientras que los microhilos que tienen un elevado contenido de Fe se comportan como lo suelen hacer los metales que no son puros (“dirty metal”). En el caso de S15, la resistividad incrementa hasta $1.25 \times 10^{7} \mu \Omega \mathrm{cm}$ a $130 \mathrm{~K}$, cuyo valor de resistencia $\left(\sim 7 \times 10^{6} \Omega\right)$ corresponde al valor máximo que es posible medir en el PPMS. 

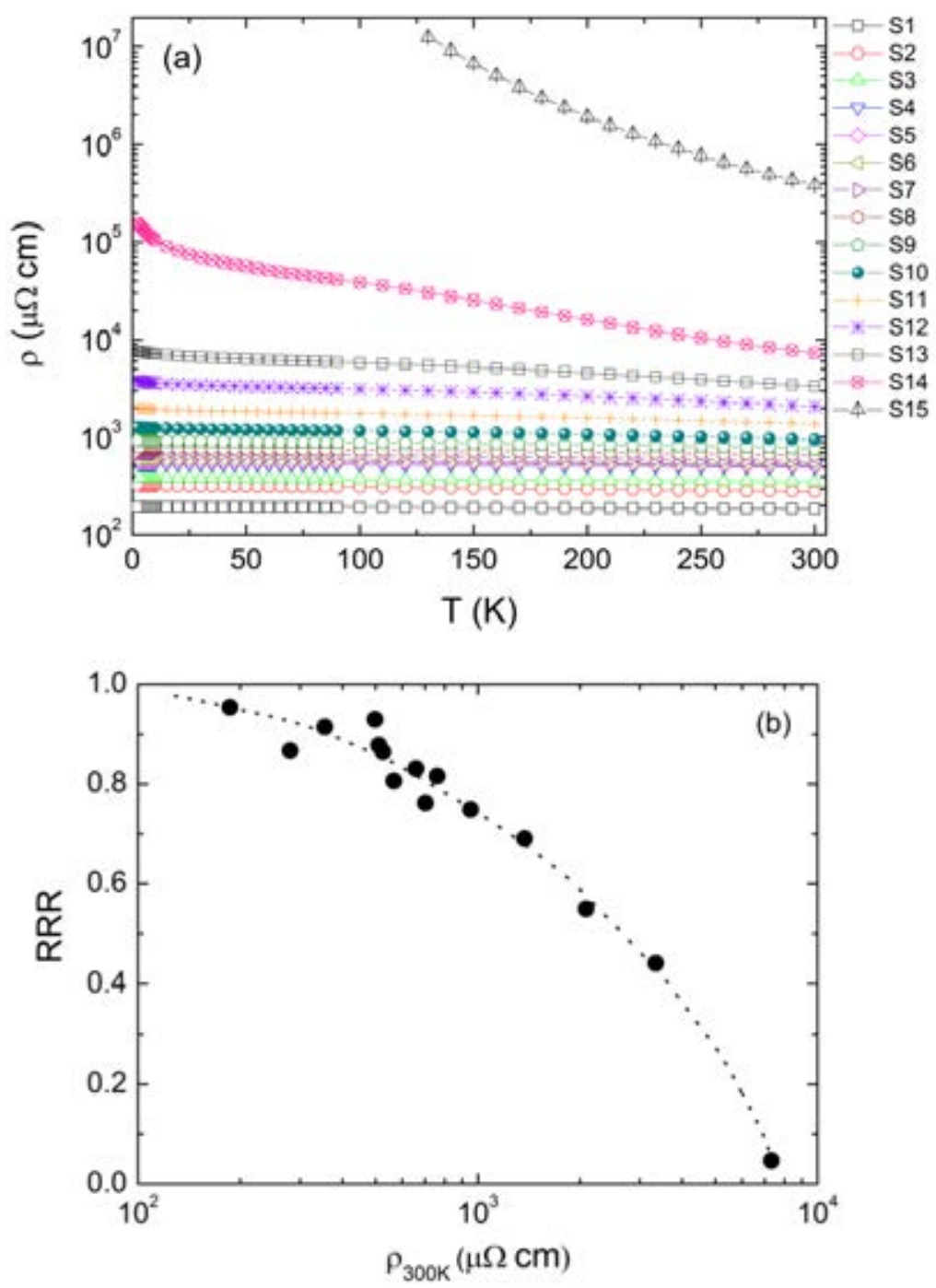

Figura 4.5: (a) Resistividad de los microhilos de Fe en función de la temperatura. (b) RRR de los microhilos de Fe en función de la resistividad a $300 \mathrm{~K}$.

A continuación, mostramos en la Figura 4.5(b), la dependencia del cociente de resistividad residual (RRR, definido como $\rho_{300 \kappa} / \rho_{2 K}$ ). Para S14, cuyo contenido de Fe es del $~ 56 \%$, $\rho$ aumenta más de un orden de magnitud de 300 a 2 K (RRR 0.05), mientras que las muestras de S1 a S4, con un contenido de Fe cercano al 70\%, $\rho$ apenas cambia con la temperatura (RRR 0.93). 
La resistividad en función del contenido de Fe a 300 y 150 K se representa en la Figura 4.6, poniéndose de manifiesto una clara correlación entre el contenido de Fe y la $\rho$ a ambas T. A medida que disminuye el contenido de Fe, la $\rho$ aumenta; la pendiente de la curva cambia drásticamente cuando el contenido de Fe es de alrededor del $~ 55 \%$. También hacemos una mención especial a la diferencia entre la $\rho$ a 300 y $150 \mathrm{~K}$, cuyo valor llega a ser más de un orden de magnitud cuando el contenido de Fe es inferior al 50\%. Este comportamiento es muy parecido al observado previamente por nuestro grupo en NWs de Pt crecidos mediante FIBID ${ }^{172}$, en cuyo trabajo se observó una transición de aislante a metal en función del cociente Pt/C.

El contenido de Fe en los depósitos desciende en favor del oxígeno como vimos en las Figuras 4.1(a) y 4.2(b), formándose cristales de $\mathrm{FeO}_{\mathrm{x}}$ potencialmente aislantes que incrementan el carácter aislante y por tanto, la resistividad de los depósitos ( $\rho$ óxidos de $\mathrm{Fe}>10^{5} \mu \Omega \mathrm{cm}$ ). El abrupto incremento de la resistividad en las muestras cuyo contenido de Fe es < 55\% se correspondería con la formación de cristales de $\mathrm{FeO}_{\mathrm{x}}$ como se han observado en las imágenes de HRTEM correspondientes a las Figuras 4.3(a) y (b). En este rango de concentración de Fe, la $\rho$ a temperatura ambiente es superior a $10^{3} \mu \Omega \mathrm{cm}$, valores similares a los del $\mathrm{Fe}_{3} \mathrm{O}_{4}$, alejándonos así del régimen de conducción metálica. En este caso, la contribución dominante al mecanismo de conducción es debida a los cristales aislantes de $\mathrm{FeO}_{\mathrm{x}}$ presentes en todo el microhilo. Éste sería el caso de S14 y S15 que se ajustan a la dependencia exponencial $\rho(T) \sim \rho_{0} \exp \left(T_{0} / T\right)^{1 / 2}$, indicando que el mecanismo de conducción puede ser explicado por el salto de rango variable, “variable range hopping” (VRH) de los electrones entre estados localizados, los cuales necesitan superar una barrera o energía de activación para pasar de un estado a otro. Los valores de $\rho$ en microhilos con un contenido de $\mathrm{Fe}>65 \%$ son inferiores a $550 \mu \Omega \mathrm{cm}$ (S1-S6), como es de esperar en un sistema denominado como "dirty metal". En ese rango del contenido de Fe, la conducción metálica se produce por la matriz Fe:O:C amorfa y metálica. Por otra parte, entre el 55\% y el 65\% de Fe (S7-S13), las muestras son completamente heterogéneas, con una mezcla de regiones unas veces dominadas por la matriz amorfa de Fe:O:C y en otras ocasiones por los óxidos de hierro aislantes, presentando una 
combinación de los mecanismos de conducción metálica y túnel. Los valores de resistividad para las muestras con un contenido de Fe superior al 60\% son menores que los valores de $\mathrm{Fe}_{2} \mathrm{O}_{3}$ y $\mathrm{Fe}_{3} \mathrm{O}_{4}$ publicados en la literatura ${ }^{173,174}$. Estos resultados demuestran que la conductividad se degrada progresivamente a medida que el contenido de Fe desciende, aproximándonos a una fase semi-aislante por debajo del $55 \%$. De este modo, las muestras con una concentración $>65 \%$ de Fe marcan el límite de la percolación metálica. El diferente cociente Fe/O y la microestructura hallados en los microhilos basados en Fe se traduce en una transición MIT con un cambio dramático en la dependencia de $\rho$ con la temperatura.

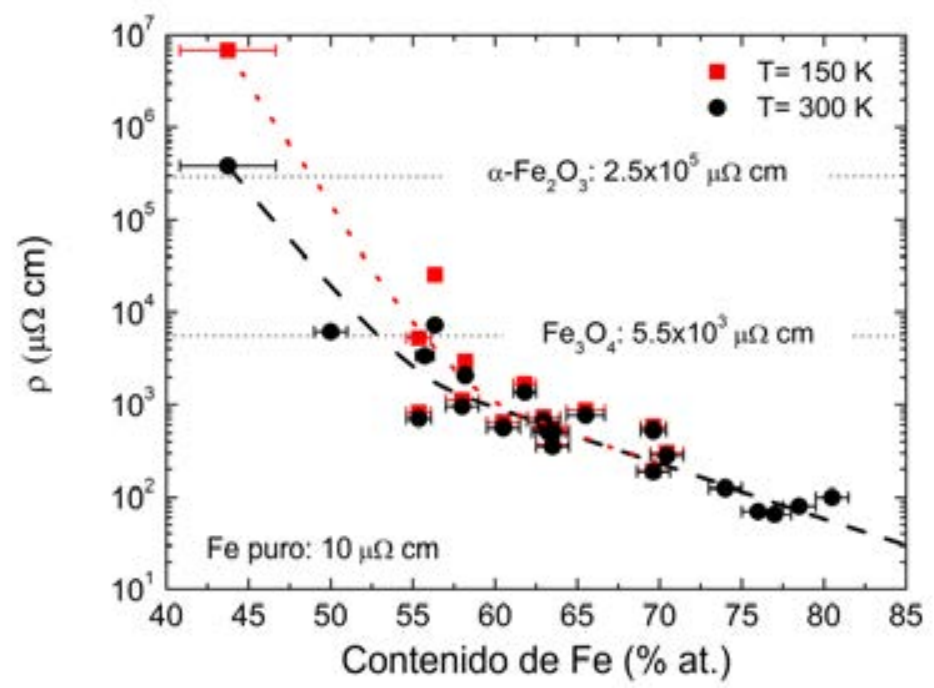

Figura 4.6: Resistividad de los microhilos de Fe a 300 y $150 \mathrm{~K}$ en función del contenido de Fe. Los valores de resistividad de los óxidos de Fe a $300 \mathrm{~K}$ están indicados. Las barras de error corresponden a la desviación estándar de los espectros analizados del contenido de Fe. 


\subsection{Propiedades magnéticas}

\subsubsection{MOKE y MR longitudinal}

La mejor forma de evaluar el potencial de las microestructuras basadas en $\mathrm{Fe}$ crecidas mediante FEBID es comparar su comportamiento magnético con el del Fe puro. Continuando en esa línea, se fabricaron muestras de Fe puro, como referencia, de dimensiones $12 \mu \mathrm{m} \times 0.5-1 \mu \mathrm{m} \times 30 \mathrm{~nm}$, $(\mathrm{l} \times \mathrm{a} \times \mathrm{e})$ usando procesos de litografía óptica, electrónica y crecimiento por “sputtering”. Las propiedades magnéticas a temperatura ambiente se determinaron utilizando la técnica de MOKE longitudinal tal y como se describió en el apartado 2.7.3 del Capítulo 2. Las medidas del apartado 4.5.1 se realizaron en la Eindhoven University of Technology (TU/e) en el marco de la colaboración ya mencionada.

En la Figura 4.7, se muestran unos diagramas explicativos de la configuración de medida de MOKE longitudinal en (a) y de la configuración de medida de la $\mathrm{MR}_{\text {long }}$ en (b)

(a)

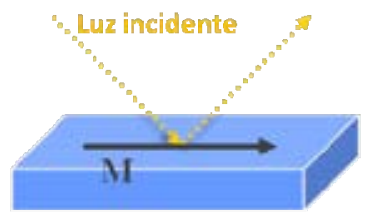

(b)

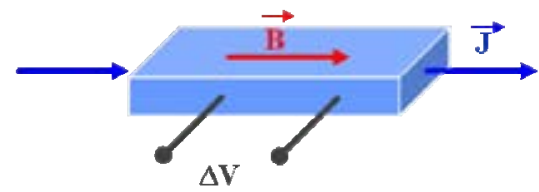

Figura 4.7: (a) Diagrama explicativo de la geometría utilizada para las medidas de MOKE longitudinal. La imanación está orientada en paralelo al plano de incidencia de la luz. (b) Diagrama explicativo de la geometría para las medidas de $\mathrm{MR}_{\text {long, }}$ el campo magnético se aplica en el plano de la estructura y en la misma dirección de la corriente. 

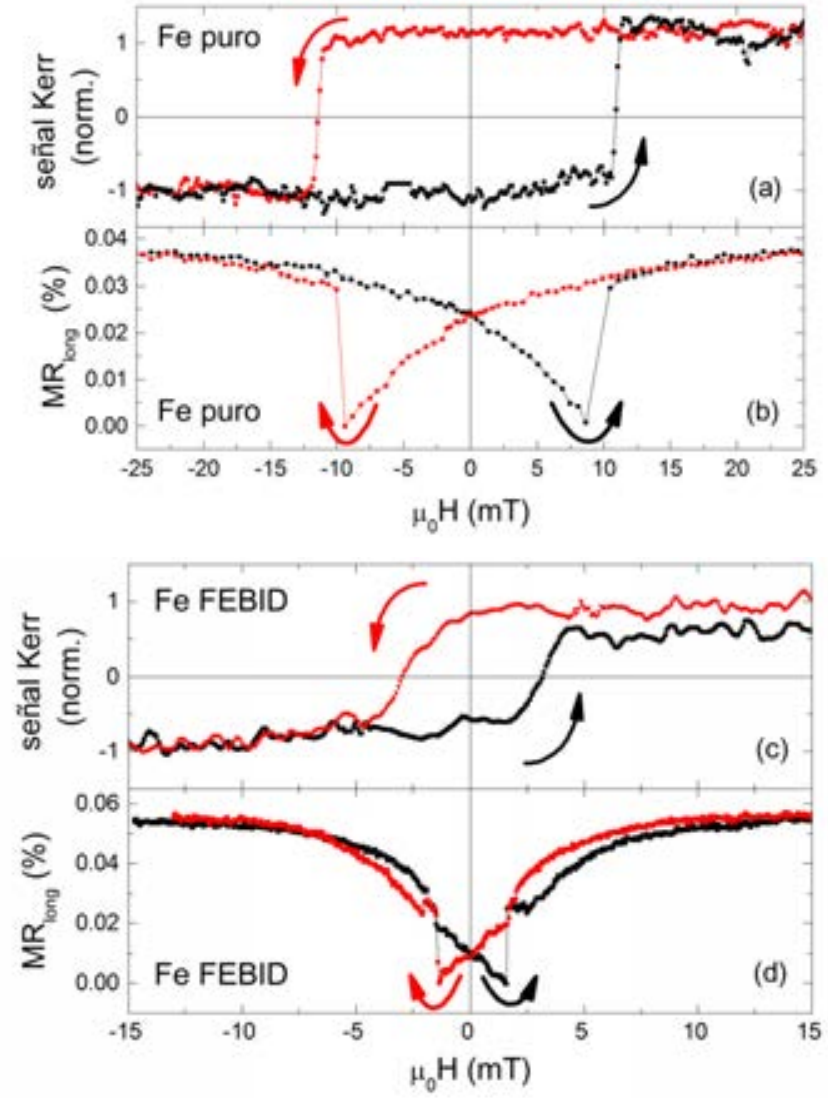

Figura 4.8: Medidas de $\operatorname{MOKE}$ (a) y (c) y $\mathrm{MR}_{\text {longitudinal }}$ (b) y (d) en función del campo magnético aplicado. (a) y (b) corresponden a una muestra de referencia de Fe puro y (c) y (d) a un microhilo de Fe crecido mediante FEBID de composición: Fe:72 O:15 C:13. Las flechas indican la dirección de barrido del campo.

En la Figura 4.8 comparamos las medidas de MOKE y MR longitudinal en función del campo magnético aplicado a lo largo del eje largo de la estructura entre un microhilo de Fe puro, mostradas en (a) y (b) y un microhilo de Fe crecido mediante FEBID de composición: Fe:72 O:15 C:13, mostradas en (c) y (d). En (a), se observa un ciclo de histéresis MOKE cuadrado como se espera en las estructuras de Fe puro con el eje fácil a lo largo del eje largo de la estructura. Mientras que en (b), se representa la MR longitudinal de la misma estructura definida como, $\mathrm{MR}_{\text {long }} \%=100 \times$ $\left[\rho(H)-\rho_{\min }\right] / \rho_{\min }$. La MR detectada es atribuida al efecto de la magnetorresistencia 
anisótropa (AMR), bien conocida para metales de transición ${ }^{175}$. La AMR refleja la dependencia de la resistencia de la muestra con el ángulo formado por la corriente y el campo magnético aplicado. En este caso, la resistencia es mayor si ambos son paralelos y menor cuando están sometidos a un ángulo. A altos campos, todos los momentos o dominios magnéticos se alinean con la corriente (a lo largo del eje largo del hilo) dando una alta resistencia, mientras que cuando el campo magnético se reduce, la estructura magnética se relaja hacia una situación energéticamente más favorable (estado multi-dominio) en la que la dirección de la imanación deja de estar alineada con la dirección de la corriente, produciéndose una resistencia más pequeña. Eventualmente, cuando el campo cambia de signo y se aumenta, la dirección de la imanación vuelve a alinearse con la de la corriente aunque en sentido opuesto, correspondiendo al ciclo de histéresis medido con MOKE en (a).

Los resultados analizados en los microhilos de Fe crecidos mediante FEBID se muestran en las Figuras 4.8(c) y (d). Respecto a la medida de MOKE, el primer hecho en el que reparamos es que el cociente señal-ruido es bajo. Esto puede ser atribuido al bajo contenido de Fe, al ancho relativamente pequeño del microhilo ( 0.5-1 $\mu \mathrm{m})$ comparado con el diámetro del láser $(2 \mu \mathrm{m})$ y a la superficie redondeada del depósito, que puede descender la eficiencia de la señal Kerr. Incluso con estas limitaciones experimentales, observamos un ciclo de histéresis claro, pero con cambio gradual indicando un eje fácil menos definido comparado con el de la estructura de Fe puro. La $\mathrm{MR}_{\text {long }}$ medida en (d) presenta un comportamiento similar al de la estructura de Fe puro, es el paradigma de una combinación entre la rotación gradual de la imanación y el volcado rápido de la imanación. Comparado con la medida del microhilo de Fe puro (b), observamos pequeños saltos adicionales en la señal, correspondientes al desplazamiento de las paredes de dominio a diferentes campos magnéticos. Además, el relativo descenso de la $\mathrm{MR}_{\text {long }}$ en remanencia comparado con el Fe puro podría indicar la presencia de una estructura de dominios magnéticos más compleja durante el proceso de giro de la imanación. La primera conclusión de la medida de MOKE y del ciclo de histéresis observado en la medida de $\mathrm{MR}_{\text {long }}$ es que ambas indican que los microhilos de Fe FEBID presentan un genuino comportamiento ferromagnético. 
Para investigar en detalle el proceso de giro de la imanación analizado en la Figura 4.8(d), se ha realizado microscopía Kerr de campo ancho en una muestra comparable de Fe FEBID en cuanto sus propiedades magnéticas, aunque de mayor tamaño, $100 \mu \mathrm{m} \times 120 \mu \mathrm{m} \times 160 \mathrm{~nm}, \mathrm{l} \times$ a $\times$ e, debido a la resolución de la técnica debida al límite de difracción por la longitud de onda empleada ( 400 nm).

En la Figura 4.9(a) mostramos un ciclo de histéresis de esta muestra midiendo la intensidad de la luz en imágenes de microscopía Kerr de campo de trabajo ancho en función del campo magnético aplicado. Los recuadros en (a) indican las imágenes Kerr tomadas cuándo la imanación de la muestra está saturada en la dirección del campo aplicado. La escala de gris/negro nos otorga el contraste magnético en la muestra. En (b) y (c), podemos advertir la estructura de dominios en el estado de remanencia indicado en (a), para la dirección longitudinal en (b) y transversal en (c). Estas direcciones en las que se mide la intensidad Kerr se indican mediante las líneas punteadas. En (b), dibujamos la estructura de dominios que se puede deducir del contraste observado en la intensidad Kerr longitudinal y en (c) la correspondiente transversal. Así, comprobamos la estructura típica de cierre de dominios magnéticos, confirmando una vez más el comportamiento ferromagnético de las estructuras de Fe crecidas por FEBID. Además, podemos observar una compleja estructura de pequeños dominios en los extremos de la película; probablemente debido al ligeramente distinto espesor de la película en esos extremos u otros defectos. Por consiguiente, el complejo ciclo de histéresis y la baja MR en el estado de remanencia mostrada en la Figura 4.8(d), pueden ser explicados por la formación de varios dominios magnéticos durante el cambio de la imanación como se observa en la Figura 4.9(b). 

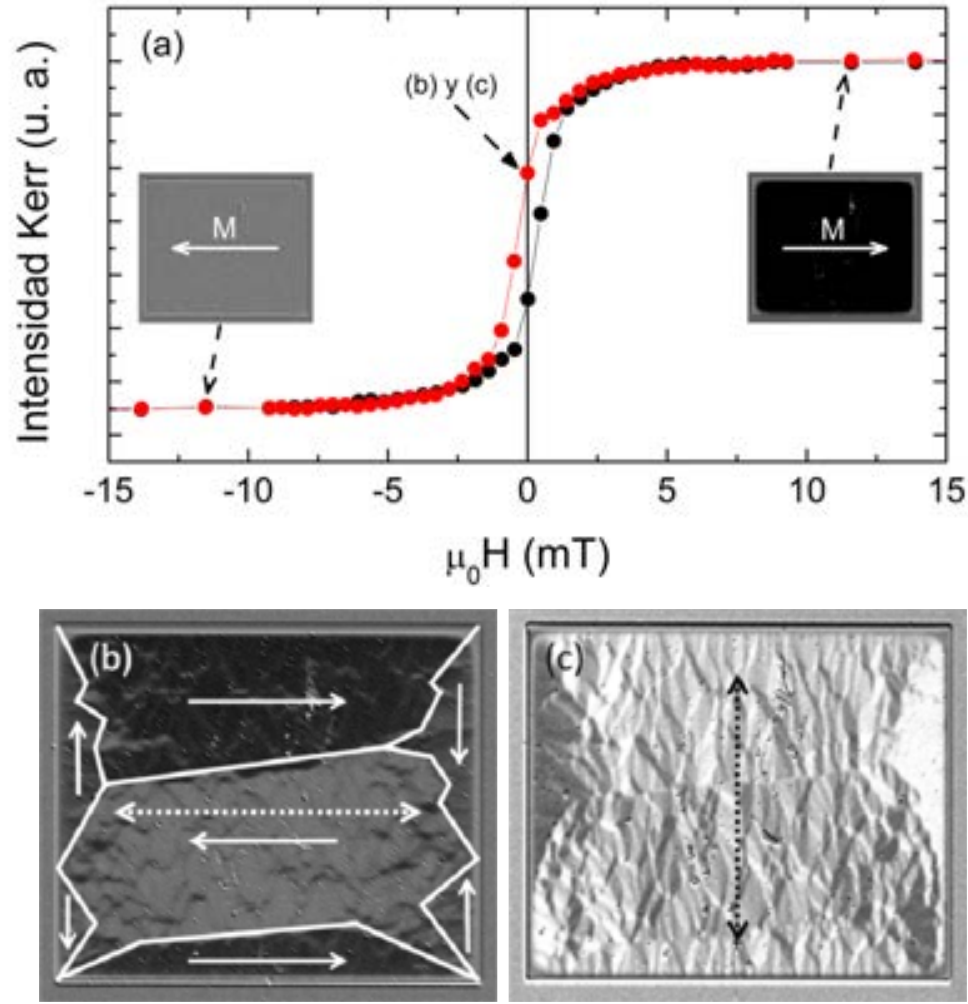

Figura 4.9: (a) Ciclo de histéresis obtenido de la intensidad de la luz mediante imágenes tomadas con un microscopio Kerr de campo ancho (sensibilidad longitudinal) en función del campo aplicado a lo largo del eje largo de la estructura. Los recuadros muestran imágenes Kerr tomadas cuando la imanación de la película está saturada en la dirección del campo aplicado; la escala de grises/negro indica el contraste magnético. (b) Imagen de sensibilidad Kerr longitudinal (flecha punteada) tomada en el estado de remanencia indicado en (a). La estructura de cierre de dominios se ha indicado con flechas continuas. (c) Imagen de sensibilidad Kerr transversal (flecha punteada) tomada en el estado de remanencia indicado en (a).

\subsubsection{Dependencia de la MR perpendicular con la temperatura}

Con el objetivo de evaluar el comportamiento magnético de los quince microhilos de Fe (analizados en el apartado 4.4 del presente Capítulo) a distintas temperaturas, se ha estudiado la dependencia de la MR con el campo magnético aplicado perpendicular al sustrato (de \pm 9 T) calculada a partir de la ecuación (1.3). 
En la Figura 4.10, presentamos un diagrama y una imagen SEM de la geometría de la configuración utilizada para las medidas de la $\mathrm{MR}_{\perp}$. Teniendo en cuenta las dimensiones de los microhilos, asumimos la rotación coherente de la imanación bajo el campo magnético aplicado.

(a)

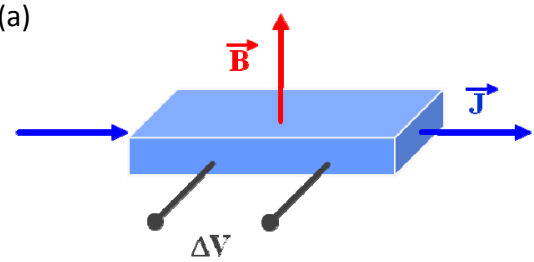

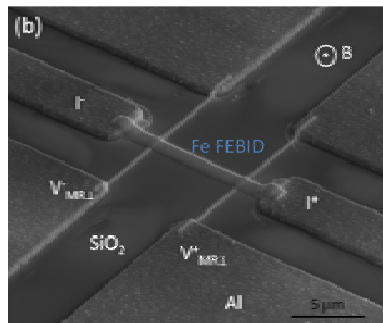

$\odot^{8}$

Figura 4.10: (a) Diagrama explicativo de la geometría para las medidas de $\mathrm{MR}_{\perp}$, dónde el campo magnético se aplica fuera del plano y perpendicular a la estructura. (b) Imagen SEM de la configuración de medidas $\mathrm{MR}_{\perp}$.

$\mathrm{La} \mathrm{MR}_{\perp}$ de las cuatro muestras más representativas se traza en la Figura 4.11. En (a), indicamos la $\mathrm{MR}_{\perp}$ de $\mathrm{S} 1$, microhilo con menor $\rho$. Este tipo de microhilo necesita un cierto campo magnético para que todos los momentos magnéticos se alineen fuera del plano. El campo necesario depende de la geometría del depósito y de la imanación de saturación (campo de desimanación). $L a \mathrm{MR}_{\perp}$, combinada con la $\mathrm{MR}_{\text {long }}$ presentada en la Figura 4.8 (d) claramente indica el efecto de la magnetorresistencia anisótropa (AMR). La $\mathrm{MR}_{\perp}$ es constante a altos campos ( $>2 \mathrm{~T}$ ) debido a que los momentos magnéticos que componen el depósito han alcanzando el valor de la imanación de saturación en la dirección perpendicular al plano. A campos entre $\pm 2 \mathrm{~T}$, los momentos magnéticos vuelven de la saturación fuera del plano, la $\mathrm{MR}_{\perp}$ tiene una dependencia cuadrática con el campo, como se espera de la rotación coherente de la imanación ${ }^{176}$. Un incremento en el valor negativo de AMR se observa cuando la temperatura desciende: $\operatorname{AMR}(300 \mathrm{~K})=-0.59 \%$ y $\operatorname{AMR}(10 \mathrm{~K})=-0.91 \%$. La presencia de la señal de AMR pura en la $\mathrm{MR}_{\perp}$ es una fuerte evidencia de la percolación del Fe en la matriz 
amorfa del microhilo S1. Sin embargo, el valor de la AMR es elevado comparado con el valor de Fe puro, $-0.2 \%{ }^{177}$. Esto puede ser explicado teniendo en cuenta la microestructura de los NWs, compuestos por una matriz amorfa de (Fe:C:O) con pequeños cristales de $\alpha$-Fe (tamaño 1-2 nm) ${ }^{121}$. Los átomos de Fe, que ocupan muchas posiciones en la superficie/interfase, son menos proclives a sufrir efectos de aniquilamiento del momento orbital producidos por el campo eléctrico de la red cristalina y darán lugar a un mayor acoplamiento espín-órbita. Este aumento del acoplamiento espín-órbita puede ser la base de la elevada AMR en este sistema desordenado. Se observó un fuerte descenso de la AMR cuando incrementamos la temperatura de 10 a $300 \mathrm{~K}$, lo cual también indica que los efectos debidos a fluctuaciones térmicas son elevados en sistemas con efectos pronunciados de interfase o átomos magnéticos con un enlace defectuoso ${ }^{70}$. La $\mathrm{MR}_{\perp}$ de S9 se representa en la Figura 4.11(b), mostrando tanto efectos de AMR como de ITMR. La ITMR es debida a la polarización del espín de los electrones y se produce por el tipo de transporte que se establece entre los granos metálicos en materiales ferromagnéticos granulares, siendo a veces difícil saturar incluso sometidos a altos campos magnéticos ${ }^{178}$. La ITMR se observa cuando el transporte eléctrico se produce debido al efecto túnel entre granos magnéticos. La probabilidad de que esto ocurra depende de la orientación magnética relativa de las interfases de esos granos. $\mathrm{La} \mathrm{MR}_{\perp}( \pm 9 \mathrm{~T})$ es $-0.37 \%$ a $300 \mathrm{~K}$ y $-0.66 \%$ a $100 \mathrm{~K}$, llegando a ser independiente de la temperatura por debajo de 100 K. Así, la $\mathrm{MR}_{\perp}$ es dominada por la $\mathrm{AMR}$ a altas temperaturas, de 300 a $200 \mathrm{~K}$ la $\mathrm{MR}_{\perp}$ está completamente saturada a $1.5 \mathrm{~T}$. Sin embargo, en el rango entre 150 y $25 \mathrm{~K}$, ambos efectos AMR y ITMR coexisten. Por debajo de $150 \mathrm{~K}$, la $\mathrm{MR}_{\perp}$ no satura al máximo campo aplicado, $\pm 9 \mathrm{~T}$, como se observó en materiales con $\mathrm{MR}_{\perp}$ dominada por el ITMR ${ }^{70}$. Este hecho está bien correlacionado con la microestructura en este rango de composición, formada por granos de Fe y óxidos de Fe embebidos en la matriz Fe:O:C.

En las muestras más resistivas, S12 y S13, podemos ver un comportamiento completamente diferente en las Figuras 4.11(c) y (d), respectivamente. El valor de la $\mathrm{MR}_{\perp}$ no llega a saturar al campo máximo que puede aplicar nuestro sistema ( $\pm 9 \mathrm{~T}$ ). 
Este comportamiento puede ser atribuido a la ITMR asociado a sistemas $\mathrm{FeO}_{\mathrm{x}}$ granulares ${ }^{179}$.

S $1 ; \rho=186 \mu \Omega \mathrm{cm} ; \mathrm{Fe}: \mathrm{C}: 0$ 70:8:22

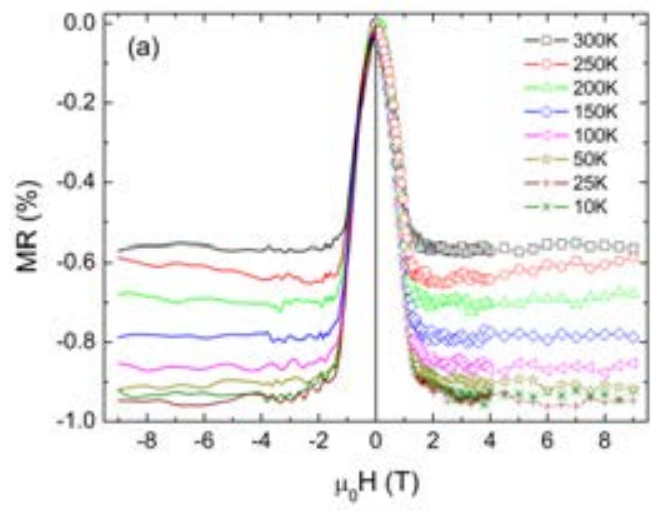

S 12; $\rho=2082 \mu \Omega \mathrm{cm} ; \mathrm{Fe}: \mathrm{C}: 0$ 58:6:36

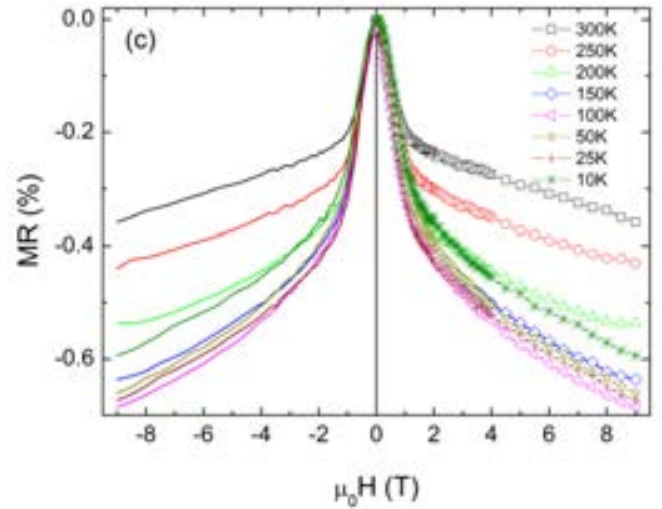

S 9; $\rho=760 \mu \Omega \mathrm{cm} ;$ Fe:C:O 66:9:25

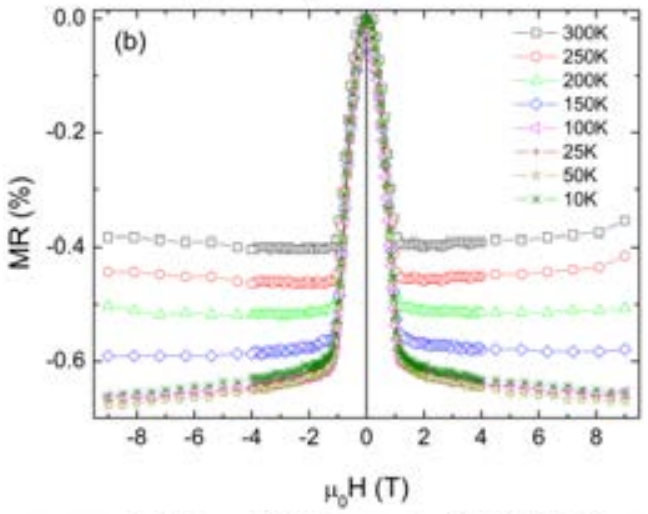

S $14 ; \rho=7306 \mu \Omega \mathrm{cm} ;$ Fe:C:O $56: 6: 38$

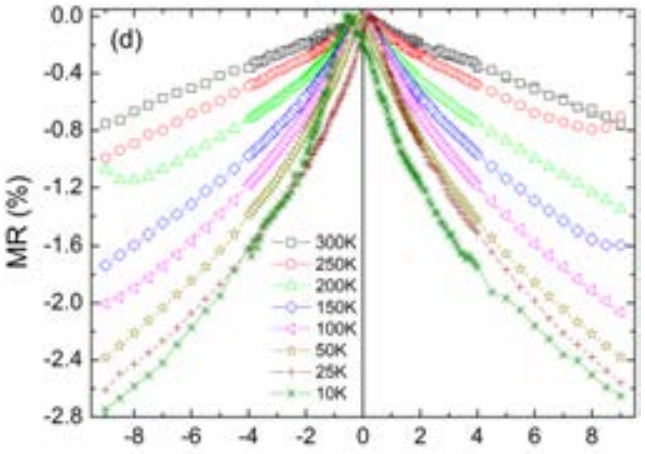

$\mu_{0} \mathrm{H}(\mathrm{T})$

Figura 4.11: $\mathrm{MR}_{\perp}$ a diferentes temperaturas en función del campo magnético aplicado de cuatro muestras representativas. (a) S1; (b) S9; (c) S12; (d) S14. S1 y S12 se midieron exclusivamente a campos magnéticos positivos; por ello dibujamos una línea a modo de guía visual indicando la $\mathrm{MR}_{\perp}$ extrapolada a los valores negativos.

En estos microhilos resulta muy difícil alinear la imanación de las interfases de estos granos con el campo magnético externo y se observa una pendiente lineal a alto campo. Un incremento de la $\mathrm{MR}_{\perp}$ de $\mathrm{S} 12$ se obtiene al descender la temperatura, la $\mathrm{MR}_{\perp}(300 \mathrm{~K})=-0.36 \%$ y la $\mathrm{MR}_{\perp}(100 \mathrm{~K})=-0.69 \%$, pero por debajo de $100 \mathrm{~K}$ permanece constante. Asumiendo el efecto dominante de la ITMR en este microhilo, 
como el valor de la $\rho$ es cercano al límite metálico establecido por la teoría de MottAnderson para materiales no cristalinos $(\rho=3000 \mu \Omega \mathrm{cm}){ }^{180}$, concluimos que S12 no presenta un mecanismo de conducción metálico. Una discusión similar podemos realizar para la S14, en la cual el dominio del efecto de la ITMR es incluso más evidente, con una MR de $-2.7 \%$ a $10 \mathrm{~K} \mathrm{y} \pm 9 \mathrm{~T}$. El efecto de la ITMR domina en estos microhilos debido a un aumento en el contenido de $\mathrm{O}(\mathrm{Fe} / \mathrm{O}=1.61)$, el cual sugiere la presencia de una significativa suma de granos de $\mathrm{FeO}_{\mathrm{x}}$ semi-aislantes en el NW.
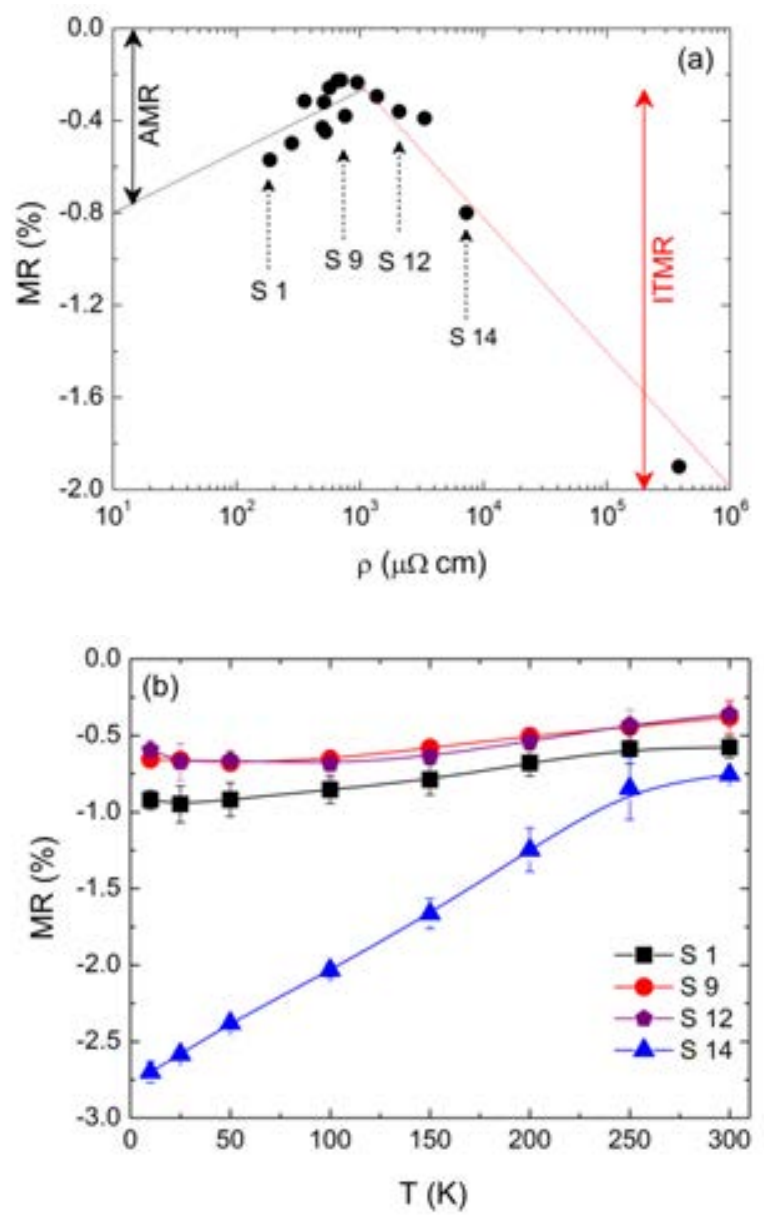

Figura 4.12: (a) $\mathrm{MR}_{\perp}$ de los microhilos de Fe estudiados en función de la resistividad a temperatura ambiente, los microhilos mostrados en la Figura 4.11 están señalados con flechas. (b) $\mathrm{MR}_{\perp}$ de los microhilos de Fe mostrados en la Figura 4.11 en función de la temperatura. Los valores de AMR e ITMR se determinaron a $\pm 9 \mathrm{~T}$. 
En la Figura 4.12(a) representamos la $\mathrm{MR}_{\perp}$ en función de la $\rho_{300 \mathrm{~K}}$ y señalamos las cuatro muestras que tomamos como representativas (Figura 4.11) mediante flechas. Los valores de la AMR y la ITMR se determinaron a $\pm 9 \mathrm{~T}$. Se observa una dependencia clara, evolucionando desde la $\mathrm{MR}_{\perp}$ gobernada principalmente por la AMR para microhilos con moderada $\rho$ hasta altas ITMR para microhilos de alta resistividad. La AMR es originada por la dispersión de electrones debido al acoplamiento espín-órbita, mientras que la ITMR es motivada por el mecanismo de conducción túnel entre los granos con polarización de espín de los electrones.

Por último, en la Figura 4.12(b) se representa la $\mathrm{MR}_{\perp}$ a $\pm 9 \mathrm{~T}$ de las cuatro muestras en las que hemos centrado el estudio en función de la temperatura. Los efectos térmicos se hacen más evidentes en muestras en las que la $\mathrm{MR}_{\perp}$ es dominada por el efecto de la ITMR. Esto es probablemente una consecuencia directa del mecanismo del efecto túnel en el cual las interfases entre granos son decisivas ${ }^{178}$. En el caso de muestras dominadas por la AMR, la influencia de la temperatura es menos decisiva y puede provenir de cambios en la dispersión fonón-electrón, combinado con las fluctuaciones térmicas actuando sobre átomos magnéticos en la interfase de la matriz amorfa.

Resumiendo esta sección, los microhilos basados en Fe presentan una transición MIT definida por su contenido de Fe y microestructura. Consecuentemente, el comportamiento de la $\mathrm{MR}_{\perp}$ presenta una transición gradual desde la AMR a la ITMR al descender el cociente $\mathrm{Fe} / \mathrm{O}$, el cual puede ser correlacionado con la resistividad del microhilo. El elevado valor de $\mathrm{MR}_{\perp}$ comparado con las películas de Fe puro ${ }^{176}$ indica que la dispersión de electrones está realzada en los microhilos de Fe crecidos mediante FEBID. Como se mostrará en el siguiente apartado, este hecho tiene un extraordinario impacto en el efecto Hall. 


\subsubsection{Estudio del efecto Hall gigante}

El estudio del efecto Hall en materiales magnéticos nos facilita información útil sobre los procesos de dispersión de electrones, la concentración de portadores y los procesos de imanación en función del campo magnético. La resistividad Hall viene definida por la expresión (1.4).

En la Figura 4.13, representamos un diagrama y una imagen SEM de la geometría utilizada en las medidas realizadas del efecto Hall.
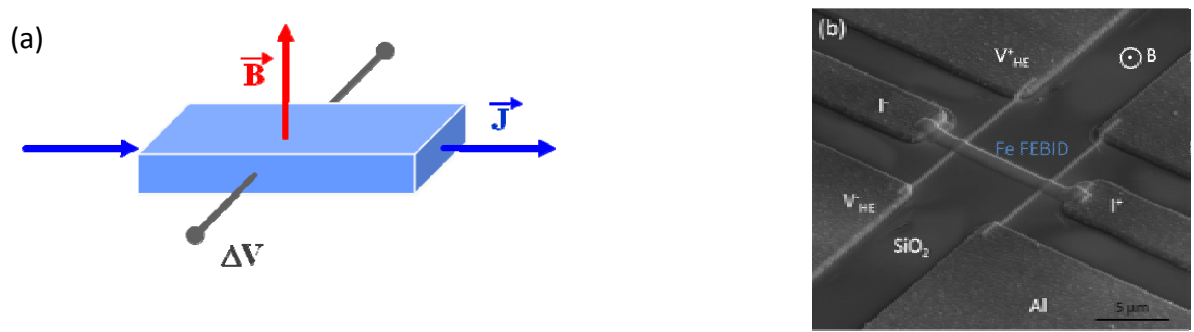

Figura 4.13: (a) Diagrama explicativo de la geometría utilizada en las medidas del efecto Hall. (b) Imagen SEM de la configuración de medida utilizada.

Con el objetivo de continuar el análisis del comportamiento magnético de los quince microhilos de Fe a distintas temperaturas, se realiza un estudio sistemático del efecto Hall en un amplio rango de temperaturas.

La contribución ordinaria se determinó ajustando la pendiente a altos campos magnéticos, una vez alcanzada la saturación magnética. La contribución anómala se determinó a bajos campos magnéticos extrapolando la pendiente a $\mu_{0} \mathrm{H}=0$. Del punto de coincidencia de los ajustes lineales para el OHE y el AHE encontramos el campo de anisotropía $\mathrm{NM}_{\mathrm{S}}, \mathrm{N}$ es el factor desimanador perpendicular al plano del microhilo estimado entre [0.73-0.86] y $\mathrm{M}_{\mathrm{S}}$ es la imanación de saturación ${ }^{181}$, una vez alcanzada la saturación magnética. En la Figura 4.15(a), vemos como la $\rho_{\mathrm{H}}$ aumenta a bajos campos hasta que se alcanza la imanación de saturación. Los ajustes de OHE y AHE están indicados mediante líneas punteadas para la isoterma de $10 \mathrm{~K}$. Los valores de $\mathrm{M}_{\mathrm{S}}$ 
se extraen mediante este método y obtenemos una dependencia clara de la $\mathrm{M}_{\mathrm{S}}$ a $300 \mathrm{~K}$ en función de la $\rho$ longitudinal, como se representa en la Figura 4.14. Como era esperable, la $M_{\mathrm{S}}$ desciende en función de la $\rho$ longitudinal, de $1371 \pm 16 \mathrm{emu} / \mathrm{cm}^{3}$ hasta $706 \pm 20 \mathrm{emu} / \mathrm{cm}^{3}$. Las barras de error se corresponden a las desviaciones estándares obtenidas en diferentes ajustes de las pendientes. Comparando con el Fe puro $\left(\mathrm{M}_{\mathrm{S}}=1700 \mathrm{emu} / \mathrm{cm}^{3}\right)$ y con óxidos de $\mathrm{Fe}\left(\mathrm{M}_{\mathrm{S}} \sim 300-600 \mathrm{emu} / \mathrm{cm}^{3}\right)$ podemos observar que el momento magnético por átomo de Fe de estas muestras se parece al del Fe puro, ya que la $\mathrm{M}_{\mathrm{S}}$ escala aproximadamente con el contenido de $\mathrm{Fe}$ (70\% de $\left.1700 \mathrm{emu} / \mathrm{cm}^{3}=1190 \mathrm{emu} / \mathrm{cm}^{3}\right)$.

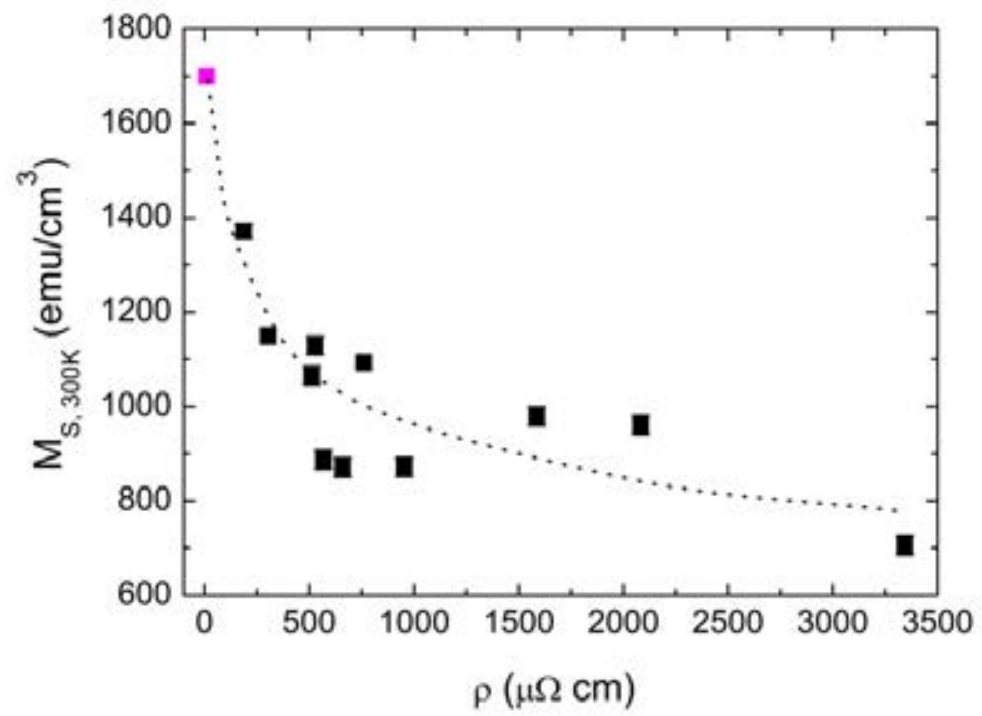

Figura 4.14: Imanación de saturación a temperatura ambiente de los microhilos de Fe en función de su resistividad; evaluada a través del análisis de las medidas del AHE. Las barras de error se precisaron a partir de diferentes ajustes de la pendiente de curva $\rho_{\mathrm{H}}$ frente a $\mu_{0} \mathrm{H}$. El valor de la $\mathrm{M}_{\mathrm{S}}$ (Fe puro)= $1700 \mathrm{emu} / \mathrm{cm}^{3}$ se indica en la gráfica por un cuadrado rosa. La línea punteada es una guía visual que comienza en la $\mathrm{M}_{\mathrm{S}}$ del Fe puro. 
Resultados anteriores del efecto Hall anómalo en películas de Fe indican que la magnitud de este efecto se correlaciona con la resistividad de la muestra ${ }^{117}$, tal y como observamos en nuestro caso.
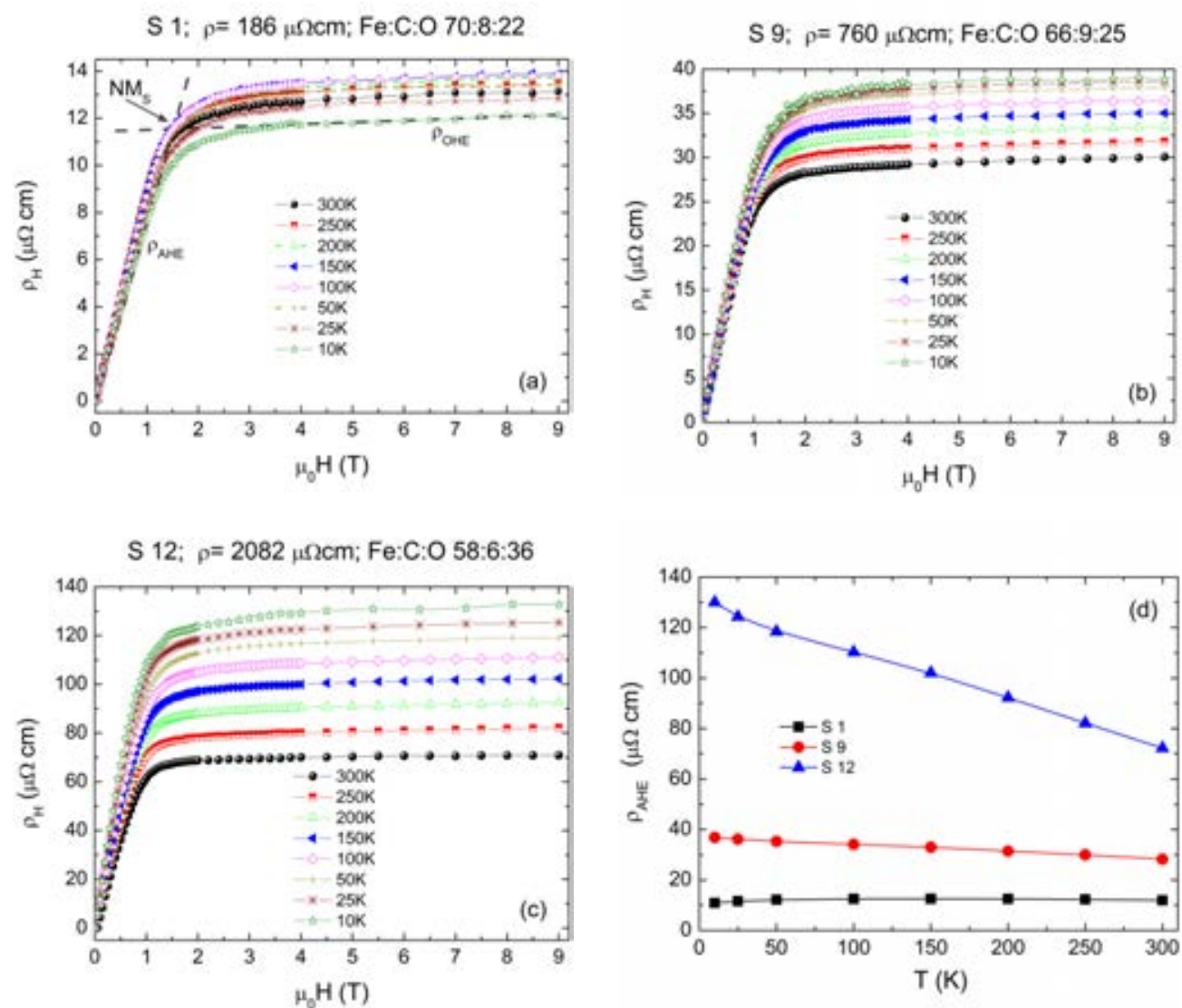

Figura 4.15: Resistividad Hall en función del campo magnético aplicado a diferentes temperaturas. La $\rho_{\mathrm{OHE}}$ se determina a altos campos, mientras que $\rho_{\mathrm{AHE}}$ se calcula extrapolando la pendiente OHE a campo cero. De la intersección de los ajustes lineales se obtiene el valor de $\mathrm{NM}_{\mathrm{S}}$ ( $\mathrm{N}$ es el factor desimanador, $\mathrm{M}_{\mathrm{S}}$ la imanación de saturación), un ejemplo se muestra en (a) para S1 a $10 \mathrm{~K}^{133}$. (a) S1; (b) S9; (c) S12; (d) Resistividad Hall anómala a $2 \mathrm{~T}$ en función de la temperatura en los microhilos mostrados en (a)-(c).

Sin embargo, la principal información extraída de las medidas del efecto Hall proviene del análisis del AHE en términos de los procesos de dispersión de los 
electrones. El primer resultado destacable es el elevado valor de $\rho_{\mathrm{H}}$ en los tres microhilos (en el rango de 10-150 $\mu \Omega \mathrm{cm}$ ) cuando los comparamos con los valores obtenidos en películas de $\mathrm{Fe}$ epitaxial ${ }^{117}$, microhilos de $\mathrm{Fe}^{170}$ y películas de $\mathrm{Fe}$ oxidado $^{177}$. De hecho, incluso en películas de Fe epitaxial con una realzada dispersión debido a efectos de superficie, la $\rho_{\mathrm{H}}$ nunca es superior a $5 \mu \Omega \mathrm{cm}^{117}$. En las películas de Fe oxidado, la $\rho_{\mathrm{H}}$ es del orden de $1 \mu \Omega \mathrm{cm}^{177}$. Por otra parte, en películas delgadas y epitaxiales de $\mathrm{Fe}_{3} \mathrm{O}_{4}$ (espesor $<40 \mathrm{~nm}$ ) se ha observado un gran AHE a temperatura ambiente ( $\rho_{\mathrm{H}} \sim 10-40 \mu \Omega \mathrm{cm}$ ), efecto que fue atribuido a un aumento del efecto de la dispersión de electrones debido a defectos de frontera de grano, ("antiphase boundaries") formados durante el crecimiento de las películas sobre sustratos de MgO $(001)^{173}$. Aunque el AHE en los NWs de Fe debería ser normalmente pequeño $(<1$ $\mu \Omega \mathrm{cm}$ ), mecanismos adicionales de la dispersión de los electrones podrían dar lugar al aumento del AHE. Ciertamente, esta hipótesis resulta muy interesante debido a que la apropiada adaptación de la microestructura y composición de los NWs de Fe podría resultar en un AHE gigante (GAHE). El GAHE observado en los microhilos de Fe fabricados mediante FEBID es debido a la naturaleza heterogénea y desordenada de los depósitos. Primero, la microestructura ampliará la dispersión de los electrones dentro de la matriz amorfa ya que el recorrido libre medio de los electrones se verá fuertemente reducido en los materiales amorfos. Segundo, la presencia de pequeños granos de Fe y óxidos de Fe será otra de las fuentes de la dispersión de los electrones observada en materiales ferromagnéticos granulares ${ }^{182}$. Es bien conocido que el valor de AHE generalmente aumenta con la resistividad longitudinal en el supuesto de que el grado de ferromagnetismo se mantenga ${ }^{71}$. Así, nosotros argumentamos que la explicación para el GAHE observado en nuestras muestras se genera por su microestructura, la cual produce un exceso en la dispersión de los electrones. Algunos de estos procesos de dispersión de los electrones serán dependientes del espín, contribuyendo al GAHE.

La primera clave en el origen de la GAHE observada, es su fuerte dependencia con la resistividad longitudinal, como se representa en la Figura 4.16(a). En una primera aproximación, se observa una dependencia lineal, sugiriendo el mecanismo de 
"skew scattering" como fuente de la GAHE. En este mecanismo extrínseco, la conducción de los electrones sufre procesos de dispersión que dependen del espín debido a la interacción espín-órbita, modificándose su trayectoria un cierto ángulo, positivo para una dirección del espín y negativo para la otra dirección ${ }^{72,73}$. En el caso de los microhilos de Fe, la fuente de este tipo de dispersión serán las impurezas magnéticas en forma de pequeños granos de Fe y de óxidos magnéticos de Fe con una cierta distribución de composición en la matriz de Fe:O:C amorfa.

Debido a la naturaleza heterogénea de estos depósitos de Fe, es complicado proponer un modelo detallado para realizar un análisis cuantitativo de los datos. Sin embargo, Gerber y sus colaboradores ${ }^{182}$ encontraron un camino para modelizar este tipo de sistemas heterogéneos asumiendo que la resistividad longitudinal sigue la regla de Matthiesen, $\rho_{\mathrm{xx}}=\rho_{0}+\rho_{\mathrm{s}}, \rho_{0}$ contiene fuentes de "ballast scattering”, lo cual no contribuye al "skew scattering”, y $\rho_{\mathrm{s}}$ contiene procesos de dispersión que contribuyen al "skew scattering”. Así, la resitividad debida al AHE puede ser expresada mediante la siguiente ecuación (4.1):

$$
\rho_{\mathrm{AHE}}=\gamma \rho_{0} \rho_{\mathrm{S}}+\gamma \rho_{\mathrm{S}}^{2}
$$

En este modelo, el "skew scattering” proporciona tanto los términos lineales como al cuadrado respecto a $\rho_{\mathrm{S}}$. Como consecuencia, la variación del AHE de muestra a muestra y en función de la temperatura será principalmente determinada por los cambios correspondientes a $\rho_{0}$ y $\rho_{\mathrm{s}}$.

Los microhilos seleccionados muestran un comportamiento diferente en este sentido. S12, con una elevada resistividad longitudinal, tendrá una mayor contribución de $\rho_{0}$ que de $\rho_{\mathrm{S}}$. Cuando esto ocurre $\left(\rho_{\mathrm{S}}<<\rho_{0}\right)$, la ecuación (4.1) se aproxima a $\rho_{\mathrm{AHE}} \approx$ $\gamma \rho_{0} \rho_{\mathrm{S}} \propto \rho_{\mathrm{xx}}$. Una dependencia lineal aproximada se espera entre el AHE y la resistividad longitudinal (principalmente debida a los centros de "ballast scattering”), como se observa en la Figura 4.16(a). Además, $\rho_{\mathrm{S}}$ no varía significativamente con la temperatura y es el término $\rho_{0}$ el que gobierna la dependencia de AHE con la 
temperatura. Sin embargo, el término cuadrático de la expresión (4.1) no puede ser omitido en las muestras S1 y S9, ecuación en la cual la resistividad longitudinal es significativamente menor y se espera que el término $\rho_{\mathrm{S}}$ contribuya de una forma más importante al valor total de la $\rho_{\mathrm{xx}}$. Este efecto es ilustrado a través del análisis de los resultados en S1, el microhilo que presenta la menor resistividad longitudinal. En la Figura 4.16(b), la $\rho_{\mathrm{H}}$ de esta muestra revela un máximo alrededor de $125 \mathrm{~K}$. Esto puede ser plausiblemente explicado por la contribución relativa de los términos lineal y cuadrático en la fórmula (4.1). Se espera que $\rho_{0}$ aumente con la temperatura debido al incremento de la dispersión del electrón-fonón. Esto explica el incremento inicial de la $\rho_{\mathrm{AHE}}$ desde 10 a $100 \mathrm{~K}$, ya que $\rho_{\mathrm{S}}$ no cambia significativamente en ese intervalo de temperatura. Sin embargo, al aumentar la temperatura se espera que $\rho_{\mathrm{S}}$ descienda porque la imanación, la polarización del espín y las correspondientes interacciones magnéticas decaerán con la temperatura. Este escenario en el cual se evidencia la dependencia de la $\rho_{\mathrm{S}}$ con la temperatura es ratificado por la AMR, también visualizada en la Figura 4.16(b), la cual refleja la misma evolución de esos parámetros por encima de $100 \mathrm{~K}$. Así, por encima de $100 \mathrm{~K}$, el término cuadrático de la ecuación (4.1) decaerá significativamente y puede producir un descenso completo de la $\rho_{\mathrm{AHE}}$. En el apartado 5.2, comentamos que el descenso de la AMR con la temperatura era mayor en comparación con lo que uno espera en el Fe puro. Esto evidencia que las fluctuaciones térmicas están afectando fuertemente al ferromagnetismo en los microhilos de Fe.

Este efecto no es extraño teniendo en cuenta la microestructura de la muestras, la cual consiste en una matriz heterogénea de Fe:O:C amorfa con granos pequeños de $\mathrm{Fe}$ y óxido de Fe dispersados. Las partículas cristalinas nanométricas de $\alpha$-Fe y de óxido de Fe observados por HRTEM serán proclives al superparamagnetismo a alta temperatura ${ }^{183}$, y así a la disminución de los procesos de “skew scattering”. La microestructura también sugiere muchos átomos magnéticos en las interfases y de enlaces defectuosos que suprimen el magnetismo y con una elevada tendencia a verse afectados por fluctuaciones térmicas. 

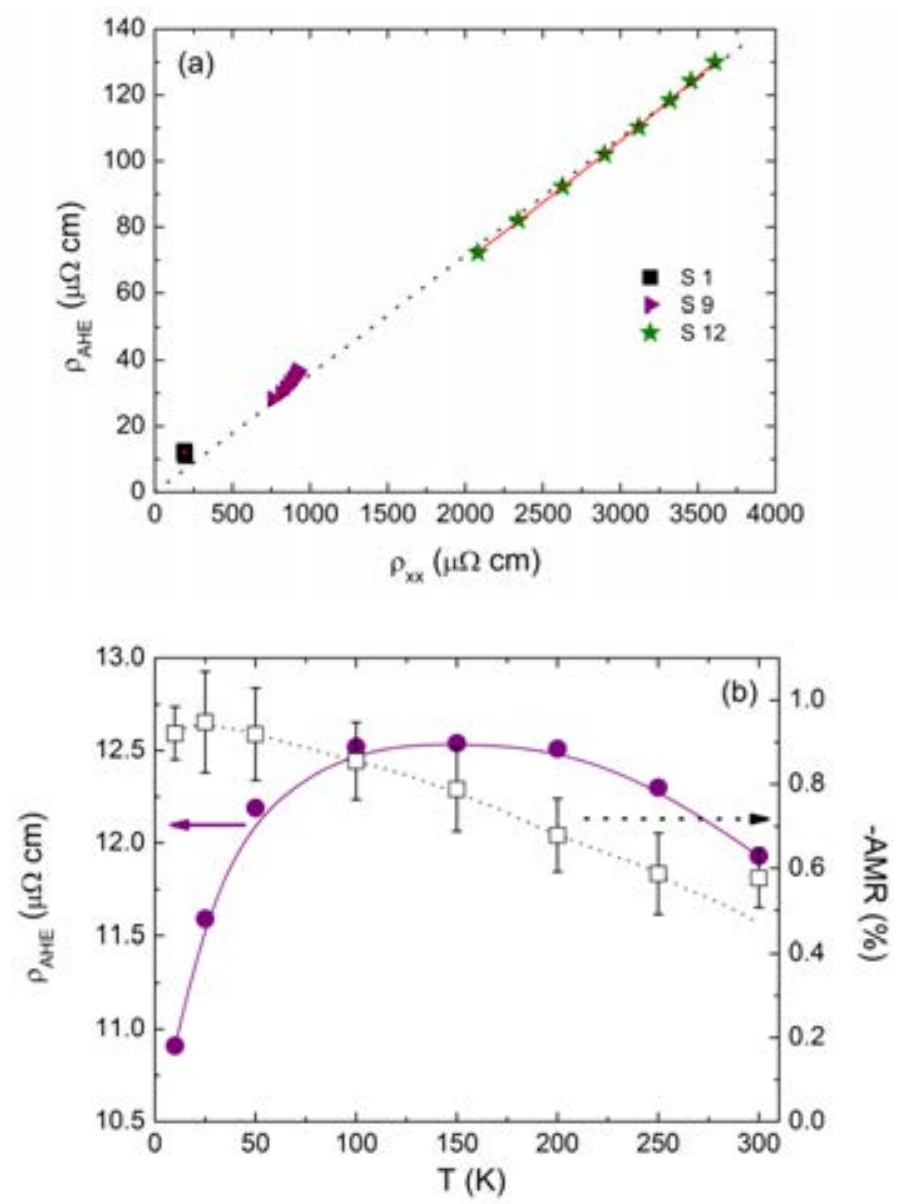

Figura 4.16: (a) Resistividad Hall anómala a 2 T en función de la resistividad longitudinal para S1, S9 y S12. (b) Resistividad Hall anómala a $2 \mathrm{~T}$ y magnetorresistencia anisótropa a \pm 9 T para S1 en función de la temperatura. 


\subsection{Conclusiones}

Nuestros resultados muestran que es posible la fabricación de microestructuras funcionales de Fe usando FEBID, las cuales exhiben un carácter ferromagnético cuando el cociente $\mathrm{Fe} / \mathrm{O}$ es alto y el contenido de $\mathrm{Fe}$ es superior al 65\% atómico. Añadiendo vapor de agua durante el crecimiento, podemos controlar el contenido de $\mathrm{Fe}$, conduciéndonos al aumento de la presencia de cristales de $\mathrm{FeO}_{\mathrm{x}}$ en el depósito como vimos mediante las imágenes de HRTEM. Afinando el cociente Fe/O mediante la adición de vapor de agua se podría abrir un camino para controlar el ciclo de histéresis magnético de los nanodepósitos.

La resistividad de los depósitos escala con el contenido de Fe en los depósitos. Las muestras con mayor contenido de Fe muestran una resistividad sólo diecinueve veces superior al Fe puro y presentan claramente una AMR. Una transición de la AMR a la ITMR se observa al decrecer el contenido de Fe (incrementando el contenido de oxígeno), indicando que la adición de vapor de agua durante el crecimiento nos lleva a la formación de granos de $\mathrm{FeO}_{\mathrm{x}}$ que presentan ITMR. La imanación de saturación obtenida a partir de las medidas del efecto Hall indicó que las propiedades magnéticas del Fe amorfo se asemejan bastante a las del Fe puro.

El principal resultado de este estudio ha sido la determinación de un gigante AHE, muy elevado comparado con el observado en microhilos de Fe puro, el cual ha sido explicado en términos de un gran "skew scattering" provocado por la compleja microestructura heterogénea de estos microhilos. En microhilos de alto contenido en Fe, debe tenerse en cuenta una sutil interacción entre las contribuciones de la dispersión que depende del espín y las independientes de éste para poder comprender la dependencia de la resistividad Hall con la temperatura. Esta interacción está modulada por el importante rol jugado por las fluctuaciones térmicas en este sistema heterogéneo. 
La utilización de la técnica FEBID permite el crecimiento de microhilos de Fe con una microestructura totalmente diferente a la producida por otras técnicas de nanofabricación, con un gran impacto en las propiedades de magnetotransporte, especialmente el GAHE observado con futuras aplicaciones en nuevos dispositivos magnéticos, como sensores Hall. 


\section{Capítulo 5}

\section{Nanodepósitos superconductores de W crecidos mediante un haz de iones focalizado}

En este capítulo presentamos la fabricación y caracterización de nanodepósitos superconductores de $W$ mediante un haz de iones focalizado. En primer lugar, estudiamos la influencia que tienen algunos parámetros de crecimiento, como el voltaje de aceleración del haz, la corriente de iones, y su ángulo de incidencia en la composición de los nanodepósitos. En segundo lugar, presentamos las propiedades superconductoras de depósitos de W variando el ancho lateral, desde microhilos hasta nanohilos ultraestrechos de $50 \mathrm{~nm}$ de resolución lateral mediante medidas de transporte eléctrico local. Por último, abordamos el estudio del voltaje no local generado en nanohilos de $W$ mediante medidas de transporte eléctrico nolocal. Los resultados obtenidos nos permiten vincular este tipo de nanoestructuras superconductoras con potenciales aplicaciones en el campo de la Nanotecnología. 


\subsection{Introducción}

En este apartado introductorio describiremos brevemente los mecanismos que tienen lugar en el crecimiento de estructuras de wolframio mediante FIBID, técnica ampliamente descrita en el apartado 1.3.5 del Capítulo 1, utilizando el W(CO) 6 como material precursor. A continuación, abordaremos el origen de su superconductividad, mencionando algunos de los trabajos previos más relevantes que versan sobre sus condiciones de crecimiento, caracterización eléctrica y, microscopía y espectroscopía de efecto túnel.

\subsubsection{Crecimiento de depósitos de W mediante FIBID}

El mecanismo de crecimiento de depósitos de W mediante FIBID tiene lugar en dos regímenes bien diferenciados (véase la Figura 5.1). En primer lugar, el crecimiento comienza con la nucleación de depósitos de $\mathrm{W}$ de tamaño nanométrico totalmente aislados sobre la superficie del sustrato. Sin embargo, la posición en el sustrato de estos puntos de nucleación no está directamente relacionada con el barrido que hace el FIB. La velocidad de crecimiento depende de muchos factores, como la naturaleza y rugosidad del sustrato, la dosis de iones, la estrategia de barrido del FIB, la temperatura del sustrato, el flujo de precursor, etc. A medida que estos nanodepósitos iniciales de $\mathrm{W}$ aumentan su tamaño y espesor, continúan conservando su posición y su forma durante el crecimiento, así unos con otros se funden formando una película continua de W. En ese momento comienza el segundo régimen de crecimiento que tiene lugar sobre la superficie de $\mathrm{W}$ crecida. La velocidad de crecimiento del $\mathrm{W}$ sobre la superficie de $\mathrm{SiO}_{2}$ es muy superior a la velocidad de crecimiento de $\mathrm{W}$ sobre el propio $\mathrm{W}$ ya crecido. Después de la formación de la película continua, el crecimiento es lineal respecto a la dosis de iones con la que se irradia. A $300 \mathrm{~K}$ estos depósitos presentaron una resistividad eléctrica de $250 \mu \Omega \mathrm{cm}$, y permiten el paso de una densidad de corriente superior a $3.53 \mathrm{MA} / \mathrm{cm}^{2}$, por lo que se consideraron muy útiles para la fabricación de nanocontactos en NEMS y MEMS ${ }^{184}$. 


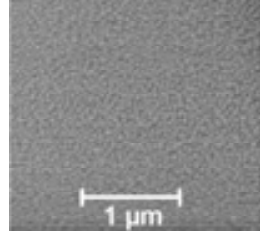

(a) $0.05 \mathrm{nC} / \mathrm{um}^{2}$

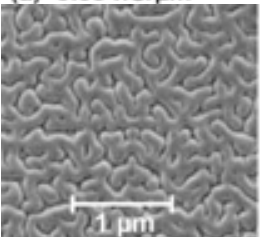

(e) $0.17 \mathrm{nC} / \mu \mathrm{m}^{2}$

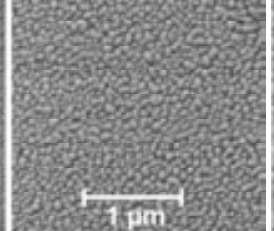

(b) $0.07 \mathrm{nC} / \mathrm{um}^{2}$

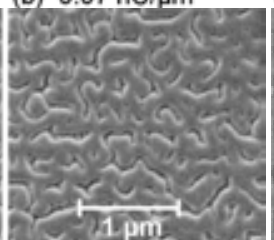

(f) $0.19 \mathrm{nC} / \mu^{2}$

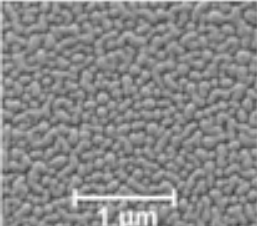

(c) $0.11 \mathrm{nC} / \mu \mathrm{m}^{2}$

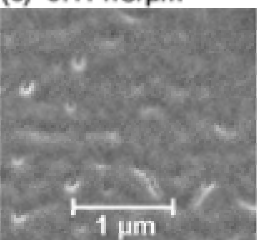

(g) $0.25 \mathrm{nC} / \mu \mathrm{m}^{2}$

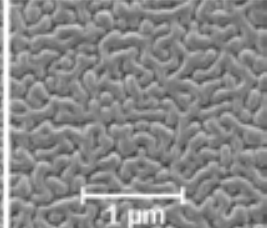

(d) $0.15 \mathrm{nC} / \mu \mathrm{m}^{2}$

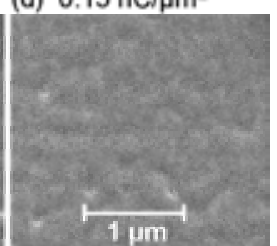

(h) $0.27 \mathrm{nC} / \mathrm{um}^{2}$

Figura 5.1: Evolución del crecimiento de películas de W mediante FIBID en función de la dosis de iones irradiada. El crecimiento comienza con la nucleación de partículas nanométricas de $\mathrm{W}$ al utilizar bajas dosis de iones. A medida que aumenta la dosis de iones las partículas van creciendo hasta que se funden formando una película continua de $\mathrm{W}$ de $150 \mathrm{~nm}$ de espesor. Figura extraída de la referencia ${ }^{184}$.

Una explicación a la etapa de nucleación observada ${ }^{184}$ respecto a la evolución del crecimiento de $\mathrm{W}$ sobre $\mathrm{SiO}_{2}$ podría tener respuesta en los estudios teóricos recientemente publicados ${ }^{185}$. En este estudio se desarrolla un modelo basado en cálculos de la teoría funcional de la densidad que simula la interacción de una molécula de $\mathrm{W}(\mathrm{CO})_{6}$ sobre un sustrato de $\mathrm{SiO}_{2}$. Para ello emplearon dos modelos de superficie diferentes, uno en el que consideraban que la superficie de $\mathrm{SiO}_{2}$ está totalmente hidroxilada $(\mathrm{FOH})$, un modelo más realista de un sustrato que ha sido preparado sin condiciones de vacío e irradiación y otro en el cual la presencia de grupos $\mathrm{OH}$ en la superficie es parcial (PHO), que podría tratarse de un sustrato sometido a la influencia de un haz de electrones/iones o de elevadas temperaturas que eliminaría parcialmente los grupos $\mathrm{OH}$ de la superficie. Sus resultados indicaron que se adsorben más moléculas de $\mathrm{W}(\mathrm{CO})_{6}$ sobre la superficie del $\mathrm{SiO}_{2} \mathrm{POH}$ que sobre la de $\mathrm{SiO}_{2} \mathrm{FOH}$. En el primer caso, se observa la disociación espontánea del precursor mediante la quimisorción de un fragmento de $\mathrm{W}(\mathrm{CO})_{5}$ sobre la superficie al extraer uno de los ligandos de CO volátiles de la molécula precursora, esto se explica por los cambios en las propiedades electrónicas y la transferencia de carga entre las moléculas 
de precursor y el sustrato. Sin embargo, en el segundo caso se observa una débil interacción entre las moléculas de $\mathrm{W}(\mathrm{CO})_{6}$ y la superficie del sustrato mediante fisisorción.

Las simulaciones de K. Muthukumar esclarecen ciertos aspectos de las interacciones que se producen entre la molécula de $\mathrm{W}(\mathrm{CO})_{6}$ y un sustrato de $\mathrm{SiO}_{2}$, resultando una herramienta útil para la comprensión de las primeras etapas del crecimiento de nanodepósitos de $\mathrm{W}$ sobre $\mathrm{SiO}_{2}$, en las cuales se forman los nanodepósitos de $\mathrm{W}$ como islas independientes ${ }^{184}$. Sin embargo, en el caso de FEBID/FIBID se deben tener en cuenta una multitud de procesos que en ese estudio se han obviado, como por ejemplo la interacción del haz con las moléculas de precursor y con el sustrato. Estas interacciones pueden producir efectos de calentamiento y carga sobre el sustrato, la emisión de electrones e iones secundarios e iones dispersados, produciendo una activación o disociación de las moléculas de $\mathrm{W}(\mathrm{CO})_{6}$.

\subsubsection{Superconductividad en depósitos de $\mathrm{W}$ crecidos mediante FIBID}

Los depósitos de wolframio crecidos mediante FIBID usando como material de partida el hexacarbonilo de wolframio, $\mathrm{W}(\mathrm{CO})_{6}$, han despertado un gran interés en el campo de la física de la materia condensada debido al estado superconductor que presentan a baja temperatura. Dicho descubrimiento fue realizado por E. S. Sadki y colaboradores en $2004{ }^{101}$. En este trabajo se mostraron algunos de los parámetros superconductores obtenidos mediante medidas de magnetotransporte, como el valor de la temperatura de transición superconductora $\left(\mathrm{T}_{\mathrm{c}}\right)$ de $\sim 5.2 \mathrm{~K}$, del campo crítico superior $\left(\mathrm{H}_{\mathrm{c} 2}\right)$ de $\sim 9.5 \mathrm{~T}$ y de la densidad de corriente crítica $\left(\mathrm{J}_{\mathrm{c}}\right)$ de $\sim 0.15 \mathrm{MA} / \mathrm{cm}^{2}$ para nanodepósitos de naturaleza amorfa de $\mathrm{W}$ de dimensiones $10 \mu \mathrm{m} \times 300 \mathrm{~nm} \times 120$ nm (longitud $\times$ ancho $\times$ espesor) y de composición W:40, C:40, Ga:20 en porcentaje atómico.

El valor de la $\mathrm{T}_{\mathrm{c}}$ de estos nanodepósitos amorfos con un desorden isotrópico es bastante elevado comparado con el valor que tiene el $\mathrm{W}$ puro y cristalino $\left(\mathrm{T}_{\mathrm{c}}=0.01 \mathrm{~K}\right)$. 
En la literatura se describen varios trabajos en los cuales películas amorfas de W, crecidas mediante otras técnicas, presentan una $\mathrm{T}_{\mathrm{c}}$ próxima a la que se obtiene en los nanodepósitos de $\mathrm{W}$ crecidos mediante FIBID. Como muestra de ello, contamos con películas amorfas de $\mathrm{W}$ evaporado y dopado con Re que presentan una $\mathrm{T}_{\mathrm{c}}$ entre 3.5 y 5 $\mathrm{K}^{186}$. Además, las películas amorfas de $\mathrm{W}$ crecidas mediante "sputtering” dopadas con Si o Ge presentan una $T_{c}$ entre 4.5 y $5 \mathrm{~K}^{187}$. Incluso, las películas amorfas de $\mathrm{W}$ depositadas mediante CVD dopadas con $\mathrm{C}$ presentan una $\mathrm{T}_{\mathrm{c}}$ de $4 \mathrm{~K}{ }^{188}$. Estos resultados parecen indicar que la naturaleza amorfa de los nanodepósitos de W crecidos mediante FIBID, cuyo desorden aumenta la "electron screening length" reduciendo el recorrido libre medio de los electrones, como la principal responsable del aumento de la $\mathrm{T}_{\mathrm{c}}$. Osofsky y colaboradores ${ }^{189}$ propusieron un modelo en el cual explicaban el origen del aumento de la superconductividad en sistemas metálicos desordenados. De acuerdo con las predicciones del modelo BCS (5.1) ${ }^{76}$, un aumento de la $T_{c}$ puede ser debido al aumento del potencial de interacción electrón-fonón $(V)$ dado por el aumento de la "electron screening length" o al aumento de la densidad de estados para fonones de baja energía.

$$
\mathrm{k}_{\mathrm{B}} \mathrm{T}_{\mathrm{c}} \sim 1.13 \hbar \omega_{\mathrm{D}} \exp \left(-1 / \mathrm{V} \mathrm{N}\left(\mathrm{E}_{\mathrm{f}}\right)\right)
$$

$\mathrm{N}\left(\mathrm{E}_{\mathrm{f}}\right)$ : densidad electrónica de estados en el nivel de Fermi.

\section{V: interacción electrón-fonón.}

Se han realizado varios trabajos posteriores al descubrimiento realizado por E. S. Sadki y colaboradores ${ }^{101}$ en el crecimiento y caracterización eléctrica de las propiedades superconductoras de nanoestructuras de wolframio crecidas mediante FIBID. En la Tabla 5.1 resumimos los trabajos más reseñables, en los cuales algunas características son comunes, como por ejemplo, el material precursor [W(CO) $\left.{ }_{6}\right]$, el voltaje de aceleración del haz de iones de $\mathrm{Ga}^{+}(30 \mathrm{kV})$ y la naturaleza amorfa del nanodepósito. 


\begin{tabular}{|c|c|c|c|c|c|c|}
\hline Referencia & $\begin{array}{c}I_{i} \\
(\mathbf{p A})\end{array}$ & $\begin{array}{l}\text { W:C:O:Ga } \\
\text { (\% atómico) }\end{array}$ & $\begin{array}{c}\rho_{300 K} \\
(\mu \Omega \mathrm{cm})\end{array}$ & $\begin{array}{c}\mathbf{T}_{\mathbf{c}} \\
(\mathbf{K})\end{array}$ & $\begin{array}{l}\mathrm{H}_{\mathrm{c} 2} \\
(\mathrm{~T})\end{array}$ & $\begin{array}{c}\mathrm{J}_{\mathrm{c}} \\
\left(\mathrm{MA} / \mathrm{cm}^{2}\right)\end{array}$ \\
\hline Sadki ${ }^{101}$ & 98 & $40: 40: 0: 20$ & 200 & 5.2 & 9.5 & $0.15(2 \mathrm{~K})$ \\
\hline Luxmoore ${ }^{190}$ & 1 & 51:37:0:12 & $\sim 200$ & $\sim 5.5$ & - & $0.3(3 \mathrm{~K})$ \\
\hline Spoddig ${ }^{191}$ & 10 & $17: 35: 4: 13$ & - & 5.2 & 6 & $\begin{array}{c}0.015 \\
(0.9 \text { K y } 0.5 \mathrm{~T})\end{array}$ \\
\hline $\mathbf{L i}^{192}$ & $1-1000$ & $\begin{array}{l}\text { 23:68:0:9- } \\
41: 37: 0: 22\end{array}$ & - & $5.1-6.2$ & - & - \\
\hline $\mathbf{L i}^{193}$ & 20 & 34:53:2:11 & $125-325$ & $5.1-5.4$ & - & $\begin{array}{l}1.0-1.74 \\
(4.2 \mathrm{~K})\end{array}$ \\
\hline
\end{tabular}

Tabla 5.1: Características y propiedades superconductoras de depósitos de wolframio presentados en la literatura.

La versatilidad de la técnica de fabricación local y directa de nanoestructuras superconductoras en un solo paso ha permitido su rápida incorporación en diversos tipos de aplicaciones. A continuación, enumeraremos los principales trabajos recientemente publicados en la literatura. Los depósitos superconductores de W se utilizaron en la modificación y reparación de dispositivos superconductores de películas delgadas de $\mathrm{Nb}$, transformando un dispositivo SQUID en un susceptómetro magnético $^{25}$. Estos dispositivos tienen una elevada sensibilidad experimental de $10^{4}$ magnetones de Bohr $/ \mathrm{Hz}^{1 / 2}$ y pueden medir en un amplio rango de frecuencias (DC-1 $\mathrm{MHz})^{59}$. Además, es posible trabajar a muy baja temperatura $(13 \mathrm{mK})$ y han permitido obtener medidas magnéticas en imanes moleculares de $\mathrm{Mn}_{12}$ y $\mathrm{HoW}_{10}{ }^{194}$. Por último, la fabricación de contactos ultraestrechos sin resistencia ${ }^{195}$ y de estructuras en tres dimensiones $^{196}$ también ofrece una gran variedad de perspectivas en dispositivos MEMS y NEMS. 


\subsubsection{Estudio de películas delgadas superconductoras de $\mathrm{W}$ crecidas por FIBID mediante STM/STS}

Las excelentes características topográficas y espectroscópicas de los depósitos de wolframio crecidos mediante FIBID los hacen idóneos para el estudio de la densidad de estados superconductora mediante microscopía y espectroscopía de efecto túnel (STM/S). Este trabajo de colaboración resumido a continuación ha sido realizado junto al grupo del Prof. Sebastián Vieira, el Dr. Hermann Suderow y la Dra. Isabel Guillamón de la Universidad Autónoma de Madrid ${ }^{102,197-199}$.

Las películas delgadas de $\mathrm{W}$ de dimensiones $30 \times 30 \times 0.2 \mu \mathrm{m}^{3}$ fueron crecidas utilizando como parámetros de crecimiento: material precursor= hexacarbonilo de wolframio, $\mathrm{W}(\mathrm{CO})_{6}$; temperatura de material precursor $=55^{\circ} \mathrm{C}$; voltaje de aceleración del haz de iones $\left(\mathrm{V}_{\mathrm{i}}\right)=30 \mathrm{kV}$; corriente del haz de iones $\left(\mathrm{I}_{\mathrm{i}}\right)=3 \mathrm{nA}$; $\mathrm{T}_{\text {sustrato }}=22{ }^{\circ} \mathrm{C} \pm 1$ ${ }^{\circ} \mathrm{C}$; $\mathrm{t}_{\mathrm{p}}=0.2 \mu \mathrm{s} ; \mathrm{s}=0 \%$; $\mathrm{t}_{\mathrm{r}}=0 \mathrm{~s} ; \mathrm{P}_{\text {base }}=1 \times 10^{-6}$ mbar; $\mathrm{P}_{\text {proceso }}=1 \times 10^{-5}$ mbar. El sustrato utilizado fue una oblea de Si sobre la que se creció una capa de Au-Pd de 100 nm de espesor mediante "sputtering".

Las propiedades superconductoras de estas películas de wolframio fueron estudiadas por I. Guillamón y colaboradores ${ }^{102}$. En la Figura 5.2(a) se representa la dependencia con la temperatura del gap superconductor, la cual se ajusta perfectamente a la teoría BCS de los superconductores de onda "s". Teniendo en cuenta que los depósitos de W se comportan como superconductores de tipo II con un acoplamiento débil y dentro del límite sucio, los parámetros superconductores se calcularon a partir de la resistividad de microhilos de W a $300 \mathrm{~K}, 275 \mu \Omega \mathrm{cm}$ y la derivada del campo magnético crítico $\mathrm{B}_{\mathrm{c} 2}(\mathrm{~T})$ a $\mathrm{T}_{\mathrm{c}}$, siendo $4.15 \mathrm{~K}$ su valor extraído de las medidas de STS, $-\left(\mathrm{dB}_{\mathrm{c} 2} / \mathrm{dT}\right)_{\mathrm{T}=\mathrm{Tc}}=2 \mathrm{~T} / \mathrm{K}$, obteniendo la longitud de coherencia, $\xi(0)=6.25 \mathrm{~nm}$; la longitud de penetración, $\lambda(0)=850 \mathrm{~nm}$ y el parámetro de GinzburgLandau, $\kappa=\lambda(0) / 1.63 \xi(0)=83$. Estos parámetros son del mismo orden que los observados en otras películas delgadas superconductoras amorfas ${ }^{200}$. Además, se obtuvo que el campo crítico termodinámico es $\mu_{0} \mathrm{H}_{\mathrm{c}}(0)=40 \mathrm{mT}$, el campo magnético crítico superior $\mathrm{B}_{\mathrm{c} 2}$ se observó a $6.4 \mathrm{~T}$ a $0.1 \mathrm{~K}$ (entendiendo como tal el valor de 
campo al cual se ha suprimido completamente la superconductividad) y el gap superconductor es $\Delta_{0}=0.66 \mathrm{meV}$. Las medidas simultáneas de topografía y de curvas de espectroscopía túnel en una zona determinada permiten la construcción de una imagen de la red de vórtices; en la cual los vórtices se ordenan disponiéndose en una configuración hexagonal. En la Figura 5.2(b) se observa la red de vórtices de Abrikosov perfectamente ordenada en experimentos realizados a $1.2 \mathrm{~K}$ y $2 \mathrm{~T}$.

El crecimiento de películas delgadas de W de superficie plana y homogénea mediante FIBID, nos permiten considerarlo como un método ideal de fabricación de sistemas superconductores para los estudios de la densidad de estados superconductora en función de la temperatura y del campo magnético externo mediante STM/S. Asimismo, debemos dar una especial relevancia a la selección de los parámetros de crecimiento y la rugosidad del sustrato, como los factores principales a tener en cuenta en la obtención de películas superconductoras con una rugosidad inferior a $1 \mathrm{~nm}$.

En este capítulo hemos investigado los depósitos de $\mathrm{W}$ fabricados mediante FIBID. En primer lugar, se están estudiando distintos parámetros de crecimiento, como el $V_{\mathrm{i}}$, la $\mathrm{I}_{\mathrm{i}}$, y el ángulo de incidencia del FIB respecto del sustrato que nos pueden guiar hacia una variación del contenido de $\mathrm{W}$ en los depósitos. En la caracterización de estas estructuras fabricadas se utilizaron técnicas avanzadas de espectroscopía y microscopía tales como EDS, AFM y HRTEM. Además, se llevaron a cabo medidas eléctricas en microhilos, nanohilos y nanohilos ultraestrechos en modo local y en nanohilos en modo no local que permitieron el estudio en profundidad de sus propiedades superconductoras en ausencia o bajo campo magnético aplicado. 
(a)

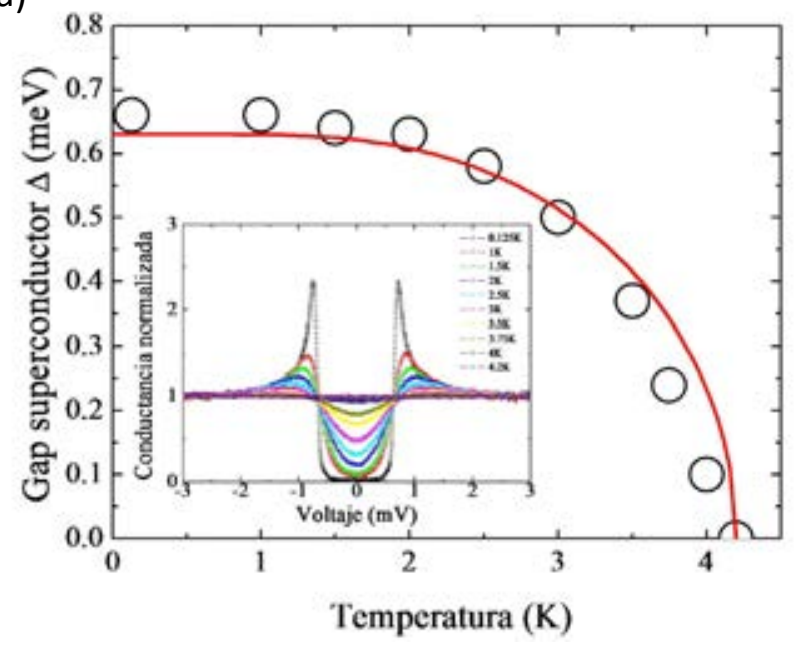

(b)

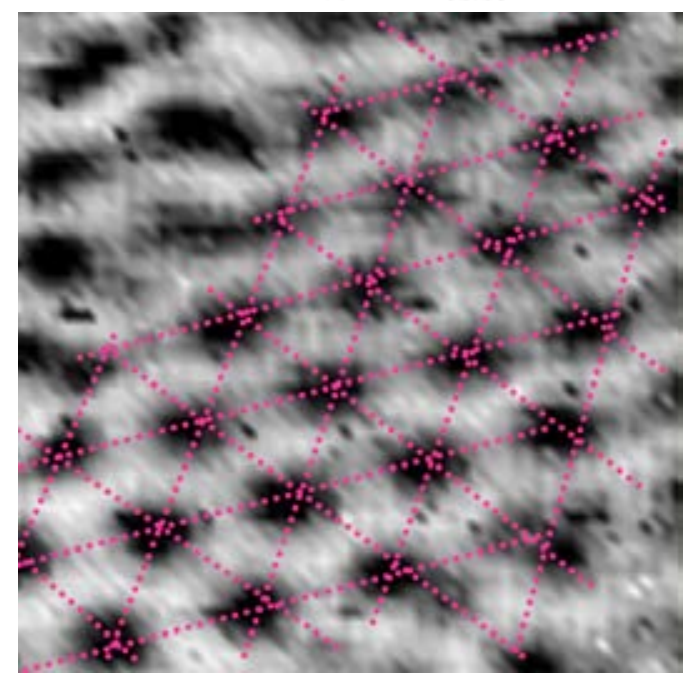

Figura 5.2: (a) Gap superconductor en función de la temperatura obtenido a partir de los ajustes de las curvas de conductancia túnel en función del voltaje mostradas en el recuadro. La línea roja es el ajuste que proviene de la expresión BCS, tomando $\Delta_{0}=1.76 \mathrm{k}_{\mathrm{B}} \mathrm{T}_{\mathrm{C}}$ con $\mathrm{T}_{\mathrm{C}}=4.15$ K. (b) Imagen de espectroscopía de la red de vórtices hexagonal a un campo magnético de $2 \mathrm{~T}$ (el tamaño lateral de la imagen es de $220 \mathrm{~nm}$, donde los vórtices individuales se representan por las áreas negras). La imagen es tomada por encima de la temperatura de desanclaje (1.2 K), así la red de vórtices está más ordenada que a bajas temperaturas. Los vórtices obtenidos de las imágenes STS están construidos a partir de la conductancia en el nivel de Fermi. Las líneas punteadas de color rosa indican la disposición de los vórtices en una red hexagonal ordenada ${ }^{90}$. 


\subsection{Crecimiento de nanoestructuras de W mediante FIBID}

La fabricación de nanoestructuras superconductoras de wolframio se realizó mediante la técnica FIBID, la cual se explicó en detalle en el apartado 1.3.5 del Capítulo 1. Los equipos que utilizamos para el crecimiento de estas estructuras son el Nova Nanolab 200 y el Helios Nanolab 600 de la compañía FEI.

Los parámetros de crecimiento de los nanodepósitos de W son los mismos que los utilizados en apartado 5.1.3, salvo los siguientes: rango del voltaje de aceleración del haz de iones $\left(\mathrm{V}_{\mathrm{i}}\right)=5-30 \mathrm{kV}$; rango de corriente de iones estudiado $\left(\mathrm{I}_{\mathrm{i}}\right)=1$ pA-9.5 nA. En los casos particulares que modifiquemos alguno de estos parámetros se comentará en el texto. El gas precursor se inyecta en la cámara de proceso a través de una aguja que se inserta cerca de la zona de trabajo, alrededor de $50 \mu \mathrm{m}$ de distancia en el plano (x/y) y $150 \mu \mathrm{m}$ de distancia de la superficie de la muestra en la dirección z. El sustrato utilizado en los experimentos fue: Si (dopaje tipo p) oxidado térmicamente, con este método obtenemos una capa de $250 \mathrm{~nm}$ de material aislante $\left(\mathrm{SiO}_{2}\right)$. Los contactos de Ti de $200 \mathrm{~nm}$ de espesor se fabricaron sobre el sustrato de Si oxidado mediante técnicas de litografía óptica.

Los depósitos de $\mathrm{W}$ de dimensiones $40 \times 2 \times 1 \mu \mathrm{m}^{3}(\mathrm{l} \times \mathrm{a} \times \mathrm{e})$ estudiados en este apartado fueron crecidos utilizando una $I_{i}$ de $1 \mathrm{nA}$ modificando $V_{i}$ para estudiar la dependencia de este parámetro en la composición de los nanodepósitos. En la Figura 5.4(a) mostramos una imagen SEM de una parte del depósito crecido a $30 \mathrm{kV}$. El análisis composicional se realizó in situ mediante EDS tras el proceso de crecimiento, así los depósitos no estuvieron expuestos a las condiciones ambientales, evitando la posibilidad de que su composición se hubiera modificado por agentes externos. Los espectros son recogidos utilizando un voltaje de aceleración del haz de electrones de 10 kV. Los resultados obtenidos a partir de los espectros se muestran en la Figura 5.3. 


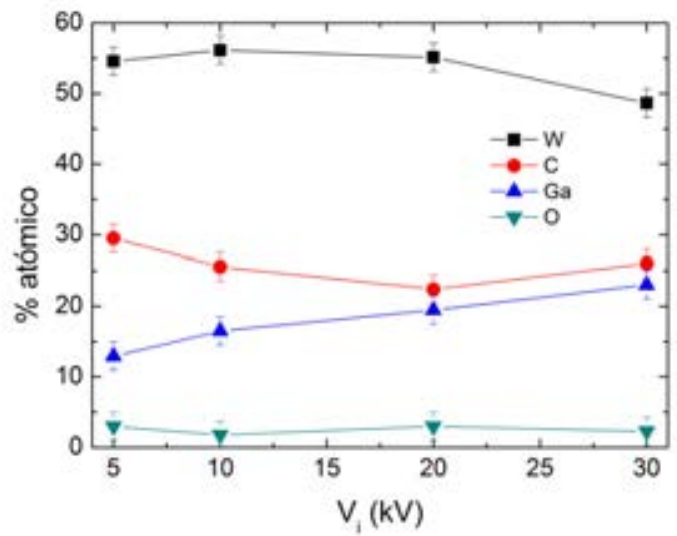

Figura 5.3: Composición de los nanodepósitos de W en función del voltaje de aceleración del FIB.

Las concentraciones de W y C no varían en más de un 10\% (en \% atómico) al modificar el $\mathrm{V}_{\mathrm{i}}$, y presentan una ligera tendencia a disminuir con $\mathrm{V}_{\mathrm{i}}$. Sin embargo, la concentración de Ga aumenta de forma monótona desde el $13 \% \pm 2 \%$ a $5 \mathrm{kV}$ hasta el $23 \% \pm 2 \%$ a $30 \mathrm{kV}$. Esto se puede explicar porque a mayor $\mathrm{V}_{\mathrm{i}}$, los iones de $\mathrm{Ga}^{+}$ penetran sobre el sustrato a mayor profundidad, la media de las trayectorias de los iones proyectadas en el sustrato es de $\sim 27 \mathrm{~nm}$ a $30 \mathrm{kV}$ y $\sim 8 \mathrm{~nm}$ a $5 \mathrm{kV}$ (datos obtenidos en simulaciones $\mathrm{TRIM}^{16}$ ) por lo que una mayor concentración de iones quedarán implantados en el material al ser menor su posibilidad de escape del material. La concentración de $\mathrm{O}$ permanece constante al modificar $\mathrm{V}_{\mathrm{i}}$, siendo menor del $3 \% \pm 2 \%$.

No debemos olvidar que alrededor del depósito de $\mathrm{W}$ crecido con las dimensiones seleccionadas se genera un depósito secundario que llamamos halo. El halo producido en los procesos FIBID de $\mathrm{W}$ proviene principalmente de la descomposición del material precursor producida principalmente por los iones de $\mathrm{Ga}^{+}$dispersados, y los electrones secundarios que estos generan ${ }^{61,184}$ (véase la Figura 5.5(a)), como ya comentamos ampliamente en el apartado 1.3.5 del Capítulo 1. Sin embargo, no podemos descartar el papel que juegan dos efectos adicionales, sobre todo cuando se 
utilizan corrientes en el rango de $\sim \mathrm{nA}$, la redeposición del material y el perfil más redondeado en lugar de Gaussiano que tiene el haz de iones ${ }^{10}$.
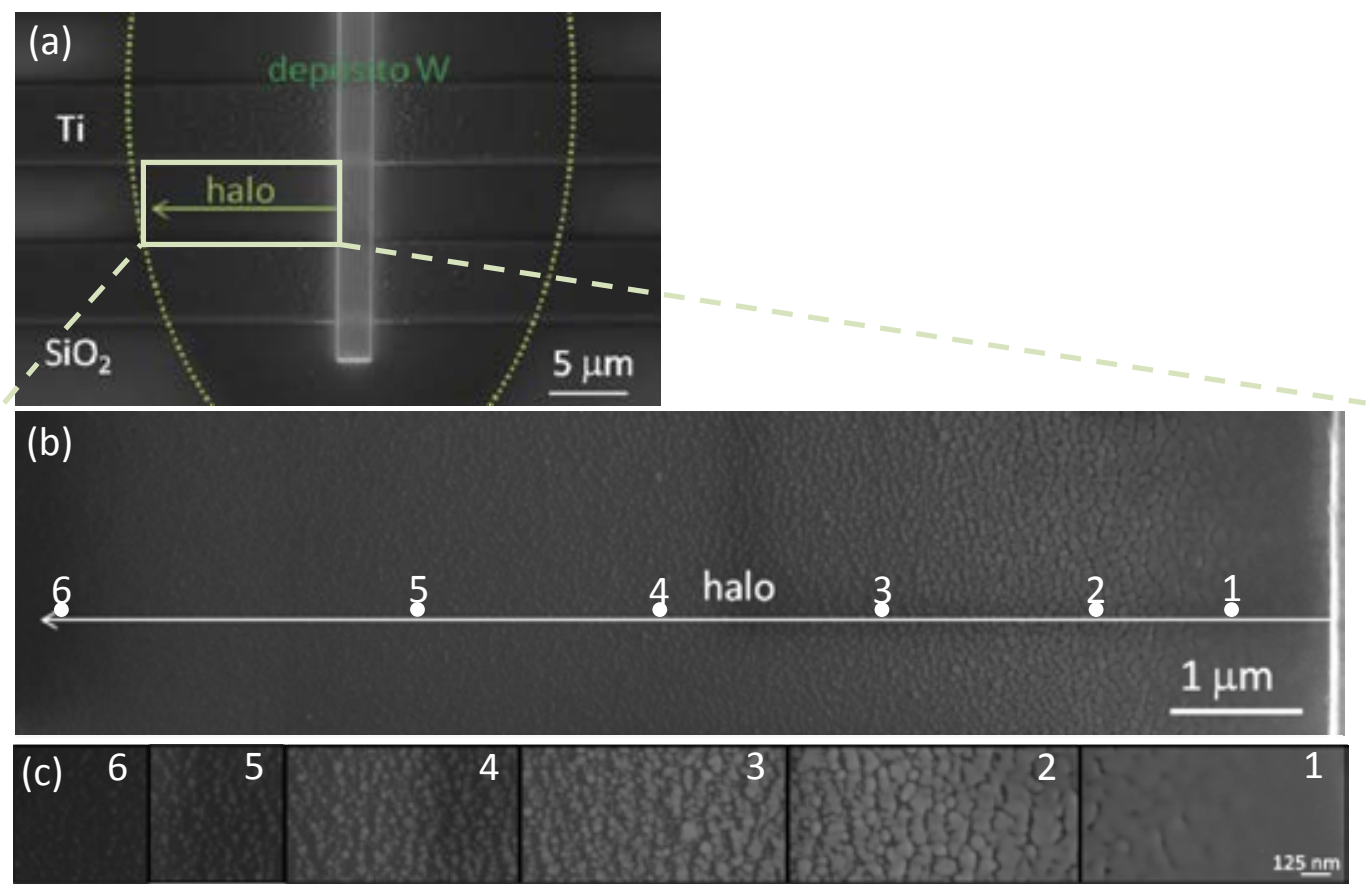

Figura 5.4: (a) Imagen SEM del halo generado alrededor del depósito indicado por la línea verde punteada. (b) Imagen SEM del halo generado alrededor del depósito marcado en (a) por el rectángulo verde claro. (c) Imágenes SEM a altos aumentos de varias zonas del halo generado en (b), indicado mediante números.

Se trata de un efecto inevitable y no deseado que se puede extender varias micras en el plano, en función de la dosis de iones con la que se irradia el sustrato, del espesor de la estructura que estamos creciendo y cuyo espesor generado junto a la estructura de $\mathrm{W}$ puede llegar a ser del 10\% del espesor de ésta. En la Figura 5.4(a), podemos observar el área donde se ha generado el halo por el cambio de contraste en la imagen y la línea punteada que lo delimita. Obviamente, a medida que nos alejamos del depósito crecido mediante FIBID, el efecto del halo va disminuyendo hasta que desaparece, como se puede observar en la Figura 5.4(b) y (c). En la zona del halo más alejada del depósito se observan pequeños granos aislados de unos 3 nm (véase Figura 
5.4(c)). A medida que nos acercamos al depósito (de izquierda a derecha en la imagen), el tamaño y la densidad de los granos aumenta, hasta que dejan de estar aislados y forman una película continua. Nótese el parecido con la Figura 5.1.

(a)

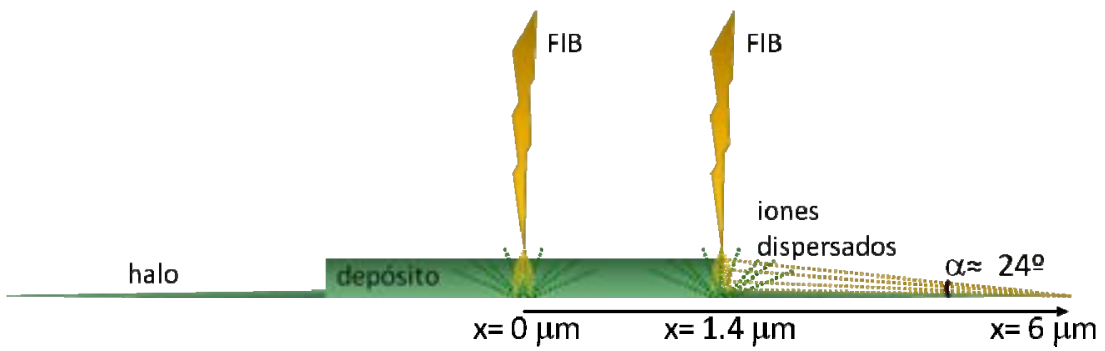

(b)

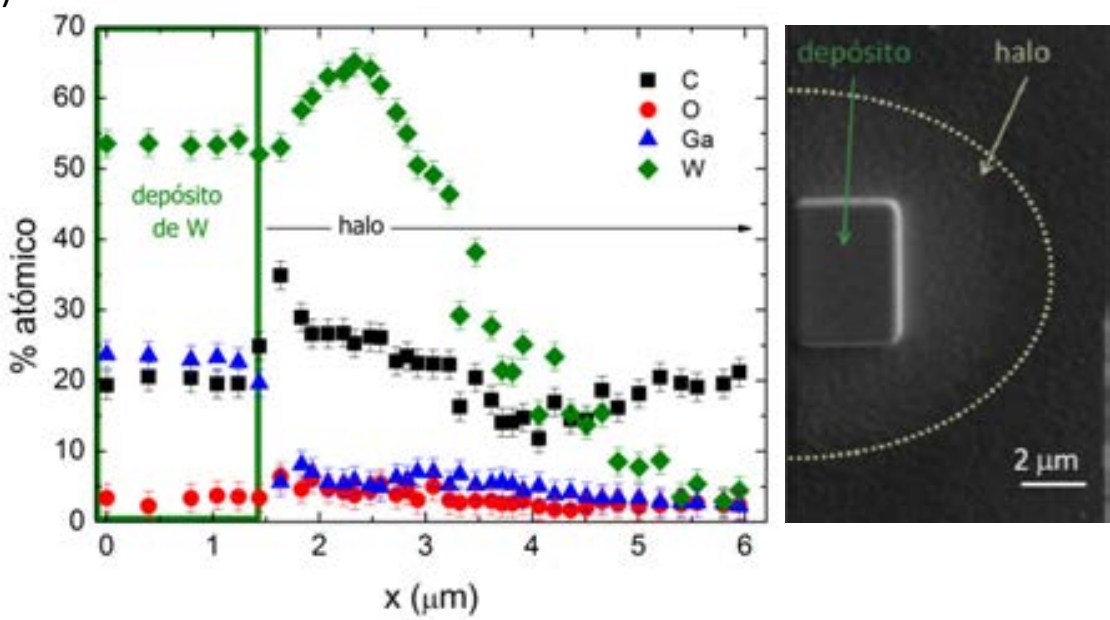

Figura 5.5: (a) Dibujo representativo del corte transversal de un depósito de $\mathrm{W}$ de $4 \mu \mathrm{m} \times$ $3 \mu \mathrm{m}$ crecido mediante FIBID. Señalamos el halo generado por los iones de $\mathrm{Ga}^{+}$dispersados y la flecha indica la posición en el plano a partir de la imagen SEM de (b). (b) Composición relativa del depósito de $\mathrm{W}$ representado en (a) y del halo generado en función de la posición en el plano. En el recuadro mostramos una imagen SEM de uno de los depósitos de W estudiado.

Con el objetivo de estudiar la composición del halo generado alrededor de los depósitos, se crecieron depósitos de $\mathrm{W}$ a $30 \mathrm{kV}$ y $0.92 \mathrm{nA}$, de dimensiones $3 \times 4 \times 2$ $\mu \mathrm{m}^{3}(\mathrm{l} \times \mathrm{a} \times \mathrm{e})$, tiempo de crecimiento= $5.5 \mathrm{~min}$. El análisis composicional se realizó in situ mediante EDS. Los espectros son recogidos utilizando un voltaje de aceleración del haz de electrones de $10 \mathrm{kV}$ y los resultados obtenidos a partir de los espectros se 
muestran en la Figura 5.5(b). Los espectros comienzan a detectar el sustrato a $\mathrm{x}=2.58$ $\mu \mathrm{m}$, y su contribución aumenta conforme aumentamos x. Su dependencia no la representamos en la gráfica para evitar confusión, por esa razón a partir de $\mathrm{x}=2.58$ $\mu \mathrm{m}$, la suma de los \% de C, O, Ga, y W no es del $100 \%$.

El contenido a lo largo del depósito (en \% atómico) es de W:54\% $\pm 2 \%$, C:19\% \pm $2 \%$, Ga:24\% $\pm 2 \%$, O:3\% $\pm 2 \%$. Sin embargo, cuándo alcanzamos el halo, en el punto $\mathrm{x}=1.6 \mu \mathrm{m}$, el contenido de Ga lógicamente desciende bruscamente hasta el $6 \% \pm 2 \%$ porque el FIB sólo barre dentro del depósito, la concentración de C aumenta hasta el $29 \% \pm 2 \%$, mientras que las concentraciones de $\mathrm{W}$ y de O permanecen prácticamente constantes. Desde $\mathrm{x}=1.6 \mu \mathrm{m}$ hasta $\mathrm{x}=2.3 \mu \mathrm{m}$, la concentración relativa de $\mathrm{W}$ aumenta hasta $65 \% \pm 2 \%$, máxima concentración obtenida y a partir de este punto desciende paulatinamente hasta que el halo desaparece. Sin embargo, debemos puntualizar que la concentración de metal $(\mathrm{W}+\mathrm{Ga})$ siempre es mayor en el depósito que en cualquier punto del halo. Además, al no recibir la irradiación directa del FIB, el nivel de amorficidad y por tanto el desorden en el halo será inferior al que presenta el depósito. Este hecho podría relacionarse con un cambio en la $\mathrm{T}_{\mathrm{c}}$ en el halo del depósito. Más adelante, mostraremos un estudio en el cual se han crecido depósitos a distinto ángulo de incidencia del FIB con la intención de aproximarnos a la composición y características del halo. 


\subsection{Microestructura de los nanodepósitos de $W$ en la nanoescala}

El objetivo de este estudio es analizar la microestructura de los depósitos de W crecidos mediante FIBID. Para realizar este tipo de observación local, la técnica más apropiada es la adquisición y el análisis de imágenes HRTEM, las cuales permiten extraer información acerca de la estructura cristalina a escala atómica.

Se crecieron depósitos de $\mathrm{W}$ sobre una rejilla comercial de $\mathrm{Cu}$ con una membrana de C (de espesor $\sim 10 \mathrm{~nm}$ ). El espesor de los mismos debe ser inferior a $40 \mathrm{~nm}$, para así tener la posibilidad de obtener imágenes de alta resolución al recopilar la información de los electrones transmitidos que atraviesan los depósitos. Los parámetros de crecimiento son los indicados en el apartado 5.2.

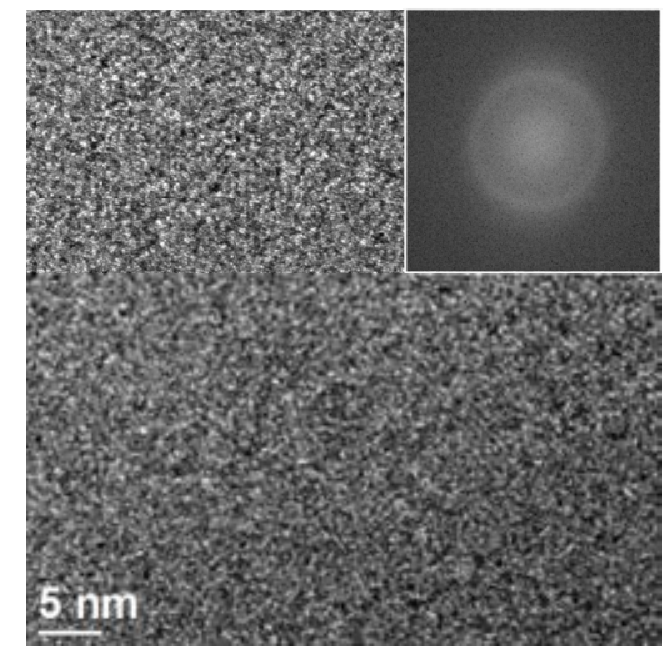

Figura 5.6: Imagen de HRTEM de un depósito de $\mathrm{W}$ de $20 \mathrm{~nm}$ de espesor crecido mediante FIBID a $30 \mathrm{kV}$ y $10 \mathrm{pA}$ sobre una rejilla de TEM de Cu. En el recuadro podemos observar la ausencia de anillos de difracción en la FFT de la imagen.

En la Figura 5.6 podemos observar una imagen de HRTEM de un depósito de W crecido a $30 \mathrm{kV}, 10 \mathrm{pA}$. Su naturaleza amorfa se pone de manifiesto por la ausencia de anillos de difracción en la Transformada de Fourier Rápida de la imagen. Tras el estudio podemos concluir que los depósitos de W crecidos por FIBID están formados 
por una matriz amorfa. Resultados similares se observaron en nanodepósitos crecidos en un rango de voltajes y corrientes de crecimiento, de $5-30 \mathrm{kV}$ y de $1 \mathrm{pA}$ a $0.10 \mathrm{nA}$, respectivamente. 


\subsection{Influencia del ángulo de incidencia del FIB}

Como comentamos anteriormente la concentración de W y Ga cambia significativamente entre el depósito crecido y el halo generado alrededor del depósito formado por la descomposición parcial de las moléculas de precursor llevada a cabo por los iones de $\mathrm{Ga}^{+}$dispersados. Por tanto, estas diferencias de composición junto con un menor nivel de amorfización del halo podrían tener una incidencia en el valor de su $\mathrm{T}_{\mathrm{c}}$.
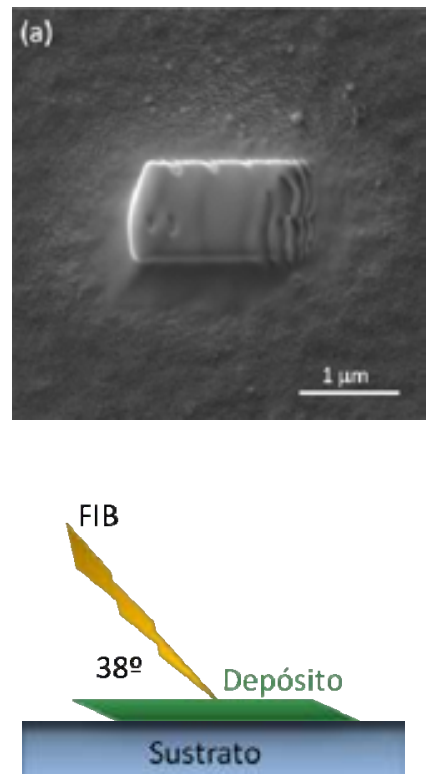

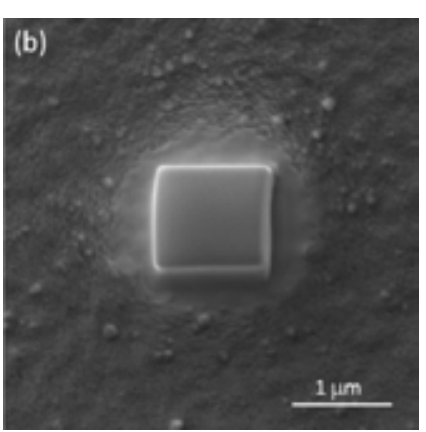

FIB

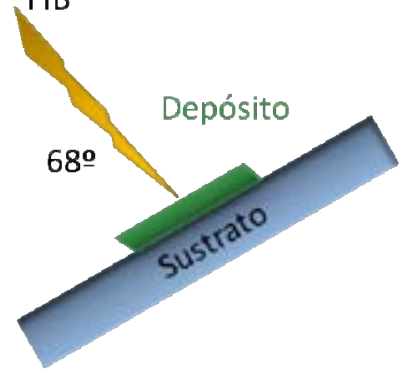

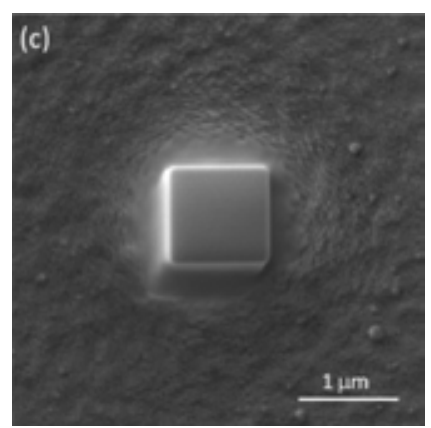

FIB

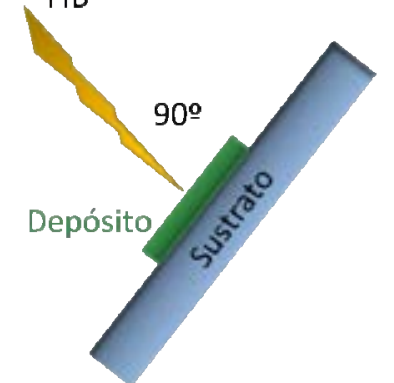

Figura 5.7: (a) Arriba, imagen SEM del depósito de W crecido con un ángulo de incidencia del FIB respecto del sustrato de $38^{\circ}$. Abajo, dibujo explicativo que indica la posición del FIB respecto del sustrato. (b) Arriba, imagen SEM del depósito de W crecido con un ángulo de incidencia del FIB respecto del sustrato de $68^{\circ}$ (c) Arriba, imagen SEM del depósito de $\mathrm{W}$ crecido con un ángulo de incidencia del FIB respecto del sustrato de $90^{\circ}$. Abajo, dibujo explicativo que indica la posición del FIB respecto del sustrato.

Con el objetivo de estudiar la posible influencia del cambio de contenido de W en la $\mathrm{T}_{\mathrm{c}}$, mostraremos un estudio en el cual se han crecido depósitos de $\mathrm{W}$ a distinto 
ángulo de incidencia del FIB con la intención de modificar el contenido de W (véase la Figura 5.7). Los parámetros de crecimiento son los siguientes: $\mathrm{V}_{\mathrm{i}}=30 \mathrm{kV} ; \mathrm{I}_{\mathrm{i}}=10$ $\mathrm{pA}$; tiempo de crecimiento= $4.17 \mathrm{~min}$; dimensiones: $1 \times 1 \times 0.2 \mu \mathrm{m}^{3}(\mathrm{l} \times \mathrm{a} \times \mathrm{e})$; ángulo de incidencia del FIB respecto el sustrato: $28-90^{\circ}$, siendo este último el ángulo normal entre FIB y sustrato. El análisis composicional se realizó in situ mediante EDS, los espectros son recogidos utilizando un $V_{\mathrm{e}}$ de $5 \mathrm{kV}$. Los resultados obtenidos en \% atómico a partir de los espectros tomados se muestran en la Figura 5.8.

En la Figura 5.7(a) vemos que el depósito crecido está deformado en una dirección cuya longitud, en vez de ser de $1 \mu \mathrm{m}$ es casi de $2 \mu \mathrm{m}$ cuando el ángulo de incidencia del FIB es de $38^{\circ}$ como se muestra en el dibujo explicativo. Este efecto ya estudiado por otros autores es debido a la dependencia de la longitud del depósito con la inversa del coseno del ángulo de incidencia del FIB ${ }^{201}$. Este efecto de distorsión del depósito en una dirección disminuye a medida que el ángulo entre el FIB y el sustrato se aproxima a $90^{\circ}$ tal y como se observa en Figura 5.7(b) y (c).

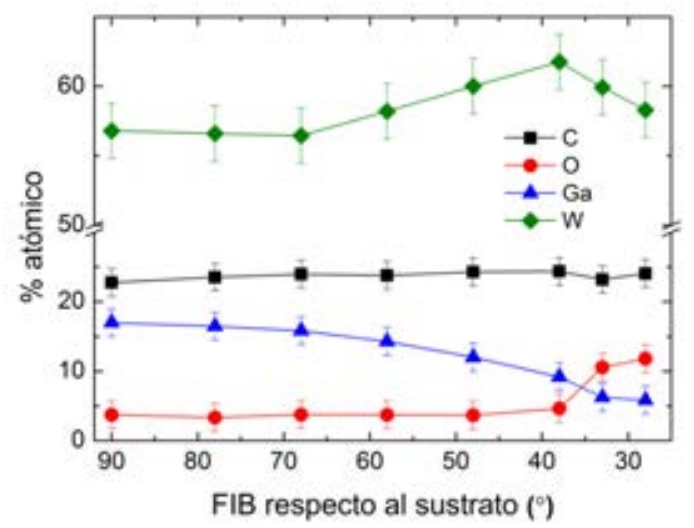

Figura 5.8: Composición de los depósitos de $\mathrm{W}$ en función del ángulo de incidencia del FIB respecto del sustrato. Fíjese en el corte en el eje de ordenadas.

La concentración de $\mathrm{W}$ aumenta del $56 \% \pm 2 \%$ a $90^{\circ}$ al $62 \% \pm 2 \%$ a $38^{\circ}$, donde encontramos el máximo, por debajo de $38^{\circ}$ vuelve a descender hasta el $58 \% \pm 2 \%$ a $28^{\circ}$. Aunque las diferencias de composición de $\mathrm{W}$ no son elevadas se observa una 
dependencia clara con un máximo a un ángulo de incidencia del FIB de $38^{\circ}$. Mientras que la concentración de Ga desciende de forma monótona desde el $17 \% \pm 2 \%$ a $90^{\circ}$ hasta el $6 \% \pm 2 \%$ a $28^{\circ}$. A menor ángulo de FIB, resulta una menor concentración de iones de $\mathrm{Ga}^{+}$que al penetrar en el sustrato quedan implantados en el material. La concentración de O permanece prácticamente constante en el $4 \% \pm 2 \%$ desde 90 a 38 , y luego aumenta hasta el $12 \% \pm 2 \%$ a $28^{\circ}$, probablemente debido a una menor eficiencia en el proceso de disociación de las moléculas de precursor a ese ángulo. La concentración de C permanece prácticamente constante al modificar el ángulo del FIB en el rango estudiado.

El software SRIM permite caracterizar el rango de distribución de los iones proyectados mediante una curva de tipo Gaussiana cuando trabajamos con dosis bajas, aunque debemos tener en cuenta que el modelo simple simulado por el programa está basado en distribuciones estadísticas de las colisiones de los iones ${ }^{16}$. En la Tabla 5.2 indicamos los valores medios de estos rangos de distribución en el sustrato donde la concentración de iones es máxima a $90^{\circ}$ y $38^{\circ}$ del ángulo de incidencia del FIB. El rango de iones se ha descrito respecto a la distribución final de los iones en función de la profundidad que alcanzan. Para el FIB con un ángulo de incidencia perpendicular a la muestra, la distribución de los iones se comporta con simetría acimutal. La propagación de iones lateralmente se puede resumir convenientemente usando un promedio donde $y_{i}$ es el valor final en el eje-y del ión, $z_{i}$, es el valor final en el eje-z del ión, y $\mathrm{N}$ es el número de los iones calculados. Así, el rango lateral es simplemente la media final del desplazamiento $\mathrm{y}-\mathrm{z}$ de los iones si se asume una incidencia perpendicular del FIB. El rango lateral proyectado se define como el promedio de los valores absolutos de los desplazamientos laterales proyectados en el eje-x. El rango radial proyectado es la media del rango de desplazamiento radial del eje-x asumiendo una simetría cilíndrica. Los resultados obtenidos en estas simulaciones explicarían el descenso del contenido de Ga al descender el ángulo de inclinación del FIB. 


\begin{tabular}{c|ccc}
\hline $\begin{array}{l}\text { Ángulo FIB respecto } \\
\text { del sustrato }\end{array}$ & $\begin{array}{c}\text { Rango longitudinal } \\
(\mathrm{nm})\end{array}$ & $\begin{array}{c}\text { Rango lateral } \\
\text { proyectado }(\mathrm{nm})\end{array}$ & $\begin{array}{c}\text { Rango radial } \\
\text { proyectado }(\mathrm{nm})\end{array}$ \\
\hline $\boldsymbol{a} \mathbf{9 0}^{\circ}$ & 27 & 5 & 8 \\
$\boldsymbol{a} \mathbf{3 8}^{\circ}$ & 17 & 21 & 22 \\
\hline
\end{tabular}

Tabla 5.2: Datos obtenidos a partir de simulaciones TRIM del haz de iones de $\mathrm{Ga}^{+}$a 30 $\mathrm{kV}$, y distinto ángulo de inclinación sobre un sustrato de $\mathrm{SiO}_{2}(250 \mathrm{~nm}) / \mathrm{Si}$.

Una vez estudiada la dependencia de la composición con el ángulo de incidencia, calculamos el volumen por dosis de cada depósito realizando un corte transversal con el FIB para medir el espesor y observar la uniformidad de cada depósito en función del crecimiento (véase la Figura 5.9). El método estándar para hacer un corte transversal consiste en: 1) depósito de otro material en la parte superior del depósito a estudiar para protegerlo y aumentar el contraste en imagen; 2) desbastado mediante el haz de iones focalizado desde la parte superior del depósito; 3) imagen SEM del corte transversal con el plano inclinado. El volumen por dosis (VD) es un parámetro que nos indica la eficiencia del proceso de crecimiento, en $\mu \mathrm{m}^{3} / \mathrm{nC}$. En la Figura 5.9 representamos el volumen por dosis de los depósitos estudiados en función del ángulo de incidencia del FIB. Este parámetro permanece prácticamente constante en 0.25 $\mu \mathrm{m}^{3} / \mathrm{nC}$ de $90^{\circ}$ a $48^{\circ}$, si continuamos descendiendo el ángulo de inclinación el VD aumenta progresivamente hasta $0.42 \mu \mathrm{m}^{3} / \mathrm{nC}$ a $28^{\circ}$, que es el valor mínimo del ángulo que hemos estudiado. Este notable incremento del ritmo de crecimiento de los depósitos de $\mathrm{W}$, podría ser debido a la mayor concentración de iones que escapan del sustrato con elevada energía y que serían capaces de disociar el material precursor adsorbido al incidir con un ángulo más rasante del habitual. Sin embargo, la dependencia mostrada parece indicar que el VD seguiría aumentando ligeramente hasta descender bruscamente cuando el ángulo del FIB fuera excesivamente rasante respecto a la superficie del sustrato $\left(\sim 15^{\circ}\right)$, tal y como ocurre con el rendimiento de pulverizado del FIB ${ }^{10}$ o en depósitos crecidos mediante FEBID ${ }^{201}$. Otros análisis en profundidad de esta situación serían requeridos para que esta conclusión fuera algo más que una explicación cualitativa. 


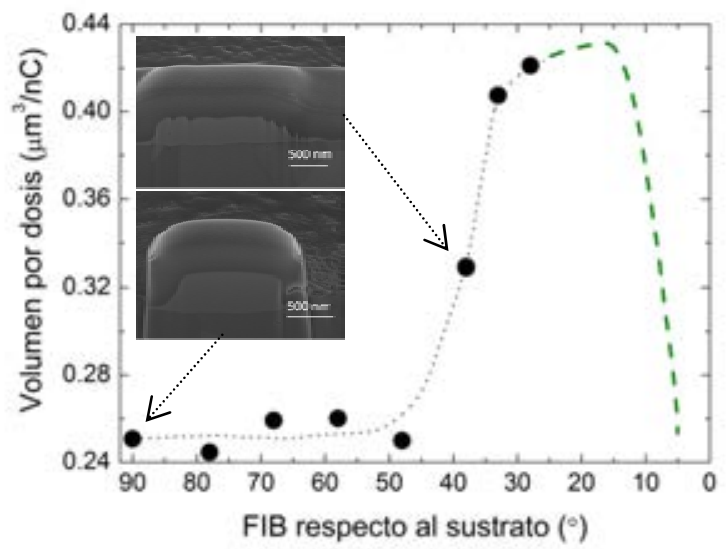

Figura 5.9: Volumen por dosis de los depósitos de W en función del ángulo de incidencia del FIB respecto del sustrato. Imágenes SEM de dos cortes transversales de los depósitos de W crecidos a $90^{\circ}$ y $38^{\circ}$.

Una vez demostrado que la concentración de elementos presentes se modifica significativamente en el depósito y en el halo generado alrededor de éste, así como en los depósitos crecidos a distintos ángulos de incidencia del FIB, nos interesa estudiar la influencia que tiene este hecho en la $T_{c}$ de estas estructuras. Por esta razón, hemos estudiado la dependencia con la temperatura de la resistencia de las nanoestructuras de W crecidas a distintos ángulos de inclinación del FIB, concretamente aquellos en los cuales hemos observado cambios en la composición química a $38^{\circ}, 48^{\circ}$ de incidencia del FIB y la de referencia a $90^{\circ}$.

En la Figura 5.10 se representa la resistencia normalizada de las tres nanoestructuras de $\mathrm{W}$ en función de la temperatura. La temperatura de transición crítica se determina como el punto medio de la transición $\left(\mathrm{R}_{\text {normalizada }}=0.5\right)$ y de esta forma observamos que la diferencia entre las $\mathrm{T}_{c}$ de las tres estructuras medidas no dista más de $0.1 \mathrm{~K}$. Con un ángulo de incidencia del FIB de $38^{\circ}, \mathrm{T}_{\mathrm{c}}=4.98 \mathrm{~K}$; a $48^{\circ}$, $\mathrm{T}_{\mathrm{c}}=5.08 \mathrm{~K}$ y por último la referencia a $90^{\circ}, \mathrm{T}_{\mathrm{c}}=5.04 \mathrm{~K}$. 


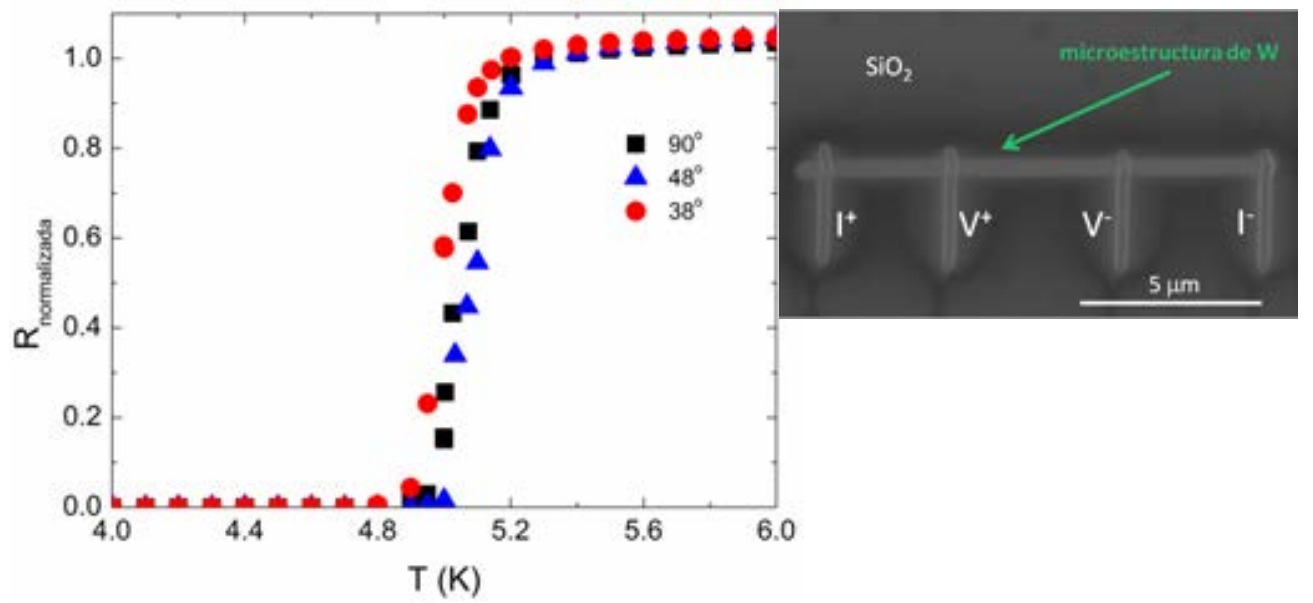

Figura 5.10: Dependencia con la temperatura de la resistencia normalizada de tres nanoestructuras de $\mathrm{W}$ crecidas a distintos ángulos de inclinación del FIB, $38^{\circ}, 48^{\circ}$ y $90^{\circ}$. En el recuadro mostramos una imagen SEM de la estructura crecida con un ángulo de inclinación del FIB de $38^{\circ}$.

De modo que no encontramos evidencia alguna de cambios significativos en la $T_{c}$ de estructuras crecidas a distintos ángulos de incidencia, de $90^{\circ}$ a $38^{\circ}$ y con diferente composición química. Aun con pequeñas variaciones en composición, la $T_{c}$ que podemos encontrar en los depósitos crecidos a distintos ángulos de incidencia del FIB, de $90^{\circ}$ a $38^{\circ}$ permanecerá constante. 


\subsection{Transporte eléctrico en modo local en depósitos superconductores de W}

En este apartado estudiaremos las propiedades superconductoras de los depósitos de $\mathrm{W}$ distinguiéndolos por su tamaño lateral, desde microhilos hasta nanohilos ultraestrechos, mediante medidas eléctricas por cuatro puntas en ausencia o con campo magnético externo perpendicular al sustrato, realizadas en el equipo PPMS descrito en el apartado 2.6.2 del Capítulo 2.

\subsubsection{Microhilos superconductores de $\mathbf{W}$}

El primer objetivo de este estudio es medir las propiedades superconductoras de los microhilos de $\mathrm{W}$ que fabricamos y compararlas con las publicadas en la literatura $^{101,190,191,193,195,202-204}$. Una vez comprobado este hecho, estudiaremos las propiedades de las estructuras al reducir las dimensiones tanto laterales como en espesor hasta el límite que nos permite la técnica FIBID.

Los parámetros de crecimiento de los microhilos de W crecidos sobre Si (dopaje tipo p) oxidado térmicamente son los siguientes: $\mathrm{V}_{\mathrm{i}}=30 \mathrm{kV}, \mathrm{I}_{\mathrm{i}}=0.92 \mathrm{nA}$, dimensiones $=39 \times 2 \times 0.3 \mu \mathrm{m}^{3}(\mathrm{l} \times \mathrm{a} \times \mathrm{e})$. Como en todas las estructuras estudiadas mediante medidas eléctricas a lo largo de esta tesis, los cuatro contactos de $\mathrm{Ti}$ utilizados para las medidas por cuatro puntas se fabricaron mediante técnicas de litografía óptica ya referidas en el apartado 2.7.1 del Capítulo 2.

Una vez crecidos los depósitos se midieron in situ (en el "Dual Beam” tal y como describimos en el apartado 2.6.1 del Capítulo 2) sus propiedades eléctricas mediante 4 puntas para comprobar que las propiedades eléctricas no se modifican con el paso del tiempo. Los valores de resistencia medidos "ex-situ” en el PPMS incluso un año después del crecimiento no varían más del $10 \%$ respecto a los iniciales medidos in situ. En la Figura 5.11(a) mostramos una imagen SEM de un ejemplo del tipo de microhilos de W fabricados. En (b), representamos la dependencia de la resistencia con la temperatura y de ahí extraemos el valor de la temperatura de transición crítica, 
$\mathrm{T}_{\mathrm{c}}=4.95 \mathrm{~K}$ (definida como el valor de la temperatura cuando $\mathrm{R}_{\text {normalizada }}=0.5$ ). $\mathrm{Al}$ representar la resistencia en escala logarítmica se observa una doble transición, la segunda transición se encuentra por debajo de $4.95 \mathrm{~K}$, y representa menos del 1\% del valor de la resistencia en el estado normal. Parece indicar que su origen puede ser debido a un pequeño cambio de sección en el microhilo, probablemente en los bordes de los cuatro contactos de Ti litografiados como representamos en la Figura 5.11(c).
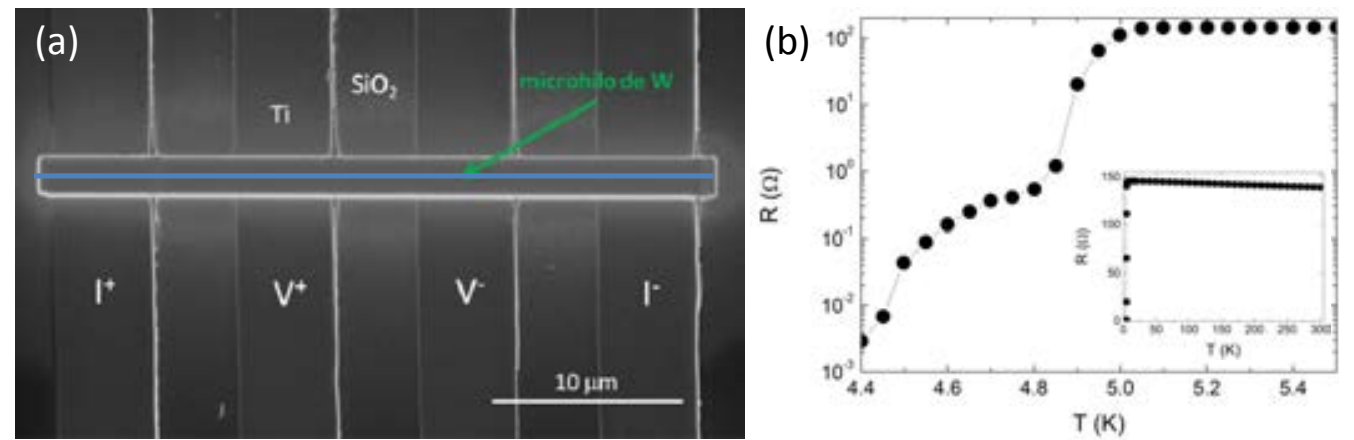

(c)

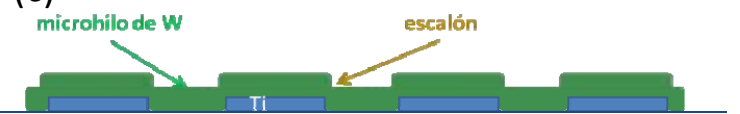

Figura 5.11: (a) Imagen SEM de un microhilo de W. (b) Resistencia del microhilo de W en función de la temperatura. (c) Representación de una sección transversal de la zona de la imagen (a) indicada por una línea azul.

Otro parámetro a tener en cuenta para las posibles aplicaciones de este tipo de estructuras es el valor de la corriente crítica, a la cual el material deja de tener un comportamiento superconductor. La dependencia de la resistencia con la corriente de medida para diferentes isotermas (2.5-4.25 K) se muestra en la Figura 5.12(a). Lo primero que debemos indicar es el cambio de pendiente observado en las curvas al representarlo en escala logarítmica. Tal y como sucedía en la dependencia de la resistencia con la temperatura de la Figura 5.11(c), la primera corriente crítica representa menos del $1 \%$ del valor de la resistencia en el estado normal, parece confirmar que en los bordes de los cuatro contactos de Ti litografiados existe un 
pequeño cambio de sección en el microhilo que induce esa transición. La corriente crítica de microhilos con una sección de $0.6 \mu \mathrm{m}^{2}$ a $2.5 \mathrm{~K}$ es del orden de $\sim 80 \mu \mathrm{A}$, valor que desciende a medida que aumentamos la temperatura. Por tanto, el valor de la densidad de corriente crítica a esa temperatura es de alrededor de $\sim 0.013 \mathrm{MA} / \mathrm{cm}^{2}$. No se han observado cambios significativos en el valor de la densidad de corriente crítica en este tipo de microestructuras asociados a variaciones de composición o a defectos estructurales.

(a)

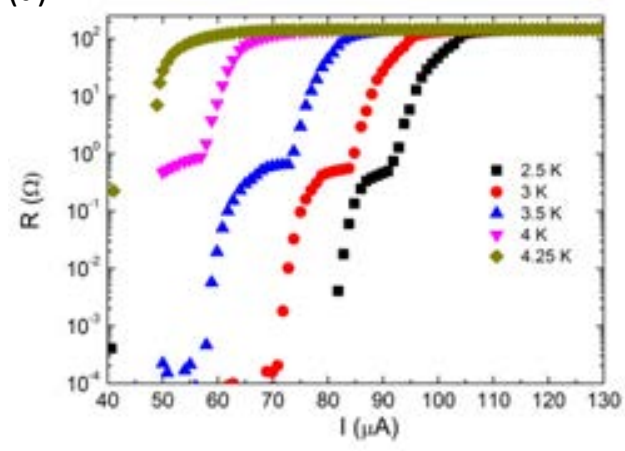

(b)

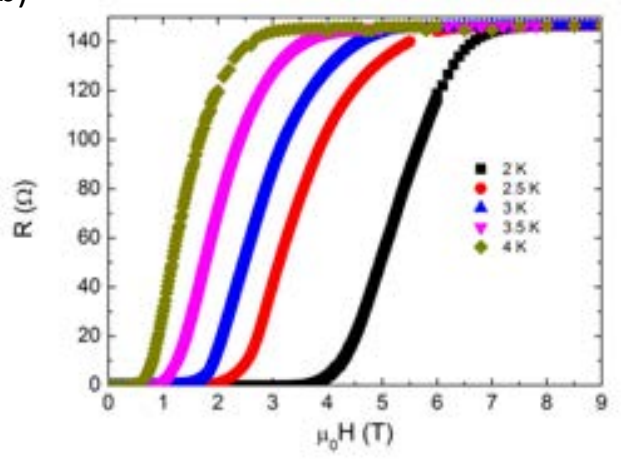

Figura 5.12: (a) Resistencia del microhilo de $\mathrm{W}$ en función de la corriente aplicada para diferentes isotermas (2.5-4.25 K). (b) Resistencia en función del campo magnético aplicado para diferentes isotermas (2-4 K).

A continuación estudiaremos el comportamiento superconductor de estos microhilos al ser sometidos a un campo magnético externo. Veremos cómo las líneas de campo o vórtices penetran en nuestro material disipando la energía que se transforma en el voltaje que medimos. Para una temperatura dada, el campo crítico $\mathrm{B}_{\mathrm{c} 2}$ sería el parámetro que nos indicaría la supresión de la superconductividad cuando la densidad de vórtices dentro del material es tal que la distancia entre ellos es menor que la longitud de coherencia del material a esa temperatura. $\mathrm{B}_{\mathrm{c} 2}$ se estima a partir del estudio de la dependencia de la resistencia con el campo magnético aplicado para diferentes isotermas (2-4 K) que representamos en la Figura 5.12(b). De esta manera, podemos conocer el rango de campos a los cuales las microestructuras continúan teniendo un comportamiento superconductor. A $2 \mathrm{~K}$ no se aprecia resistencia finita, 
con la sensibilidad de nuestro sistema de medida, hasta que el campo aplicado no es de al menos 3 T. A partir de ese valor de campo, la resistencia continúa aumentando hasta que la superconductividad se inhibe completamente a $\mathrm{B}_{\mathrm{c} 2} \sim 7 \mathrm{~T}$, cuyo valor se va reduciendo a medida que aumentamos la temperatura y nos vamos acercando a la $T_{c}$.

Los parámetros superconductores esgrimidos por los microhilos de W caracterizados en este apartado $\left(\mathrm{T}_{\mathrm{c}}=4.95 \mathrm{~K}, \mathrm{~J}_{\mathrm{c}}(2.5 \mathrm{~K}) \sim 0.013 \mathrm{MA} / \mathrm{cm}^{2}\right.$ y $\mathrm{B}_{\mathrm{c} 2}(2 \mathrm{~K}) \sim 7$ T) son del mismo orden que los obtenidos por otros autores ${ }^{101,190,191,193,195,202-204}$. Sin embargo, en los sucesivos estudios utilizaremos otro tipo de geometrías en las nanoestructuras para evitar efectos de doble transición observados en este apartado por diferencias de sección de las estructuras en los bordes de los contactos de Ti.

\subsubsection{Nanohilos superconductores de W}

En este apartado abordamos el crecimiento y caracterización de NWs superconductores de $\mathrm{W}$ crecidos mediante FIBID, con un ancho lateral y espesor de 200 nm. Las imágenes SEM in situ se realizaron en los mismos equipos en los que se fabricaron las muestras, permitiendo capturar imágenes de alta resolución de los NWs para la determinación del tamaño lateral. Las medidas de AFM se realizaron para investigar el espesor y uniformidad a lo largo de la longitud de los NWs. Las nanoestructuras de $\mathrm{W}$ se crecieron a $\mathrm{V}_{\mathrm{i}}=30 \mathrm{kV}, \mathrm{I}_{\mathrm{i}}=29 \mathrm{pA}$.

\subsubsection{Configuración de medida}

En la Figura 5.13 se muestra una imagen SEM en la que podemos observar la configuración de las estructuras crecidas para realizar medidas eléctricas por cuatro puntas en el modo local. En primer lugar, se crece la nanoestructura de W que está compuesta por un NW vertical de $5 \mu \mathrm{m}$ de longitud y cuatro NWs perpendiculares al primero de $3 \mu \mathrm{m}$ de longitud utilizados como contactos $\mathrm{I}^{+}, \mathrm{V}^{+}, \mathrm{V}^{-}$y $\mathrm{I}^{-}$. La distancia 
entre los contactos de voltaje es de $3 \mu \mathrm{m}$. A continuación, se crecieron mediante FIBID cuatro microhilos de Pt para conectar la nanoestructura de $\mathrm{W}$ y los contactos de $\mathrm{Ti}^{116,172}$. El punto de coincidencia entre el FEB y el FIB está perfectamente alineado, de forma que ajustamos la posición en la cual queremos crecer los NWs utilizando el barrido con electrones, evitando en todo momento la irradiación por FIB del área donde se encuentra el NW perpendicular de W.

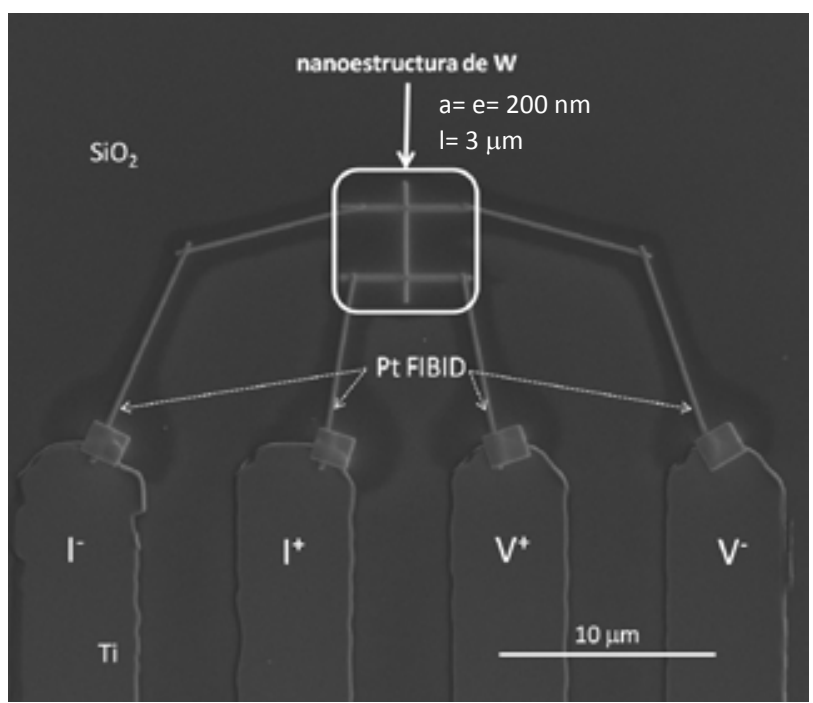

Figura 5.13: Imagen SEM de la configuración para las medidas eléctricas por cuatro puntas en el modo local, indicamos con el cuadrado blanco la nanoestructura de $\mathrm{W}$, y mediante flechas blancas los cuatro microhilos de Pt FIBID que la conectan con las líneas de Ti.

\subsubsection{Dependencia de la resistencia con la temperatura}

En la Figura 5.14 representamos la dependencia de la resistencia en función de la temperatura para una de las nanoestructuras de $\mathrm{W}$ estudiadas. La $\mathrm{T}_{\mathrm{c}}$ se determina como el punto medio de la transición $\left(\mathrm{R}_{\text {normalizada }}=0.5\right)$ y los valores estimados están alrededor de $5.1 \mathrm{~K}$, como los valores obtenidos para las nanoestructuras de $\mathrm{W}$ por otros autores e incluso en nuestros experimentos previos, de $\mathrm{T}_{\mathrm{C}} \sim 5 \mathrm{~K}^{190,191,193,195 \text {, 202- }}$ 204. En el recuadro de la Figura 5.14 podemos observar que la transición del estado 
normal al superconductor no se desplaza al utilizar diferentes corrientes aplicadas, 0.1 $\mu \mathrm{A}, 0.5 \mu \mathrm{A}$ у $1 \mu \mathrm{A}$.

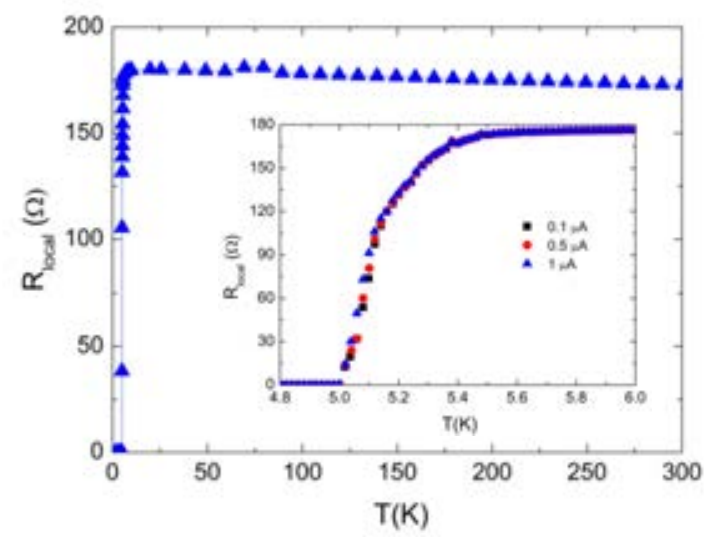

Figura 5.14: Resistencia local en función de la temperatura a varias corrientes aplicadas, $0.1,0.5$ y $1 \mu \mathrm{A}$. En el recuadro con más detalle.

\subsubsection{Dependencia de la resistencia con la corriente}

En primer lugar, determinamos la densidad de corriente crítica del NW superconductor a distintas temperaturas (entre 1 y $4.25 \mathrm{~K}$ ) y en ausencia de campo magnético. Como ejemplo de ello, en la Figura 5.15 mostramos la resistencia normalizada de la muestra en función de la corriente aplicada para distintas temperaturas en ausencia de campo magnético externo. La corriente crítica del nanohilo a $1 \mathrm{~K}$ es del orden de $\sim 37.5 \mu \mathrm{A}$, valor que desciende a medida que aumentamos la temperatura y nos aproximamos a la $T_{c}$ de este material. Por tanto, el valor de la densidad de corriente crítica a $1 \mathrm{~K}$ es de alrededor de $\sim 0.094 \mathrm{MA} / \mathrm{cm}^{2}$. Además, no se han observado cambios significativos en el valor de la densidad de corriente crítica en este tipo de nanoestructuras asociados a pequeñas variaciones de composición o a defectos estructurales. 


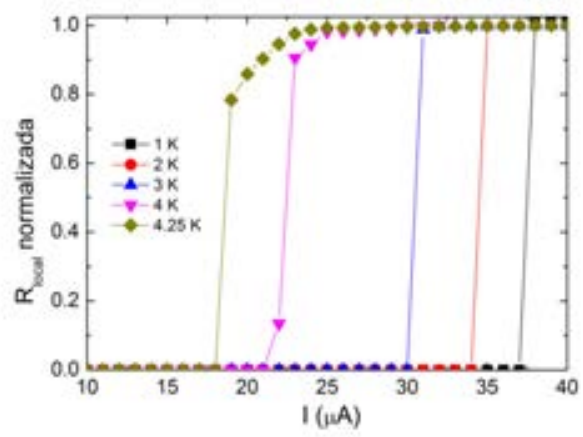

Figura 5.15: Resistencia normalizada en función de la corriente aplicada a distintas temperaturas y en ausencia de campo magnético.

A continuación, centraremos el estudio en la evolución de la disipación de energía en nuestro material superconductor en función de la corriente aplicada al someterlo a un campo magnético externo constante. De esta forma, mostraremos los resultados más significativos obtenidos de curvas de resistencia local en función de la corriente aplicada para distintos campos magnéticos a una temperatura fijada.

En la Figura 5.16 representamos la resistencia en función de la corriente aplicada para distintos campos magnéticos aplicados a (a) $1 \mathrm{~K}$ y a (b) $4 \mathrm{~K}$. En primer lugar, debemos hacer hincapié en que la disipación de energía debida al movimiento de los vórtices por la corriente aplicada presenta un comportamiento no lineal que lo desvía de la dependencia que seguiría si el movimiento de los vórtices únicamente estuviera gobernado por el régimen "flux-flow", tal y como se explicó en el apartado 1.6.2.1 del Capítulo 1. La disipación de energía debida a la dispersión inelástica electrón-fonón sería la principal causa de estas inestabilidades respecto al régimen "flux-flow”. La cual podría generar un aumento de la temperatura de los electrones dentro de los vórtices ${ }^{205,206}$ que crearían cuasi-partículas adicionales y de esa foma disminuirían el gap superconductor.

En la Figura 5.17 representamos el campo eléctrico $\left(E=\rho_{f} J\right)$ generado en función de la densidad de corriente a baja temperatura, (a) $1 \mathrm{~K}$, y (b) $3 \mathrm{~K}$ para varios valores 
de campo magnético externo aplicado indicados en la leyenda; siendo $\rho_{\mathrm{f}}$ la resistividad "flux-flow" y J la densidad de corriente aplicada. Sin embargo, para sistemas que se encuentran fuera del régimen "flux-flow" podemos aplicar la ecuación $J=0.9 \sigma_{n} E / b+J_{c}$ ${ }^{207}\left(\sigma_{\mathrm{n}}\right.$ es la conductividad en el estado normal, $\mathrm{b}=\mathrm{B} / \mathrm{B}_{\mathrm{c} 2}$, $\mathrm{J}_{\mathrm{c}}$ es la densidad de corriente crítica para producir el desanclaje de los vórtices) para valores bajos de campo magnético aplicado. En la Figura 5.17, se representa el ajuste parcial de esta ecuación a densidades de corriente bajas por medio de líneas punteadas. Un análisis más profundo se llevará a cabo en el futuro para determinar las causas del régimen "fluxflow” fuera del estado de equilibrio observado en nuestro sistema.

(a)

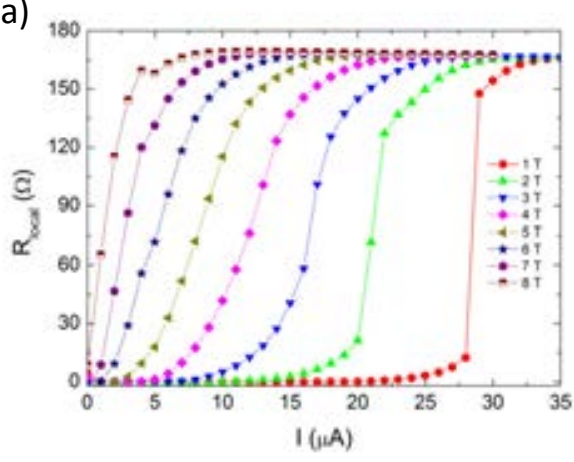

(b)

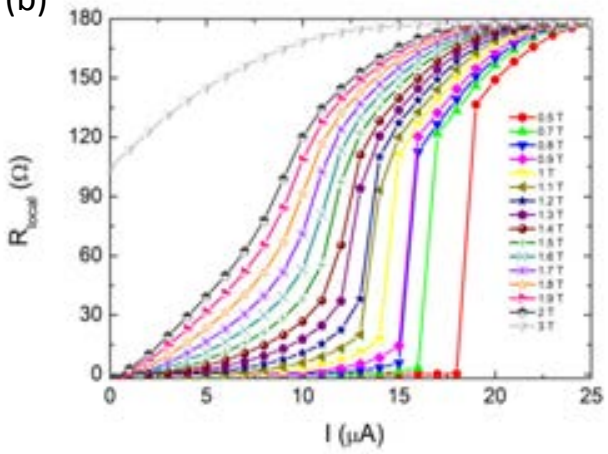

Figura 5.16: Resistencia local en función de la corriente aplicada a distintos campos magnéticos indicados en la leyenda y a temperaturas (a) $1 \mathrm{~K}$ y (b) $4 \mathrm{~K}$.

(a)

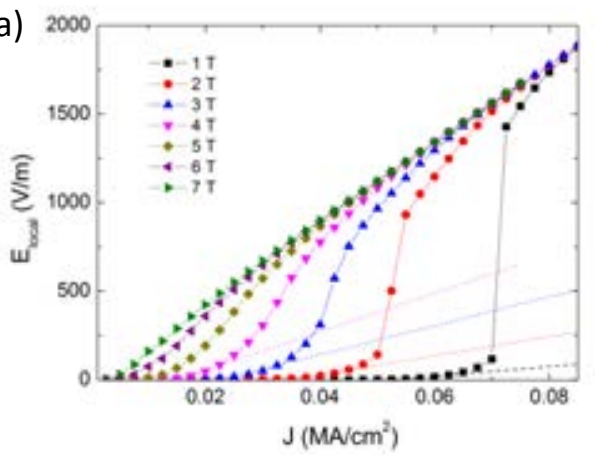

(b)

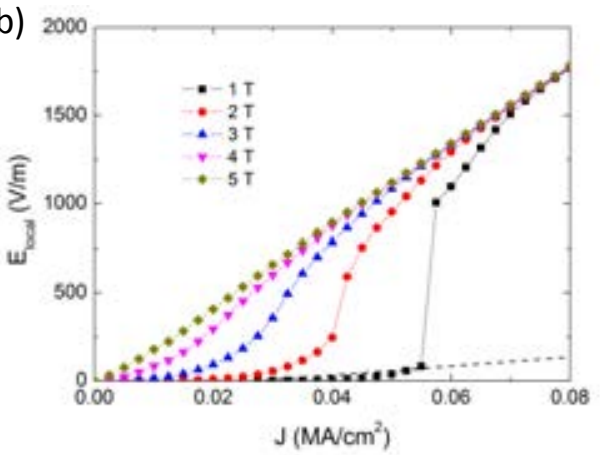

Figura 5.17: Campo eléctrico en función de la densidad de corriente a distintos campos magnéticos indicados en la leyenda y a temperaturas (a) $1 \mathrm{~K}$ y (b) $3 \mathrm{~K}$. 


\subsubsection{Dependencia de la resistencia en función del campo magnético externo}

Como introdujimos en el apartado 1.6 del Capítulo 1, el campo crítico superior, $\mathrm{B}_{\mathrm{c} 2}$, es aquel al cual se suprime la superconductividad de un material. Por tanto, es un importante parámetro a tener en cuenta en nuestro estudio. $\mathrm{B}_{\mathrm{c} 2}$ se estima a partir del estudio de la dependencia de la resistencia con el campo magnético aplicado para diferentes isotermas (2-4.25 K). De esta manera, podemos conocer el rango de campos a los cuales las microestructuras continúan teniendo un comportamiento superconductor. A $2 \mathrm{~K}$, no se aprecia resistencia finita al menor valor de corriente utilizado $(0.1 \mu \mathrm{A})$ con la sensibilidad de nuestro sistema de medida hasta que el campo aplicado no es de al menos $3 \mathrm{~T}$. A partir de ese valor de campo, la resistencia continúa aumentando hasta que la superconductividad se inhibe completamente a $\mathrm{B}_{\mathrm{c} 2}$ 8.44 $\mathrm{T}$ (definida como el valor de campo al cual $\mathrm{R}=0.9 \mathrm{R}_{\mathrm{N}}$ ). El valor de $\mathrm{B}_{\mathrm{c} 2}$ se va reduciendo a medida que aumentamos la temperatura y nos vamos acercando a la $T_{c}$. En la Figura 5.18(a) mostramos los resultados obtenidos en las medidas de la resistencia en función del campo magnético aplicado a distintas corrientes aplicadas a 2 K. Los resultados obtenidos en las medidas de la resistencia en función del campo magnético a distintas temperaturas (entre 0.5 y $4.25 \mathrm{~K}$ ) aplicando $1 \mu \mathrm{A}$ de corriente se representan en la Figura 5.18(b).

De las curvas de la resistencia en función del campo magnético aplicado a distintas corrientes aplicadas extraemos los valores de $B_{c 2}$ y en la Figura 5.19(a) los representamos en función de la densidad de corriente aplicada en el rango de temperaturas estudiado y en la Figura 5.19(b) en función de la temperatura a las distintas corrientes de medida. Como podemos apreciar en la Figura 5.19(a), los valores de $\mathrm{B}_{\mathrm{c} 2}$ para una temperatura fijada apenas varía a baja densidad de corriente. Sin embargo, por encima de $2.5 \times 10^{-3} \mathrm{MA} / \mathrm{cm}^{2}$ descienden más bruscamente al continuar aumentando la densidad de corriente aplicada en todas las isotermas debido a que aumentamos el movimiento de los vórtices y por tanto la disipación de energía que se transforma en valores de resistencia finita. De igual manera, la dependencia de 
$\mathrm{B}_{\mathrm{c} 2}$ en función de la temperatura es decreciente, porque a medida que nos aproximamos a temperaturas cercanas a la $T_{c}$, la longitud de coherencia del material superconductor aumenta como describen las ecuaciones de Ginzburg-Landau (5.1), (5.2), así la densidad de vórtices que penetra en el material necesaria para que el material alcance el estado normal es menor que a baja temperatura.

(a)

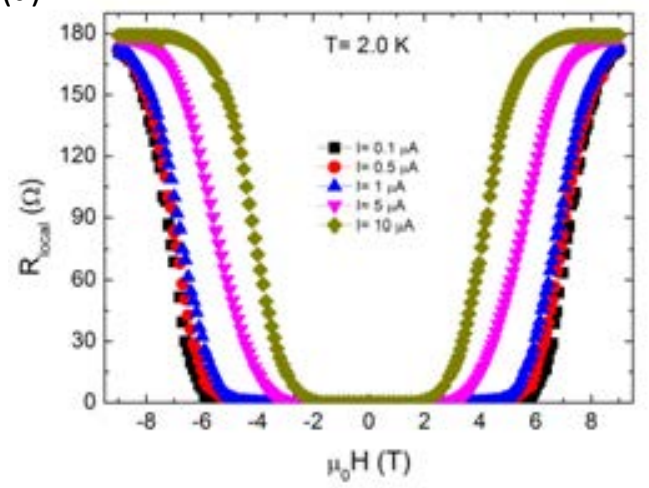

(b)

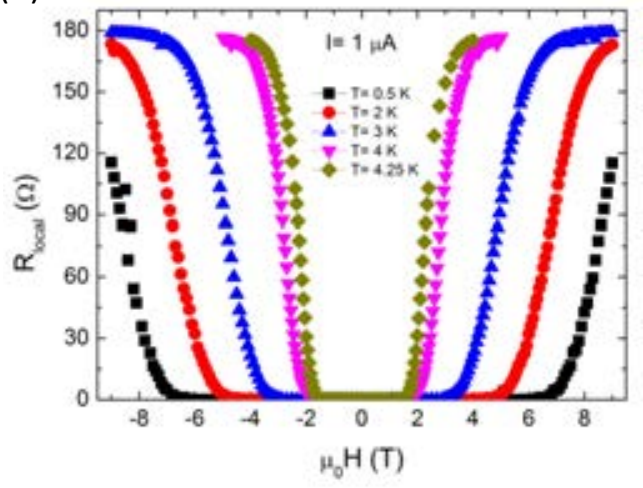

Figura 5.18: (a) Resistencia local en función del campo magnético aplicado positivo y negativo a $2 \mathrm{~K}$ y a corrientes aplicadas de, 0.1, 0.5, 1, 5 y $10 \mu \mathrm{A}$. (b) Resistencia local en función del campo magnético aplicado positivo y negativo a distintas temperaturas (0.5, 2, 3, 4 y $4.25 \mathrm{~K}$ ) a $1 \mu \mathrm{A}$ corriente aplicada.

$$
\begin{aligned}
& \xi \propto \frac{1}{\left(T_{c}-T\right)^{1 / 2}} \\
& H_{c 2}=\frac{\Phi_{0}}{2 \pi \mu_{0} \xi^{2}} \propto 1-\frac{T}{T_{c}}
\end{aligned}
$$


(a)

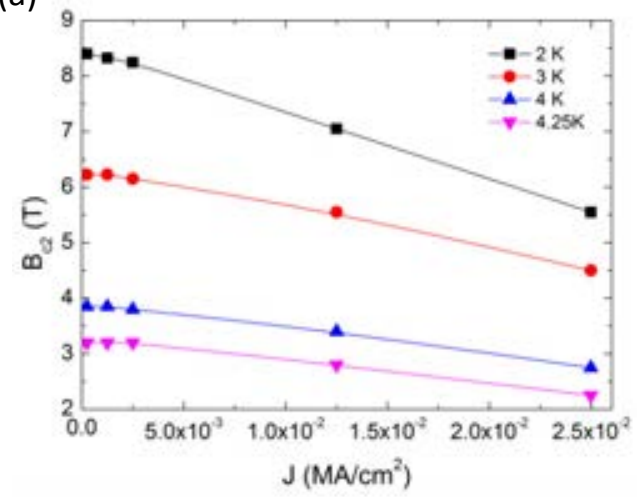

(b)

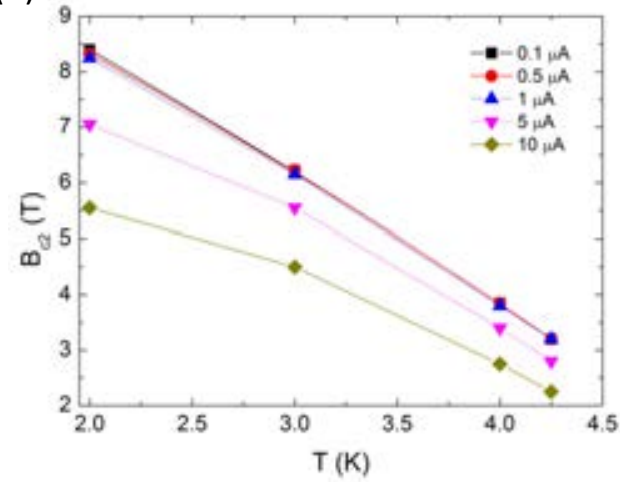

Figura 5.19: Campo magnético crítico superior (definido como el valor de campo al cual $\mathrm{R}=0.9 \mathrm{R}_{\mathrm{N}}$ ) en función de (a) la densidad de corriente a 2, 3, 4 y $4.25 \mathrm{~K}$ y (b) la temperatura a las distintas corrientes aplicadas $(0.1,0.5,1,5$ y $10 \mu \mathrm{A})$.

\subsubsection{Nanohilos superconductores de W ultraestrechos}

En este apartado abordamos el crecimiento y caracterización de NWs superconductores de $\mathrm{W}$ ultraestrechos crecidos mediante FIBID, con un ancho mínimo de $50 \mathrm{~nm}$. Las imágenes SEM in situ se realizaron en los mismos equipos donde se fabricaron las muestras (Nova Nanolab 200, Helios Nanolab 600), permitiendo obtener imágenes de alta resolución de los NWs para la determinación del tamaño lateral. Las medidas de AFM se realizaron para investigar el espesor y uniformidad a lo largo de la longitud de los NWs.

Seis muestras, a las que etiquetamos como M1 a M6 se crecieron utilizando los mismos parámetros de crecimiento: $\mathrm{V}_{\mathrm{i}}=30 \mathrm{kV} ; \mathrm{I}_{\mathrm{i}}=1 \mathrm{pA}$; tiempo de crecimiento= 1 min. En la Figura 5.20(a) se muestra una imagen SEM en la que podemos observar la configuración de las estructuras crecidas para realizar medidas eléctricas por cuatro puntas. En primer lugar, se crece la nanoestructura de W que está compuesta por un NW horizontal de $8 \mu \mathrm{m}$ de longitud y cuatro NWs equidistantes y perpendiculares al primero de $2 \mu \mathrm{m}$ de longitud utilizados como contactos $\mathrm{I}^{+}, \mathrm{V}^{+}, \mathrm{V}^{-}$e $\mathrm{I}^{-}$. La distancia entre los contactos de voltaje es de $2.6 \mu \mathrm{m}$. A continuación, cuatro microhilos de Pt se 
crecieron mediante FIBID utilizando como gas precursor $\left(\mathrm{CH}_{3}\right)_{3} \mathrm{Pt}\left(\mathrm{CpCH}_{3}\right)$ para conectar la nanoestructura de $\mathrm{W}$ y los contactos de $\mathrm{Ti}^{116,172}$. El punto de coincidencia entre el FEB y el FIB está perfectamente alineado, de forma que ajustamos la posición dónde queremos crecer los microhilos utilizando el barrido con electrones, evitando en todo momento la irradiación por FIB del área dónde se encuentra el NW horizontal de W. En la Figura 5.20(b) mostramos una imagen de la muestra M1 de 50 nm de ancho de línea y en (c), mostramos una imagen de AFM de M1 de 30 nm de espesor.

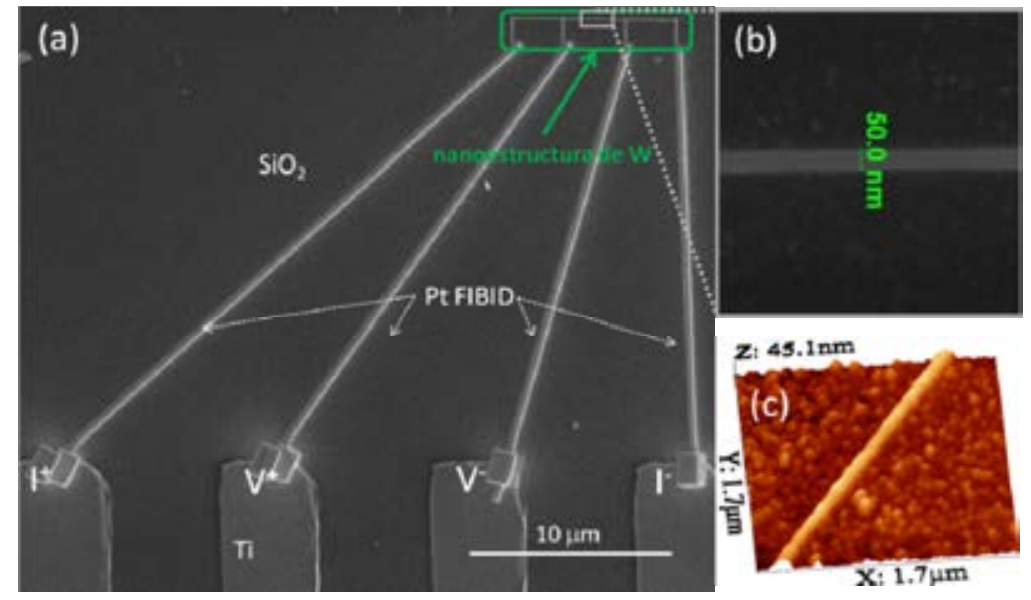

Figura 5.20: (a) Imagen SEM de la configuración para las medidas eléctricas por cuatro puntas, donde indicamos con el cuadrado verde la nanoestructura de $\mathrm{W}$, y mediante flechas blancas los cuatro microhilos de Pt FIBID que la conectan con las líneas de Ti. (b) Imagen SEM del NW horizontal de W M1 a altos aumentos. (c) Imagen AFM del NW horizontal de W M1.

Tomamos la muestra M1 como ejemplo de las muestras estudiadas. Así, representamos la dependencia de su resistencia normalizada en función de la temperatura aplicándole una corriente de medida de $0.1 \mu \mathrm{A}$ en la Figura 5.21(a) y la resistencia normalizada en función de la corriente aplicada para distintas temperaturas en la Figura 5.21(b). La $\mathrm{T}_{\mathrm{c}}$ se determina como el punto medio de la transición $\left(R_{\text {normalizada }}=0.5\right)$ y los valores estimados para las seis muestras están entre $4.2 \mathrm{~K}$ y 4.8 
$\mathrm{K}$, muy próximos a los valores obtenidos para las nanoestructuras de $\mathrm{W}$ tanto por otros autores como en nuestros experimentos previos, de $\mathrm{T}_{\mathrm{c}} \sim 5 \mathrm{~K}^{190,191,193,195,202-204}$.

(a)

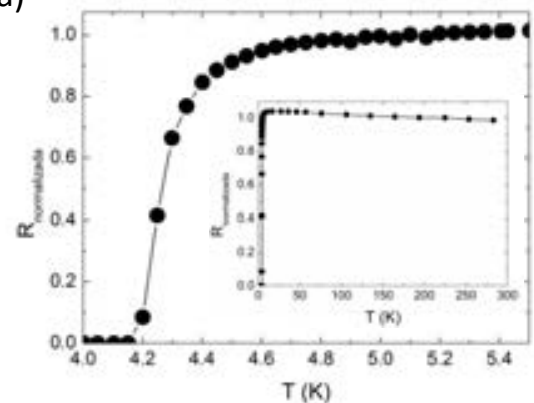

(b)

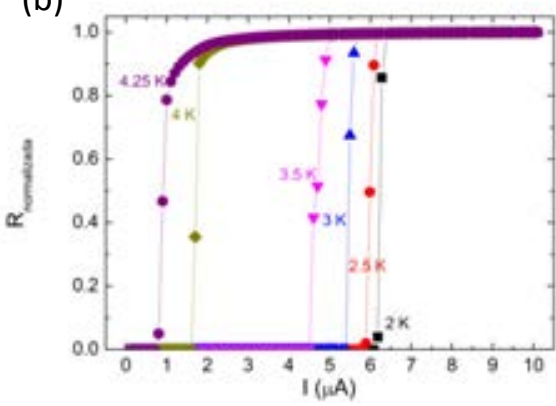

Figura 5.21: (a) Resistencia normalizada en función de la temperatura del NW de W ultraestrecho M1. (b) Resistencia normalizada en función de la corriente aplicada del NW de W ultraestrecho M1.

\begin{tabular}{c|ccccc}
\hline Muestra & $\begin{array}{c}\text { ancho } \\
(\mathbf{n m})\end{array}$ & $\begin{array}{c}\text { espesor } \\
(\mathbf{n m})\end{array}$ & $\begin{array}{c}\boldsymbol{\rho}_{300 K} \\
(\boldsymbol{\mu} \boldsymbol{\Omega} \mathbf{c m})\end{array}$ & $\begin{array}{c}\boldsymbol{T}_{\boldsymbol{c}} \\
(\boldsymbol{K})\end{array}$ & $\begin{array}{c}\boldsymbol{J}_{\boldsymbol{c} \mathbf{2 K}} \\
\left(\mathbf{M A} \mathbf{c m} \mathbf{c m}^{2}\right)\end{array}$ \\
\hline M1 & $50 \pm 5$ & $30 \pm 5$ & 172 & 4.25 & 0.41 \\
M2 & $60 \pm 5$ & $49 \pm 5$ & 254 & 4.50 & 0.22 \\
M3 & $60 \pm 5$ & $37 \pm 5$ & 215 & 4.75 & 0.19 \\
M4 & $65 \pm 5$ & $44 \pm 5$ & 223 & 4.42 & 0.16 \\
M5 & $70 \pm 5$ & $44 \pm 5$ & 276 & 4.37 & 0.15 \\
M6 & $50 \pm 5$ & $30 \pm 5$ & 205 & 4.80 & 0.36 \\
\hline
\end{tabular}

Tabla 5.3: Dimensiones de los NWs (ancho y espesor) y propiedades físicas estudiadas (resistividad a $300 \mathrm{~K}$, temperatura de transición crítica y densidad de la corriente crítica a $2 \mathrm{~K}$ ).

En la Tabla 5.3 resumimos los parámetros más relevantes de los NWs ultraestrechos superconductores de W. Las medidas de la corriente crítica reproducen la relativamente alta $\mathrm{J}_{\mathrm{c}}$ (en el rango de $\sim 10^{5} \mathrm{~A} / \mathrm{cm}^{2}$ ) previamente obtenida para este material ${ }^{101}$. 
A continuación, centraremos el estudio en la dependencia de la resistencia con el campo magnético aplicado en la muestra M1, aunque el mismo efecto ha sido evidenciado en las demás nanoestructuras estudiadas en este apartado. Las medidas de magnetotransporte de varias isotermas muestran la presencia de un mínimo en resistencia, o lo que es lo mismo, la reentrada de un estado libre de disipación de energía asociada a un rango de campos magnéticos bien definidos. En la Figura 5.22 representamos la resistencia normalizada de M1 en función del campo magnético a distintas isotermas (de 3.2 a $4 \mathrm{~K}$ ) al aplicar $0.5 \mu \mathrm{A}$ de corriente.

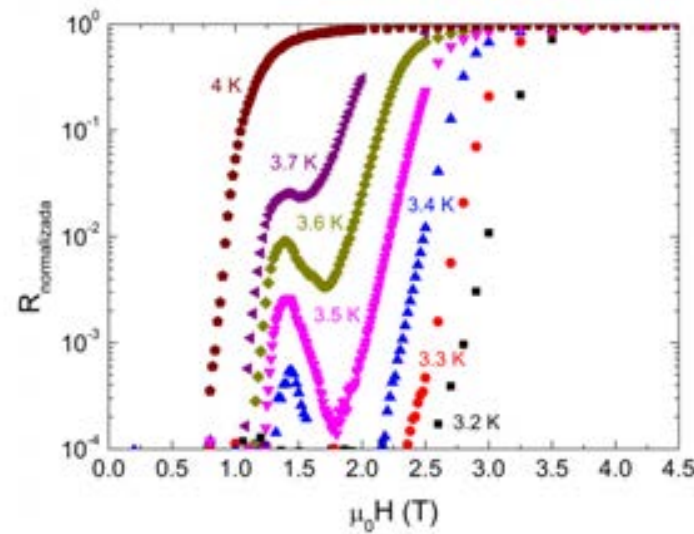

Figura 5.22: Resistencia normalizada de la muestra M1 (en escala logarítmica) en función del campo magnético aplicado a distintas temperaturas, de $3.2 \mathrm{~K}$ a $4.0 \mathrm{~K}$ a $0.5 \mu \mathrm{A}$ de corriente aplicada.

Lo primero que destacamos teniendo en cuenta la sensibilidad del instrumento de medida (nivel de ruido $100 \mathrm{nV}$ ) es que a $\mathrm{B}<0.78 \mathrm{~T}$ no se observa un valor de resistencia finita. A $4 \mathrm{~K}$ podemos medir $10^{-4}$ de $\mathrm{R}_{\text {normalizada }}$ a $0.78 \mathrm{~T}$, que lo llamaremos $\mathrm{B}_{\text {inicio }} \mathrm{y}$ depende de la temperatura. Si continuamos incrementando el campo magnético aplicado, primero la resistencia aumenta exponencialmente de acuerdo con la ecuación (1.15) que se correspondería al mecanismo de "phase slips” y entonces crece suavemente hasta que alcanza el valor de $R_{\text {normalizada }}$ A baja temperatura este comportamiento cambia radicalmente, la curva de resistencia en función del campo 
magnético aplicado adquiere una peculiar forma de $N$. Por encima de $B_{\text {inicio }}(T)$, el aumento de resistencia continúa describiendo un crecimiento de tipo exponencial, este comportamiento se detiene para alcanzar un máximo en $\mathrm{B}_{\text {máx }} \mathrm{y}$ después desciende hasta un mínimo a $\mathrm{B}_{\text {mín. }}$ Al descender la temperatura, los valores de $\mathrm{B}_{\text {inicio }}$, $\mathrm{B}_{\text {máx }}, \mathrm{B}_{\text {mín }}$ aumentan ligeramente, la forma de $\mathrm{N}$ de la curva es más pronunciada y el descenso de la resistencia hasta $\mathrm{B}_{\text {mín }}$ es mucho más rápido. Por debajo de $3.3 \mathrm{~K}$, la resistencia cae a valores por debajo de lo que podemos medir en nuestro sistema de medida, sin que se pueda apreciar la subida de la resistencia en $\mathrm{B}_{\text {máx }} \mathrm{y}$ comenzamos a medir valores de resistencia a B> 2 T. Un mínimo en resistencia similar se observó en hilos superconductores de $\mathrm{Pb}$ amorfos $\mathrm{y}$ homogéneos crecidos in situ ${ }^{208}$. Las nanoestructuras estudiadas tienen tanto el ancho de línea como el espesor del mismo orden de magnitud que la longitud de coherencia, $\xi$. De esta forma, sus propiedades pueden verse afectadas por la superconductividad de superficie que debemos tener en consideración en el análisis de nuestros resultados, así el campo crítico a considerar es $\mathrm{B}=\mathrm{B}_{\mathrm{c} 3}=1.695 \mathrm{~B}_{\mathrm{c} 2}{ }^{209}$. La superconductividad en las muestras masivas se suprime cuando $\mathrm{B}_{\mathrm{c} 2}<\mathrm{B}<\mathrm{B}_{\mathrm{c} 3}$, pero una capa superconductora persiste cerca de la superficie. Por ejemplo, el parámetro de orden $\Psi$ es máximo en los bordes y desciende cuando se adentra en el material masivo ${ }^{76}$. Así, la capa superconductora cortocircuitaría la resistencia formando canales en los bordes que llevarían la mayoría de las supercorrientes. La reentrada de la superconductividad podría explicarse por la superconductividad generada en los bordes de nuestras nanoestructuras cuando las dimensiones laterales de los NWs de wolframio son comparables a su $\xi$. La superposición de las dos ramas del $\Psi$ correspondería a la nucleación en sus bordes, llevándonos a una cadena equidistante de nodos de $\Psi$ a lo largo del plano. Esto se corresponde con una cadena de vórtices que estarían separados una distancia que se puede estimar como $a \approx \phi_{0} /\left[\left(w-w_{c}\right) B\right]$, donde $\phi_{0}$ es un cuanto de flujo y $\mathrm{w}_{\mathrm{c}}$ es el ancho crítico del NW que puede acomodar vórtices ${ }^{76}$ con un valor cercano a $\mathrm{w}_{\mathrm{c}} \approx 1.8 \xi$ 210 .

La reentrada de la superconductividad en nuestras muestras se observó a $\mathrm{T} \leq 3.7$ K. A $3.7 \mathrm{~K}$, la longitud de coherencia es de $17.2 \mathrm{~nm}$, la cual es próxima a $\sim \mathrm{W} / 3$. Se 
realizaron simulaciones numéricas a partir de las ecuaciones de Ginzburg-Landau teniendo en cuenta los parámetros superconductores de nuestro material en M1 (véase la Figura 5.23(a)); con las cuales verificamos que el NW está dentro del régimen en el que la disipación de energía está dominada por el movimiento de los vórtices y en la posición de equilibrio solamente una cadena de vórtices podría ajustarse en M1. Detalles del proceso de minimización de la energía libre realizado por el Dr. J. J. Palacios se pueden encontrar en la referencia ${ }^{211}$. De esta manera, podríamos explicar que el mecanismo de disipación de energía observado en la Figura 5.22 está gobernado por la dinámica de una fila de vórtices que se mueve cruzando el nanohilo. El cambio rápido en la resistencia como respuesta al moderado cambio en la temperatura de operación indica un comportamiento del mecanismo de disipación activado térmicamente.

El desplazamiento de un único vórtice fuera de la cadena y su posterior salida es energéticamente más favorable que el movimiento lateral de la cadena como un todo, porque el vórtice que se desvía de la línea de la cadena sufre la fuerza de repulsión de otros vórtices en la cadena intentando expulsarlo aún más lejos. A la inversa, para la penetración de los vórtices en el NW, la interacción de atracción entre los vórtices es más débil que la energía por vórtice debido a la interacción de la cadena de vórtices con su imagen. La solución numérica de las ecuaciones de Ginzburg-Landau permite obtener una distribución espacial del parámetro de orden a distintas temperaturas y campos magnéticos como podemos observar en la Figura 5.23(a). En primer lugar debemos señalar que por encima de $\mathrm{T} \approx 3.8 \mathrm{~K}$, los vórtices no se ajustan en el NW a ningún campo magnético de acuerdo con los resultados obtenidos por Fink et al. ${ }^{210}$, por tanto la disipación de energía se produce debido al régimen de "phase slips". En los paneles superiores de la Figura 5.23(a) se representa el parámetro de orden a $3.1 \mathrm{~K}$ y en los paneles inferiores a $3.7 \mathrm{~K}$. Los campos $\mathrm{B}=1.9 \mathrm{~T}$ y $\mathrm{B}=1.326 \mathrm{~T}$, corresponden a los valores de campo a los cuales las barreras de energía por vórtice son máximas a su respectiva temperatura cuando la cadena de vórtices se mueve a través de la superficie y los campos $\mathrm{B}=2.35 \mathrm{~T}$ y $\mathrm{B}=1.53 \mathrm{~T}$ corresponden a la total inhibición de la 
superconductividad, donde el núcleo de los vórtices comienza a solaparse a su respectiva temperatura (véanse los paneles inferiores de la Figura 5.23(a)).

(a)

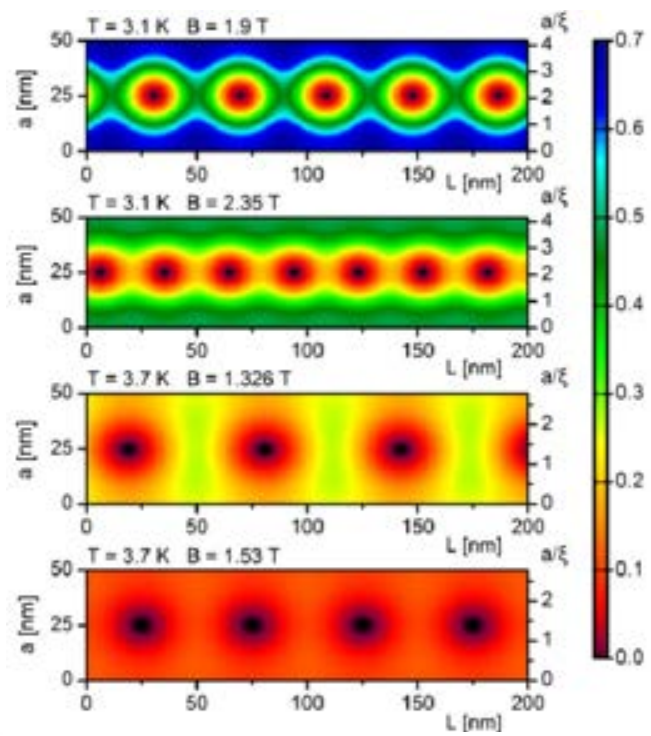

(b)

\begin{tabular}{l|ccccc}
\hline$T(K)$ & 4.25 & 4.0 & 3.7 & 3.4 & 3.1 \\
\hline$\xi(\mathrm{nm})$ & 35 & 27 & 18 & 14 & 12 \\
$\mathrm{H}_{\mathrm{c} 1}(\mathrm{~T})$ & & & 1.10 & 1.14 & 1.29 \\
$\mathrm{H}_{\mathrm{c} 3}(\mathrm{~T})$ & 0.67 & 0.88 & 1.73 & 2.84 & 3.86 \\
\hline
\end{tabular}

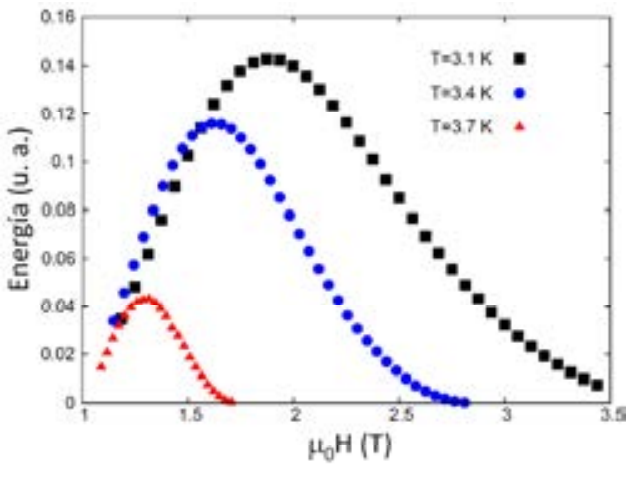

Figura 5.23: (a) Distribución del parámetro de orden $|\Psi|^{2}$ en el NW superconductor a 3.1 $\mathrm{K}$ (dos paneles superiores) y campos $\mathrm{B}=1.9 \mathrm{~T}$ y $\mathrm{B}=2.35 \mathrm{~T}$, y a $3.7 \mathrm{~K}$ (dos paneles inferiores) y campos $\mathrm{B}=1.326 \mathrm{~T}$ and $\mathrm{B}=1.53 \mathrm{~T}$. Los campos $\mathrm{B}=1.9 \mathrm{~T}$ y $\mathrm{B}=1.326 \mathrm{~T}$ corresponden a campos magnéticos donde las alturas de las barreras por vórtices tienen su máximo a la respectiva temperatura. Los campos $\mathrm{B}=2.35 \mathrm{~T}$ y $\mathrm{B}=1.53 \mathrm{~T}$ se toman cerca de la total inhibición de la superconductividad en el hilo. Todos los paneles muestran la reentrada de la superconductividad cerca de los bordes, pero a la menor temperatura $3.1 \mathrm{~K}$ este efecto es relativamente más pronunciado. (b) Altura de la barrera de superficie para varias temperaturas en función del campo magnético. Primero, la energía libre de una fila de vórtices está en función de su posición a lo largo de la estructura, $\mathrm{G}(\mathrm{x})$, se ha calculado respecto a la energía libre estable termodinámicamente, estado de corriente cero, $\mathrm{G}(0)$. La altura de la barrera se identifica con la máxima diferencia obtenida (normalmente cuando los vórtices están cerca del borde).

De forma cualitativa podemos observar claramente en la Figura 5.23(a), el realce del parámetro de orden cerca de los bordes. Estos canales de superconductividad de 
ancho $\sim \xi$ representan las barreras de entrada y salida de vórtices. En el intervalo de campo $\mathrm{B}_{\mathrm{c} 2}<\mathrm{B}<\mathrm{B}_{\mathrm{c} 3}$ el interior del NW se vuelve normal, salvo en los bordes donde la superconductividad sobrevive hasta $\mathrm{B}=\mathrm{B}_{\mathrm{c} 3}$, la llamada superconductividad de superficie ${ }^{209}$.

Por otra parte, la reentrada del estado de resistencia nula podría reforzarse por la formación de un hipervórtice en el centro del NW debido al solapamiento de los núcleos de los vórtices que permitiría la existencia de tres capas dentro del NW, una normal en el centro y dos superconductoras en los extremos como podemos observar en la Figura 5.24.

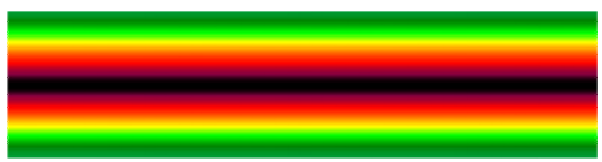

Figura 5.24: Dibujo explicativo del estado en el cual el NW formado por tres capas recupera la superconductividad. La banda central de color negro indica el estado metálico y las bandas estrechas de color verde muestran la superconductividad realzada en los bordes del NW. El solapamiento de los núcleos de los vórtices nos lleva hacia la formación de un hipervórtice en el centro del NW y canales superconductores en los bordes del NW en el rango $\mathrm{B}_{\text {máx }}<\mathrm{B}<\mathrm{B}_{\mathrm{c} 3}$.

Un comportamiento similar en las curvas con forma de $\mathrm{N}$ se observa al descender la corriente aplicada a $0.25 \mu \mathrm{A}$ y $0.1 \mu \mathrm{A}$ e incluso aumentándola hasta $1 \mu \mathrm{A}$, en las cuales el mínimo en resistencia se observa entre 3.2-3.7 K. Con el objetivo de verificar que el efecto de la reentrada de la superconductividad observada no depende del modo de medida, ni se modifica con el cambio de polaridad del campo magnético aplicado se realizaron medidas en modo AC y $\mathrm{DC}$ de +9 a $-9 \mathrm{~T}$ dentro del rango de temperaturas adecuadas. No se observó histéresis en el valor del campo en el que la resistencia alcanza el mínimo tanto a campos positivos como negativos. 
El estudio de la dinámica de vórtices en estas nanoestructuras mediante técnicas de STM/S, nos proporcionaría la imagen directa de la disposición de los vórtices y aportaría más luz a los efectos de la reentrada de la superconductividad en el estudio del magnetotransporte. Este estudio de gran interés, es sin embargo extremadamente complejo y no ha podido abordarse con éxito hasta la fecha.

\subsubsection{Resumen y conclusiones}

En la Tabla 5.4 resumimos los parámetros de crecimiento y las propiedades superconductoras estudiadas en las distintas estructuras superconductoras de wolframio mediante medidas eléctricas en el modo local.

\begin{tabular}{l|ccc}
\hline & Microhilos & Nanohilos & $\begin{array}{c}\text { Nanohilos } \\
\text { ultraestrechos }\end{array}$ \\
\hline $\mathrm{V}_{\mathrm{i}}(\mathrm{kV})$ & 30 & 30 & 30 \\
$\mathrm{I}_{\mathrm{i}}(\mathrm{nA})$ & 0.92 & 0.029 & 0.001 \\
Ancho $(\mathrm{nm})$ & 2000 & 200 & 50 \\
Espesor $(\mathrm{nm})$ & 300 & 200 & 30 \\
$\rho_{300 \mathrm{~K}}(\mu \Omega \mathrm{cm})$ & 214 & 255 & 172 \\
$\mathrm{~T}_{\mathrm{c}}(\mathrm{K})$ & 4.95 & 5.10 & 4.25 \\
$\mathrm{~J}_{\mathrm{c}}\left(\mathrm{MA} / \mathrm{cm}^{2}\right)$ & $0.013(2.5 \mathrm{~K})$ & $0.094(1 \mathrm{~K})$ & $0.41(2 \mathrm{~K})$ \\
$\mathrm{B}_{\mathrm{c} 2,2 \mathrm{~K}}(\mathrm{~T})$ & $\sim 7$ & 8.44 & 4.72 \\
\hline
\end{tabular}

Tabla 5.4: Resumen de los parámetros de crecimiento, dimensiones (ancho y espesor), resistividad a $300 \mathrm{~K}$ y propiedades superconductoras (temperatura de transición crítica, densidad de la corriente crítica y campo crítico superior) de las distintas estructuras superconductoras de wolframio estudiadas mediante medidas eléctricas en el modo local. 
Además de la reentrada de la superconductividad observada en los NWs superconductores ultraestrechos y explicada en detalle en el apartado anterior, las diferencias fundamentales detectadas entre estructuras de distinto ancho lateral se encuentran en los valores de $\mathrm{J}_{\mathrm{c}}$ y $\mathrm{B}_{\mathrm{c} 2,2 \mathrm{~K}}$. La densidad de corriente crítica en ausencia de campo magnético externo en los NWs superconductores ultraestrechos de W es un orden de magnitud superior que los valores explorados tanto en microhilos como en nanohilos. En un material masivo, como consideraríamos a los microhilos y nanohilos de $\mathrm{W}$, los valores de la densidad de corriente crítica vendrían gobernados por la fuerza de anclaje. Sin embargo, al reducir las dimensiones de las estructuras a valores próximos a $\xi$, se conserva la superconductividad en los bordes de las estructuras, por lo que se necesita más densidad de corriente para superar esa barrera de energía ${ }^{212-214}$. Sin embargo, el campo crítico superior en los NWs superconductores ultraestrechos de $\mathrm{W}$ es al menos un factor 1.5 inferior que los resultados obtenidos en microhilos y en nanohilos. Este comportamiento vendría dado por el mecanismo de disipación de energía que gobierna exclusivamente en este tipo de nanoestructuras ultraestrechas en las cuales el ancho de línea o espesor es del mismo orden que la longitud de coherencia. En este caso concreto, el fenómeno de "phase slip" es el mecanismo que gobierna la disipación de energía en las curvas de resistencia en función del campo magnético externo al aplicar una corriente de medida por encima de $3.8 \mathrm{~K}$. 


\subsection{Transporte eléctrico en modo no local en nanohilos superconductores de wolframio}

En este apartado abordamos la caracterización del transporte eléctrico no local en los NWs superconductores de $\mathrm{W}$ crecidos mediante FIBID, con un ancho lateral y espesor de $\sim 200 \mathrm{~nm}$ que mostramos en el apartado 5.2 del presente capítulo.

En sistemas superconductores de tipo II con anclaje débil sometidos a un campo magnético aplicado perpendicular al plano, y a una corriente en el NW horizontal superior que actúa sobre los vórtices situados en esa región, empujándolos en la dirección del NW vertical debido a la fuerza de Lorentz, se genera un voltaje no local en el NW horizontal inferior (véase la Figura 5.25 y 1.25). La repulsión entre los vórtices junto con la densidad de vórtices determinada por el campo magnético externo aplicado nos lleva a una eficiente transferencia de presión de la fuerza generada de la red de vórtices a través del NW vertical, y una vez que los vórtices se mueven hacia la cruz de abajo, un voltaje no local se genera mediante la relación de éste con el campo eléctrico, ecuación (1.7), $\vec{E}=\vec{B} \times \vec{v}_{\phi}{ }^{106-109}$.

Teniendo en cuenta la geometría de la muestra ( $\mathrm{L}=$ largo, a=ancho, e=espesor), a una densidad de vórtices dada por el campo magnético aplicado $n_{\phi}=B / \phi_{0}$, existe un número de vórtices $\mathrm{N}=\mathrm{n}_{\phi} \mathrm{a}^{2}$ en la cruz superior del $\mathrm{NW}$ horizontal que experimentan la fuerza de Lorentz $\mathrm{F}_{\mathrm{L}}=\mathrm{J} \phi_{0} \mathrm{e}$ debido a la densidad de corriente aplicada $\mathrm{J}=\mathrm{I} / \mathrm{ae}$, aplicando una presión sobre los vórtices en el canal vertical tal que:

$$
p=\frac{n_{\Phi} \Phi_{0} I}{e}
$$

Multiplicando por el área, la fuerza de empuje por unidad de longitud es:

$$
f=\frac{p A}{e}=p a
$$


el área, $A=a e$. Sustituimos (5.3) en (5.4) y lo equilibramos con la fuerza necesaria para mover un número de vórtices $\mathrm{N}$ a través del canal venciendo la fuerza de fricción que experimentan los vórtices (5.5).

$$
\frac{n_{\Phi} \Phi_{0} I a}{e}=n_{\Phi} L a \eta v_{\varphi}
$$

$v_{\varphi}$ es la velocidad de un vórtice en el NW. Despejamos $v_{\varphi}$ de la ecuación (5.5) y llegamos a la (5.6).

$$
v_{\varphi}=\frac{\Phi_{0} I}{\eta L e}
$$

Teniendo en cuenta que $V_{\text {no local }}=a B v_{\varphi}$, sustituimos (5.6) en esta expresión y obtenemos la ecuación (5.7).

$$
\begin{aligned}
V_{\text {no local }} & =\frac{a B \Phi_{0} I}{\eta L e} \\
R_{\text {no local }} & =\frac{V_{\text {no local }}}{I}=\frac{a B \Phi_{0}}{\eta L e}
\end{aligned}
$$

El modelo propuesto explica muy bien el comportamiento observado de la señal no local. La fuerza de anclaje impide el movimiento de vórtices por debajo de un cierto umbral de campo magnético, tanto en la señal local como en la no local. Nuestro material amorfo y con anclaje débil parece tener una fuerte densidad de centros de anclaje que primero se ocupan durante la nucleación de los vórtices, y cuando estos están saturados, los vórtices pueden moverse a lo largo del eje fácil. El hecho de que la señal no local se pueda propagar a lo largo de distancias del orden de micras comparadas con la distancia de separación entre vórtices puede ser atribuido a la rigidez de la red de vórtices. En el mecanismo propuesto, el confinamiento de los vórtices a lo largo del NW podría ser debido al anclaje superficial a lo largo de los bordes de éste. Medidas en NWs más estrechos con menos transferencia eficaz de la 
presión señalan hacia una región del orden de 50 nm donde los vórtices están fuertemente anclados a lo largo de los bordes, de tal manera que dentro de la muestra los caminos de flujo están formados ${ }^{215}$.

Otro resultado de Grigorieva ${ }^{78}$ fue la exitosa atribución de la estructura fina de la señal no local a cambios en la configuración de los vórtices, tales como la entrada de vórtices adicionales, o disclinaciones de la red debido al bloqueo de los vórtices en la cruz de abajo.

\subsubsection{Configuración de medida}

En la Figura 5.25 se muestra una imagen SEM en la que podemos observar la configuración de las estructuras superconductoras de $\mathrm{W}$ crecidas mediante FIBID a $\mathrm{V}_{\mathrm{i}}=30 \mathrm{kV}, \mathrm{I}_{\mathrm{i}}=29 \mathrm{pA}$, con un ancho lateral y espesor de $\sim 200 \mathrm{~nm}$. Esta configuración es propicia para realizar medidas eléctricas en el modo no local, en la cual los contactos donde se inyecta corriente y se mide la caída de voltaje están indicados. La nanoestructura de W está compuesta por un NW vertical de $5 \mu \mathrm{m}$ de longitud y cuatro NWs perpendiculares al primero de $3 \mu \mathrm{m}$ de longitud utilizados como contactos $\mathrm{I}^{+}, \mathrm{V}^{+}$, $\mathrm{V}^{-}$y I'. La distancia entre los contactos de corriente y de voltaje es de $3 \mu \mathrm{m}$. A continuación, se crecieron mediante FIBID cuatro microhilos de Pt para conectar la nanoestructura de $\mathrm{W}$ y los contactos de $\mathrm{Ti}^{116,172}$. El punto de coincidencia entre el FEB y el FIB está perfectamente alineado, de forma que ajustamos la posición en la cual queremos crecer los NWs utilizando el barrido con electrones, evitando en todo momento la irradiación por FIB del área en la que se encuentra el NW perpendicular de W. 


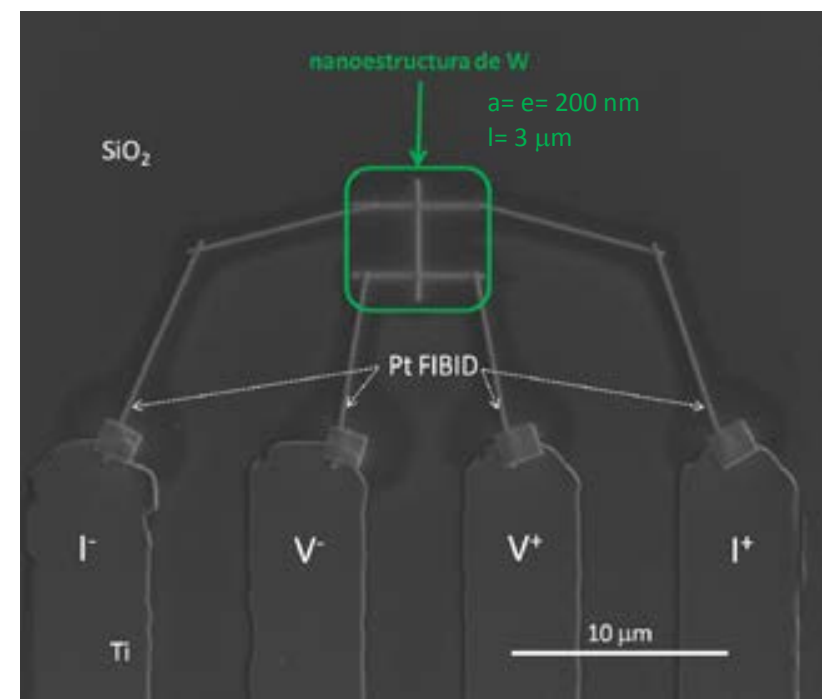

Figura 5.25: Imagen SEM de la configuración para las medidas eléctricas no locales. Indicamos con el cuadrado verde la nanoestructura de $\mathrm{W}$, y mediante flechas blancas los cuatro microhilos de Pt FIBID que la conectan con las líneas metálicas de Ti.

\subsubsection{Dependencia del voltaje no local con la corriente bajo campo magnético externo}

De forma sistemática se realizaron medidas del voltaje no local en función de la corriente aplicada (de 0 a $40 \mu \mathrm{A}$ ) en modo AC a bajas temperaturas $(0.5,1,2 \mathrm{~K}$ ) y a campos magnéticos aplicados (de 1 a 9 T) indicados en la leyenda. En la Figura 5.26 mostramos la evolución de las curvas en las cuales se ha observado un voltaje no local a $0.5 \mathrm{~K}$ que se ajustaría al modelo descrito previamente a través de la ecuación (5.7). La eficiente transferencia de presión que se produce sobre el NW vertical debida a la fuerza de Lorentz generada en la cruz superior perpendicular a la corriente aplicada desplaza la red de vórtices por el NW vertical hasta llegar a la cruz inferior donde se mide el voltaje no local. Sin embargo, debemos tener una densidad de vórtices mínima en el NW para que se produzca la eficiente transferencia de presión y además, superar la fuerza de anclaje de la red para desplazarla a lo largo del NW vertical. Así, a medida que se incrementa el campo magnético aplicado, el $V_{\text {no local }}$ máximo aumenta 
hasta que se anula a $9 \mathrm{~T}$, cuando el NW alcanza el estado normal. Debemos hacer constar que el $V_{\text {no local }}$ no se observa en todos los casos desde el momento en el que se hace pasar una corriente por el NW horizontal superior tal y como se observa en las referencias ${ }^{106,108,109}$. A cada valor de campo, la red de vórtices tiene una fuerza de anclaje distinta que vencer que hace que el pico o $\mathrm{V}_{\text {no local }}$ máximo se observe a menor corriente cuanto mayor es el campo magnético aplicado, es decir, cuanto mayor es la densidad de vórtices en el NW, menor es la densidad de corriente necesaria para desanclar los vórtices y que éstos se desplacen a lo largo del NW vertical.

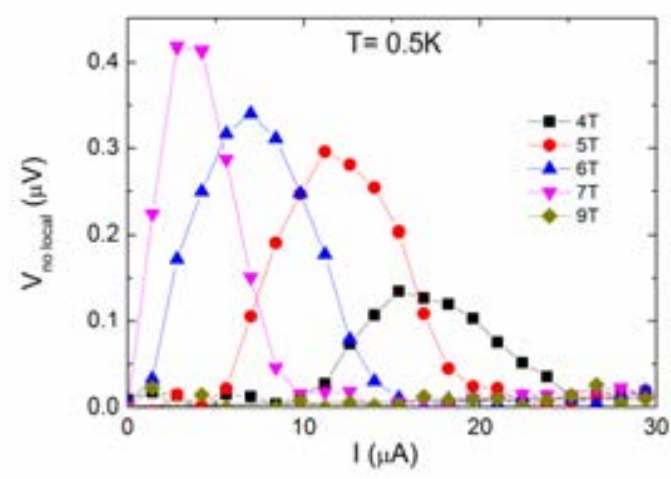

Figura 5.26: (a) Voltaje no local en función de la corriente aplicada a $0.5 \mathrm{~K}$ y a distintos campos magnéticos.

Además, observamos que a partir de un cierto valor de corriente, el $\mathrm{V}_{\text {no local }}$ descience hasta anularse completamente. Este efecto estaría asociado a valores de corriente próximos a los de la corriente crítica a esa temperatura y campo magnético aplicado.

Para comprobar el efecto de la polaridad de la corriente en el $\mathrm{V}_{\text {no local }}$ de nuestras muestras realizamos medidas en modo DC. La curva del $V_{\text {no local }}$ en función de la corriente entre $50 \mu \mathrm{A}$ y $-50 \mu \mathrm{A}$ medido a $2 \mathrm{~K}$ y $-5 \mathrm{~T}$ en modo DC se representa en la Figura 5.27, junto con la curva de $\mathrm{V}_{\text {no local }}$ en función de la corriente de 0 a $30 \mu \mathrm{A}$ medido a $2 \mathrm{~K}$ y $5 \mathrm{~T}$ en modo AC. Lo primero que destacamos es la asimetría de la 
señal no local y su dependencia lineal a baja corriente, entre 5 y $-5 \mu \mathrm{A}$, que seguiría la misma dependencia que la medida realizada en el modo AC. Por encima de $20 \mu \mathrm{A}$, la señal se convierte en una señal no local simétrica que no depende de la polaridad de la corriente y por tanto, en la medida en el modo AC se anula. Como la corriente sólo se aplica en el NW horizontal superior podemos esperar que se genere un gradiente de temperatura entre ese NW y el NW horizontal inferior y el vertical, lo cual implicaría la existencia del movimiento debido a un gradiente térmico que explicaría la señal simétrica del $\mathrm{V}_{\text {no local }}$ en la medida en DC, una vez que el NW horizontal superior fuera normal.

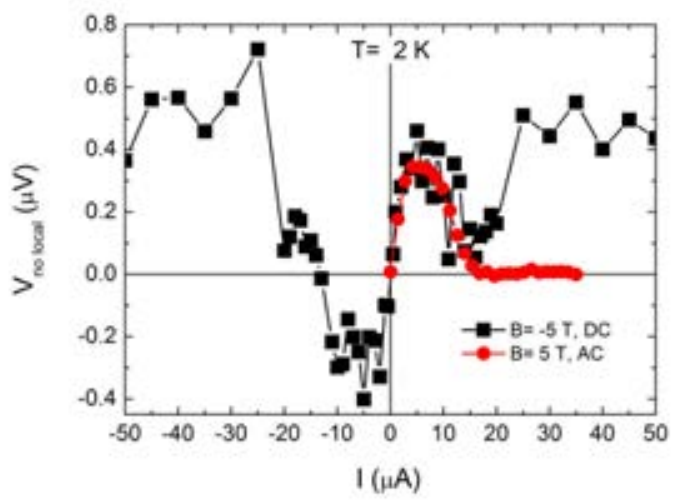

Figura 5.27: Voltaje no local en función de la corriente aplicada a $2 \mathrm{~K}$ en el modo DC a -5 $\mathrm{T}$ y en el modo AC a $5 \mathrm{~T}$.

\subsubsection{Dependencia de la resistencia no local en función del campo magnético externo}

El voltaje no local generado a una temperatura y una corriente dadas aparece a un cierto valor de campo magnético aplicado perpendicular a la muestra, el cual puede estar asociado con el desanclaje de la red de vórtices y específicamente, con la saturación de centros de anclaje antes de que a elevadas densidades de vórtices la red pueda moverse. Entonces se alcanza el máximo valor de resistencia no local alrededor de un valor de campo y se va reduciendo hasta cero cuando nos acercamos al valor del 
campo crítico superior $\left(\mathrm{B}_{\mathrm{c} 2}\right)$. Como ejemplo de ello, mostramos la $\mathrm{R}_{\text {no local }} \mathrm{y}$ la $\mathrm{R}_{\text {local }}$ medidas en el modo AC a $2 \mathrm{~K}$ y $0.5 \mu \mathrm{A}$ de corriente aplicada en función del campo magnético (de 9 T a -9 T) en la Figura 5.28(a) y la $\mathrm{R}_{\text {no local }}$ en el modo DC a 2 K y 1, 5 y $10 \mu \mathrm{A}$ de corriente aplicada en función del campo magnético (de 9 T a -9 T) en la Figura 5.28(b). La única diferencia entre los resultados obtenidos en el modo AC y DC, es que en modo DC tenemos una señal más ruidosa, debido al tipo de medida como explicamos en el apartado 2.6.2 del Capítulo 2.

(a)

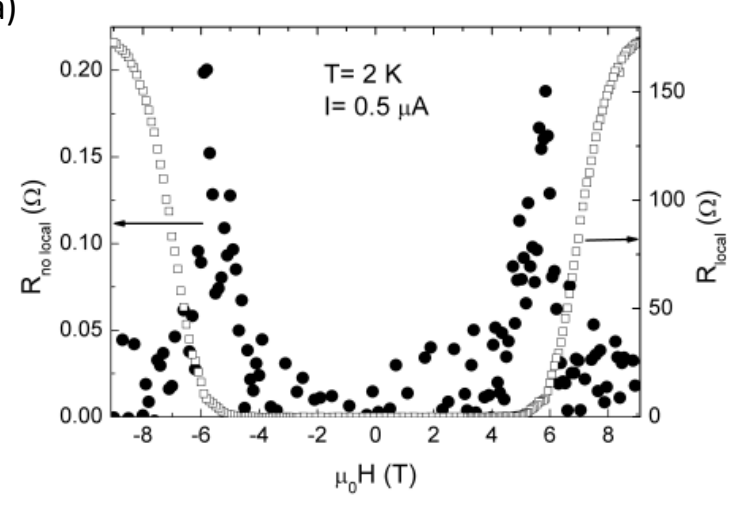

(b)

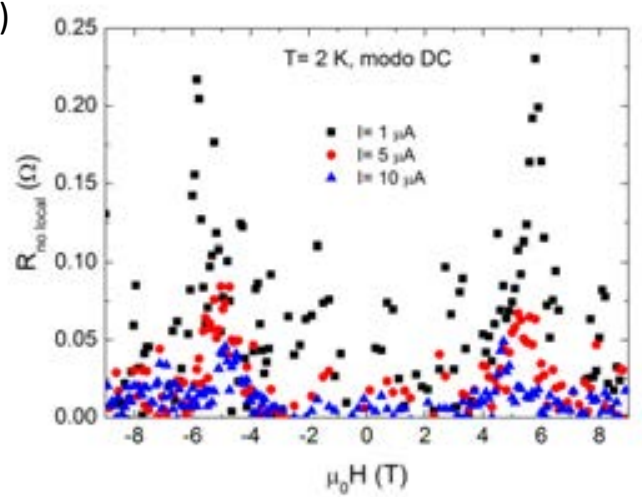

Figura 5.28: (a) Resistencia no local y local medida en modo AC en función del campo magnético aplicado positivo y negativo a $2 \mathrm{~K}$ y $0.5 \mu \mathrm{A}$ de corriente aplicada. (b) Resistencia no local medida en el modo DC en función del campo magnético aplicado positivo y negativo a 2 $\mathrm{K}$ y 1,5 y $10 \mu \mathrm{A}$ de corriente aplicada. 
En la Figura 5.29(a), mostraremos las medidas realizadas en modo AC de la resistencia no local en función del campo magnético aplicado a varias temperaturas, de 0.5 a $5 \mathrm{~K}$ y a $1 \mu \mathrm{A}$ de corriente aplicada. Se ha aplicado sucesivamente un offset en el valor de la $\mathrm{R}_{\text {no local }}$ para que la gráfica resultase más visual.

(a)

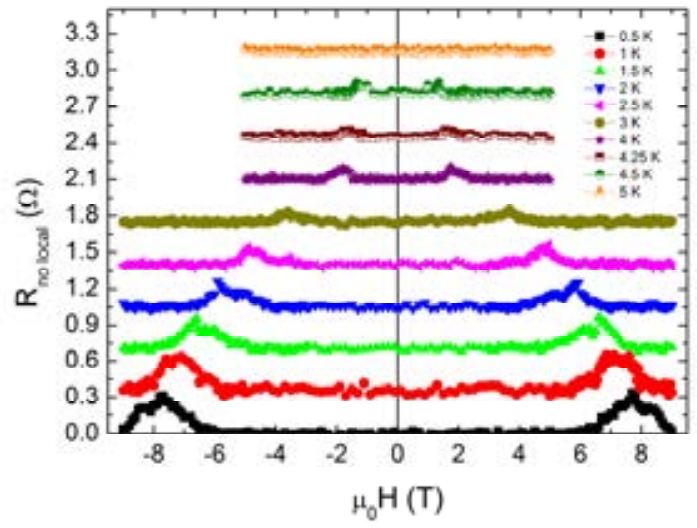

(b)

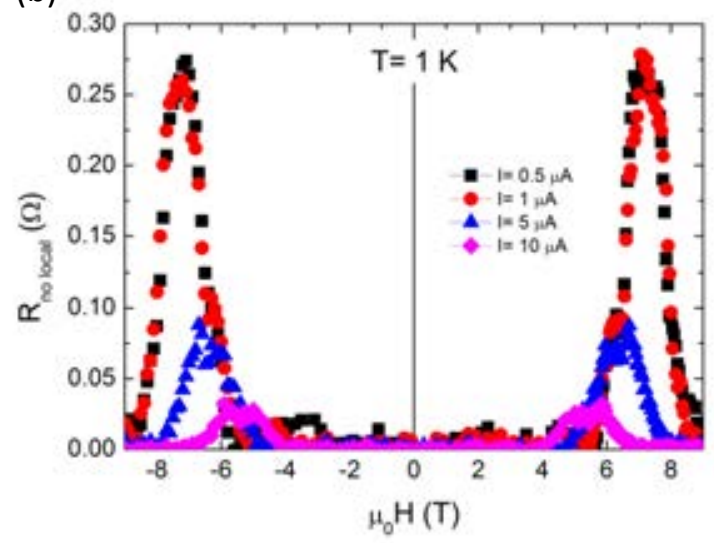

Figura 5.29: (a) Resistencia no local en función del campo magnético positivo y negativo a distintas temperaturas (de 0.5 a $5 \mathrm{~K}$ ) y a $1 \mu \mathrm{A}$ de corriente aplicada. Se ha aplicado un offset en el valor de la $\mathrm{R}_{\mathrm{no}}$ local para que la gráfica resultara más visual. (b) Resistencia no local en función del campo magnético aplicado positivo y negativo a $1 \mathrm{~K}$ y a distintas corrientes indicadas en la leyenda. 
Lo primero que debemos indicar es que la dependencia de la $\mathrm{R}_{\text {no local }}$ es simétrica al aplicar valores de campo magnético positivos y negativos. El valor máximo de la $\mathrm{R}_{\text {no local }}=0.32 \Omega$ a $0.5 \mathrm{~K}$ desciende al aumentar la temperatura de $0.5 \mathrm{~K}$ a $3 \mathrm{~K}\left(\mathrm{t}=\mathrm{T} / \mathrm{T}_{\mathrm{c}}=\right.$ [0.1-0.6]) debido a un mayor crecimiento de $B_{\max }$ (valor de campo en el que se observa el máximo de $\mathrm{R}_{\text {no local }}$ ) que el coeficiente de fricción con la temperatura \{Helzel, 2006 \#253\}. Por encima de $3 \mathrm{~K}$, los valores máximos de la $\mathrm{R}_{\mathrm{no}}$ local no se modifican significativamente hasta que a $5 \mathrm{~K}, 0.98 \mathrm{~T}_{\mathrm{c}}$ la señal no local desaparece. Este efecto podría ser explicado por el confinamiento de vórtices por las barreras de superficie, una vez que la red de vórtices se ha fundido a temperaturas próximas a la $\mathrm{T}_{\mathrm{c}}$. La señal no local aparece a $b_{\min }=B_{\min }(T) / B_{c 2}(T)=[0.35-0.64]$, alcanza el valor máximo a $b_{\max }=$ $\mathrm{B}_{\max }(\mathrm{T}) / \mathrm{B}_{\mathrm{c} 2}(\mathrm{~T})=[0.46-0.82]$ y despúes de superar $\mathrm{b}_{\max }$ desciende hasta cancelarse. La dependencia de la $\mathrm{R}_{\text {no local }}$ con la corriente a baja temperatura, $1 \mathrm{~K}$ está representada en detalle en la Figura 5.29(b). El descenso de la $\mathrm{R}_{\text {no local }}$ tendría su origen en la aproximación a los valores de corriente crítica a esa temperatura y campo magnético aplicado. 


\subsection{Conclusiones y perspectivas}

A lo largo de este capítulo hemos estudiado minuciosamente los depósitos de W crecidos mediante FIBID, utilizando como material precursor el $\mathrm{W}(\mathrm{CO})_{6} \mathrm{y}$ a través de diversas caracterizaciones, tales como EDS, HRTEM, y medidas de magnetotransporte tanto en modo local como no local.
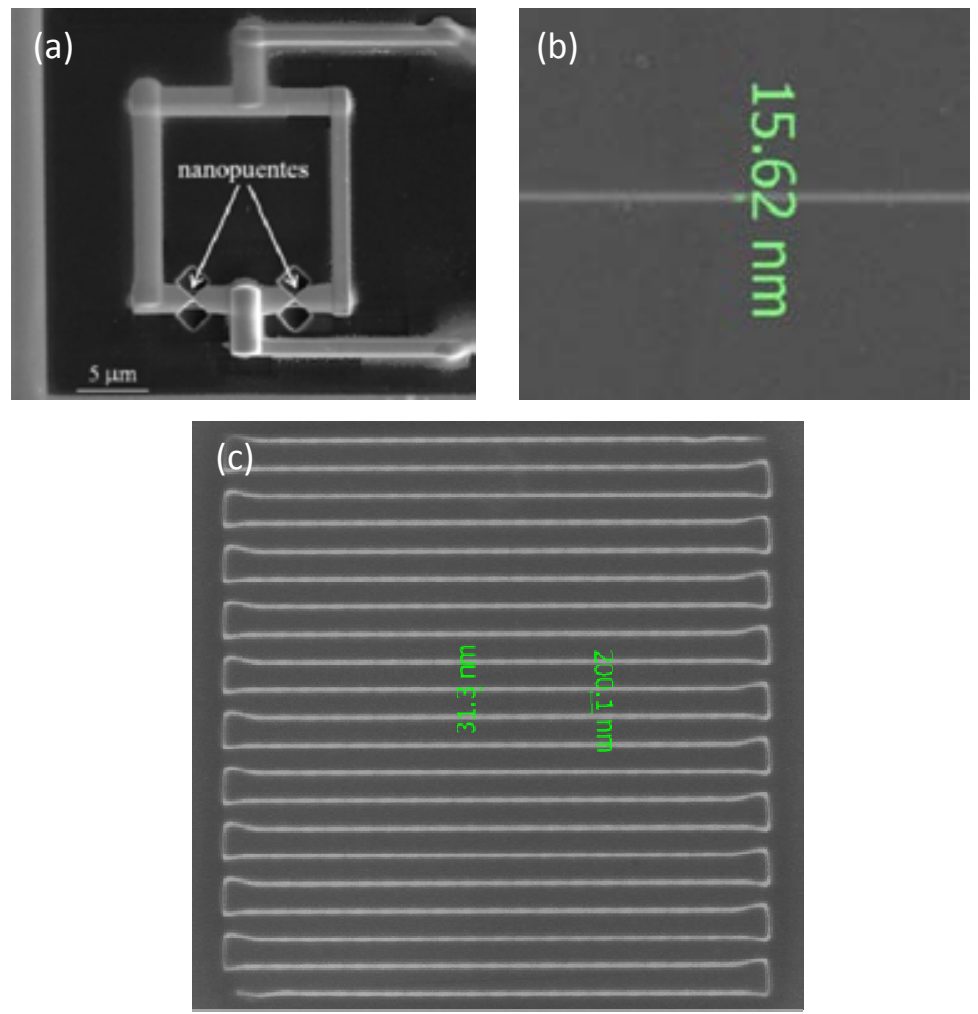

Figura 5.30: Imágenes SEM de estructuras superconductoras de W fabricadas mediante FIBID, (a) un microSQUID, (b) un NW ultraestrecho y (c) un meandro para SSPD.

El control en el crecimiento y diseño de materiales superconductores en la escala nanométrica está abriendo interesantes campos de aplicación en física de la materia condensada. Recientemente, se han abordado estudios básicos de superconductividad en una dimensión ${ }^{77}$, confinamiento de vórtices ${ }^{78,216}$, anclaje de vórtices ${ }^{79}$, etc. La fabricación de nanoSQUIDs ${ }^{81,217}$, de estructuras en tres dimensiones; así como, de 
material de soporte para bits superconductores cuánticos, $\mathrm{SQB}^{83}$, la fabricación de detectores de un único fotón, "superconducting single photon detectors" (SSPD) 218219 o de partículas ${ }^{220}$ y uniones cuánticas basadas en "quantum phase slip centers" $(\mathrm{QPSC})^{221}$ son algunas de las atractivas aplicaciones de tales nano-superconductores. En la Figura 5.30 mostramos algunos ejemplos de las perspectivas de futuro que ofrecen estas nanoestructuras. 



\section{Capítulo 6}

\section{Resumen y conclusiones generales}

El crecimiento de nanoestructuras mediante haces focalizados, ya sean de electrones o como de iones supone un novedoso y potencial método de nanofabricación. Estas técnicas de crecimiento conocidas como FEBID y FIBID se han desarrollado en los últimos 30 años y en la actualidad se están destinando un elevado número de recursos científico-técnicos con la finalidad de obtener numerosos objetivos en el ámbito de la Nanotecnología. A continuación enumeraremos algunos de estos objetivos, los cuales consideramos fundamentales: 1) Comprender los fenómenos físicos asociados al crecimiento de materiales, a través del trabajo experimental en el laboratorio junto con complejas simulaciones del proceso. 2) Obtención de los mínimos valores en la resolución lateral y de espesor que permite la técnica. 3) Fabricación de nanoestructuras que presenten interesantes propiedades físicas aplicables en micro y nanoelectrónica. 
La presente tesis doctoral se ha orientado hacia la preparación de nanoestructuras de Co, Fe y W mediante el crecimiento por un haz de electrones/ iones focalizado (FEBID/FIBID) y sus posteriores caracterizaciones. Estos materiales de Co y $\mathrm{Fe}$ presentan aplicaciones potenciales en Espintrónica por su magnetorresistencia y efecto Hall a campos moderados y a temperatura ambiente. Mientras que los materiales basados en $\mathrm{W}$ exhiben propiedades superconductoras a moderadas temperaturas; presentando unas excelentes cualidades para estudios de investigación básica de los fenómenos asociados a la superconductividad y para estudios de investigación aplicada en el marco de la Nanotecnología.

En la elaboración de esta tesis ha sido fundamental la participación del Laboratorio de Microscopía Avanzadas (LMA)- Instituto Universitario de Nanociencia de Aragón (INA), institución perteneciente a la Universidad de Zaragoza, centro de referencia en la investigación de la Física de nanosistemas, y provisto de las más punteras infraestructuras y capital humano necesarios para su estudio.

Los principales resultados presentados en esta tesis se resumen en los siguientes puntos:

1) Fabricación de nanoestructuras ferromagnéticas de Co mediante FEBID:

- Nanoestructuras de Co (> 90\%) fabricadas mediante FEBID, utilizando como material precursor el $\mathrm{Co}_{2}(\mathrm{CO})_{8}$ modificando de forma controlada distintos parámetros de crecimiento ${ }^{48,133}$. El contenido de Co en los depósitos tiene una gran influencia en sus propiedades magnéticas y por ende en sus futuras aplicaciones en el campo de la lógica, sensores y almacenamiento magnético.

- Variación de la microestructura y composición de los nanodepósitos en la nanoescala en función de su concentración de Co. Se obtienen desde depósitos compuestos por nanocristales de Co hcp y especies de Co oxidadas embebidas en una matriz carbonosa para $\sim 65 \%$ Co hasta películas de cobalto policristalino hcp y fcc para $\sim 90 \% \mathrm{Co}^{122}$. 
- Nanoestructuras ferromagnéticas de Co de $30 \mathrm{~nm}$ de ancho lateral, gran avance para la funcionalidad de la técnica FEBID $^{155}$, en el cual la fabricación de depósitos más estrechos que $10 \mathrm{~nm}$ es posible ${ }^{8}$, así como la fabricación de estructuras ferromagnéticas en tres dimensiones ${ }^{161}$.

2) Fabricación de depósitos ferromagnéticos de Fe mediante FEBID:

- Microhilos de Fe fabricados mediante FEBID, utilizando como material precursor el $\mathrm{Fe}_{2}(\mathrm{CO})_{9}$, exhiben carácter ferromagnético cuando el cociente $\mathrm{Fe} / \mathrm{O}$ es alto y el contenido de Fe es superior al 65\% atómico. Presentan una microestructura totalmente diferente a la obtenida por otras técnicas de crecimiento, con un gran impacto en las propiedades de magnetotransporte ${ }^{121}$.

- La resistividad de los depósitos escala con el contenido de Fe y su evolución con la temperatura nos lleva de un sistema semiconductor a un "dirty metal” en función de la concentración de Fe. Las muestras con mayor contenido de Fe muestran una resistividad sólo diecinueve veces superior al Fe puro y además presentan una AMR. Una transición de la AMR a la ITMR se observó al disminuir el contenido de Fe (incrementando el contenido de oxígeno) $^{121}$.

- Determinación de un AHE gigante, muy elevado comparado con el observado en microhilos de Fe puro, el cual ha sido explicado en términos de un gran "skew scattering" provocado por la compleja microestructura heterogénea de este sistema ${ }^{222}$ y con futuras aplicaciones en nuevos dispositivos magnéticos, como sensores magnéticos.

3) Fabricación de depósitos superconductores de W mediante FIBID:

- Depósitos superconductores de W crecidos mediante FIBID, utilizando como material precursor el $\mathrm{W}(\mathrm{CO})_{6}$, modificando distintos parámetros de crecimiento.

- Correlación entre las propiedades superconductoras de depósitos de W al modificar el ancho lateral de las estructuras, desde microhilos hasta NWs 
ultraestrechos de $50 \mathrm{~nm}$. La densidad de corriente crítica aumenta un orden de magnitud en los NWs ultraestrechos respecto a microhilos y NWs de ancho $200 \mathrm{~nm}$ debido al efecto de la barrera de energía en los bordes. Se observó la reentrada de la superconductividad en los NWs ultraestrechos debido al realce de la superconductividad en los bordes del NW y a la formación de un hipervórtice en el centro del NW.

- Observación de un voltaje no local asociado al movimiento de los vórtices transversal a la corriente aplicada debido a la fuerza de Lorentz, a través de un camino por el cual no circula la corriente.

El control en el crecimiento y diseño de materiales superconductores en la escala nanométrica está abriendo interesantes campos de aplicación en física de la materia condensada, habiéndose abordado en el presente trabajo doctoral tanto estudios básicos de superconductividad como estudios en los que adaptan estas estructuras para su aplicación en Nanotecnología. 


\section{Apéndice A}

\section{Nanodepósitos de $W$ crecidos mediante un haz de electrones focalizado}

En este apéndice presentamos la fabricación y caracterización de depósitos de W mediante el análisis composicional y de su microestructura. Además, de un completo estudio de sus propiedades eléctricas in situ durante su crecimiento a temperatura ambiente y "exsitu" en un amplio rango de temperaturas ( $2.2 \mathrm{~K}$ a $300 \mathrm{~K})$ y campo magnético aplicado perpendicular al sustrato (-9 T a 9 T). La obtención de depósitos de W con diferente contenido metálico variando la corriente de electrones incidente, nos permite estudiar su diferente comportamiento eléctrico al presentar una transición de aislante a metal. 
Uno de los depósitos más estudiados en la literatura mediante FEBID está basado en wolframio. Los materiales precursores más utilizados para este fin son el hexacarbonilo de wolframio, $\mathrm{W}(\mathrm{CO})_{6} \mathrm{y}$ el hexafluoruro de wolframio, $\mathrm{WF}_{6}$.

La mayoría de estudios se han centrado en el estudio de materiales crecidos a partir del $\mathrm{W}(\mathrm{CO})_{6}{ }^{223-226}$, probablemente debido a que es más sencillo de adaptar tecnológicamente a un microscopio electrónico, evitando posibles daños que podría provocar el $\mathrm{WF}_{6}$ (puede corroer el acero inoxidable en presencia de humedad), en fase gas a temperatura ambiente. El interés suscitado en este tipo de nanoestructuras viene dado por sus prometedoras propiedades de transporte eléctrico ${ }^{227,228}$, en las cuales se observa la transición de aislante a metal en función de su contenido metálico ${ }^{229,230}$, como también se observó en el crecimiento de Pt mediante FEBID ${ }^{231}$ y FIBID ${ }^{116,172}$. Este tipo de propiedades intrínsecas de los depósitos permite su utilización en una gran variedad de aplicaciones en Nanotecnología como por ejemplo, la fabricación de nanocontactos metálicos en dos y tres dimensiones ${ }^{56,57}$, la reparación de máscaras de litografía, la fabricación de sensores ${ }^{232,233}$. Además, podemos encontrar trabajos en los que se ha utilizado el $\mathrm{WF}_{6}$ como material de partida para crecer con éxito nanoestructuras de $\mathrm{W}^{44,234-236}$, en las cuales evitamos añadir compuestos carbonosos en el depósito final.

En la literatura se han encontrado trabajos en los cuales se muestra una mejora en el contenido metálico de los depósitos crecidos mediante FEBID al aumentar la corriente del haz de electrones incidente ${ }^{47,133}$.

\section{A.1. Crecimiento y caracterización de nanoestructuras de $\mathrm{W}$ mediante FEBID}

El crecimiento de nanohilos de W se llevó a cabo asistido por un FEB. Los parámetros de crecimiento utilizados son los siguientes: material precursor= hexacarbonilo de wolframio, $\mathrm{W}(\mathrm{CO})_{6}$; temperatura del material precursor $=55^{\circ} \mathrm{C} ; \mathrm{V}_{\mathrm{e}}=$ $5 \mathrm{kV} ; \mathrm{I}_{\mathrm{e}}=98 \mathrm{pA}-0.40 \mathrm{nA}-1.6 \mathrm{nA}-6.3 \mathrm{nA} ; \mathrm{t}_{\mathrm{p}}=1 \mu \mathrm{s} ; \mathrm{s}=0 \%$; $\mathrm{t}_{\mathrm{r}}=0 \mathrm{~s} ; \mathrm{P}_{\mathrm{b}}=1 \times 10^{-6}$ mbar; 
$\mathrm{P}_{\mathrm{p}}=1 \times 10^{-5}$ mbar. El sustrato utilizado en todos los experimentos es $\mathrm{Si}$ dopado con boro (dopaje tipo p), previamente oxidado térmicamente; con este método obtenemos unos $250 \mathrm{~nm}$ de material aislante $\left(\mathrm{SiO}_{2}\right)$. Los contactos de Ti fueron fabricados sobre el sustrato oxidado mediante técnicas de litografía óptica. Los nanohilos de W estudiados tienen las siguientes dimensiones: longitud $=7 \mu \mathrm{m}$, ancho $=500-1000 \mathrm{~nm}$, espesor $250 \mathrm{~nm}$.

El análisis composicional de los nanodepósitos se realizó in situ mediante microanálisis por EDS. Los espectros son recogidos utilizando un voltaje de aceleración del haz de electrones de $5 \mathrm{kV}$. En la Tabla A.1 mostramos los resultados de tres nanohilos representativos, el M1 crecido a $6.3 \mathrm{nA}$, el M2 a $1.6 \mathrm{nA}$, y el M3 a $0.4 \mathrm{nA}$.

Con el objetivo de estudiar su microestructura se crecieron depósitos de W sobre una rejilla comercial de $\mathrm{Cu}$ con una membrana de $\mathrm{C}$ (de espesor $\sim 10 \mathrm{~nm}$ ), variando la corriente del haz de electrones, de entre $0.4 \mathrm{nA}$ y $6.3 \mathrm{nA}$. El espesor de los mismos debe ser inferior a $40 \mathrm{~nm}$, para así tener la posibilidad de obtener imágenes de alta resolución al recopilar la información de los electrones transmitidos que atraviesan los depósitos.

\begin{tabular}{c|cccc}
\hline Muestra & $\boldsymbol{I}_{\boldsymbol{e}}(\mathbf{n A})$ & $\boldsymbol{C}$ (\% at.) & $\boldsymbol{O}$ (\% at.) & W (\% at.) \\
\hline M 1 & 6.3 & 25.69 & 31.94 & 42.37 \\
M 2 & 1.6 & 46.70 & 29.24 & 24.06 \\
M 3 & 0.4 & 55.20 & 23.70 & 21.10 \\
\hline
\end{tabular}

Tabla A.1: Análisis composicional de los depósitos de W crecidos a distintas corrientes de electrones.

En la Figura A.1 podemos observar una imagen de HRTEM de un depósito de W crecido a $5 \mathrm{kV}, 0.40 \mathrm{nA}$, de naturaleza mayoritariamente amorfa con pequeñas inclusiones de $\mathrm{W}$ (zonas oscuras de la imagen), como se pone de manifiesto por la ausencia de anillos de difracción en la FFT de la imagen. Concluimos que estos depósitos están formados principalmente por una matriz de W-C-O amorfa. 


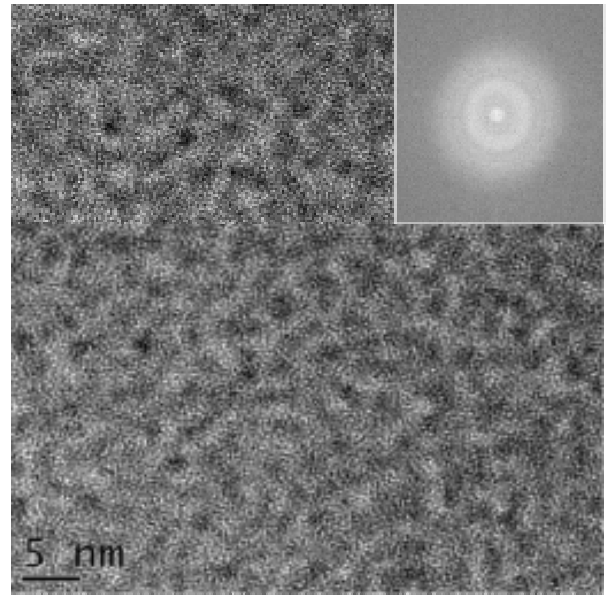

Figura A.1: Imagen de HRTEM de un depósito de $\mathrm{W}$ crecido a 5 kV, 0.4 nA. En el recuadro podemos observar la ausencia de anillos de difracción en la FFT de la imagen.

\section{A.2. Medidas de transporte eléctrico in situ}

Las medidas de transporte eléctrico de los depósitos de W se realizaron in situ (durante el crecimiento en la cámara de proceso del “Dual Beam”) como se relató en el apartado 2.6.2 del Capítulo 2. En primer lugar, se crecieron cuatro nanocontactos auxiliares de Pt mediante FIBID, que van desde los cuatro microcontactos de $\mathrm{Ti}$ al sustrato de silicio oxidado térmicamente, como podemos observar en la Figura A.2(a). Los contactos se realizan para medir por cuatro puntas, y así evitar efectos asociados a la resistencia de los $\operatorname{contactos}^{116}$. Además, facilitan el crecimiento homogéneo del nanohilo de $\mathrm{W}$ a lo largo de toda su longitud debido a que no tienen un perfil rectangular abrupto, sino más bien con una forma Gaussiana. De esta forma, facilita el crecimiento homogéneo del nanohilo a estudiar y su monitorización de la resistencia real durante todo el crecimiento. 


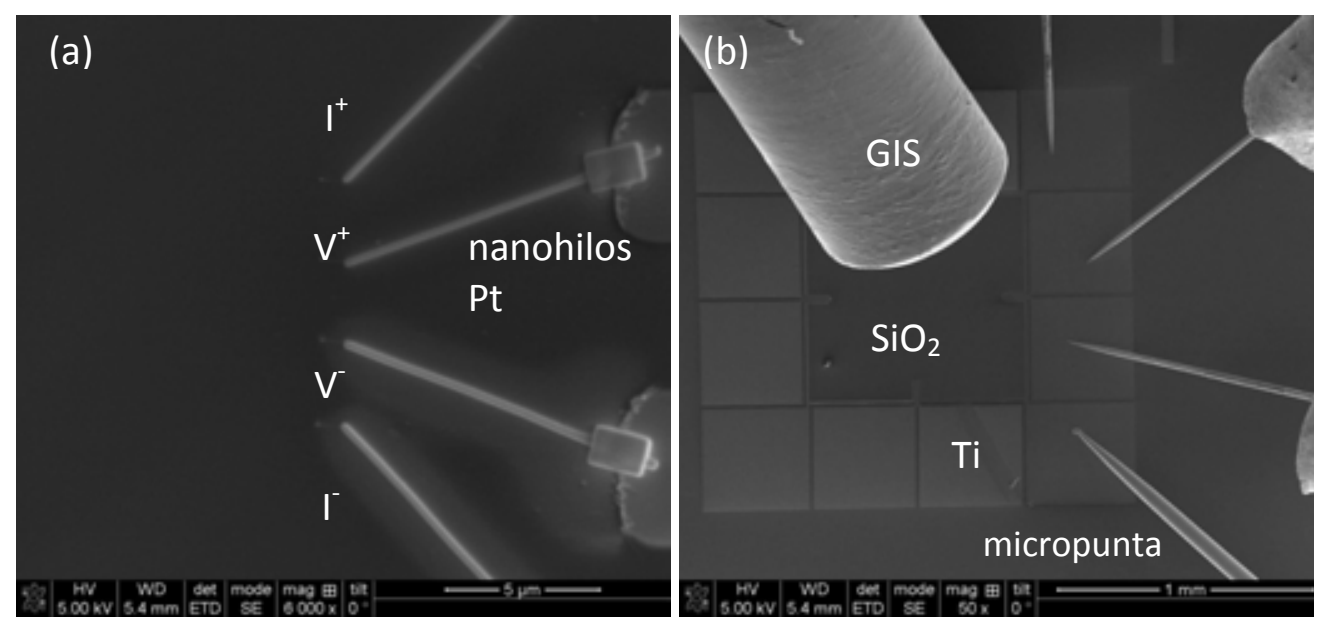

Figura A.2: (a) Imagen SEM de los contactos de Ti, con sus posteriores 4 contactos de PtC crecidos mediante FIBID. (b) Imagen SEM de las 4 puntas contactadas en los 4 contactos de Ti y la aguja del precursor de $\mathrm{W}$ insertada.

A continuación, situamos las cuatro micropuntas sobre los contactos de Ti (ver Figura A.2(b)) y comprobamos que los cuatro contactos auxiliares están completamente aislados antes del crecimiento del nanohilo de W. Para ello, aplicamos una corriente constante entre los dos electrodos situados en los extremos, y medimos la caída de voltaje entre los electrodos interiores. Los valores de corriente de medida utilizados se sitúan entre 100 nA y $1 \mu \mathrm{A}$. Finalmente, comenzamos el proceso de crecimiento del nanohilo de $\mathrm{W}$ mientras monitorizamos el valor de su resistencia. El proceso continúa hasta que se alcanza un valor cercano al de saturación de su resistencia.

Una vez el nanohilo está crecido, realizamos una medida de voltaje en función de la corriente (I-V) para caracterizar su comportamiento eléctrico a temperatura ambiente. En la Figura A.3, podemos ver la imagen SEM del nanohilo M1 tras finalizar el proceso de crecimiento.

Los valores de resistividad que hemos obtenido son similares a los de otros autores utilizando parámetros de crecimiento similares (véase la Tabla A.2), como por ejemplo el obtenido por Luxmoore et al., $2500 \mu \Omega \mathrm{cm}^{190}$. 


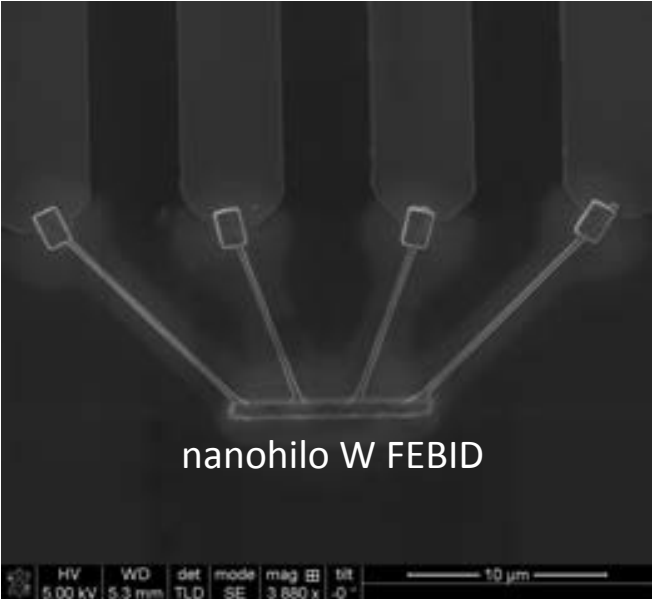

Figura A.3: Imagen SEM del nanohilo M1.

\begin{tabular}{c|ccc}
\hline & M1 & M2 & M3 \\
\hline$\rho_{\text {in-situ }}(\mu \boldsymbol{\Omega} \mathbf{~ c m})$ & 3000 & 5200 & $3.5 \times 10^{4}$ \\
\hline
\end{tabular}

Tabla A.2: Valores de la resistividad obtenida in situ de los depósitos de $\mathrm{W}$ crecidos a distintas corrientes de electrones.

Aunque la resistividad de nuestros depósitos de W se alejan del W puro (5.6 $\mu \Omega \mathrm{cm}$ ), estos manifiestan un carácter metálico a temperatura ambiente que los hace apropiados para la fabricación de nanocontactos metálicos.

\section{A.3. Medidas de transporte eléctrico "ex-situ"}

Para completar la caracterización eléctrica de este material, se midieron "ex-situ" las propiedades de transporte de los depósitos de W en función de la temperatura.

Se escogieron los nanohilos que presentaban menor resistividad a temperatura ambiente tras su crecimiento, el M1 y el M2. En primer lugar, detectamos que el valor de la resistencia a $300 \mathrm{~K}$ aumentó casi un factor dos, en M1 y un factor doce, en M2. A pesar de observar el notorio deterioro de su conductividad eléctrica con el tiempo y 
contacto con el ambiente, una medida I-V a $300 \mathrm{~K}$ nos permitió atestiguar de nuevo, el carácter metálico de los nanohilos a $300 \mathrm{~K}$ (veáse Tabla A.3).

La degradación de la conductividad es menor en los depósitos crecidos a mayor corriente (6.3 nA), como M1 que los crecidos a media corriente (1.4 nA), como M2. Esto puede ser debido a que posiblemente sólo los granos más superficiales del depósito se hayan oxidado y degradado. De esta forma, los depósitos con mayor contenido en W, serían más compactos y evitarían la oxidación de los granos internos y la posterior degradación de la conductividad eléctrica, como hemos podido estudiar en depósitos de Co crecidos mediante la misma técnica ${ }^{122}$. A este respecto, otros autores han observado que depósitos con un contenido de W entre el 34\% y el 19\%, sufren un descenso del valor de la conductividad, entre un factor dos y cuatro tras un año de su preparación ${ }^{230}$ y que la presencia de oxígeno residual y vapor de agua dentro de la cámara de proceso es suficiente para oxidar depósitos de W crecidos a partir de hexafluoruro de tungsteno $\left(\mathrm{WF}_{6}\right)$ como material precursor ${ }^{236}$.

Teniendo en cuenta las posibles aplicaciones de este tipo de estructuras en el campo de la Nanotecnología es importante conseguir depósitos con el suficiente contenido metálico y compactación en la matriz de carbono que impidan el deterioro de sus propiedades físicas al ser expuestas a las condiciones ambientales y al paso del tiempo.

En la Figura A.4, representamos la resistividad en función de la temperatura de los nanohilos M1 y M2. Podemos observar que el comportamiento es completamente distinto. Mientras que M1, presenta una ligera pendiente negativa, M2 presenta una pendiente negativa de carácter exponencial. Este diferente comportamiento eléctrico de los nanohilos con la temperatura, indica la transición de aislante a metal en función de su contenido metálico ${ }^{172,222,230 .}$

En la Tabla A.3 hemos resumido algunos de los resultados de las medidas de transporte eléctrico in situ y "ex-situ”; donde RRR se ha definido como el cociente entre $\rho_{300 \mathrm{~K}} / \rho_{2.6 \mathrm{~K}}$. Nos parece relevante mencionar la importancia que tiene la resistividad del nanohilo a $300 \mathrm{~K}$, con su posterior evolución con la temperatura. A 
partir de valores de $\rho_{300 \mathrm{~K}}>10^{4} \mu \Omega \mathrm{cm}$, su comportamiento suele ser semi-aislante, con una dependencia térmica negativa y un valor de RRR muy próximo a $\sim 0$. Este hecho se ha observado tanto para depósitos de $\mathrm{W}^{230}$ 237, como para depósitos de $\mathrm{Fe}^{222}$, Co crecidos mediante FEBID ${ }^{133}$, y Pt crecidos mediante FEBID y FIBID ${ }^{116,172}$.

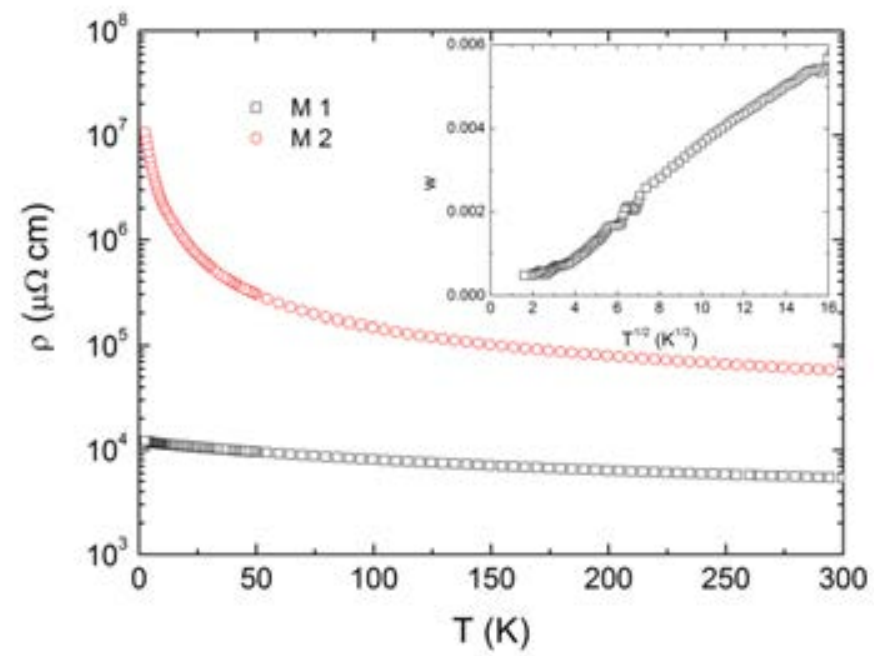

Figura A.4: Resistividad en función de la temperatura de M1 y M2. En el recuadro se representa la variable $\mathrm{w}$ frente a $\mathrm{T}^{1 / 2}$ de la muestra M1.

\begin{tabular}{c|cccccc}
\hline Muestra & $\boldsymbol{R}_{\text {in-situ }}$ & $\boldsymbol{R}_{\text {ex-situ }}$ & $\rho_{\text {in-situ }}$ & $\rho_{\text {ex-situ 300K }}$ & $\rho_{\text {ex-situ 2.6K }}$ & $R R R$ \\
& $(\Omega)$ & $(\Omega)$ & $(\mu \boldsymbol{\Omega} \mathbf{c m})$ & $(\mu \boldsymbol{\Omega c m})$ & $(\mu \boldsymbol{s} \mathbf{c m})$ & \\
\hline M1 & 120 & 224 & 3000 & 5396 & $1.2 \times 10^{4}$ & 0.44 \\
\hline M2 & 240 & 2900 & 5200 & $6.5 \times 10^{4}$ & $8.5 \times 10^{5}$ & 0.08 \\
\hline
\end{tabular}

Tabla A.3: Resultados más relevantes de las medidas de transporte eléctrico in situ y "exsitu”.

La variable $\mathrm{w}(\mathrm{T})$ definida como la derivada del logaritmo neperiano de la conductividad en función del logaritmo neperiano de la temperatura, nos permite tener más sensibilidad en la dependencia de $\rho$ con la T. De esta forma, si w $\rightarrow 0$ cuando 
$\mathrm{T} \rightarrow 0$ indica que el mecanismo de conducción es metálico y si w diverge o bien es finito implica que el nanohilo es aislante ${ }^{238}$.

$$
w(T)=\frac{d\left(\ln \rho^{-1}\right)}{d(\ln T)}
$$

La T más baja que medimos es $2.2 \mathrm{~K}$, por lo que los datos experimentales de los que disponemos nos permiten realizar la aproximación de $T \rightarrow 0$. En el recuadro de la Figura A.4, representamos w en función de $\mathrm{T}^{1 / 2}$ para M1.

M1, cuyo valor de resistividad a $300 \mathrm{~K}$ es $5396 \mu \Omega \mathrm{cm}$, presenta un comportamiento típico de semiconductores extrínsecos, es decir, altamente dopado, donde $\mathrm{w}$ tiende a 0 cuándo $\mathrm{T} \rightarrow 0$. El contenido de $\mathrm{W}$ está por encima del límite de percolación y se produce el acoplamiento entre los átomos de $\mathrm{W}$ contenidos en la matriz amorfa que permiten una conducción metálica entre ellos ${ }^{172}$. Sin embargo, el nanohilo M2, cuyo valor de resistividad a $300 \mathrm{~K}$ es $6.5 \times 10^{4} \mu \Omega \mathrm{cm}$, presenta un comportamiento típico de VRH de los electrones en estados localizados. El contenido de W está por debajo del límite de percolación y por tanto no se produce el acoplamiento entre los átomos de $\mathrm{W}$ que forman parte de la matriz amorfa. El buen ajuste de M2 a la ecuación A.2 (Figura A.5), en la cual podemos ver la evolución de la resistividad en este tipo de sistemas, con una barrera de activación con un valor de $\mathrm{T}_{0}=$ $6.5 \mathrm{~K}$ y exponente $\mathrm{N}=0.25^{180}$ nos permite afirmar que el VRH es el mecanismo de transporte que domina en M2 en el rango de temperaturas estudiado.

$$
\rho(T)=\rho_{\infty} \exp \left(\mathrm{T}_{0} / \mathrm{T}\right)^{\mathrm{N}}
$$

Otros autores han encontrado el mismo comportamiento en estructuras amorfas aislantes dopadas por inhomogeneidades metálicas ${ }^{239}$. La microestructura heterogénea en nuestros depósitos de W estudiada mediante HRTEM, en los cuales se observaba una matriz de W-C-O amorfa, podría introducir el desorden suficiente en este material como para observar la transición aislante-metal. Si el contenido metálico es bajo como en M2, la conducción se produciría a través de saltos de los portadores a estados localizados, mientras que si el contenido de metal es elevado (M1), la conducción se realiza a través de los estados localizados extendidos, como se observó en $\mathrm{Pt}^{172}$. 


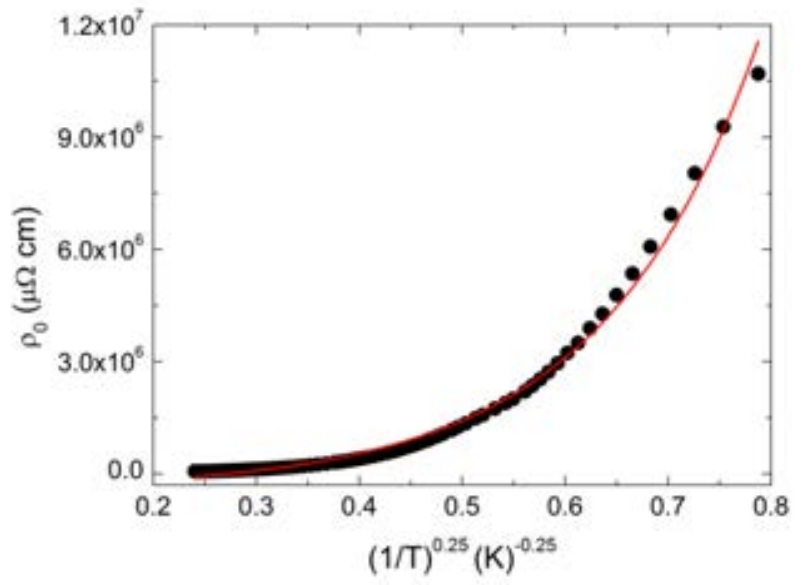

Figura A.5: Resistividad en función de $\mathrm{T}^{-0.25}$ del nanohilo M2.

Se realizaron medidas de I-V a baja temperatura (2.2 K, 5 K y $10 \mathrm{~K})$ para $\mathrm{M} 1$ y M2. En M1, las I-V son lineales indicando su carácter metálico en el rango de temperaturas estudiado (de $2.2 \mathrm{~K}$ a $300 \mathrm{~K}$ ). Sin embargo, como esperábamos tras el análisis de la $\rho(\mathrm{T})$, donde se dilucidaba su mecanismo de conducción a través de VRH, las medidas de I-V en M2 no son lineales. En la Figura A.6, representamos la conductancia diferencial normalizada en función del voltaje aplicado a bajas temperaturas. $\mathrm{G}_{0}$ es el valor mínimo de la conductancia diferencial a cada temperatura. A medida que bajamos la temperatura, más nos alejamos de la linealidad. Este incremento de la conductancia diferencial puede explicarse por el mecanismo de conducción túnel o "hopping” entre los átomos de W que forman parte de la matriz aislante de carbono ${ }^{240}$. 


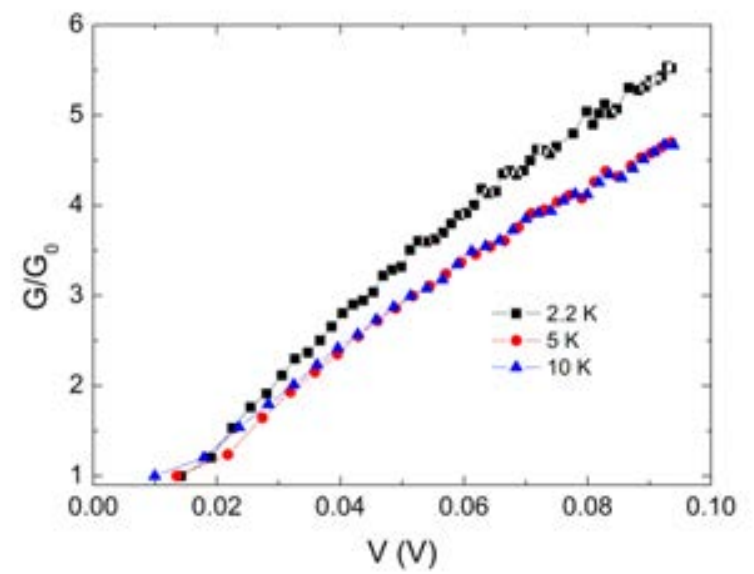

Figura A.6: Conductancia normalizada $\left(\mathrm{G} / \mathrm{G}_{0}\right)$ en función del voltaje a $2.2 \mathrm{~K}, 5$ K y $10 \mathrm{~K}$ de M2. 



\section{Apéndice B}

\section{Nanodepósitos de Pt crecidos mediante un haz de electrones $o$ iones focalizado}

En este apéndice mostramos los estudios de volumen por dosis, composición y microscopía electrónica de transmisión de alta resolución realizados a depósitos de Pt crecidos mediante un haz de electrones/iones focalizado. Los resultados obtenidos permiten establecer una correlación entre las propiedades estudiadas y los distintos mecanismos de conducción propuestos en la literatura. 
Sin ninguna duda, el tipo de depósito más estudiado en la literatura basado en las técnicas de crecimiento inducido por un haz de electrones o de iones focalizado es el Pt. El secreto de su éxito estriba en gran medida en la naturaleza de los materiales precursores utilizados para este fin, en la mayoría de los casos de la familia de los organometálicos, bien conocidos en los procesos de crecimiento en fase vapor mediante reacción química (CVD). Por lo tanto son de fácil adaptación a la tecnología disponible en un sistema "Dual Beam”.

Consideramos de gran importancia conocer el ritmo de depósito, la composición y la microestructura de los mismos para entender y justificar los distintos mecanismos de conducción propuestos por diversos autores. En estudios previos, los valores de resistividad de nanohilos de Pt crecidos mediante FEBID y FIBID difieren considerablemente en función de los parámetros de crecimiento, aunque, en general, los depósitos crecidos mediante FIBID mostraron valores de resistividad más bajos ${ }^{240-}$ ${ }^{244}$. Se han propuesto diferentes mecanismos de conducción en estos nanodepósitos de Pt, pero no se ha establecido una idea global clara, principalmente debido al importante papel jugado por la matriz carbonosa. El bajo porcentaje de Pt en los depósitos comparado con el del carbono proveniente del material precursor es el principal hándicap para la observación de conductividad metálica.

\section{B.1. Crecimiento de nanoestructuras de Pt mediante FEBID y FIBID}

El material precursor utilizado en nuestro estudio fue el ciclopentadienil trimetil platino $\left(\mathrm{CH}_{3}\right)_{3} \mathrm{Pt}\left(\mathrm{C}_{\mathrm{p}} \mathrm{CH}_{3}\right)$, sólido a temperatura ambiente. Este precursor se calienta a $45^{\circ} \mathrm{C}$, temperatura próxima a su temperatura de sublimación, así el compuesto entra en la cámara de proceso en fase gaseosa. Los depósitos de platino, de dimensiones $5 \times$ $5 \mu \mathrm{m}^{2}$ se crecieron sobre un sustrato de Si dopado con boro. Los parámetros de crecimiento que se mantuvieron constantes para FEBID fueron: $\mathrm{s}=0 \%, \mathrm{t}_{\mathrm{p}}=1 \mu \mathrm{s}, \mathrm{t}_{\mathrm{r}}=0$ $\mathrm{s}, \mathrm{P}_{\mathrm{b}}=1 \times 10^{-6}$ mbar, $\mathrm{P}_{\mathrm{p}}=2 \times 10^{-5}$ mbar. Para FIBID fueron: $\mathrm{s}=0 \%, \mathrm{t}_{\mathrm{p}}=0.2 \mu \mathrm{s}, \mathrm{t}_{\mathrm{r}}=0 \mathrm{~s}$, $\mathrm{P}_{\mathrm{b}}=1 \times 10^{-6}$ mbar, $\mathrm{P}_{\mathrm{p}}=2 \times 10^{-5}$ mbar. Otros parámetros fundamentales como el voltaje de aceleración y la corriente del haz de electrones/iones han sido modificados para 
estudiar su dependencia con el contenido de Pt, el volumen por dosis y su microestructura.

Para calcular el volumen por dosis, VD $\left(\mu \mathrm{m}^{3} / \mathrm{nC}\right)$ de los depósitos con forma cuadrada $5 \times 5 \mu^{2}$ debemos conocer el espesor, obtenido tras realizar cortes transversales, así como dosis de electrones o iones recibida por la muestra. Éste se calculó para un gran número de nanodepósitos con diferentes parámetros de crecimiento que a continuación detallaremos (véase la Figura B.1).

El protocolo seguido fue el siguiente: se crecieron depósitos de Pt mediante FEBID, a varios voltajes de aceleración del haz, $\mathrm{V}_{\mathrm{e}}$, entre 1 y $30 \mathrm{kV}$ y a cada voltaje fijo, se crecieron varios depósitos a 5 corrientes diferentes, $\mathrm{I}_{\mathrm{e}}$, de valores entre 0.4 y $9.5 \mathrm{nA}$. Se observó que la corriente del haz de electrones no tiene una relevancia significativa en el volumen por dosis obtenido; lo que sugiere un régimen de crecimiento limitado por electrones.

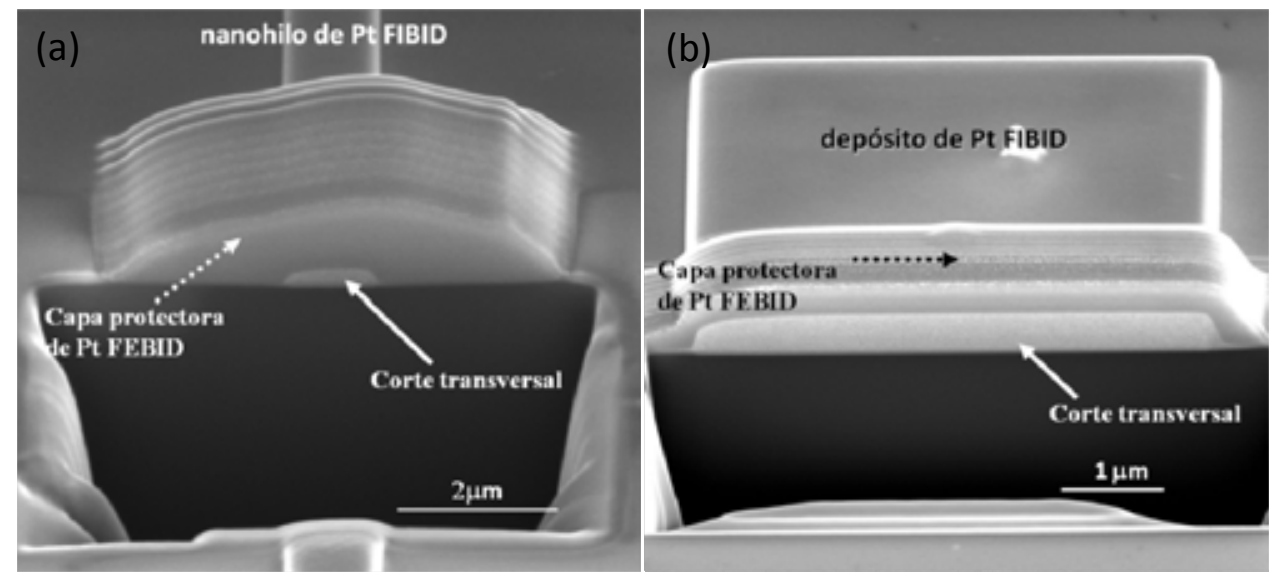

Figura B.1: Imágenes de SEM del corte transversal realizado en (a) nanohilo de Pt crecido mediante FIBID y (b) depósito en forma de cuadrado crecido mediante FIBID. En ambos casos, para proteger la zona a investigar y conseguir buen contraste en la imagen, y así medir el espesor del depósito de interés antes del ataque por iones, se deposita una capa de Pt crecida mediante FEBID en la parte superior de éste. 
En la Figura B.2(a), se representa el VD en función del $V_{e}$. Puede observarse que el VD decrece en función del $V_{e}$, como está descrito para depósitos de Pt crecidos mediante FEBID ${ }^{245,246}$. Como ya se observó, el descenso es bastante pronunciado hasta valores por encima de $5 \mathrm{kV}$ y se allana alrededor de $15 \mathrm{kV}$. El VD a $30 \mathrm{kV}$ es cuatro veces inferior que a $1 \mathrm{kV}$. Esta dependencia se explica por el descenso en la suma de electrones secundarios generados en el sustrato y que alcanzan la superficie de la muestra ${ }^{40,41,46,245,246}$.

(a)

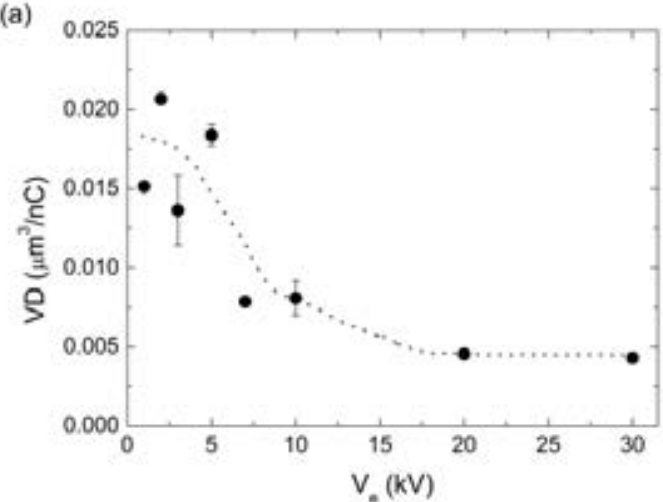

(b)

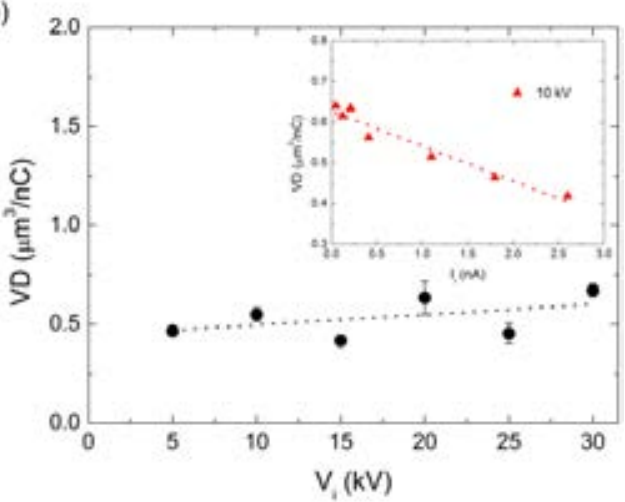

Figure B.2: (a) Media del VD y su desviación estándar en los depósitos de Pt crecidos mediante FEBID a todas las corrientes investigadas en función del $\mathrm{V}_{\mathrm{e}}$. (b) Media del VD y su desviación estándar en los depósitos de Pt crecidos mediante FIBID a todas las corrientes investigadas en función del $\mathrm{V}_{\mathrm{i}}$. El recuadro muestra el VD de los depósitos crecidos a $10 \mathrm{kV}$ mediante FIBID en función de la $\mathrm{I}_{\mathrm{i}}$.

La probabilidad de disociación de la molécula del precursor es máxima a cierta energía en el rango de unas pocas decenas de eV. Por otra parte, la distribución de electrones secundarios generada por el haz de electrones incidente es máxima en el mismo rango de energías, lo cual favorece que los electrones secundarios contribuyan en gran medida a la disociación de la molécula del precursor. Como el rendimiento de los electrones secundarios decrece con el voltaje de aceleración incidente, es obvio el descenso del rendimiento de crecimiento al aumentar $\mathrm{V}_{\mathrm{e}}$. 
Se crecieron depósitos de Pt mediante FIBID, a varios $\mathrm{V}_{\mathrm{i}}$, entre $5 \mathrm{kV}$ y $30 \mathrm{kV}$ (ver Figura B.2(b)). A cada voltaje fijo, se crecieron varios depósitos a $I_{i}$ diferentes, de valores entre 44 pA y $2.6 \mathrm{nA}$. El VD aumenta ligeramente en función del $\mathrm{V}_{\mathrm{i}}$. El volumen de interacción de los iones de $\mathrm{Ga}^{+}$, incluso acelerados a $30 \mathrm{kV}$, sobre silicio es de unos $\sim 50 \mathrm{~nm}$ (simulaciones SRIM) ${ }^{16}$, lo cual permite que se generen un número elevado de electrones secundarios que alcanzan más fácilmente la superficie del material y descomponen las moléculas del precursor, aumentando en dos órdenes de magnitud el VD del proceso FIBID en comparación con el FEBID. Sin embargo, debemos seleccionar la $I_{\mathrm{i}}$ apropiada para que el balance entre el crecimiento y el desbastado se incline hacia el primero, de lo contario veríamos efectos como el que se representa en el recuadro de la Figura B.2(b), donde el VD decrece en función de la $\mathrm{I}_{\mathrm{i}}$.

\section{B.2. Análisis de la composición y microestructura de los depósitos de Pt}

El análisis composicional de los depósitos se realizó in situ tras el proceso de crecimiento para que los depósitos no estuvieran expuestos a las condiciones ambientales, evitando la posibilidad de que su composición se hubiera modificado. El espesor de los nanodepósitos crecidos es de alrededor de $160 \mathrm{~nm}$. El $\mathrm{V}_{\mathrm{e}}$ utilizado para tomar los espectros fue de $10 \mathrm{kV}$. En la Figura B.3(a), representamos el contenido medio de Pt en los depósitos crecidos mediante FEBID en función del $\mathrm{V}_{\mathrm{e}}$ utilizado en el crecimiento. Se observa que al aumentar el $\mathrm{V}_{\mathrm{e}}$, el contenido de Pt disminuye del $17 \%$ al $11 \%$. Mientras que el contenido de $\mathrm{C}$ en el depósito es dominante, con más del 80\%. Este descenso del contenido de Pt es debido a que cuanto mayor es $V_{\mathrm{e}}$, la suma de electrones secundarios generados en el sustrato que alcanzan la superficie de la muestra capaz de descomponer las moléculas de gas precursor desciende. Sin embargo, la interacción entre el haz primario, los SEs y los SEs de $2^{\circ}$ orden generados a partir de los electrones BSEs componen un escenario complejo del proceso completo. No se observaron cambios significativos en el contenido de los depósitos en función de la corriente de electrones. Parece evidente 
que la matriz carbonosa (> 80\% atómico en algunos casos) jugará un papel crucial en el mecanismo de conducción de este tipo de depósitos.

En la Figura B.3(b), representamos el contenido medio de Pt y Ga en los depósitos crecidos mediante FIBID en función del $\mathrm{V}_{\mathrm{i}}$ utilizado en el crecimiento. Mientras que el contenido de Ga es aproximadamente constante $\sim 10 \%$, se observa que el contenido de Pt disminuye del $27 \%$ al $17 \%$. Mientras que el contenido de C sigue siendo significativo, con más del 60\%, aunque la suma del contenido metálico ( $\mathrm{Pt}+$ Ga) es relativamente alta, la cual, como se discutirá a continuación, puede ser responsable de las propiedades de transporte que manifiestan este tipo de depósitos.

(a)

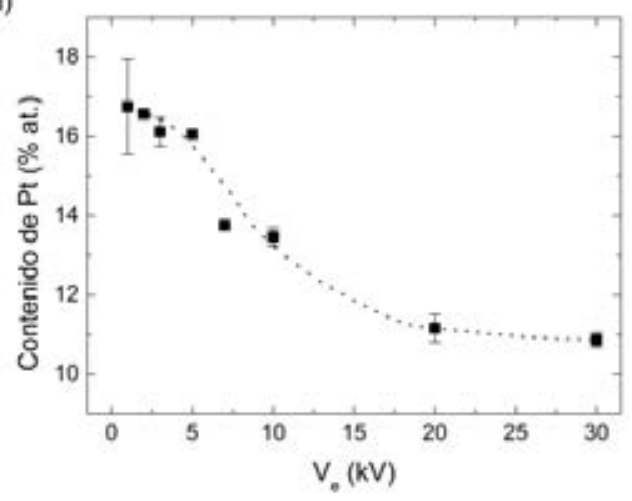

(b)

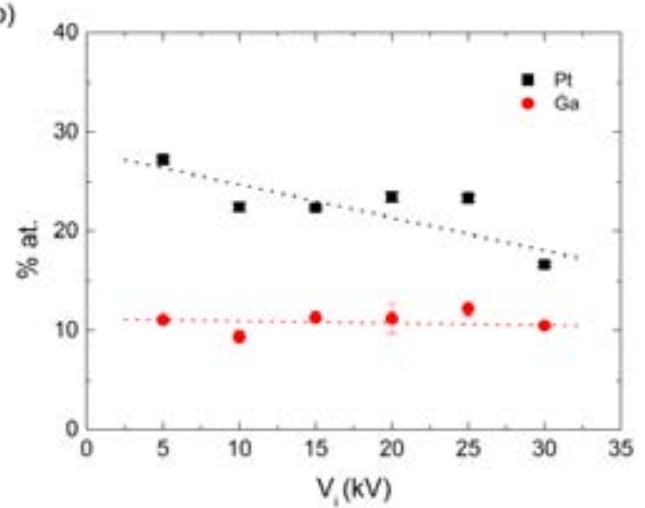

Figura B.3: (a) Media del contenido de Pt y su desviación estándar en los depósitos de Pt crecidos mediante FEBID a todas las $\mathrm{I}_{\mathrm{e}}$ investigadas en función del $\mathrm{V}_{\mathrm{e}}$. (b) Composición de Pt y Ga en \% atómico y su desviación estándar en los depósitos de Pt crecidos mediante FIBID a todas las $\mathrm{I}_{\mathrm{i}}$ investigadas en función del $\mathrm{V}_{\mathrm{i}}$.

El estudio de la microestructura de los depósitos se realizó mediante medidas de HRTEM. El estudio se realizó en unos depósitos de Pt crecidos directamente sobre una rejilla de $\mathrm{Cu}$ comercial, con una membrana secundaria de carbono transparente a los electrones. Otros depósitos de Pt, se estudiaron mediante la inspección de una lamela preparada de espesor inferior a $50 \mathrm{~nm}$, después del crecimiento del depósito sobre un sustrato de silicio. En la primera aproximación obtenemos imágenes más 
claras aunque han sido crecidas en diferentes sustratos. Ambos estudios se muestran para demostrar que ambos resultados son compatibles.

De los resultados de EDS, sabemos que los principales elementos que constituyen los depósitos son C y Pt. Sin embargo, la interpretación de las imágenes de HRTEM puede ser peliaguda porque obtenemos imágenes en 2 dimensiones de objetos que realmente tienen 3 dimensiones, conteniendo información a lo largo de todo el espesor de la muestra ( $\sim 50 \mathrm{~nm})$. Los granos son pequeños comparados con el espesor de la muestra, y los electrones transmitidos pueden reunir varios granos a lo largo de su trayectoria a través de la muestra. Las imágenes obtenidas de los depósitos crecidos mediante FEBID y FIBID a partir de las lamelas se muestran en la Figura B.4.

La distribución heterogénea de Pt y C en la microestructura de los depósitos como ya se ha publicado previamente ${ }^{240-244}$ es explicado como nanopartículas de Pt de tamaño $<5 \mathrm{~nm}$ embebidas en la matriz de carbono amorfa. Sin embargo, la ausencia de una observación directa de planos atómicos es un inconveniente para la correcta interpretación de las imágenes. Por otra parte, la observación de planos atómicos en los depósitos crecidos directamente sobre las rejillas de Cu permite una interpretación más fidedigna de las imágenes. Como se puede observar en la Figura B.5, los depósitos de Pt crecidos mediante FEBID y FIBID consisten en granos de Pt cristalinos de forma elipsoidal embebidos en una matriz de carbono amorfa. A partir de la FFT de las imágenes, se obtienen los puntos correspondientes a las distancias interplanares correspondientes al Pt; que tiene una estructura cristalina cúbica centrada en las caras (fcc), cuyo parámetro de red es $0.3924 \mathrm{~nm}$. 

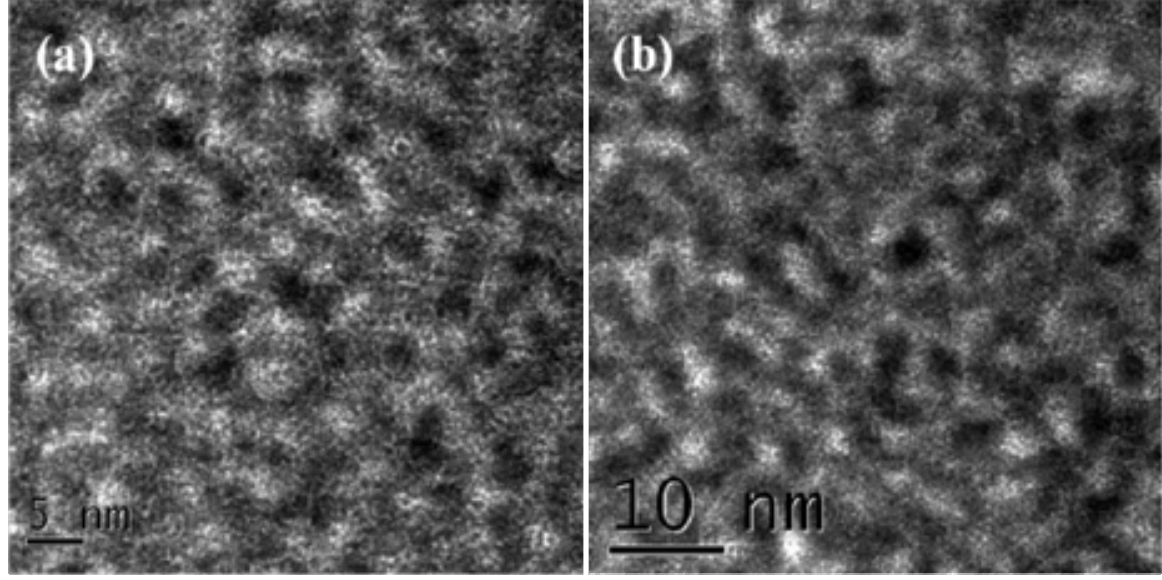

Figura B.4: Imágenes de HRTEM de depósitos de Pt crecidos a 5 kV mediante (a) FIBID y (b) FEBID, a partir del método de preparación llevado a cabo con el Dual Beam.

Se han estudiado depósitos crecidos a diferentes voltajes y corrientes, tanto por FEBID como por FIBID. Tras analizar en cada imagen al menos 50 granos individuales, encontramos que el tamaño medio de los cristales de Pt en los depósitos es de $3.2 \pm 0.8 \mathrm{~nm}$.

A través de las imágenes de HRTEM de los depósitos de Pt crecidos por FEBID y FIBID, obtenidas a partir de las lamelas o bien de los depósitos crecidos directamente sobre rejillas de $\mathrm{Cu}$, cualitativamente la microestructura es muy similar. Sin embargo, para un análisis cuantitativo sólo los depósitos crecidos sobre las rejillas de Cu nos permiten extraer conclusiones. 

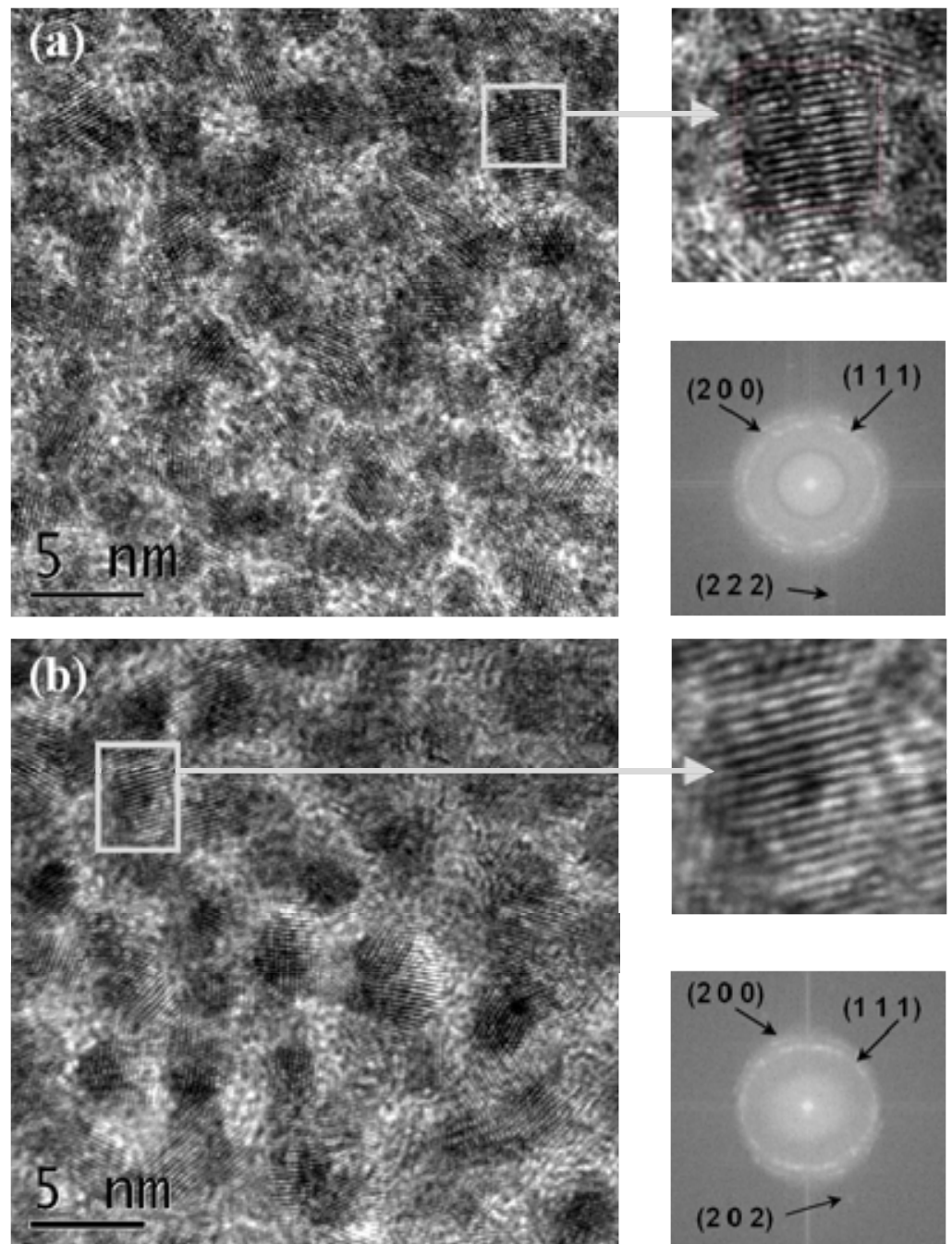

Figura B.5: Imágenes de HRTEM de depósitos de Pt crecidos directamente sobre una rejilla de Cu comercial a $30 \mathrm{kV}$ mediante (a) FIBID y (b) FEBID. Se ha seleccionado en cada caso uno de los granos para una clara observación de los planos atómicos correspondientes. La FFT de toda la imagen nos proporciona los puntos de difracción que corresponden a los planos atómicos del Pt fcc. 


\section{Apéndice C}

\section{Nanodepósitos de $C$ crecidos mediante un haz de iones focalizado}

En este apéndice presentamos el estudio de nanoestructuras de carbono fabricadas mediante un haz de iones focalizado usando naftaleno, $\mathrm{C}_{10} \mathrm{H}_{8}$ como material precursor. Esta caracterización consiste en el análisis composicional y las medidas de transporte eléctrico en función de la temperatura que se llevaron a cabo en nanohilos con un ancho inferior a 100 $n m$. 
La reciente publicación de Dhakal y colaboradores ${ }^{247}$, en la cual observaban superconductividad en nanohilos basados en carbono fabricados mediante FIBID, utilizando fenantreno $\mathrm{C}_{14} \mathrm{H}_{10}$ como material de partida, despertó una serie de incertidumbres acerca del origen de la superconductividad en este tipo de depósitos y por otra parte, una gran expectación ante la aparición de otro material superconductor crecido mediante FIBID. En los últimos años, numerosos autores han informado del carácter superconductor de depósitos basados en wolframio crecidos con la misma técnica ${ }^{101}$, cuyo origen y propiedades se comentó extensamente en el Capítulo 5 de esta tesis.

En la investigación llevada a cabo por Dhakal, la transición superconductora de este material se observa a $7 \mathrm{~K}$, y el campo crítico está por encima de $9 \mathrm{~T}$. Los depósitos son de naturaleza amorfa, como ya se observó en el caso de los depósitos de W y su composición química en porcentaje atómico es del 34\% C, 38\% O y 26\% Ga. Según los autores, el origen de la superconductividad parece estar en el contenido de Ga y O, ya que con \% más bajos de $\mathrm{O}$, el material no transita por encima de $2 \mathrm{~K}$.

Este hallazgo inspira nuestro estudio con el objetivo de obtener estructuras superconductores mediante FIBID usando como material precursor el naftaleno, $\mathrm{C}_{10} \mathrm{H}_{8}$ de similar naturaleza que el $\mathrm{C}_{14} \mathrm{H}_{10}$ (véase la Figura C.1).
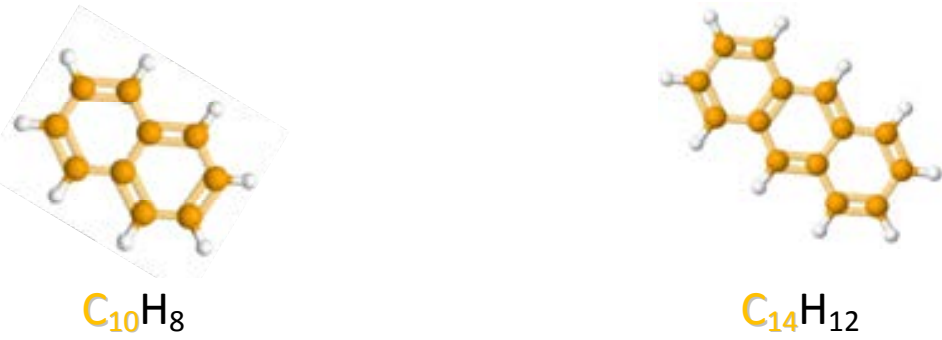

Figura C.1: Moléculas de los materiales precursores de carbono. 
Los parámetros de crecimiento de los NWs utilizados son los siguientes: material precursor $=$ naftaleno, $\mathrm{C}_{10} \mathrm{H}_{8}$; temperatura del material precursor $=35^{\circ} \mathrm{C} ; \mathrm{V}_{\mathrm{i}}=30 \mathrm{kV}$; $\mathrm{I}_{\mathrm{i}}=1.1 \mathrm{pA} ; \mathrm{t}_{\mathrm{p}}=100 \mathrm{~ns} ; \mathrm{s}=0 \% \mathrm{t}_{\mathrm{r}}=0 \mathrm{~s} ; \mathrm{P}_{\mathrm{b}}=1 \times 10^{-6}$ mbar; $\mathrm{P}_{\mathrm{p}}=1 \times 10^{-5}$ mbar. El sustrato utilizado en todos los experimentos es Si dopado con boro (dopaje tipo p), previamente oxidado térmicamente; con un espesor de óxido de unos $250 \mathrm{~nm}$. Los contactos de Ti fueron fabricados sobre el sustrato oxidado mediante técnicas de litografía óptica. Los nanohilos de C estudiados tienen las siguientes dimensiones: longitud $=7 \mu \mathrm{m}$, ancho $\sim 90 \mathrm{~nm}$, espesor $\sim 50 \mathrm{~nm}$.

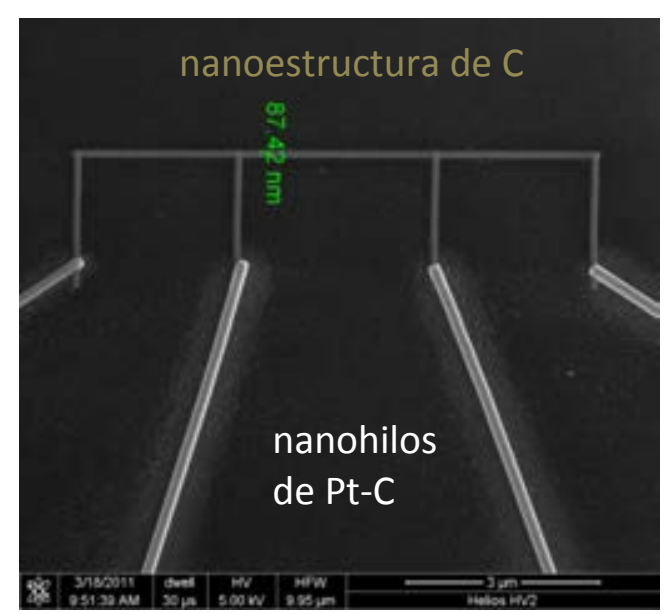

Figura C.2: Imagen SEM de una nanoestructura de C contactada a los 4 nanohilos de Pt crecidos mediante FIBID.

En segundo lugar, se realizaron 4 nanocontactos auxiliares de Pt crecidos mediante FIBID, que van desde los 4 microcontactos metálicos a la nanoestructura de C. La configuración del "Dual Beam” nos permite ajustar la posición de los dos haces con una precisión nanométrica, evitando la irradiación del haz de iones sobre la nanoestructura crecida con anterioridad (veáse la Figura C.2).

El análisis composicional de los nanohilos se realizó in situ tras el proceso de crecimiento. El $\mathrm{V}_{\mathrm{e}}$ utilizado para capturar los espectros fue de $3 \mathrm{kV}$. La composición 
de los nanodepósitos obtenida en \% atómico es de $58 \pm 5$ de C, $24 \pm 5$ de O y el $18 \pm 5$ de Ga.

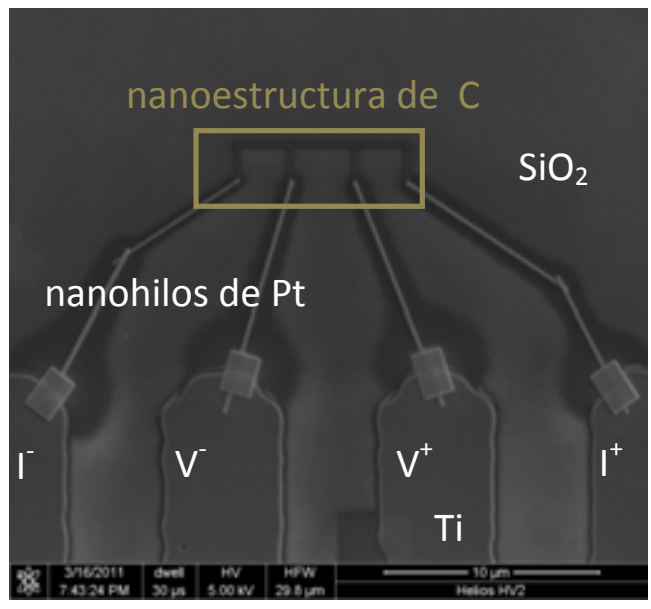

Figura C.3: Imagen SEM de un depósito de C conectado a los 4 contactos de Pt crecidos mediante FIBID, a su vez contactados a las pistas metálicas de Ti.

Las medidas de transporte eléctrico "ex-situ" en función de la temperatura se realizaron en el PPMS. En la Figura C.3, vemos una imagen de SEM tomada de una de las nanoestructuras de C fabricadas, en la cual se indica que por los contactos extremos de las nanoestructura aplicamos una corriente y medimos la caída de voltaje por los contactos internos.

En la Figura C.4, representamos la resistencia en función de la temperatura de una de las nanoestructuras de C típica. El primer hecho remarcable en este tipo de depósitos es el valor de la resistencia a $300 \mathrm{~K}$, del orden de $\sim \mathrm{M} \Omega$. El nanohilo se hace más resistivo al descender la temperatura, hasta alcanzar valores de resistencia próximos al valor máximo que se puede medir con el PPMS. Así, estas nanoestructuras presentan una conducción eléctrica típica de semiconductores intrínsecos, cuya dependencia con la temperatura es de tipo exponencial como se indica en la ecuación C.1. 


$$
R(T) \sim \exp (1 / \mathrm{kT})^{\mathrm{N}}
$$

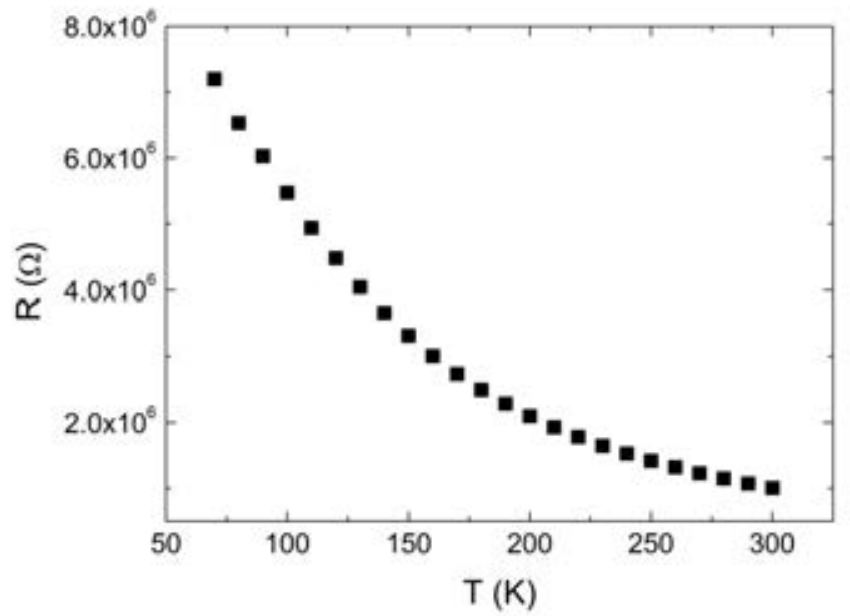

Figura C.4: Resistencia en función de la temperatura de una nanoestructura de C.

En la Figura C.5, representamos la conductancia, $\ln (\mathrm{G})$, en función de $\mathrm{T}^{-1 / 2}$ de la misma nanoestructura de C. El ajuste de la curva a la ecuación C. 1 tomando N=0.5 por debajo de $125 \mathrm{~K}$ nos permite concluir que el mecanismo que domina la conducción en este tipo de depósitos en el rango de temperaturas indicado es ES-VRH ${ }^{180,}{ }^{248}$. Por encima de $125 \mathrm{~K}$, la energía térmica es lo suficientemente alta como para desviarse de la dependencia con $\mathrm{T}^{-1 / 2}$ al permitir otro tipo de procesos electrónicos como la activación térmica vía "hopping” ${ }^{180}$. La misma dependencia con la temperatura ha sido observada para depósitos de Pt crecidos mediante FEBID/FIBID ${ }^{116,172 .}$ 


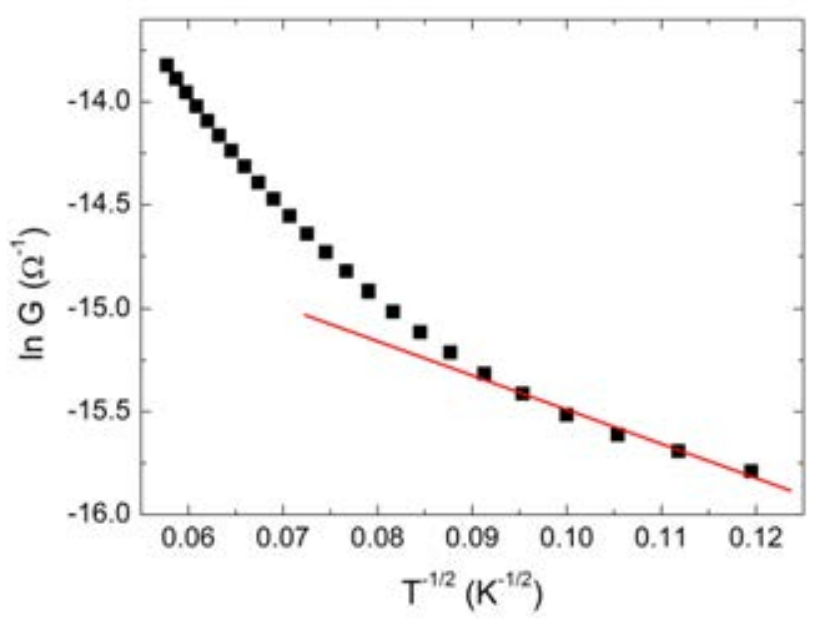

Figura C.5: ln (G) en función de $T^{-1 / 2}$ de una nanoestructura de C. La línea roja indica el ajuste al modelo de VRH (veáse la ecuación C.1) por debajo de $125 \mathrm{~K}$.

En conclusión, los NWs de C estudiados presentan el comportamiento típico de los materiales semiconductores, cuya conducción se realiza a través de la matriz de carbono amorfa.

Como hemos podido ver los resultados obtenidos distan bastante de los que obtuvieron Dhakal y sus colaboradores en NWs de C-Ga-O. A continuación, intentaremos explicar las hipótesis por las cuales observan un comportamiento distinto. En primer lugar, debemos tener en cuenta que el oxígeno presente en los NWs y en el cual los autores se apoyan al argumentar que otros NWs con menor contenido de oxígeno no presentan una temperatura de transición por encima de $2 \mathrm{~K}$, no proviene del material precursor $\left(\mathrm{C}_{14} \mathrm{H}_{12}\right)$. El elevado contenido de oxígeno en estos NWs puede provenir del vapor de agua que se encuentra en la cámara de proceso de su sistema. Sin embargo, aunque el elevado contenido de $\mathrm{O}$ fuera el responsable de que los NWs de C presenten una temperatura de transición cerca de $7 \mathrm{~K}$, sería un efecto totalmente arbitrario, ya que dependería en gran medida de las especies contaminantes presentes en la cámara de proceso en cada momento. 
En segundo lugar, tenemos la hipótesis que barajamos como más acertada para explicar el fenómeno de superconductividad observado en estos NWs. En las imágenes SEM y AFM del NW que los autores muestran en el artículo ${ }^{247}$ es muy difícil ver tal NW, realmente lo que se observa con claridad es una zanja de unos 200 $\mathrm{nm}$ de ancho lateral producida por el FIB. Ello nos lleva a pensar que al barrer con el FIB de $\mathrm{Ga}^{+}$un sustrato de Si se puede producir el dopaje del Si con iones de Ga. De forma que la implantación de Ga en el sustrato de $\mathrm{Si}$ podría producir el efecto observado por los autores, al observar una $\mathrm{T}_{\mathrm{C}} \sim 7 \mathrm{~K}$. Otros autores ya han observado ese valor de $\mathrm{T}_{\mathrm{c}} \mathrm{y} \mathrm{B}_{\mathrm{c} 2} \sim 9 \mathrm{~T}$ en películas de Si dopadas con $\mathrm{Ga}^{249,250}$. 


\section{Acrónimos}

AFM Atomic Force Microscope/Microscopio de Fuerzas Atómicas

AHE Anomalous Hall effect/Efecto Hall Anómalo

AMR Anisotropic Magnetoresistance/Magnetorresistencia Anisótropa

BE Binding Energy/Energía de enlace

BSE Backscattered electrons/Electrones retrodispersados

CASINO monte CArlo SImulation of electroNs in sOlids/Simulación de la interacción de los electrones sobre sólidos basado en el método de Monte Carlo

CVD Chemical Vapor Deposition/Crecimiento químico en fase vapor

DC Direct current/Corriente continua

DOS Density of States/Densidad de estados

EBL Electron Beam Lithography/Litografía electrónica

EDS Energy Dispersive X-Ray spectroscopy/Espectroscopia de dispersión de energía de Rayos-X

EELS Electron Energy Loss Spectroscopy/Espectroscopía de pérdida de energía de los electrones

ELNES Energy Loss Near Edge Structure/Análisis de la estructura fina por la pérdida de energía de los electrones 
ES-VRH Efros-Shklovskii Variable Range Hopping/Salto de rango variable

ETD Everhart Thornley Detector/Detector de electrones secundarios

FCC Face centered cubic structure/Estructura cúbica centrada en las caras

FEB Focused Electron Beam/Haz de electrones focalizado

FEBID Focused Electron Beam Induced Deposition/Crecimiento inducido por un haz de electrones focalizado

FEBIE Electron Beam Induced Etching/ Ataque inducido por un haz de electrones focalizado

FEG Field Emission Gun/Cañón de emisión de campo

FIB Focused Ion Beam/Haz de iones focalizado

FIBID Focused Ion Beam Induced Deposition/Crecimiento inducido por un haz de iones focalizado

FFT Fast Fourier Transform/Transformada rápida de Fourier

GAHE Giant Anomalous Hall effect/Efecto Hall anómalo gigante

GIS Gas Injection System/Sistema de inyección de gases

GMR Giant Magnetoresistance/Magnetorresistencia Gigante

HAADF High Angle Annular Dark Field/Campo oscuro anular de alto ángulo

HCP Hexagonal closed packed/Empaquetado Hexagonal cerrado

HDD Hard Disk/Disco duro

HRTEM High Resolution Transmission Electron Microscopy/Microscopía electrónica de transmisión de alta resolución

HV High Vacuum/Alto vacío

ITMR Intergranular Tunneling Magnetoresistance/Magnetorresistencia túnel intergranular 
LMIS Liquid Metal Ion Source/Fuente líquida de iones metálicos

MBE Molecular Beam Epitaxy/Crecimiento epitaxial por haces moleculares

MBJ Mechanical Break Junctions/Uniones de ruptura mecánica

MEMS Micro-Electronic Mechanical Systems/Sistemas micro-electro-mecánicos

MFM Magnetic Force Microscopy/Microscopio de fuerzas magnéticas

MIT Metal Insulator Transition/Transición de aislante a metal

MOKE Magneto Optical Kerr Effect/Efecto Kerr magnetoóptico

MR Magnetoresistance/Magnetorresistencia

MRAM Magnetic Random Access Memory/Memoria magnética de acceso aleatorio

$\mathrm{M}_{\mathrm{s}}$ Saturation magnetization/Imanación de saturación

MTJ Magnetic Tunnel Junction/Unión túnel magnética

NEMS Nano-Electronic Mechanical Systems/Sistemas Nano-Electro-Mecánicos

NWs Nanowires/Nanohilos

OHE Ordinary Hall effect/Efecto Hall ordinario

PCA Principal Components Analysis/Análisis de Componentes Principales

PE Primary electrons/electrones primarios

PPMS Physical Properties Measurement System/Sistema de medidas de propiedades físicas (Quantum Design).

RAM Random Access Memory/Memoria de acceso aleatorio

RGA Residual Gas Analyzer/Analizador de gases residuales

RIE Reactive ion etching/Ataque mediante iones reactivos

RRR Residual Resistivity Ratio/Cociente de resistividad residual

SCs Superconductor Materials/Materiales superconductores 
SE Secondary Electrons/Electrones secundarios

SEM Scanning Electron Microscope/Microscopio electrónico de barrido

SQUID Superconducting Quantum Interference Device/Dispositivo de interferencia cuántica superconductor

SRIM Stopping \& Range of Ions in Matter/Parada y rango de iones en la materia

STEM Scanning Transmission Electron Microscopy/ Microscopía electrónica de transmisión de barrido

STM Scanning Tunneling Microscopy/Microscopía de efecto túnel

STS Scanning Tunneling Spectroscopy/Espectroscopía de efecto túnel

TEM Transmission Electron Microscopy/Microscopía electrónica de transmisión

TLD Through-the-Lens Detector/Detector de ultra-alta-resolución a través de las lentes

TRIM Transport of Ions in Matter/Transporte de iones en la materia

UHV Ultrahigh Vacuum/Ultra-alto vacío

VRH Variable Range Hoping/Salto de rango variable 


\section{Bibliografía}

1. Feynman, R. P., There's Plenty of Room at the Bottom. Engineering and Science 1960.

2. Spaldin, N., In Magnetic Materials, Fundamentals and Device applications, Cambridge University Press: 2003.

3. Allwood, D. A.; Xiong, G.; Faulkner, C. C.; Atkinson, D.; Petit, D.; Cowburn, R. P., Magnetic domain-wall logic. Science 2005, 309, (5741), 1688-1692.

4. Novoselov, K. S.; Geim, A. K.; Morozov, S. V.; Jiang, D.; Zhang, Y.; Dubonos, S. V.; Grigorieva, I. V.; Firsov, A. A., Electric field effect in atomically thin carbon films. Science 2004, 306, (5696), 666-669.

5. Novoselov, K. S.; Geim, A. K.; Morozov, S. V.; Jiang, D.; Katsnelson, M. I.; Grigorieva, I. V.; Dubonos, S. V.; Firsov, A. A., Two-dimensional gas of massless Dirac fermions in graphene. Nature 2005, 438, (7065), 197-200.

6. Novoselov, K. S., Nobel Lecture: Graphene: Materials in the Flatland. Reviews of Modern Physics 2011, 83, (3), 837-849.

7. Britnell, L.; Gorbachev, R. V.; Jalil, R.; Belle, B. D.; Schedin, F.; Mishchenko, A.; Georgiou, T.; Katsnelson, M. I.; Eaves, L.; Morozov, S. V.; Peres, N. M. R.; Leist, J.; Geim, A. K.; Novoselov, K. S.; Ponomarenko, L. A., Field-effect tunneling transistor based on vertical graphene heterostructures. Science (New York, N.Y.) 2012, 335, (6071), 947-50.

8. van Kouwen, L.; Botman, A.; Hagen, C. W., Focused Electron-Beam-Induced Deposition of $3 \mathrm{~nm}$ Dots in a Scanning Electron Microscope. Nano Letters 2009, 9, (5), 2149-2152.

9. Jonckheere, R.; Bret, T.; Van den Heuvel, D.; Magana, J.; Gao, W.; Waiblinger, M., Repair of natural EUV reticle defects. In Photomask Technology 2011, Maurer, W.; Abboud, F. E., Eds. Spie-Int Soc Optical Engineering: Bellingham, 2011; Vol. 8166. 
10. Giannuzzi, L. A.; Stevie, F. A., Introduction to focused ion beams. Springer Science: Boston, 2005; p 357.

11. Reyntjens, S.; Puers, R., A review of focused ion beam applications in microsystem technology. Journal of Micromechanics and Microengineering 2001, 11, (4), 287-300.

12. Drouin, D. Programa de simulación, CASINO, 1996.

13. Drouin, D.; Couture, A. R.; Joly, D.; Tastet, X.; Aimez, V.; Gauvin, R., CASINO V2.42 - A fast and easy-to-use modeling tool for scanning electron microscopy and microanalysis users. Scanning 2007, 29, (3), 92-101.

14. Krasheninnikov, A. V.; Nordlund, K., Ion and electron irradiation-induced effects in nanostructured materials. Journal of Applied Physics 2010, 107, (7), 071301.

15. Gomer, R., Mechanims of liquid-metal electron and ion sources. Applied Physics 1979, 19, (4), 365-375.

16. Ziegler, J. P.; Biersack, M. D.; Ziegler, M. D., The Stopping and Range of Ions in Solids. 2008.

17. Rius, G.; Llobet, J.; Arcamone, J.; Borrise, X.; Perez-Murano, F., Electronand ion-beam lithography for the fabrication of nanomechanical devices integrated on CMOS circuits. Microelectronic Engineering 2009, 86, (4-6), 1046-1049.

18. Rius, G.; Llobet, J.; Borrise, X.; Mestres, N.; Retolaza, A.; Merino, S.; PerezMurano, F., Fabrication of complementary metal-oxide-semiconductor integrated nanomechanical devices by ion beam patterning. Journal of Vacuum Science \& Technology B 2009, 27, (6), 2691-2697.

19. Melngailis, J.; Mondelli, A. A.; Berry, I. L.; Mohondro, R., A review of ion projection lithography. Journal of Vacuum Science \& Technology B 1998, 16, (3), 927-957.

20. Tseng, A. A., Recent developments in micromilling using focused ion beam technology. Journal of Micromechanics and Microengineering 2004, 14, (4), R15R34.

21. Tseng, A. A., Recent developments in nanofabrication using focused ion beams. Small 2005, 1, (10), 924-939.

22. Miller, M. K.; Russell, K. F., Atom probe specimen preparation with a dual beam SEM/FIB miller. Ultramicroscopy 2007, 107, (9), 761-766. 
23. Miller, M. K.; Russell, K. F.; Thompson, G. B., Strategies for fabricating atom probe specimens with a dual beam FIB. Ultramicroscopy 2005, 102, (4), 287-298.

24. Randolph, S. J.; Fowlkes, J. D.; Rack, P. D., Focused, nanoscale electronbeam-induced deposition and etching. Critical Reviews in Solid State and Materials Sciences 2006, 31, (3), 55-89.

25. Martínez-Pérez, M. J.; Sesé, J.; Córdoba, R.; Luis, F.; Drung, D.; Schuring, T., Circuit edit of superconducting microcircuits. Superconductor Science and Technology 2009, 22, (12), 125020.

26. Randolph, S. J.; Fowlkes, J. D.; Rack, P. D., Focused electron-beam-induced etching of silicon dioxide. Journal of Applied Physics 2005, 98, (3), 034902.

27. Yemini, M.; Hadad, B.; Liebes, Y.; Goldner, A.; Ashkenasy, N., The controlled fabrication of nanopores by focused electron-beam-induced etching. Nanotechnology 2009, 20, (24), 245302.

28. Bret, T.; Afra, B.; Becker, R.; Hofmann, T.; Edinger, K.; Liang, T.; Hoffmann, P., Gas assisted focused electron beam induced etching of alumina. Journal of Vacuum Science \& Technology B 2009, 27, (6), 2727-2731.

29. Wang, J. H.; Griffis, D. P.; Garcia, R.; Russell, P. E., Etching characteristics of chromium thin films by an electron beam induced surface reaction. Semiconductor Science and Technology 2003, 18, (4), 199-205.

30. Wang, S.; Sun, Y. M.; White, J. M.; Stivers, A.; Liang, T., Electron-beamassisted etching of $\mathrm{CrO}_{x}$ films by $\mathrm{Cl}_{2}$. Journal of Vacuum Science \& Technology B 2005, 23, (1), 206-209.

31. Ganczarczyk, A.; Geller, M.; Lorke, A., $\mathrm{XeF}_{2}$ gas-assisted focused-electronbeam-induced etching of GaAs with $30 \mathrm{~nm}$ resolution. Nanotechnology 2011, 22, (4), 045301.

32. Lassiter, M. G.; Liang, T.; Rack, P. D., Inhibiting spontaneous etching of nanoscale electron beam induced etching features: Solutions for nanoscale repair of extreme ultraviolet lithography masks. Journal of Vacuum Science \& Technology B 2008, 26, (3), 963-967.

33. Roediger, P.; Wanzenboeck, H. D.; Hochleitner, G.; Bertagnolli, E., Crystallinity-retaining removal of germanium by direct-write focused electron beam induced etching. Journal of Vacuum Science \& Technology B 2011, 29, (4), 041801.

34. Schoenaker, F. J.; Córdoba, R.; Fernández-Pacheco, R.; Magén, C.; Stephan, O.; Zuriaga-Monroy, C.; Ibarra, M. R.; De Teresa, J. M., Focused electron beam induced etching of titanium with $\mathrm{XeF}_{2}$. Nanotechnology 2011, 22, (26), 265304. 
35. Santschi, C.; Jenke, M.; Hoffmann, P.; Brugger, J., Interdigitated 50 nm Ti electrode arrays fabricated using $\mathrm{XeF}_{2}$ enhanced focused ion beam etching. Nanotechnology 2006, 17, (11), 2722-2729.

36. Matsui, S.; Mori, K., New selective deposition technology by electron-beam induced surface-reaction. Japanese Journal of Applied Physics Part 2-Letters 1984, 23, (9), L706-L708.

37. Matsui, S.; Mori, K., New selective deposition technology by electron-beam induced surface-reaction. Journal of Vacuum Science \& Technology B 1986, 4, (1), 299-304.

38. Koops, H. W. P.; Weiel, R.; Kern, D. P.; Baum, T. H., High-resolution electron-beam induced deposition. Journal of Vacuum Science \& Technology B 1988, 6, (1), 477-481.

39. Silvis-Cividjian, N.; Hagen, C. W., Electron-beam-induced nanometer-scale deposition. In Advances in Imaging and Electron Physics, Vol 143, Elsevier Academic Press Inc: San Diego, 2006; Vol. 143.

40. van Dorp, W. F.; Hagen, C. W., A critical literature review of focused electron beam induced deposition. Journal of Applied Physics 2008, 104, (8), 081301.

41. Utke, I.; Hoffmann, P.; Melngailis, J., Gas-assisted focused electron beam and ion beam processing and fabrication. Journal of Vacuum Science \& Technology B 2008, 26, (4), 1197-1276.

42. Wnuk, J. D.; Gorham, J. M.; Rosenberg, S. G.; van Dorp, W. F.; Madey, T. E.; Hagen, C. W.; Fairbrother, D. H., Electron Induced Surface Reactions of the Organometallic Precursor Trimethyl(methylcyclopentadienyl)platinum(IV). Journal of Physical Chemistry C 2009, 113, (6), 2487-2496.

43. Fowlkes, J. D.; Rack, P. D., Fundamental Electron-Precursor-Solid Interactions Derived from Time-Dependent Electron-Beam-Induced Deposition Simulations and Experiments. Acs Nano 2010, 4, (3), 1619-1629.

44. Li, W.; Joy, D. C., Study of temperature influence on electron beam induced deposition. Journal of Vacuum Science \& Technology A 2006, 24, (3), 431-436.

45. Fowlkes, J. D.; Randolph, S. J.; Rack, P. D., Growth and simulation of highaspect ratio nanopillars by primary and secondary electron-induced deposition. Journal of Vacuum Science \& Technology B 2005, 23, (6), 2825-2832.

46. Silvis-Cividjian, N.; Hagen, C. W.; Kruit, P., Spatial resolution limits in electron-beam-induced deposition. Journal of Applied Physics 2005, 98, (8), 084905. 
47. Botman, A.; Mulders, J. J. L.; Hagen, C. W., Creating pure nanostructures from electron-beam-induced deposition using purification techniques: a technology perspective. Nanotechnology 2009, 20, (37), 372001.

48. Córdoba, R.; Sesé, J.; De Teresa, J. M.; Ibarra, M. R., High-purity cobalt nanostructures grown by focused-electron-beam-induced deposition at low current. Microelectronic Engineering 2010, 87, (5-8), 1550-1553.

49. Mulders, J. J. L.; Belova, L. M.; Riazanova, A., Electron beam induced deposition at elevated temperatures: compositional changes and purity improvement. Nanotechnology 2011, 22, (5), 055302.

50. Belova, L. M.; Dahlberg, E. D.; Riazanova, A.; Mulders, J. J. L.; Christophersen, C.; Eckert, J., Rapid electron beam assisted patterning of pure cobalt at elevated temperatures via seeded growth. Nanotechnology 2011, 22, (14), 145305.

51. Tripathi, S. K.; Shukla, N.; Rajput, N. S.; Kulkarni, V. N., The out of beam sight effects in focused ion beam processing. Nanotechnology 2009, 20, (27), 275301.

52. Hernández-Ramírez, F.; Rodríguez, J.; Casals, O.; Russinyol, E.; Vila, A.; Romano-Rodríguez, A.; Morante, J. R.; Abid, M., Characterization of metal-oxide nanosensors fabricated with focused ion beam (FIB). Sensors and Actuators BChemical 2006, 118, (1-2), 198-203.

53. Li, W. X.; Warburton, P. A., Low-current focused-ion-beam induced deposition of three-dimensional tungsten nanoscale conductors. Nanotechnology 2007, 18, (48), 485305.

54. Hernández-Ramírez, F.; et al., Portable microsensors based on individual $\mathrm{SnO}_{2}$ nanowires. Nanotechnology 2007, 18, (49), 495501.

55. Rius, G.; Llobet, J.; Esplandiu, M. J.; Sole, L.; Borrise, X.; Perez-Murano, F., Using electron and ion beams on carbon nanotube-based devices. Effects and considerations for nanofabrication. Microelectronic Engineering 2009, 86, (4-6), 892894.

56. Marcano, N.; Sangiao, S.; Plaza, M.; Perez, L.; Fernández Pacheco, A.; Córdoba, R.; Sanchez, M. C.; Morellón, L.; Ibarra, M. R.; De Teresa, J. M., Weakantilocalization signatures in the magnetotransport properties of individual electrodeposited Bi Nanowires. Applied Physics Letters 2010, 96, (8), 082110.

57. Muñoz-Rojas, D.; Córdoba, R.; Fernández-Pacheco, A.; De Teresa, J. M.; Sauthier, G.; Fraxedas, J.; Walton, R. I.; Casan-Pastor, N., High Conductivity in Hydrothermally Grown $\mathrm{AgCuO}_{2}$ Single Crystals Verified Using Focused-Ion-BeamDeposited Nanocontacts. Inorganic Chemistry 2010, 49, (23), 10977-10983. 
58. Puers, R.; Reyntjens, S., Fabrication and testing of custom vacuum encapsulations deposited by focused ion beam direct-write CVD. Sensors and Actuators a-Physical 2001, 92, (1-3), 249-256.

59. Martínez-Pérez, M. J.; Sesé, J.; Luis, F.; Córdoba, R.; Drung, D.; Schurig, T.; Bellido, E.; de Miguel, R.; Gomez-Moreno, C.; Lostao, A.; Ruiz-Molina, D., Ultrasensitive Broad Band SQUID Microsusceptometer for Magnetic Measurements at Very Low Temperatures. IEEE Transactions on Applied Superconductivity 2011, 21, (3), 345-348.

60. Tripathi, S. K.; Shukla, N.; Rajput, N. S.; Singh, A. K.; Kulkarni, V. N., Comprehensive analysis of the deposition caused by scattered Ga ions during focused ion-beam-induced deposition. Micro \& Nano Letters 2010, 5, (5), 254-257.

61. Tripathi, S. K.; Shukla, N.; Kulkarni, V. N., Exploring a new strategy for nanofabrication: deposition by scattered $G$ a ions using focused ion beam. Nanotechnology 2009, 20, (7), 075304.

62. Neugebauer, C. A.; Webb, M. B., Electrical conduction mechanism in ultrathin, evaporated metal films. Journal of Applied Physics 1962, 33, (1), 74-82.

63. Edwards, P. P.; Ramakrishnan, T. V.; Rao, C. N. R., The metal-nonmetal transition - a global perspective. Journal of Physical Chemistry 1995, 99, (15), 52285239.

64. Baibich, M. N.; Broto, J. M.; Fert, A.; Vandau, F. N.; Petroff, F.; Eitenne, P.; Creuzet, G.; Friederich, A.; Chazelas, J., Giant magnetoresistance of (001)Fe/(001)Cr magnetic superlattices. Physical Review Letters 1988, 61, (21), 2472-2475.

65. Kondo, J., Anomalous hall effect and magnetoresistance of ferromagnetic metals. Progress of Theoretical Physics 1962, 27, (4), 772-792.

66. Julliere, M., Tunneling between ferromagnetic-films. Physics Letters A 1975, 54, (3), 225-226.

67. Fujimori, H.; Mitani, S.; Ohnuma, S., Tunnel-type GMR in Co-Al-O insulated granular system - Its oxygen-concentration dependence. Journal of Magnetism and Magnetic Materials 1996, 156, (1-3), 311-314.

68. Mitani, S.; Fujimori, H.; Takanashi, K.; Yakushiji, K.; Ha, J. G.; Takahashi, S.; Maekawa, S.; Ohnuma, S.; Kobayashi, N.; Masumoto, T.; Ohnuma, M.; Hono, K., Tunnel-MR and spin electronics in metal-nonmetal granular systems. Journal of Magnetism and Magnetic Materials 1999, 198-99, 179-184. 
69. Honda, S.; Okada, T.; Nawate, M.; Tokumoto, M., Tunneling giant magnetoresistance in heterogeneous $\mathrm{Fe}_{-} \mathrm{SiO}_{2}$ granular films. Physical Review B 1997, 56, (22), 14566-14573.

70. García-García, A.; Vovk, A.; Pardo, J. A.; Strichovanec, P.; Algarabel, P. A.; Magén, C.; De Teresa, J. M.; Morellón, L.; Ibarra, M. R., Tunneling magnetoresistance in Fe/MgO granular multilayers. Journal of Applied Physics 2010, 107, (3), 033704.

71. Nagaosa, N.; Sinova, J.; Onoda, S.; MacDonald, A. H.; Ong, N. P., Anomalous Hall effect. Reviews of Modern Physics 2010, 82, (2), 1539-1592.

72. Smit, J., The spontaneous hall effect in ferromagnetics.1. Physica 1955, 21, (11), 877-887.

73. Smit, J., The spontaneous hall effect in ferromagnetics-II. Physica 1958, 24, (1), 39-51.

74. Berger, L., Application of side-jump model to hall-effect and Nernst effect in ferromagnets. Physical Review B 1972, 5, (5), 1862.

75. Onnes, H. K., Leiden Commun 1911, 120.

76. Tinkham, M., Introduction to Superconductivity. Second ed.; Dover Publications, Inc.: 1996.

77. Arutyunov, K. Y.; Golubev, D. S.; Zaikin, A. D., Superconductivity in one dimension. Physics Reports-Review Section of Physics Letters 2008, 464, (1-2), 1-70.

78. Grigorieva, I. V.; Geim, A. K.; Dubonos, S. V.; Novoselov, K. S.; Vodolazov, D. Y.; Peeters, F. M.; Kes, P. H.; Hesselberth, M., Long-range nonlocal flow of vortices in narrow superconducting channels. Physical Review Letters 2004, 92, (23), 237001.

79. Velez, M.; Martin, J. I.; Villegas, J. E.; Hoffmann, A.; Gonzalez, E. M.; Vicent, J. L.; Schuller, I. K., Superconducting vortex pinning with artificial magnetic nanostructures. Journal of Magnetism and Magnetic Materials 2008, 320, (21), 25472562.

80. Wu, C. H.; Chou, Y. T.; Kuo, W. C.; Chen, J. H.; Wang, L. M.; Chen, J. C.; Chen, K. L.; Sou, U. C.; Yang, H. C.; Jeng, J. T., Fabrication and characterization of high- $\mathrm{T}_{\mathrm{c}} \quad \mathrm{YBa}_{2} \mathrm{Cu}_{3} \mathrm{O}_{(7-\mathrm{x})}$ nanoSQUIDs made by focused ion beam milling. Nanotechnology 2008, 19, (31), 315304.

81. Foley, C. P.; Hilgenkamp, H., Why NanoSQUIDs are important: an introduction to the focus issue. Superconductor Science \& Technology 2009, 22, (6), 064001. 
82. Lam, S. K. H.; Clem, J. R.; Yang, W., A nanoscale SQUID operating at high magnetic fields. Nanotechnology 2011, 22, (45), 455501.

83. Clarke, J.; Wilhelm, F. K., Superconducting quantum bits. Nature 2008, 453, (7198), 1031-1042.

84. Leggett, A. J., Physics - Superconducting qubits - a major roadblock dissolved? Science 2002, 296, (5569), 861-862.

85. Bednorz, J. G.; Muller, K. A., Possible high-Tc superconductivity in the BaLa-Cu-O system. Zeitschrift Fur Physik B-Condensed Matter 1986, 64, (2), 189-193.

86. Kamihara, Y.; Watanabe, T.; Hirano, M.; Hosono, H., Iron-based layered superconductor $\mathrm{La}\left[\mathrm{O}_{1-\mathrm{x}} \mathrm{F}_{\mathrm{x}}\right] \mathrm{FeAs}(\mathrm{x}=0.05-0.12)$ with $\mathrm{T}_{\mathrm{c}}=26 \mathrm{~K}$. Journal of the American Chemical Society 2008, 130, (11), 3296.

87. Meissner, W.; Ochsenfeld, R., Short initial announcements. Naturwissenschaften 1933, 21, 787-788.

88. Ginzburg, V. L., On the macroscopic theory of superconductivity. Soviet Physics Jetp-Ussr 1956, 2, (4), 589-600.

89. Abrikosov, A. A., On the magnetic properties of superconductors of the second group. Soviet Physics Jetp-Ussr 1957, 5, (6), 1174-1183.

90. Guillamón, I. Orden y desorden en superconductividad. Universidad Autónoma de Madrid, 2009.

91. Bardeen, J.; Cooper, L. N.; Schrieffer, J. R., Theory of superconductivity. Physical Review 1957, 108, (5), 1175-1204.

92. Cooper, L. N., Bound electron pairs in a degenerate fermi gas. Physical Review 1956, 104, (4), 1189-1190.

93. Frohlich, H., Theory of the superconducting state .1. The ground state at the absolute zero of temperature. Physical Review 1950, 79, (5), 845-856.

94. Blatter, G.; Feigelman, M. V.; Geshkenbein, V. B.; Larkin, A. I.; Vinokur, V. M., Vortices in high-temperature superconductors. Reviews of Modern Physics 1994, 66, (4), 1125-1388.

95. Larkin, A. I.; Ovchinnikov, Y. N., Vortex motion in superconductors. In Nonequilibrium Superconductivity, North Holland, Amsterdam, 1986. 
96. Bezryadin, A., Quantum suppression of superconductivity in nanowires. Journal of Physics-Condensed Matter 2008, 20, (4), 043202.

97. Li, P.; Wu, P. M.; Bomze, Y.; Borzenets, I. V.; Finkelstein, G.; Chang, A. M., Switching Currents Limited by Single Phase Slips in One-Dimensional Superconducting Al Nanowires. Physical Review Letters 2011, 107, (13), 137004.

98. Papari, G.; Carillo, F.; Stornaiuolo, D.; Longobardi, L.; Beltram, F.; Tafuri, F., High critical current density and scaling of phase-slip processes in $\mathrm{YBaCuO}$ nanowires. Superconductor Science \& Technology 2012, 25, (3), 035011.

99. Langer, J. S.; Ambegaokar, V., Intrinsic resistive transition in narrow superconducting channels. Physical Review 1967, 164, (2), 498.

100. McCumber, D. E.; Halperin, B. I., Time scale of intrinsic resistive fluctuations in thin superconducting wires. Physical Review B-Solid State 1970, 1, (3), 1054.

101. Sadki, E. S.; Ooi, S.; Hirata, K., Focused-ion-beam-induced deposition of superconducting nanowires. Applied Physics Letters 2004, 85, (25), 6206-6208.

102. Guillamón, I.; Suderow, H.; Vieira, S.; Fernández-Pacheco, A.; Sesé, J.; Córdoba, R.; De Teresa, J. M.; Ibarra, M. R., Nanoscale superconducting properties of amorphous W-based deposits grown with a focused-ion-beam. New Journal of Physics 2008, 10, (9), 093005.

103. Giaever, I., Magnetic coupling between 2 adjacent type-2 superconductors. Physical Review Letters 1965, 15, (21), 825.

104. Wortis, R.; Huse, D. A., Nonlocal conductivity in the vortex-liquid regime of a two-dimensional superconductor. Physical Review B 1996, 54, (17), 12413-12420.

105. López, D.; Kwok, W. K.; Safar, H.; Olsson, R. J.; Petrean, A. M.; Paulius, L.; Crabtree, G. W., Spatially resolved dynamic correlation in the vortex state of high temperature superconductors. Physical Review Letters 1999, 82, (6), 1277-1280.

106. Helzel, A.; Kokanovic, I.; Babic, D.; Litvin, L. V.; Rohlfing, F.; Otto, F.; Surgers, C.; Strunk, C., Nonlocal vortex motion in mesoscopic amorphous $\mathrm{Nb}_{0.7} \mathrm{Ge}_{0.3}$ structures. Physical Review B 2006, 74, (22), 220510.

107. Otto, F. Nonlinear vortex transport in mesoscopic channel of amorphous NbGe. Universitätsverlag Regensburg, 2009.

108. Otto, F.; Bilusic, A.; Babic, D.; Vodolazov, D. Y.; Suergers, C.; Strunk, C., Nonlocal versus local vortex dynamics in the transversal flux transformer effect. Physical Review B 2010, 81, (17), 174521. 
109. Otto, F.; Bilusic, A.; Babic, D.; Vodolazov, D. Y.; Suergers, C.; Strunk, C., Reversal of Nonlocal Vortex Motion in the Regime of Strong Nonequilibrium. Physical Review Letters 2010, 104, (2), 027005.

110. FEI www.fei.com.

111. Friedli, V.; Utke, I., Optimized molecule supply from nozzle-based gas injection systems for focused electron- and ion-beam induced deposition and etching: simulation and experiment. Journal of Physics D-Applied Physics 2009, 42, (12), 125305.

112. Castaing, R.; Descamps, J., Sur les bases physiques de lanalyse ponctuelle par spectrographie-X. Journal De Physique Et Le Radium 1955, 16, (4), 304-317.

113. Langford, R. M.; Rogers, M., In situ lift-out: Steps to improve yield and a comparison with other FIB TEM sample preparation techniques. Micron 2008, 39, (8), 1325-1330.

114. Mayer, J.; Giannuzzi, L. A.; Kamino, T.; Michael, J., TEM sample preparation and FIB-induced damage. Mrs Bulletin 2007, 32, (5), 400-407.

115. Young, R. J.; Kirk, E. C. G.; Williams, D. A.; Ahmed, H., Fabrication of planar and cross-sectional tem specimens using a focused ion-beam. Materials Research Soc: Pittsburgh, 1990; Vol. 199, p 205-216.

116. De Teresa, J. M.; Córdoba, R.; Fernández-Pacheco, A.; Montero, O.; Strichovanec, P.; Ibarra, M. R., Origin of the Difference in the Resistivity of AsGrown Focused-Ion- and Focused-Electron-Beam-Induced Pt Nanodeposits. Journal of Nanomaterials 2009, 2009, 936863.

117. Sangiao, S.; Morellon, L.; Simon, G.; Teresa, J. M. D.; Pardo, J. A.; Arbiol, J.; Ibarra, M. R., Anomalous Hall effect in Fe (001) epitaxial thin films over a wide range in conductivity. Physical Review B (Condensed Matter and Materials Physics) 2009, 79, (1), 014431.

118. Estradè, S.; Rebled, J. M.; Arbiol, J.; Peiró, F.; Infante, I. C.; Herranz, G.; Sanchez, F.; Fontcuberta, J.; Córdoba, R.; Mendis, B. G.; Bleloch, A. L., Effects of thickness on the cation segregation in epitaxial (001) and (110) $\mathrm{La}_{2 / 3} \mathrm{Ca}_{1 / 3} \mathrm{MnO}_{3}$ thin films. Applied Physics Letters 2009, 95, (7), 072507.

119. Marcano, N.; Sangiao, S.; Magen, C.; Morellon, L.; Ibarra, M. R.; Plaza, M.; Perez, L.; De Teresa, J. M., Role of the surface states in the magnetotransport properties of ultrathin bismuth films. Physical Review B 2010, 82, (12). 
120. Estradè, S.; Rebled, J. M.; Walls, M. G.; de la Pena, F.; Colliex, C.; Córdoba, R.; Infante, I. C.; Herranz, G.; Sanchez, F.; Fontcuberta, J.; Peiro, F., Effect of the capping on the local Mn oxidation state in buried (001) and (110) $\mathrm{SrTiO}_{3} / \mathrm{La}_{2 / 3} \mathrm{Ca}_{1 / 3} \mathrm{MnO}_{3}$ interfaces. Journal of Applied Physics 2011, 110, (10), 103903.

121. Lavrijsen, R.; Córdoba, R.; Schoenaker, F. J.; Ellis, T. H.; Barcones, B.; Kohlhepp, J. T.; Swagten, H. J. M.; Koopmans, B.; De Teresa, J. M.; Magén, C.; Ibarra, M. R.; Trompenaars, P.; Mulders, J. J. L., Fe:O:C grown by focused-electronbeam-induced deposition: magnetic and electric properties. Nanotechnology 2011, 22, (2), 025302.

122. Córdoba, R.; Fernández-Pacheco, R.; Fernández-Pacheco, A.; Gloter, A.; Magén, C.; Stephan, O.; Ibarra, M. R.; De Teresa, J. M., Nanoscale chemical and structural study of Co-based FEBID structures by STEM-EELS and HRTEM. Nanoscale Research Letters 2011, 6, 1-6.

123. Lin, T.; Tsang, C.; Fontana, R. E.; Howard, J. K., Exchange-coupled Ni$\mathrm{Fe} / \mathrm{Fe}-\mathrm{Mn}, \mathrm{Ni}-\mathrm{Fe} / \mathrm{Ni}-\mathrm{Mn}$ and $\mathrm{NiO} / \mathrm{Ni}-\mathrm{Fe}$ films for stabilization of magnetoresistive sensors. IEEE Transactions on Magnetics 1995, 31, (6), 2585-2590.

124. Chappert, C.; Fert, A.; Van Dau, F. N., The emergence of spin electronics in data storage. Nature Materials 2007, 6, (11), 813-823.

125. Martins, V. C.; Germano, J.; Cardoso, F. A.; Loureiro, J.; Cardoso, S.; Sousa, L.; Piedade, M.; Fonseca, L. P.; Freitas, P. P., Challenges and trends in the development of a magnetoresistive biochip portable platform. Journal of Magnetism and Magnetic Materials 2008, 322, (9-12), 1655-1663.

126. Utke, I.; Hoffmann, P.; Berger, R.; Scandella, L., High-resolution magnetic Co supertips grown by a focused electron beam. Applied Physics Letters 2002, 80, (25), 4792-4794.

127. Utke, I.; Bret, T.; Laub, D.; Buffat, P.; Scandella, L.; Hoffmann, P., Thermal effects during focused electron beam induced deposition of nanocomposite magneticcobalt-containing tips. Microelectronic Engineering 2004, 73-74, 553-558.

128. Utke, I.; Michler, J.; Gasser, P.; Santschi, C.; Laub, D.; Cantoni, M.; Buffat, P. A.; Jiao, C.; Hoffmann, P., Cross section investigations of compositions and substructures of tips obtained by focused electron beam induced deposition. Advanced Engineering Materials 2005, 7, (5), 323-331.

129. Lau, Y. M.; Chee, P. C.; Thong, J. T. L.; Ng, V., Properties and applications of cobalt-based Material produced by electron-beam-induced deposition. Journal of Vacuum Science \& Technology a-Vacuum Surfaces and Films 2002, 20, (4), 12951302. 
130. Fernández-Pacheco, A.; De Teresa, J. M.; Szkudlarek, A.; Córdoba, R.; Ibarra, M. R.; Petit, D.; O'Brien, L.; Lewis, E. R.; Read, D. E.; Zeng, H. T.; Cowburn, R. P., Magnetization reversal in individual cobalt micro- and nanowires grown by focused-electron-beam-induced-deposition. Nanotechnology 2009, 20, 475704.

131. Gazzadi, G. C.; Mulders, J. J. L.; Trompenaars, P.; Ghirri, A.; Rota, A.; Affronte, M.; Frabboni, S., Characterization of a new cobalt precursor for focused beam deposition of magnetic nanostructures. Microelectronic Engineering 2011, 88, (8), 1955-1958.

132. Gazzadi, G. C.; Mulders, H.; Trompenaars, P.; Ghirri, A.; Affronte, M.; Grillo, V.; Frabboni, S., Focused Electron Beam Deposition of Nanowires from Cobalt Tricarbonyl Nitrosyl (Co(CO)(3)NO) Precursor. Journal of Physical Chemistry C 2011, 115, (40), 19606-19611.

133. Fernández-Pacheco, A.; De Teresa, J. M.; Córdoba, R.; Ibarra, M. R., Magnetotransport properties of high-quality cobalt nanowires grown by focusedelectron-beam-induced deposition. Journal of Physics D: Applied Physics 2009, 42, (5), 055005.

134. Jeanguillaume, C.; Colliex, C., Spectrum-image - the next step in EELS digital acquisition and processing. Ultramicroscopy 1989, 28, (1-4), 252-257.

135. Gloter, A., In Private communication.

136. Trebbia, P.; Bonnet, N., EELS elemental mapping with unconventional methods .1. Theoretical basis - image-analysis with multivariate-statistics and entropy concepts. Ultramicroscopy 1990, 34, (3), 165-178.

137. Mitterbauer, C.; Kothleitner, G.; Grogger, W.; Zandbergen, H.; Freitag, B.; Tiemeijer, P.; Hofer, F., Electron energy-loss near-edge structures of 3d transition metal oxides recorded at high-energy resolution. Ultramicroscopy 2003, 96, (3-4), 469-480.

138. Golla-Schindler, U.; Benner, G.; Putnis, A., Laterally resolved EELS for ELNES mapping of the Fe L-2,L-3- and OK-edge. Ultramicroscopy 2003, 96, (3-4), 573-582.

139. Fernández-Pacheco, A.; De Teresa, J. M.; Córdoba, R.; Ibarra, M. R.; Petit, D.; Read, D. E.; O'Brien, L.; Lewis, E. R.; Zeng, H. T.; Cowburn, R. P., Domain wall conduit behavior in cobalt nanowires grown by focused electron beam induced deposition. Applied Physics Letters 2009, 94, (19), 192509. 
140. Utke, I.; Golzhauser, A., Small, Minimally Invasive, Direct: Electrons Induce Local Reactions of Adsorbed Functional Molecules on the Nanoscale. Angewandte Chemie-International Edition 2010, 49, (49), 9328-9330.

141. Bernau, L.; Gabureac, M.; Erni, R.; Utke, I., Tunable Nanosynthesis of Composite Materials by Electron-Impact Reaction. Angewandte Chemie-International Edition 2010, 49, (47), 8880-8884.

142. Boero, G.; Utke, I.; Bret, T.; Quack, N.; Todorova, M.; Mouaziz, S.; Kejik, P.; Brugger, J.; Popovic, R. S.; Hoffmann, P., Submicrometer Hall devices fabricated by focused electron-beam-induced deposition. Applied Physics Letters 2005, 86, (4), 042503.

143. Gabureac, M.; Bernau, L.; Utke, I.; Boero, G., Granular Co-C nano-Hall sensors by focused-beam-induced deposition. Nanotechnology 2010, 21, (11), 115503.

144. Molhave, K.; Madsen, D. N.; Rasmussen, A. M.; Carlsson, A.; Appel, C. C.; Brorson, M.; Jacobsen, C. J. H.; Boggild, P., Solid gold nanostructures fabricated by electron beam deposition. Nano Letters 2003, 3, (11), 1499-1503.

145. Kunz, R. R.; Mayer, T. M., Catalytic growth-rate enhancement of electronbeam deposited iron films. Applied Physics Letters 1987, 50, (15), 962-964.

146. Ye, D. X.; Pimanpang, S.; Jezewski, C.; Tang, F.; Senkevich, J. J.; Wang, G. C.; Lu, T. M., Low temperature chemical vapor deposition of Co thin films from $\mathrm{Co}_{2}(\mathrm{CO})_{8}$. Thin Solid Films 2005, 485, (1-2), 95-100.

147. Liao, Z. M.; Xu, J.; Zhang, X. Z.; Yu, D. P., The relationship between quantum transport and microstructure evolution in carbon-sheathed Pt granular metal nanowires. Nanotechnology 2008, 19, (30), 305402.

148. Lukasczyk, T.; Schirmer, M.; Steinruck, H. P.; Marbach, H., Electron-beaminduced deposition in ultrahigh vacuum: Lithographic fabrication of clean iron nanostructures. Small 2008, 4, (6), 841-846.

149. Lukasczyk, T.; Schirmer, M.; Steinrueck, H.-P.; Marbach, H., Generation of Clean Iron Structures by Electron-Beam-Induced Deposition and Selective Catalytic Decomposition of Iron Pentacarbonyl on Rh(110). Langmuir 2009, 25, (19), 1193011939.

150. Walz, M.-M.; Schirmer, M.; Vollnhals, F.; Lukasczyk, T.; Steinrueck, H.-P.; Marbach, H., Electrons as "Invisible Ink": Fabrication of Nanostructures by Local Electron Beam Induced Activation of $\mathrm{SiO}_{\mathrm{x}}$. Angewandte Chemie-International Edition 2010, 49, (27), 4669-4673. 
151. Hirose, F.; Sakamoto, H., Low-temperature Si selective epitaxial growth using electron-beam-induced reaction. Japanese Journal of Applied Physics Part 1Regular Papers Short Notes \& Review Papers 1995, 34, (11), 5904-5907.

152. Matsui, S.; Ichihashi, T.; Mito, M., Electron-beam induced selective etching and deposition technology. Journal of Vacuum Science \& Technology B 1989, 7, (5), 1182-1190.

153. Beaulieu, D.; Ding, Y.; Wang, Z. L.; Lackey, W. J., Influence of process variables on electron beam chemical vapor deposition of platinum. Journal of Vacuum Science \& Technology B 2005, 23, (5), 2151-2159.

154. Kohlmann, K. T.; Buchmann, L. M.; Brunger, W. H., Repair of open stencil masks for ion projection lithography by e-beam induced metal-deposition. Microelectronic Engineering 1992, 17, (1-4), 427-430.

155. Serrano-Ramón, L.; Córdoba, R.; Rodriguez, L. A.; Magén, C.; Snoeck, E.; Gatel, C.; Serrano, I.; Ibarra, M. R.; De Teresa, J. M., Ultrasmall Functional Ferromagnetic Nanostructures Grown by Focused Electron-Beam-Induced Deposition. ACS Nano 2011, 5, (10), 7781-7787.

156. Kotzler, J.; Gil, W., Anomalous Hall resistivity of cobalt films: Evidence for the intrinsic spin-orbit effect. Physical Review B 2005, 72, (6), 060412.

157. Kirk, K. J.; Chapman, J. N.; Wilkinson, C. D. W., Lorentz microscopy of small magnetic structures (invited). Journal of Applied Physics 1999, 85, (8), 52375242.

158. Tonomura, A., Electron holography of magnetic-materials and observation of flux-line dynamics. Ultramicroscopy 1992, 47, (4), 419-424.

159. Moritz, J.; Rodmacq, B.; Auffret, S.; Dieny, B., Extraordinary Hall effect in thin magnetic films and its potential for sensors, memories and magnetic logic applications. Journal of Physics D-Applied Physics 2008, 41, (13), 135001.

160. Sandhu, A.; Sanbonsugi, H.; Shibasaki, I.; Abe, M.; Handa, H., High sensitivity InSb ultra-thin film micro-hall sensors for bioscreening applications. Japanese Journal of Applied Physics Part 2-Letters \& Express Letters 2004, 43, (7A), L868-L870.

161. Serrano-Ramón, L. E. Tesis doctoral. Universidad de Zaragoza, en fase de desarrollo. 
162. Takeguchi, M.; Shimojo, M.; Furuya, K., Fabrication of magnetic nanostructures using electron beam induced chemical vapour deposition. Nanotechnology 2005, 16, (8), 1321-1325.

163. Takeguchi, M.; Shimojo, M.; Furuya, K., Nanostructure fabrication by electron-beam-induced deposition with metal carbonyl precursor and water vapor. Japanese Journal of Applied Physics Part 1-Regular Papers Brief Communications \& Review Papers 2007, 46, (9B), 6183-6186.

164. Zhang, W.; Shimojo, M.; Takeguchi, M.; Che, R.-c.; Furuya, K., Generation mechanism and in situ growth behavior of alpha-iron nanocrystals by electron beam induced deposition. Advanced Engineering Materials 2006, 8, (8), 711-714.

165. Takeguchi, M.; Shimojo, M.; Mitsuishi, K.; Tanaka, M.; Che, R.; Furuya, K., Fabrication of nanostructures with different iron concentration by electron beam induced deposition with a mixture gas of iron carbonyl and ferrocene, and their magnetic properties. Journal of Materials Science 2006, 41, (14), 4532-4536.

166. Bruk, M. A.; Zhikharev, E. N.; Grigor'ev, E. I.; Spirin, A. V.; Kal'nov, V. A.; Kardash, I. E., Focused electron beam-induced deposition of iron- and carboncontaining nanostructures from triiron dodecacarbonyl vapor. High Energy Chemistry 2005, 39, (2), 65-68.

167. Shimojo, M.; Takeguchi, M.; Mitsuishi, K.; Tanaka, M.; Furuya, K., Fabrication of iron oxide nanostructures by electron beam-induced deposition. In Pacific Rim International Conference on Advanced Materials and Processing, 2007; Vol. 561-565, pp 1101-1104.

168. Hochleitner, G.; Wanzenboeck, H. D.; Bertagnolli, E., Electron beam induced deposition of iron nanostructures. Journal of Vacuum Science \& Technology B 2008, 26, (3), 939-944.

169. Walz, M.-M.; Vollnhals, F.; Schirmer, M.; Steinrueck, H.-P.; Marbach, H., Generation of clean iron nanocrystals on an ultra-thin $\mathrm{SiO}_{\mathrm{x}}$ film on $\mathrm{Si}(001)$. Physical Chemistry Chemical Physics 2011, 13, (38), 17333-17338.

170. Porrati, F.; Sachser, R.; Walz, M. M.; Vollnhals, F.; Steinrueck, H. P.; Marbach, H.; Huth, M., Magnetotransport properties of iron microwires fabricated by focused electron beam induced autocatalytic growth. Journal of Physics D-Applied Physics 2011, 44, (42), 425001.

171. Shimojo, M.; Takeguchi, M.; Mitsuishi, K.; Tanaka, M.; Furuya, K., Mechanisms of crystalline iron oxide formation in electron beam-induced deposition. Japanese Journal of Applied Physics Part 1-Regular Papers Brief Communications \& Review Papers 2007, 46, (9B), 6247-6249. 
172. Fernández-Pacheco, A.; De Teresa, J. M.; Córdoba, R.; Ibarra, M. R., Metalinsulator transition in Pt-C nanowires grown by focused-ion-beam-induced deposition. Physical Review B 2009, 79, (17), 174204.

173. Fernández-Pacheco, A.; De Teresa, J. M.; Orna, J.; Morellón, L.; Algarabel, P. A.; Pardo, J. A.; Ibarra, M. R., Universal scaling of the anomalous Hall effect in $\mathrm{Fe}_{3} \mathrm{O}_{4}$ epitaxial thin films. Physical Review B 2008, 77, (10), 100403

174. Mei, Y.; Zhou, Z. J.; Luo, H. L., Electrical-resistivity of rf-sputtered ironoxide thin-films. Journal of Applied Physics 1987, 61, (8), 4388-4389.

175. McGuire, T. R.; Potter, R. I., Anisotropic magnetoresistance in ferromagnetic 3d alloys. IEEE Transactions on Magnetics 1975, 11, (4), 1018-1038.

176. Leven, B.; Dumpich, G., Resistance behavior and magnetization reversal analysis of individual Co nanowires. Physical Review B 2005, 71, (6), 064411.

177. Stankiewicz, J.; Jimenez-Villacorta, F.; Prieto, C., Magnetotransport properties of oxidized iron thin films. Physical Review B 2006, 73, (1), 014429.

178. Serrate, D.; De Teresa, J. M.; Algarabel, P. A.; Ibarra, M. R.; Galibert, J., Intergrain magnetoresistance up to $50 \mathrm{~T}$ in the half-metallic $\left(\mathrm{Ba}_{0.8} \mathrm{Sr}_{0.2}\right)_{2} \mathrm{FeMoO}_{6}$ double perovskite: Spin-glass behavior of the grain boundary. Physical Review $B$ 2005, 71, (10), 104409.

179. Ziese, M., Extrinsic magnetotransport phenomena in ferromagnetic oxides. Reports on Progress in Physics 2002, 65, (2), 143-249.

180. Mott, N. F., Metal-insulator transition. Reviews of Modern Physics 1968, 40, (4), 677.

181. Aharoni, A., Demagnetizing factors for rectangular ferromagnetic prisms. Journal of Applied Physics 1998, 83, (6), 3432-3434.

182. Gerber, A.; Milner, A.; Finkler, A.; Karpovski, M.; Goldsmith, L.; TuaillonCombes, J.; Boisron, O.; Melinon, P.; Perez, A., Correlation between the extraordinary Hall effect and resistivity. Physical Review B 2004, 69, (22), 224403.

183. García-García, A.; Vovk, A.; Pardo, J. A.; Strichovanec, P.; Magén, C.; Snoeck, E.; Algarabel, P. A.; De Teresa, J. M.; Morellón, L.; Ibarra, M. R., Magnetic properties of $\mathrm{Fe} / \mathrm{MgO}$ granular multilayers prepared by pulsed laser deposition. Journal of Applied Physics 2009, 105, (6), 063909. 
184. Langfischer, H.; Basnar, B.; Hutter, H.; Bertagnolli, E., Evolution of tungsten film deposition induced by focused ion beam. Journal of Vacuum Science \& Technology a-Vacuum Surfaces and Films 2002, 20, (4), 1408-1415.

185. Muthukumar, K.; Opahle, I.; Shen, J.; Jeschke, H. O.; Valenti, R., Interaction of $\mathrm{W}(\mathrm{CO})_{6}$ with $\mathrm{SiO}_{2}$ surfaces: A density functional study. Physical Review B 2011, 84, (20), 205442.

186. Collver, M. M.; Hammond, R. H., Superconductivity in amorphous transition-metal alloy films. Physical Review Letters 1973, 30, (3), 92-95.

187. Kondo, S., Superconducting characteristics and the thermal-stability of tungsten-based amorphous thin-films. Journal of Materials Research 1992, 7, (4), 853-860.

188. Miki, H.; Takeno, T.; Takagi, T.; Bozhko, A.; Shupegin, M.; Onodera, H.; Komiyama, T.; Aoyama, T., Superconductivity in W-containing diamond-like nanocomposite films. Diamond and Related Materials 2006, 15, (11-12), 1898-1901.

189. Osofsky, M. S.; Soulen, R. J.; Claassen, J. H.; Trotter, G.; Kim, H.; Horwitz, J. S., New insight into enhanced superconductivity in metals near the metal-insulator transition. Physical Review Letters 2001, 87, (19), 197004.

190. Luxmoore, I. J.; Ross, I. M.; Cullis, A. G.; Fry, P. W.; Orr, J.; Buckle, P. D.; Jefferson, J. H., Low temperature electrical characterisation of tungsten nano-wires fabricated by electron and ion beam induced chemical vapour deposition. Thin Solid Films 2007, 515, (17), 6791-6797.

191. Spoddig, D.; Schindler, K.; Roediger, P.; Barzola-Quiquia, J.; Fritsch, K.; Mulders, H.; Esquinazi, P., Transport properties and growth parameters of PdC and WC nanowires prepared in a dual-beam microscope. Nanotechnology 2007, 18, (49), 495202.

192. Li, W. X.; Fenton, J. C.; Wang, Y. Q.; McComb, D. W.; Warburton, P. A., Tunability of the superconductivity of tungsten films grown by focused-ion-beam direct writing. Journal of Applied Physics 2008, 104, (9), 093913.

193. Li, W.; Fenton, J. C.; Warburton, P. A., Focused-Ion-Beam Direct-Writing of Ultra-Thin Superconducting Tungsten Composite Films. IEEE Transactions on Applied Superconductivity 2009, 19, (3), 2819-2822.

194. Martínez-Pérez, M. J.; Sesé, J.; Luis, F.; Drung, D.; Schurig, T., Highly sensitive superconducting quantum interference device microsusceptometers operating at high frequencies and very low temperatures inside the mixing chamber of a dilution refrigerator. Review of Scientific Instruments 2010, 81, (1), 016108. 
195. Li, W.; Fenton, J. C.; Gu, C.; Warburton, P. A., Superconductivity of ultrafine tungsten nanowires grown by focused-ion-beam direct-writing. Microelectronic Engineering 2011, 88, (8), 2636-2638.

196. Cui, A.; Li, W.; Luo, Q.; Liu, Z.; Gu, C., Freestanding nanostructures for three-dimensional superconducting nanodevices. Applied Physics Letters 2012, 100, (14), 143106.

197. Guillamón, I.; et al., Superconducting density of states at the border of an amorphous thin film grown by focused-ion-beam. Journal of Physics: Conference Series 2009, 150, (5), 052064.

198. Guillamón, I.; Suderow, H.; Fernández-Pacheco, A.; Sesé, J.; Córdoba, R.; De Teresa, J. M.; Ibarra, M. R.; Vieira, S., Direct observation of melting in a twodimensional superconducting vortex lattice. Nature Physics 2009, 5, (9), 651-655.

199. Guillamón, I.; Suderow, H.; Vieira, S.; Sesé, J.; Córdoba, R.; De Teresa, J. M.; Ibarra, M. R., Direct Observation of Stress Accumulation and Relaxation in Small Bundles of Superconducting Vortices in Tungsten Thin Films. Physical Review Letters 2011, 106, (7), 077001.

200. Kes, P. H.; Tsuei, C. C., Two-dimensional collective flux pinning, defects, and structural relaxation in amorphous superconducting films. Physical Review B 1983, 28, (9), 5126-5139.

201. Sychugov, I.; Nakayama, Y.; Mitsuishi, K., Manifold enhancement of electron beam induced deposition rate at grazing incidence. Nanotechnology 2010, 21, (2), 025303.

202. Li, J. T.; Toth, M.; Tileli, V.; Dunn, K. A.; Lobo, C. J.; Thiel, B. L., Evolution of the nanostructure of deposits grown by electron beam induced deposition. Applied Physics Letters 2008, 93, (2), 23130.

203. Romans, E. J.; Osley, E. J.; Young, L.; Warburton, P. A.; Li, W., Threedimensional nanoscale superconducting quantum interference device pickup loops. Applied Physics Letters 2010, 97, (22), 222506.

204. De Teresa, J. M.; Fernández-Pacheco, A.; Córdoba, R.; Sesé, J.; Ibarra, M. R.; Guillamón, I.; Suderow, H.; Vieira, S., Transport properties of superconducting amorphous W-based nanowires fabricated by focused-ion-beam-induced-deposition for applications in Nanotechnology. Mater. Res. Soc. Symp. Proc. 2009, 1180.

205. Kunchur, M. N., Unstable flux flow due to heated electrons in superconducting films. Physical Review Letters 2002, 89, (13), 137005. 
206. Babic, D., Amorphous Nb-Ge thin films as a model system for experiments on fundamental properties of vortex transport. In New Frontiers in Superconductivity Research, Martins, B. S., Ed. Nova Science Publishers: Hauppauge NY, 2006; pp 107143.

207. Babic, D.; Bentner, J.; Surgers, C.; Strunk, C., Flux-flow instabilities in amorphous $\mathrm{Nb}_{0.7} \mathrm{Ge}_{0.3}$ microbridges. Physical Review B 2004, 69, (9), 092510.

208. Xiong, P.; Herzog, A. V.; Dynes, R. C., Negative magnetoresistance in homogeneous amorphous superconducting $\mathrm{Pb}$ wires. Physical Review Letters 1997, 78, (5), 927-930.

209. Saint-James, D.; De Gennes, P., Onset of superconductivity in decreasing fields. Phys. Lett. 1963, 7, 306.

210. Fink, H. J., Superconducting surface sheath of a type-2 superconductor below upper critical field $\mathrm{H}_{\mathrm{c} 2}$. Physical Review Letters 1965, 14, (9), 309.

211. Palacios, J. J., Vortex lattices in strong type-II superconducting twodimensional strips. Physical Review B 1998, 57, (17), 10873-10876.

212. Tahara, S.; Anlage, S. M.; Halbritter, J.; Eom, C.-B.; Fork, D. K.; Geballe, T. H.; Beasley, M. R., Critical currents, pinning, and edge barriers in narrow $\mathrm{YBa}_{2} \mathrm{Cu}_{3} \mathrm{O}_{7-\delta}$ thin films. Physical Review B 1990, 41, (16), 11203-11208.

213. Jones, W. A.; Barnes, P. N.; Mullins, M. J.; Baca, F. J.; Emergo, R. L. S.; Wu, J.; Haugan, T. J.; Clem, J. R., Impact of edge-barrier pinning in superconducting thin films. Applied Physics Letters 2010, 97, (26), 262503.

214. Elistratov, A. A.; Vodolazov, D. Y.; Maksimov, I. L.; Clem, J. R., Fielddependent critical current in type-II superconducting strips: Combined effect of bulk pinning and geometrical edge barrier. Physical Review B 2002, 66, (22), 220506.

215. Córdoba, R.; Sesé, J.; Ibarra, M. R.; Guillamón, I.; Suderow, H.; Vieira, S.; De Teresa, J. M., manuscrito en preparación.

216. Chibotaru, L. F.; Ceulemans, A.; Bruyndoncx, V.; Moshchalkov, V. V., Symmetry-induced formation of antivortices in mesoscopic superconductors. Nature 2000, 408, (6814), 833-835.

217. Hao, L.; Macfarlane, J. C.; Gallop, J. C.; Cox, D.; Beyer, J.; Drung, D.; Schurig, T., Measurement and noise performance of nano-superconducting-quantuminterference devices fabricated by focused ion beam. Applied Physics Letters 2008, 92, (19), 192507.

218. Gol'tsman, G. N.; Okunev, O.; Chulkova, G.; Lipatov, A.; Semenov, A.; Smirnov, K.; Voronov, B.; Dzardanov, A.; Williams, C.; Sobolewski, R., Picosecond 
superconducting single-photon optical detector. Applied Physics Letters 2001, 79, (6), 705-707.

219. Najafi, F.; Marsili, F.; Dauler, E.; Molnar, R. J.; Berggren, K. K., Timing performance of 30-nm-wide superconducting nanowire avalanche photodetectors. Applied Physics Letters 2012, 100, (15), 152602.

220. Sclafani, M.; Marksteiner, M.; Keir, F. M.; Divochiy, A.; Korneev, A.; Semenov, A.; Gol'tsman, G.; Arndt, M., Sensitivity of a superconducting nanowire detector for single ions at low energy. Nanotechnology 2012, 23, (6).

221. Mooij, J. E.; Nazarov, Y. V., Superconducting nanowires as quantum phaseslip junctions. Nature Physics 2006, 2, (3), 169-172.

222. Córdoba, R.; Lavrijsen, R.; Fernández-Pacheco, A.; Ibarra, M. R.; Schoenaker, F.; Ellis, T.; Barcones-Campo, B.; Kohlhepp, J. T.; Swagten, H. J. M.; Koopmans, B.; Mulders, J. J. L.; De Teresa, J. M., Giant anomalous Hall effect in Febased microwires grown by focused-electron-beam-induced deposition. Journal of Physics D-Applied Physics 2012, 45, (3), 035001.

223. Kohlmannvonplaten, K. T.; Buchmann, L. M.; Petzold, H. C.; Brunger, W. H., Electron-beam induced tungsten deposition - growth-rate enhancement and applications in microelectronics. Journal of Vacuum Science \& Technology B 1992, 10, (6), 2690-2694.

224. Kohlmannvonplaten, K. T.; Chlebek, J.; Weiss, M.; Reimer, K.; Oertel, H.; Brunger, W. H., Resolution limits in electron-beam-induced tungsten deposition. Journal of Vacuum Science \& Technology B 1993, 11, (6), 2219-2223.

225. Hoyle, P. C.; Cleaver, J. R. A.; Ahmed, H., Electron beam induced deposition from $\mathrm{W}(\mathrm{CO})_{6}$ at 2 to $20 \mathrm{keV}$ and its applications. Journal of Vacuum Science \& Technology B 1996, 14, (2), 662-673.

226. Liu, Z.-Q.; Mitsuishi, K.; Furuya, K., Fabrication and investigation of tungsten deposit on top and bottom surfaces of thin film substrate. Japanese Journal of Applied Physics Part 1-Regular Papers Brief Communications \& Review Papers 2007, 46, (9B), 6254-6257.

227. Hoyle, P. C.; Ogasawara, M.; Cleaver, J. R. A.; Ahmed, H., Electricalresistance of electron-beam-induced deposits from tungsten hexacarbonyl. Applied Physics Letters 1993, 62, (23), 3043-3045.

228. Sachser, R.; Porrati, F.; Huth, M., Hard energy gap and current-path switching in ordered two-dimensional nanodot arrays prepared by focused electronbeam-induced deposition. Physical Review B 2009, 80, (19), 195416. 
229. Huth, M.; Klingenberger, D.; Grimm, C.; Porrati, F.; Sachser, R., Conductance regimes of W-based granular metals prepared by electron beam induced deposition. New Journal of Physics 2009, 11, 033032.

230. Porrati, F.; Sachser, R.; Huth, M., The transient electrical conductivity of Wbased electron-beam-induced deposits during growth, irradiation and exposure to air. Nanotechnology 2009, 20, (19), 195301.

231. Porrati, F.; Sachser, R.; Schwalb, C. H.; Frangakis, A. S.; Huth, M., Tuning the electrical conductivity of Pt-containing granular metals by postgrowth electron irradiation. Journal of Applied Physics 2011, 109, (6), 063715.

232. Schwalb, C. H.; Grimm, C.; Baranowski, M.; Sachser, R.; Porrati, F.; Reith, H.; Das, P.; Mueller, J.; Voelklein, F.; Kaya, A.; Huth, M., A Tunable Strain Sensor Using Nanogranular Metals. Sensors 2010, 10, (11), 9847-9856.

233. Huth, M., Granular metals: From electronic correlations to strain-sensing applications. Journal of Applied Physics 2010, 107, (11), 113709.

234. Bell, D. A.; Falconer, J. L.; Lu, Z. M.; McConica, C. M., Electron-beaminduced deposition of tungsten. Journal of Vacuum Science \& Technology B 1994, 12, (5), 2976-2979.

235. Yang, X.; Simpson, M. L.; Randolph, S. J.; Rack, P. D.; Baylor, L. R.; Cui, H.; Gardner, W. L., Integrated tungsten nanofiber field emission cathodes selectively grown by nanoscale electron beam-induced deposition. Applied Physics Letters 2005, 86, (18), 183106.

236. Klein, K. L.; Randolph, S. J.; Fowlkes, J. D.; Allard, L. F.; Meyer, H. M.; Simpson, M. L.; Rack, P. D., Single-crystal nanowires grown via electron-beaminduced deposition. Nanotechnology 2008, 19, (34).

237. Porrati, F.; Sachser, R.; Strauss, M.; Andrusenko, I.; Gorelik, T.; Kolb, U.; Bayarjargal, L.; Winkler, B.; Huth, M., Artificial granularity in two-dimensional arrays of nanodots fabricated by focused-electron-beam-induced deposition. Nanotechnology 2010, 21, (37), 375302.

238. Möbius, A.; Frenzel, C.; Thielsch, R.; Rosenbaum, R.; Adkins, C. J.; Schreiber, M.; Bauer, H. D.; Grötzschel, R.; Hoffmann, V.; Krieg, T.; Matz, N.; Vinzelberg, H.; Witcomb, M., Metal-insulator transition in amorphous $\mathrm{Si}_{1-\mathrm{x}} \mathrm{Ni}_{\mathrm{x}}$ : Evidence for Mott's minimum metallic conductivity. Physical Review B 1999, 60, (20), 14209.

239. De Marzi, G.; Iacopino, D.; Quinn, A. J.; Redmond, G., Probing intrinsic transport properties of single metal nanowires: Direct-write contact formation using a focused ion beam. Journal of Applied Physics 2004, 96, (6), 3458-3462. 
240. Rotkina, L.; Lin, J. F.; Bird, J. P., Nonlinear current-voltage characteristics of Pt nanowires and nanowire transistors fabricated by electron-beam deposition. Applied Physics Letters 2003, 83, (21), 4426-4428.

241. Langford, R. M.; Wang, T. X.; Ozkaya, D., Reducing the resistivity of electron and ion beam assisted deposited Pt. Microelectronic Engineering 2007, 84, (5-8), 784-788.

242. Lin, J. F.; Bird, J. P.; Rotkina, L.; Sergeev, A.; Mitin, V., Large effects due to electron-phonon-impurity interference in the resistivity of $\mathrm{Pt} / \mathrm{C}-\mathrm{Ga}$ composite nanowires. Applied Physics Letters 2004, 84, (19), 3828-3830.

243. Lin, J. F.; Bird, J. P.; Rotkina, L.; Bennett, P. A., Classical and quantum transport in focused-ion-beam-deposited Pt nanointerconnects. Applied Physics Letters 2003, 82, (5), 802-804.

244. Peñate-Quesada, L.; Mitra, J.; Dawson, P., Non-linear electronic transport in Pt nanowires deposited by focused ion beam. Nanotechnology 2007, 18, (21), 215203.

245. Lipp, S.; Frey, L.; Lehrer, C.; Demm, E.; Pauthner, S.; Ryssel, H., A comparison of focused ion beam and electron beam induced deposition processes. Microelectronics and Reliability 1996, 36, (11-12), 1779-1782.

246. Takai, M.; Jarupoonphol, W.; Ochiai, C.; Yavas, O.; Park, Y. K., Processing of vacuum microelectronic devices by focused ion and electron beams. Applied Physics A: Materials Science \& Processing 2003, 76, (7), 1007-1012.

247. Dhakal, P.; McMahon, G.; Shepard, S.; Kirkpatrick, T.; Oh, J. I.; Naughton, M. J., Direct-write, focused ion beam-deposited, $7 \mathrm{~K}$ superconducting C-Ga-O nanowire. Applied Physics Letters 2010, 96, (26), 262511.

248. Efros, A. L.; Shklovskii, B. I., Coulomb gap and low-temperature conductivity of disordered systems. Journal of Physics C-Solid State Physics 1975, 8, (4), L49-L51.

249. Skrotzki, R.; Fiedler, J.; Herrmannsdoerfer, T.; Heera, V.; Voelskow, M.; Muecklich, A.; Schmidt, B.; Skorupa, W.; Gobsch, G.; Helm, M.; Wosnitza, J., Onchip superconductivity via gallium overdoping of silicon. Applied Physics Letters 2010, 97, (19), 192505.

250. Fiedler, J.; Heera, V.; Skrotzki, R.; Herrmannsdoerfer, T.; Voelskow, M.; Muecklich, A.; Oswald, S.; Schmidt, B.; Skorupa, W.; Gobsch, G.; Wosnitza, J.; Helm, M., Superconducting films fabricated by high-fluence Ga implantation in Si. Physical Review B 2011, 83, (21), 214504. 


\section{Listado de publicaciones}

Listado de publicaciones directamente relacionado con el desarrollo de esta tesis:

1. R. Córdoba, J. Sesé, M. R. Ibarra, and J. M. De Teresa, “Autocatalytic growth of Co on pure Co surfaces using $\mathrm{Co}_{2}(\mathrm{CO})_{8}$ precursor", Applied Surface Science 263, 242-246 (2012).

2. R. Córdoba, R. Lavrijsen, A. Fernández-Pacheco, F. J. Schoenaker, T. H. Ellis, B. Barcones, J. T. Kohlepp, H. J. M. Swagten, B. Koopmans, M. R. Ibarra, J. J. L. Mulders and J. M. De Teresa, "Giant anomalous effect in Fe- based microwires grown by focused-electron-beam-induced deposition”, Journal of Physics D: Applied Physics 45, 035001 (2012).

3. R. Córdoba, R. Fernández-Pacheco, A. Fernández-Pacheco, A. Gloter, C. Magén, O. Stéphan, M. R. Ibarra, J. M. De Teresa, “Nanoscale chemical and structural study of Co- based FEBID structures by STEM-EELS and HRTEM”, Nanoscale Research Letters 6, 1-6 (2011).

4. L. Serrano-Ramón, R. Córdoba, L. A. Rodríguez, C. Magén, E. Snoeck, C. Gatel, I. Serrano, M. R. Ibarra and J. M. De Teresa, "Ultra-Small Functional Ferromagnetic Nanostructures grown by Focused-ElectronBeam-Induced Deposition”, ACS Nano 5, 10, 7781-7787 (2011).

5. R. Lavrijsen, R. Córdoba, F. J. Schoenaker, T. H. Ellis, B. Barcones, J. T. Kohlepp, H. J. M. Swagten, B. Koopmans, J. M. De Teresa, C. Magén, M. R. Ibarra, P. Trompenaars, and J. J. L. Mulders, "Fe:O:C grown by focused-electron-beam-induced deposition; magnetic and electric properties”, Nanotechnology 22, 21, 025302 (2011). 
6. ․ Córdoba, J. Sesé, J. M. De Teresa, and M. R. Ibarra, "High-purity cobalt nanostructures grown by focused-electron-beam-induced deposition at low current”, Microelectronic Engineering 87, 1550-1553 (2010).

7. J. M. De Teresa, A. Fernández-Pacheco, R. Córdoba, J. Sesé, M. R. Ibarra, I. Guillamón, H. Suderow, S. Vieira, “Transport properties of superconducting amorphous W-based nanowires fabricated by focused-ionbeam-induced-deposition for applications in Nanotechnology”, Mater. Res. Soc. Symp. Proc. 1181, 1180-CC04-09 (2009).

8. J. M. De Teresa, R. Córdoba, A. Fernández-Pacheco, O. Montero, P. Strichovanec, M. R. Ibarra, “Origin of the difference in the resistivity of asgrown focused-ion- and electron-beam-induced Pt nanodeposits”, Journal of Nanomaterials 2009, 936863 (2009).

9. A. Fernández-Pacheco, J. M. De Teresa, R. Córdoba, M. R. Ibarra, “Highquality magnetic and transport properties of cobalt nanowires grown by focused-electron-beam-induced deposition”, Journal of Physics D: Applied Physics 42, 055005 (2009).

10. A. Fernández-Pacheco, J. M. De Teresa, R. Córdoba, M. R. Ibarra, “Metalinsulator transition in Pt-C nanowires grown by focused-ion-beam-induced deposition”, Physical Review B 79, 17, 174204 (2009).

11. I. Guillamón, H. Suderow, S. Vieira, A. Fernández-Pacheco, J. Sesé, $\underline{\text { R. }}$ Córdoba, J. M. De Teresa and M. R. Ibarra, "Nanoscale superconducting properties of amorphous W-based deposits grown with focused-ion-beam”, New Journal of Physics 10, 093005 (2008).

Listado de trabajos directamente relacionado con el desarrollo de esta tesis pendiente de publicar:

12. R. Córdoba, J. Sesé, T. I. Baturina, A. Y. Mironov, J. M. De Teresa, M. R. Ibarra, J. J. Palacios, I. Guillamón, H. Suderow, S. Vieira, M. Baklanov, and V. M. Vinokur, "Reentrant dissipation-free state in nanopatterned 
superconducting systems”, manuscrito aceptado en Nature Communications.

13. R. Córdoba, J. Sesé, M. R. Ibarra, I. Guillamón, H. Suderow, S. Vieira, and J. M. De Teresa, "Non-local voltage in superconducting W-based nanowires grown by focused-ion-beam-induced-deposition”, manuscrito en desarrollo.

Listado de publicaciones relacionado con el desarrollo de esta tesis mediante colaboraciones:

14. I. Guillamón, R. Córdoba, J. Sesé, J. M. De Teresa, M. R. Ibarra, S. Vieira, H. Suderow, "Direct imaging of a non-thermal Berezinskii-KosterlitzThouless transition in a two-dimensional vortex lattice”, manuscrito enviado a Nature.

15. A. Fernández-Pacheco, L. E. Serrano-Ramón, T. Tyliszczak, K. W. Chou, R. Córdoba, A. Szkudlarek, L. O’Brien, Cz. Kapusta, M. R. Ibarra, J. M. De Teresa, "Correlation between the magnetic imaging of cobalt nanoconstrictions and their magnetoresistance response”, Nanotechnology 23, 10, 105703 (2012).

16. S. Estrade, J. M. Rebled, M. G. Walls, F. de la Pena, C. Colliex, $\underline{\text { R. }}$ Córdoba, I. C. Infante, G. Herranz, F. Sanchez, J. Fontcuberta, F. Peiro, , "Effect of the capping on the local Mn oxidation state in buried (001) and (110) $\mathrm{SrTiO}_{3} / \mathrm{La}_{2 / 3} \mathrm{Ca}_{1 / 3} \mathrm{MnO}_{3}$ interfaces”, Journal of Applied Physics 110, 10, 103903 (2011).

17. F. J. Schoenaker, R. Córdoba, R. Fernández-Pacheco, C. Magén, O. Stephan, C. Zuriaga-Monroy, M. R. Ibarra, J. M. De Teresa, "Focused electron beam induced etching of titanium with $\mathrm{XeF}_{2}$ ", Nanotechnology 22, 26, 265304 (2011).

18. M. J. Martinez-Perez, J. Sese, F. Luis, R. Córdoba, D. Drung, T. Schurig, E. Bellido, R. de Miguel, C. Gomez-Moreno, A. Lostao, D. Ruiz-Molina, "Ultrasensitive Broad Band SQUID Microsusceptometer for Magnetic 
Measurements at Very Low Temperatures”, IEEE Transactions on Applied Superconductivity 21, 3, 345-348 (2011).

19. I. Guillamón, H. Suderow, S. Vieira, J. Sesé, R. Córdoba, J. M. De Teresa and M. R. Ibarra, "Direct Observation of Stress Accumulation and Relaxation in Small Bundles of Superconducting Vortices in Tungsten Thin Films”, Physical Review Letters 106, 7, 077001 (2011).

20. D. Muñoz-Rojas, R. Córdoba, A. Fernández-Pacheco, J. M. De Teresa, G. Sauthier, J. Fraxedas, R. I. Walton, and N. Casañ, "High Conductivity in Hydrothermally Grown $\mathrm{AgCuO}_{2}$ Single Crystals Verified Using FocusedIon-Beam-Deposited Nanocontacts”, Inorganic Chemistry 49, 23, 1097710983 (2010).

21. N. Marcano, S. Sangiao, M. Plaza, L. Perez, A. Fernández-Pacheco, $\underline{\text { R. }}$ Córdoba, M. C. Sanchez, L. Morellón, M. R. Ibarra, J. M. De Teresa, "Weak-antilocalization signatures in the magnetotransport properties of individual electrodeposited Bi Nanowires”, Applied Physics Letters 96, 8, 082110 (2010).

22. A. Fernández-Pacheco, J. M. De Teresa, R. Córdoba, M. R. Ibarra, "Tunneling and anisotropic-tunneling magnetoresistance in iron nanoconstrictions fabricated by focused-ion-beam”, Ion Beams and NanoEngineering, Materials Research Society Symposium Proceedings 1181, 35-40 (2010).

23. A. Fernández-Pacheco, J. M. De Teresa, A. Szkudlarek, R. Córdoba, M. R. Ibarra, D. Petit, L. O’Brien, H. T. Zeng, E. R. Lewis, D. E. Read, and R. P. Cowburn, "Magnetization reversal in individual cobalt micro- and nanowires grown by focused-electron-beam-induced-deposition”, Nanotechnology 20, 475704 (2009).

24. A. Fernández-Pacheco, J. M. De Teresa, R. Córdoba, M. R. Ibarra, D. Petit, D. E. Read, L. O'Brien, E. R. Lewis, H. T. Zeng, R. P. Cowburn, “Domain 
wall conduit behaviour in cobalt nanowires grown by Focused-ElectronBeam Induced Deposition”, Applied Phys. Letters 94, 192509 (2009).

25. M. J. Martínez-Pérez, J. Sesé, R. Córdoba, F. Luis, D. Drung, and T. Schurig, "Circuit edit of superconducting microcircuits", Superconductor Science and Technology 22, 12, 125020 (2009).

26. I. Guillamón, H. Suderow, A. Fernández-Pacheco, J. Sesé, R. Córdoba, J. M. De Teresa, M. R. Ibarra and S. Vieira, "Direct observation of melting in a two-dimensional superconducting vortex lattice”, Nature Physics 5, 9, 651-655 (2009).

27. S. Estradè, J. M. Rebled, J. Arbiol, F. Peiró, I. C. Infante, G. Herranz, F. Sanchez, J. Fontcuberta, R. Córdoba, B. G. Mendis, A. L. Bleloch, “Effects of thickness on the cation segregation in epitaxial (001) and (110) $\mathrm{La}_{2 / 3} \mathrm{Ca}_{1 / 3} \mathrm{MnO}_{3}$ thin films”, Applied Physics Letters 95, 7, 072507 (2009).

28. J. V. Obona, J. M. De Teresa, R. Córdoba, A. Fernández-Pacheco, M. R. Ibarra, "Creation of stable nanoconstrictions in metallic thin films via progressive narrowing by focused-ion-beam technique and in situ control of resistance”, Microelectronic Engineering 86, 4-6, 639-641 (2009).

29. A. Fernández-Pacheco, J. M. De Teresa, R. Córdoba, M. R. Ibarra, "Exploring the conduction in atomic-sized metallic constrictions created by controlled ion etching”, Nanotechnology 19, 41, 415302 (2008).

Capítulo de libro:

30. J. M. De Teresa, A. Fernández-Pacheco, R. Córdoba, M. R. Ibarra, Capítulo 23 "Electrical transport properties of metallic nanowires and nanoconstrictions created by FIB”, página inicial: 668, final: 685; Libro: Nanofabrication Using Focused Ion and Electron Beams: principles and applications (2012). Editors: P. E. Russell, I. Utke, S. Moshkalev, Oxford University Press. ISBN: 9780199734214 




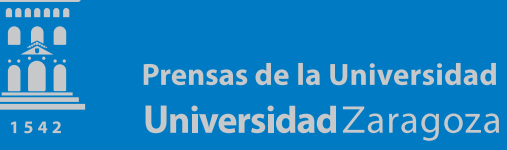

